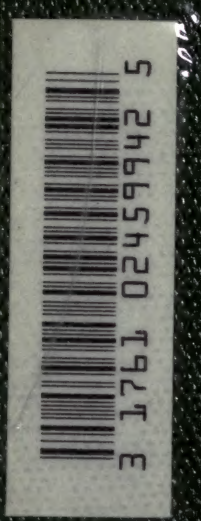


11 

Digitized by the Internet Archive in 2007 with funding from Microsoft Corporation 


\section{THE FUNGAL DISEASES OF THE COMMON LARCH}




\section{- OXFORD UNIVERSITY PRESS}

LONDON EDINBURGH GLASGOW NEW YORK TORONTO MELBOURNE CAPE TOWN BOMBAY HUMPHREY MILFORD PUBLISHER TO THE UNIVERSITY 


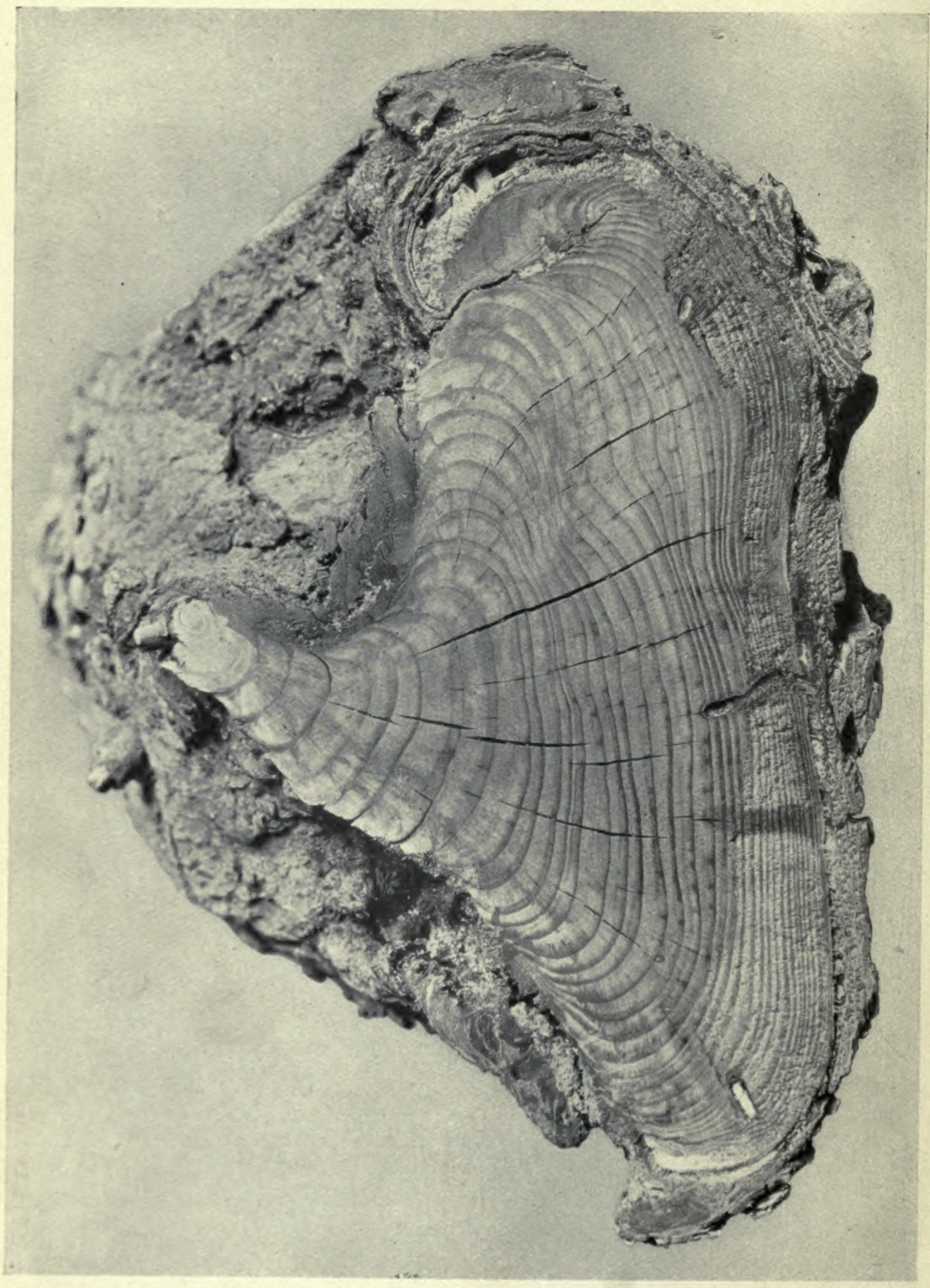




\section{THE FUNGAL DISEASES}

OF THE

\section{COMMON LARCH}

W. E. HILEY, M.A.

SCHOOL OF FORESTRY, OXFORD

\section{OXFORD}

\section{A'T THE CLARENDON PRESS}




$$
\begin{aligned}
& S B \\
& 608 \\
& \angle 3 H 5
\end{aligned}
$$




\section{PREFACE}

THIs book arose from an investigation which Sir William Schlich asked me to make into the larch canker, a disease on which many articles and papers have been published, though no full and connected account of it has ever been written in English. While studying the canker in the field, I very frequently encountered certain other diseases on the larch, especially the heart-rot and the honey fungus, and it seemed better to include these in the scope of the investigation. For the sake of completeness, all the known diseases on the common larch have also been described, and it is hoped that a book of more general usefulness has been thereby produced. Certain fungi, such as Lophodermium laricis and Botrytis cinerea, which have occasionally been reported as parasitic on the larch, have been omitted, as no reliable evidence of their causing disease has been forthcoming.

The arrangement of the diseases bears no relation to the systematic position of the fungi. They are mostly given in the order in which they were studied, which approximates closely to the order of their importance.

The work was made possible by a grant from the Development Commissioners, received through the Board of Agriculture and Fisheries, and latterly through the Interim Forest Authority. Especial acknowledgement is due to these departments, particularly to the last named, which has assisted me in a variety of ways. I also desire to thank Sir William Schlich for constant help and encouragement, and Messrs. A. W. Borthwick and Malcolm Wilson for permission to reproduce Fig. 72 from the Transactions of the Royal Scottish Arboricultural Society.

OxFord, August 1919. 



\section{CONTENTS}

CHAP.

I. INTRODUCTION.

The relation of a fungus to its host. Life-history of a fungus. The morphology of the larch; long and dwarf shoots ; internal structure of the stem

\section{THE LARCH CANKER.}

General. Historical. The mycelium of Dasyscypha calycina and its effect on the tissues. The canker as a pathological structure

III. THE LARCH CANKER (continued).

The reproductive organs of the fungus. Germination of spores. Pure cultures on nutrient media. Artificial infection with canker

IV. THE LARCH CANKER (concluded).

On the mode of infection in nature. Importance of wounds as a source of canker. Contributory causes of canker. Methods of prevention. The synonymy of Dasyscypha calycina . .

V. HEART-ROT. Fomes annosus.

Various fungi which cause heart-rot. Fomes annosus : general ; historical. Secretions induced by Fomes annosus : turpentine and resin ; soluble gum ; insoluble gum. Decomposition of the wood .

VI. HEART-ROT. Fomes annosus (concluded).

Reproductive organs: fructifications; conidiophores. Pure cultures on artificial media. Cultures on natural media. Infection experiments. Mode of attack in nature. The frequency of heart-rot in plantations which form the first rotation on cultivated soil. Methods of prevention . . . . . .

\section{HEART-ROT CAUSED BY OTHER FUNGI.}

Polyporus Schweinitzii, Poria vaporaria, Polyporus sulphureus, Trametes Pini 
CHAP.

VIII. ARMILLARIA MELLEA, THE HONEY FUNGUS.

General. Microscopic details of the fructification. Rhizomorphs. Effect on the host. The black line and resin flow. The method of infection. Means of prevention

IX. LEAF AND SEEDLING DISEASES.

The larch needle-cast (Sphaerella laricina). Meria laricis. Hypodermella laricis. The larch needle-rusts: Melampsoridium betulinum, Melampsora tremulae, \&c. Damping-off diseases: Phytophthora omnivora; Fusoma parasiticum . . . 168

X. GENERAL SUMMARY : . . . . . 182

BIBLIOGRAPHY • . . . . . . 193

INDEX . . . . . . . . . . . 200 


\section{LIST OF ILLUSTRATIONS}

FIG.

1. Section through canker . . . . . frontispiece

2. Transverse section of one-year-old stem of larch $\begin{array}{llll}\text {. page } 8 & 8\end{array}$

3. , , , , three-year-old stem of larch . facing page 8

4. , , " , abnormal wood . . , , , 8

5. Method of formation of periderm : . . . . page 10

6. Longitudinal section of phloem . . . . . . . , 11

7. Transverse section of phloem . . . . . . . . , 13

8. Canker healed on both sides . $\quad$. $\quad$. $\quad$. $\quad$. facing page 18

9. Canker which has nearly girdled stem * . . . , , 18

10. Mycelium of Dasyscypha in wood of larch . . . page 27

11. Radial longitudinal section of abnormal wood . . . . , , 32

12. Stages in the development of a canker . . . . . , 34

13. Canker on young larch showing swelling at back . facing page 36

14. Canker showing swelling at sides . . . . . . , , , 36

15. Apothecia of Dasyscypha calycina on dead larch stem.

Dry weather . . . . . . . . , , , 37

16. Apothecia of Dasyscypha calycina on dead larch stem.

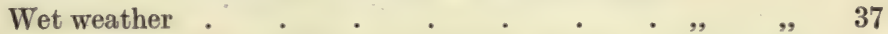

17. Section through apothecium of Dasyscypha calycina . - page 38

18. Dasyscypha calycina, reproductive organs . . . . , 40

19. Ascus which has discharged its spores . . . . . , 41

20. Spores and germination. . . . . . . . . , , 43

21. Growth of mycelium in drop cultures . . . . . , , 45

22. Pure culture of Dasyscypha calycina on nutrient gelatine . . . . . . facing page 48

23. Pure culture on sterilized larch stems showing apothecium . . . . . . . . , . . 4 48

24. Canker showing origin from branch . . , , , , 56

25.

Subsequently

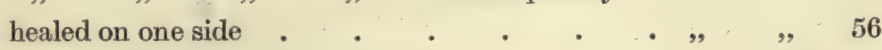

26. Cork layer across base of branch . . . . . page 60

27. Canker fungus spreading down from a branch . . facing page 61

28. Spread of fungus down the branches ... . . , , , 61 
FIG.

29. Single fructification of Fomes annosus. Upper surface facing page 85

30.

Lower surface , , ,

31. Fomes annosus. Annular rot with a central unrotted core

32. Fomes annosus. Figured rot

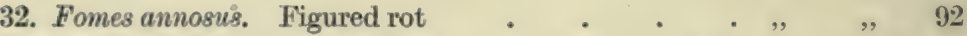

33. Black specks in wood of larch caused by Fomes annosus . page 94

34. Transverse section of black speck in wood of larch _ . . , , 96

35. Longitudinal section near edge of black speck • • • , , 97

36. Fomes annosus. Figured arrangement of rot - . facing page 99

37. ",$\quad$ Base of larch trunk excavated $\therefore$ underneath . . . . , , , 99

38. , ", Fructification showing pores in longitudinal section . . . , , 101

39. ",$\quad$ Under surface of fructification showing mouths of pores . . , , , 101

40. Upper surface of fructification showing concentric furrows and white margin . . . . . . . , , 101

41. Fomes annosus . . . . . . . . . page 102

42. Diagram showing necessity for pores to be vertical . . , 103

43. Fomes annosus. Conidiophore and conidia . . . . , 105 44, 45. Cultures of Fomes annosus . . . . . facing page 108

46. Polyporus Schweinitzii. Stipitate fructification , , , 127

47. ". , " Bracket-shaped fructification " " 127

48. Hymenial layer of Polyporus Schweinitzii _ • • - page 128

49,50. Sections of larch-tree showing rot caused by Polyporus Schweinitzii . . . . . . facing page 128

51. Piece of larch wood rotted by Polyporus Schweinitzii , , , , 130

52. Section of Scots pine stem with rot caused by Poly-

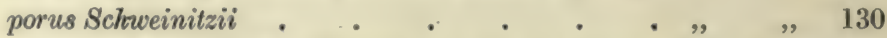

53. Mycelium of Polyporus Schweinitzii in wood of larch • page 131

54. Section of larch wood after attack by Polyporus Schweinitzii , 132

55. Poria vaporaria .. . . . . . . . . . . , 136

56, 57. Sections of larch wood rotted by Trametes Pini : facing page 143 58, 59. Armillaria mellea. Group of toadstools growing from base of deodar . . , , , 145

60, 61. " " Toadstools growing from rhizomorphs in soil . . " , ", 
FIG.

62. Hymenial layer of Armillaria mellea

63. Rhizomorphs of Armillaria mellea between bark and wood of larch stem . . . . . . . . . facing page 150

64. Small portion of Fig. 63 enlarged . . . . . . " , , 150

65. Section of larch stem attacked by Armillaria mellea . , , , , 155

66. Hollow larch stem rotted by Polyporus sulphureus . , , , 155

67. Armillaria mellea. Radial longitudinal section of larch wood showing 'black line' . . page 155

68. , , Transverse section of larch wood showing 'black line' : : , 157

69, 70. Living larch-trees with honey fungus growing from their roots . . . . . . . . . . facing page 166

71. Diagram showing life-cycle of heteroecious rust . . . . page 174

72. Melampsoridium betulinum - . . . . facing page 175

73. Sporangiophore of Phytophthora omnivora and conidiophore of Fusoma parasiticum. ․ . . . . page 180 



\section{CHAPTER I}

\section{INTRODUCTION}

The relation of a fungus to its host. Life-history of a fungus. The morphology of the larch; long and dwarf shoots; internal structure of the stem.

Historical. The history of larch-growing in Britain presents features of peculiar interest. In no other tree have such high hopes been placed, hopes which too often have led to disappointment, and with no other tree has it been so necessary to modify the method of sylvicultural treatment on account of liability to disease.

The story is as follows. The larch, which is a native of the Alps, Carpathians, and a part of southern Russia, was introduced in the early part of the seventeenth century. It was then only grown for decorative purposes, and a hundred years elapsed before the larch was employed as a timberproducing species. From 1730 onwards, however, it was planted extensively in Scotland, particularly by three successive Dukes of Atholl on their estates of Atholl and Dunkeld, and the faith of its ducal sponsors proved to be so well founded that the tree waxed great in popularity, and before the close of the century large plantations might have been found on the south as well as on the north side of the Tweed.

In 1820 a frigate was built for the navy of Scotch larch to test the durability of the wood under conditions of exposure. She was appropriately called the Athol, after the duke who grew the timber, and for the sake of comparison the Nieman, also a ship of war, was built at about the same time of Baltic fir (i. e. Scots pine). According to Laslett, who wrote in 1875, when he was Inspector of Timber to the Admiralty, the former lasted for a very 
long time without any considerable repairs, whilst the other decayed very rapidly, and from this comparison the superiority of Scotch larch over Scots pine, for durability, was considered to be pretty well established. If Scotland could grow larch timber which was more durable than Baltic fir, there was no reason to despair of British forestry, and the reputation of larch, already great, was still further enhanced.

So foresters continued to plant larch wherever the site was suitable, and in a great many places where it was not. It was used for railway sleepers and other outdoor purposes, and further experience confirmed the belief in its capacity for bearing exposure ; and it must have been at this time, about 1840 to 1850 , that its popularity reached the height from which it subsequently and continuously declined. It was fast-growing, straight, and easy to handle, but it had one great weakness : it became extremely liable to disease. A book on the larch, written by Mackintosh in 1860, is a sufficient index of the change that had come over the opinion of foresters, and nearly all writings since this date have partaken of the nature of apologetics for a tree that had failed to fulfil its early promise.

The disease that Mackintosh was most concerned with was variously known as heart-rot, dry-rot, piping, pumping, and internal decay, and was believed to be caused by a fungus which they called Polyporus destructor. Exactly what disease this was is not clear, but it was no doubt one of the heart-rots as we know them to-day, and very likely Fomes annosus was alone responsible for it. In addition to this, larch canker was becoming frequent, and in time proved to be an even more serious trouble than heart-rot, or, at any rate, one that was more visible to the eye and consequently more feared. At the present day there is scarcely a young plantation anywhere in the country which is entirely free from canker, and felling all too frequently discloses the presence of heart-rot as well. So larch is no longer the favourite tree that it was, and the tendency is to use it less often in pure plantations, though it is still very frequently employed in admixture with other trees since canker is 
less to be feared in mixtures than in pure stands. So far is this true that in Germany larch now scarcely appears at all, except in mixed forest.

The relation of fungus to host. What is the cause of disease ? Why, when the disease has once appeared, does it spread and become more and more general ? It is the object of this book to answer these questions; but before going into the details of various forms of disease, it will add to the clearness of subsequent descriptions to explain a few of the fundamental ideas on which all our knowledge of tree diseases is based; and as all the diseases described in this book are caused by fungi, the peculiar nature of fungal nutrition and the parasitism which it often involves should be made clear at the outset.

The normal green plant is self-supporting in a sense which is not applicable to other organisms, even to the higher animals. That is to say, it can obtain all its food without the intervention of any other living being. Water and mineral salts it obtains from the soil through its roots, and carbon-compounds it manufactures from the carbon dioxide of the air which diffuses in through the pores of the leaves. Combining the carbon dioxide with water and giving out part of the oxygen, the plant forms carbohydrates, and subsequently more complex organic compounds. But this process of carbon assimilation can only be performed by those parts of plants which contain the green colouring matter, chlorophyll, and, even so, only in the light. Such plants are called autotrophic, or self-feeding.

In the course of evolution some plants have taken to living on carbon compounds which have already bein elaborated; that is to say, these plants have become either parasitic on other living plants or animals, or else saprophytic on the remains of such plants or animals. Such plants always tend to lose their chlorophyll, and are called heterotrophic. Some of the higher plants are heterotrophic, such as the bird's-nest orchis, but the phenomenon is most commonly seen in the large group of lower plants known as the Fungi. In no member of this group has chlorophyll 
been found, and the green colour seen in some fungi is due to another pigment. Thus all fungi have to live either parasitically or saprophytically, and their mode of life has become entirely specialized to assist them in this kind of existence. Though the distinction between parasites and saprophytes is not always easy to draw, there is a very marked difference between the two modes of life, at any rate in the extreme cases, and in pathology, which is the science of disease, we shall naturally be chiefly interested in parasites. But, as will be shown later, saprophytes must also claim our attention for the reason that they can sometimes live on the dead parts of a living tree, such as the heart-wood of the trunk, and thereby not only destroy the timber but weaken the tree and render it more easily blown by the wind.

Parasites, again, are not all of the same kind. Some can thrive only on living organisms, and are called obligate parasites, and others can grow either on living organisms or on dead ones, and are therefore called facultative parasites. An example of the former is any one of the rusts such as Peridermium and Coeoma on larch needles, and of the latter the canker fungus or the heart-rot fungus which are to be described. The common mushroom will serve as an instance of a saprophyte, as it lives on the organic remains in the soil.

Life-history of a fungus. The part of the fungus which absorbs food from whatever it is growing on is called the mycelium, and is composed of a more or less felted mass of fine threads or hyphae. Each hypha grows at its extremity and may also branch, giving rise to numerous other hyphae as shown in fig. 21. It contains protoplasm and nuclei, and certain spaces in the protoplasm, known as vacuoles, filled with an aqueous solution, besides drops of oil and other food reserves. The mycelium is formed of these hyphae growing and becoming intermingled, and, though a single hypha is too fine to be seen with the naked eye, the mycelium as a whole may be very conspicuous, and is often seen as a white felt-like mass on pulling away the bark of a rotten 
stump. The mycelium may itself become reproductive in various ways, but, in principle, it is the vegetative part of the fungus. The true reproductive part is generally very specialized, and in nearly all the fungi considered in this book it has a marked form peculiar to each species of fungus, and is (somewhat loosely) called the fructification. This fructification bears a large number of spores or single, generally very small, cells which are distributed by wind or other agencies; and each spore, if it falls on a suitable feeding ground, is capable of producing a new mycelium, which in its turn produces a fresh fructification. A familiar fructification is a mushroom or any toadstool, which is solely a reproducing organ, and is nourished entirely by the mycelium, which is out of sight and buried in the soil. The large bracket fungi found on trees are also fructifications, only these fungi differ from a mushroom in the fact that their mycelium lives and grows in the trees instead of in the ground.

The fructifications of the fungi which grow on trees are often very large, and when it is remembered that all the food necessary to produce them is derived from the tree, it will be clear that the tree must suffer accordingly. Frequently the tree is killed, but if the fungus is a facultative and not an obligate parasite, its growth will not immediately be checked by the death of the tree, and not uncommonly dead trees are a dangerous source of infection to living ones. The tree or other plant on which a parasite grows is somewhat unkindly called its host.

When investigating the life-history of a fungus it is often found that there is another form of reproduction besides the fructification. In some species almost any part of the mycelium may give rise to specialized hyphae, which bear cells which are not unlike spores and have the same faculty of reproducing the plant. These cells are given the distinguishing name of conidia, and the hypha that bears them is called a conidiophore. The distinction between spores and conidia has given rise to much controversy, and is now based chiefly on certain nuclear phenomena which 
precede their formation; but as nuclear phenomena will not be dealt with in this book, the application of the terms will have to be taken on trust. At the same time the word conidium is very useful as a term for an extra reproductive cell which is generally not an essential part of the life-cycle of the fungus: the qualification is used advisedly, for in a large number of fungi no typical fructifications have ever been found, so that they must reproduce themselves solely by conidia. The discovery of the formation of conidia in the life-history of any fungus is manifestly of the first importance to the pathologist, for infection may be caused by conidia just as well as by spores. For instance, a whole plantation of larch may be heart-rotted by Fomes annosus without a single fructification being produced, and this is probably due solely to infection by conidia. (For conidia of this fungus, see fig. 43.)

The morphology of the larch. The study of disease thus resolves itself into a study of the relationship of the parasite and host. 'The complete life-history of the parasite must be known as well as the structure and mode of growth of the host. In this book many different parasites are dealt with, but the host is always the same; so a description of those parts of the host with which we shall be chiefly concerned will be given at the outset. The account will be made as simple as is consistent with accuracy, and only those parts will be described which are necessary to an understanding of the more important diseases.

Long and dwarf shoots. When growing under forest conditions the leading shoot of a larch grows rapidly and maintains its vertical direction until maturity, while the lateral branches are mainly horizontal. The apical bud of each shoot, and those other buds which develop into branches, elongate in the spring and become what are called long shoots, i. e. shoots in which the internodes, or portions of the stem between the leaf insertions, are lengthened. The young stems are at first green, but soon put on a layer of bark and then appear yellowish brown. The leaf bases are decurrent, so that any transverse section shows five swellings 
which reach down from the five leaves next above. The leaves are deciduous and bear buds in their axils which develop in the following year. The majority of these buds, however, do not develop into long shoots, but remain stunted, and are called dwarf shoots. In these shoots the internodes do not lengthen, so that all the leaves borne by them are inserted very close together, and appear in a rosette. These dwarf shoots generally bear leaves for a number of years, and their age can be determined by counting the whorls of dark-brown bud-scales which remain attached at their bases. The dwarf shoots may, under favourable circumstances, grow out into long shoots, but they more commonly get left behind by the growth of the tree, and when they become too much shaded by other branches the shoots die and remain on the branches as tufts of brown bud-scales, until they are ultimately cast off the tree.

Internal structure of the stem. This will be described in detail, as the stem forms the feeding ground for the mycelia of all the most important disease-causing fungi. As it will be necessary to introduce a number of botanical terms which could not be explained except at great length, readers who are unacquainted with the general features of a plant's anatomy are recommended to omit this seotion and pass on to the general account of larch canker in the next chapter.

If a first-year shoot, about $1.5 \mathrm{~mm}$. in diameter, be cut in winter and a transverse section examined under the low power of a microscope, the tissues will be found to be arranged as in fig. 2. On the outside are five protrusions, the decurrent leaf-bases or' 'leaf-cushions', between which are narrow furrows. The cushions are nearly $1 \mathrm{~mm}$. in breadth and about $0.2 \mathrm{~mm}$. in thickness. These cushions contain rather large resin ducts, one near each edge, which pass down from the leaves and end blindly in the cortex. Their length is one to four times that of an internode, so that any section may disclose their presence in one to four cushions. Not infrequently one resin duct in a cushion is 
longer than the other, so that only one of a pair is cut across in a transverse section of some cushions.

Immediately inside the cushions is a continuous cork layer, which kills the outer cortex and epidermis, and inside this again is the inner cortex composed of live cells, with intercellular spaces, somewhat thick cellulose walls, and living contents with chloroplasts. A narrow continuous layer of phloem surrounds the wood cylinder, and imme-

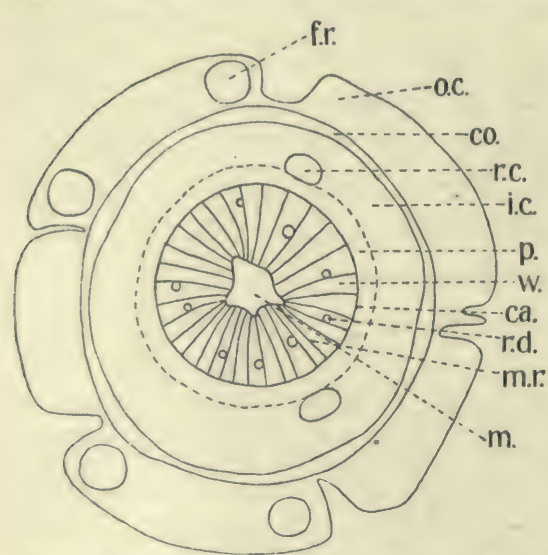

Fig. 2.-Diagram of a transverse section of a one-year-old stem of larch. ca., cambium; co., cork; i.c., inner cortex; f.r., foliar resin duct; $m$., medulla or pith ; m.r., medullary ray; o.c., outer cortex; $p$., phloem; r.c., resin cyst; r.d., resin duct in wood; $w$. , wood.

diately outside the phloem are a few nearly spherical resin cysts, which look like resin ducts in section, but are not extended longitudinally. The wood cylinder may be 4 or $5 \mathrm{~mm}$. in breadth, and contains a few resin ducts; and in the centre is a starshaped medulla.

Sections of older stems show progressive stages of thickening. Theleaf-cushions gradually disintegrate and fall off, and are usually indistinguishable after the fifth year. New cork layers are formed immediately under the first one. These layers are not always complete, and, in the second year especially, partial layers are frequently formed stretching under the furrows. In general a new cork layer is formed each year. The inner cortex remains living for an indefinite time, but loses its chlorophyll after a while. The phloem becomes thicker, and the outer firstmade elements are so stretched tangentially as to leave numerous large intercellular spaces. A fresh ring of wood is put on each year.

Detailed structure of tissues : epidermis. The cells measure 


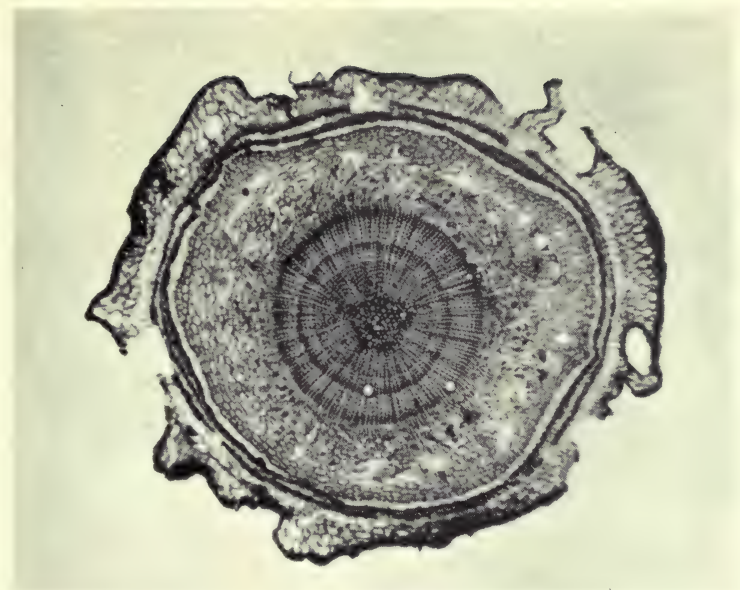

FrG. 3.-Microphotograph of transverse section of three-year-old stem of larch.

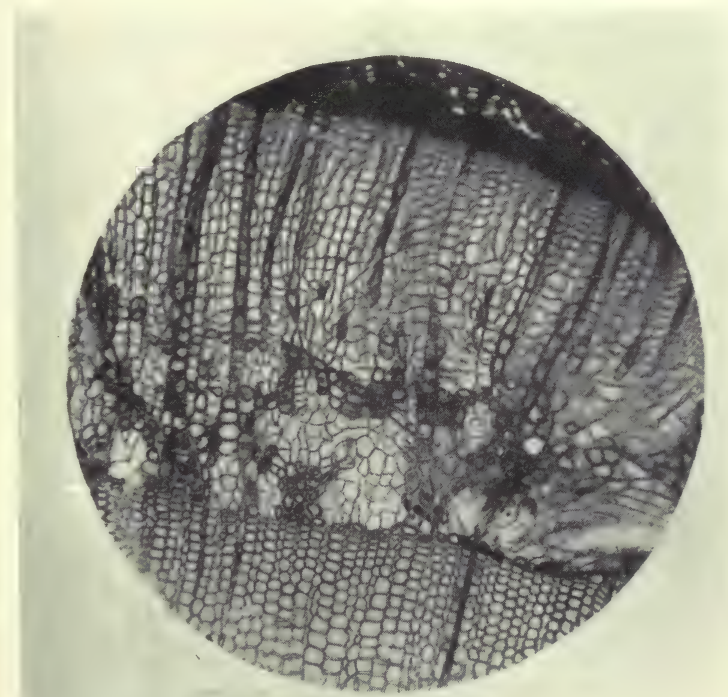

FIG. 4.-Microphotograph of transverse section of abnormal wood. 

10-20 $\mu$ tangentially, $17 \mu$ radially, and are longitudinally extended to about $400 \mu$. They are not only covered by a thick cuticle, but the outer and radial walls are strongly cuticularized, and a cellulose wall is superposed on this cuticularized wall, leaving a lumen with a diameter about half that of the original cell. Owing to the formation of the cork layer, this and the outer cortical layers are killed before the lapse of the first year.

Outer cortex. Next the epidermis are one to three layers of collenchyma, the walls of which give both the chlor-zinciodine reaction for cellulose and the phloroglucol and hydrochloric acid reaction for lignified walls. The walls are thick, with well-marked secondary and tertiary layers, and there are small intercellular spaces at the corners.

The parenchyma inside this is composed of large cells $30-100 \mu$ in diameter, and nearly isodiametric in all three planes. The resin ducts of the cushions are formed in this tissue, and may either touch the collenchyma or be separated from it by one or two layers of parenchyma. They are up to $170 \mu$ in breadth, and are lined by an epithelium protected by small parenchymatous cells on the outside. There is no further mechanical tissue to prevent their being crushed. These, with all the parenchyma in the cushions, are cut off by the primary cork layer, and are thus functional for less than one year.

Periderm. The phellogen is first formed in the layer of parenchyma immediately inside the collenchyma at the furrows, and forms a circle by cutting across the parenchyma of the leaf cushions (see fig. 2). The phellogen forms 1-3 layers of cork cells on the outside, and as many layers of phelloderm cells on the inside.

A new cork layer is formed each year in the following way. The innermost phelloderm layer becomes meristematic, and forms a new phellogen. The outer phelloderm cells and the phellogen of the previous year develop thick walls, become lignified, and take on the appearance of stone cells. In this way layers of stone cells, laterally welded together, are formed, and the walls become so thick 
that it is often nearly impossible to find the lumina or to distinguish one cell from another; the layer may be two cells in thickness, or it may be only half a cell in thickness, only one side of the cell having taken on a thick wall. The new phellogen then forms a few layers of cork cells and a fresh phelloderm.

This process is repeated year by year, so that a large number of cork layers are formed, all in the same radial rows with the rest, except where phellogen cells have

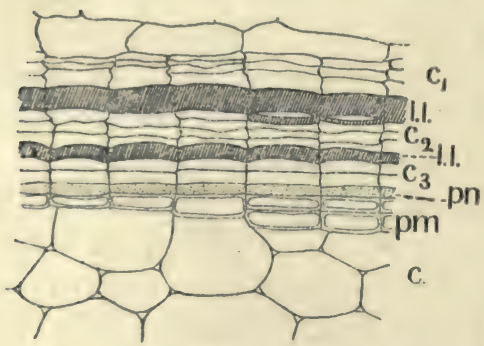

Fio. 5.-Diagram showing method of formation of periderm : c., cortex; $c_{1}$, first-year cork; $c_{2}$, second-year cork; $c_{3}$, third-year cork; l.l., lignified layer; pm, phelloderm; $p n$, phellogen. divided tangentially, and without encroaching on the inner cortex, which remains intact.

In special cases, however, e. g. where the cortex has become injured, a fresh phellogen may be formed through the cortex or outer phloem, as in ordinary scale bark trees.

A longitudinal section shows at the top of each leaf cushion a leaf scar where the abscission layer has cut off the leaf. A poorly developed cork layer is formed under the abscission layer, and the cells beneath this become suberized. The cork layer is joined on to the primary cork layer of the stem on all sides. These leaf scars would appear to be weak points in the defensive armour of the stem. At the same time they may serve for the interchange of gases, since no lenticels are present in the cork until the second year.

Inner cortex. The parenchyma inside the cork layer remains alive, and the cells contain chloroplasts. The cells are at first nearly circular in all sections, but later become extended tangentially to keep pace with the increasing girth of the stem. These cells usually divide by radial walls, and each elongated cell is replaced by two or three circular ones. This continued vitality of the cortex is rendered necessary by the peculiar form of periderm 
formation, which leaves the inner cortex intact even in old stems.

Two kinds of specialized elements occur in this layer. The first are small cells set aside for the purpose of containing crystals of calcium oxalate. These cells are only found in older stems, and are very frequent in the neighbourhood of cankers. The second are irregularly branched sclerenchymatous cells with very thick walls (fig. 6, s.e.). These elements grow longitudinally; forcing their way between the parenchymatous cells, and often braneh. The branching occurs when a sclerenchymatous cell encounters a parenchymatous cell broadside, and one branch grows down on each side of the obstructing cell. The function of these cells is obscure.

There is no distinction between the cortex and pericycle, but in the parenchyma immediately abutting on the phloem (and thus presumably pericycle) there are here and there large intercellular spaces which contain resin. When young they are small and chymatous element; s.t., sieve spherical, but with the in -

creased girth of the stem they become laterally extended and are conspicuous objects in all sections; they also acquire a poorly developed epithelium. They appear to be associated with some of the larger medullary rays, which, when followed into the xylem, are found to be in contact with resin ducts in the first-year wood.

The phloem is composed of sieve tubes, crystal-containing 
cells, parenchyma, branched sclerenchymatous elements, medullary rays, resin sacs, and horizontal resin ducts. When young these elements are found to be in regular radial rows, but in the older phloem the increased girth ruptures the rows and they become still more irregular through the tangential expansion of the medullary rays.

(i) The sieve tubes (figs. 6 and 7, s.t.) are small in section, tangential and radial dimensions being 8-20 $\mu$ and 5-8 $\mu$ respectively. Their length is difficult to determine, but has in certain cases been estimated at 0.8 to $1 \mathrm{~mm}$. The walls are rather thick, with sieve areas of the normal Abietineae type (vide Hill, 1901); these sieve areas are especially numerous on the radial walls, where they are uniseriate, and less numerous on the tangential walls, where they are uni- or bi-seriate. In winter the young sieve tubes contain a small amount of protein, but the older ones appear to be empty.

(ii) The crystal-containing cells (fig. 7 , c.c.) are of the same size and shape as the sieve tubes, but have thinner walls. They contain crystals of monohydrated calcium oxalate $\left(\mathrm{CaC}_{2} \mathrm{O}_{4} \cdot \mathrm{H}_{2} \mathrm{O}\right)$. These crystals are rhombs of the monoclinic (klinorhombic) system; the angle of the rhomb is $78-80^{\circ}$, and in polarized light the extinction is straight and the double refraction strong. They are very small and numerous, and occur in two or three series lying in a tangential plane. The growth of the crystals often causes radial swellings in the walls. Besides crystals the cells contain an emulsion which responds to stains for protein, tannin, and resin. No nucleus has been observed.

(iii) The cells of phloem parenchyma are large, $20-40 \times$ $20-35 \mu$ in transverse section, but only $60-90 \mu$ in length. They are formed in longitudinal series and have thin cellulose walls. Each cell has a lining layer of protoplasm and a rather large nucleus flattened against one side. Some cells in each series contain tannin (ferric chloride and potassium bichromate tests), whilst intervening elements are entirely without this substance. The osmic acid test also discloses the presence of fat, especially in the older 
parts of the phloem. Tetroctohedric crystals of trihydrated calcium oxalate $\left(\mathrm{CaC}_{2} \mathrm{O}_{4} \cdot 3 \mathrm{H}_{2} \mathrm{O}\right)$ are occasionally present in the vacuoles of these cells (fig. $6, p . p$.$) . These crystals are$ larger than those in the small crystal-containing cells.

The phloem parenchymatous elements occur more or less regularly in tangential rows, giving the effect of annual rings. Also the number of rings is approximately equal to the number of years that the stem has grown, but they are not sufficiently definite to determine an exact correspondence.

(iv) Branched sclerenchymatous elements, like those in the cortex, may also be found in the outer phloem. They seem to replace elements of phloem parenchyma.

(v) Medullary rays are very numerous, and may be from one to ten cells high. They are at first only one cell in thickness,

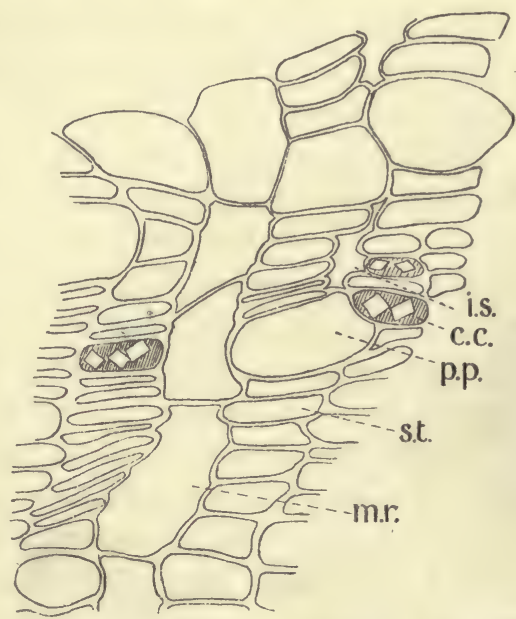

Fig. 7.-Transverse section of phloem $(\times 420)$ : c.c., crystal-containing cell ; i.s., intercellular space ; m.r., medullary ray; p.p., phloem parenchyma; s.t., sieve tube.

but through cell divisions they may become two or more cells thick. The cells remain thin walled, and contain protoplasm and nuclei; among the contents may also be seen numerous resin drops, especially in the vicinity of the cambium, and these drops are apparently conducted outwards to the resin sacs. The dimensions are about 5-20 $\mu$ in tangential, $20 \mu$ in longitudinal, and $40 \mu$ in radial direction, but the cells at the top and bottom of a ray are often extended longitudinally.

(vi) Resin cysts may also be found in the outer phloem. They have the same form as those in the pericycle, and are made by the expansion of a two-cell-thick medullary ray. 
(vii) Horizontal resin ducts are formed in some of the medullary rays. According to Willkomm these may be made as early as the second year, but I have not observed any ducts in such young stems.

Cambium. This is composed of very narrow thin-walled elongated cells. They are mostly about $10-20 \mu$ in tangential direction, but those which form medullary rays are narrower.

Xylem. This has the characteristically simple form of the Abietineae, and is composed of tracheides, tannincontaining cells, resin ducts, and medullary rays.

(i) The tracheides compose the greater part of the wood. In transverse section they are $10-20 \mu$ square in the spring wood, but in summer wood they may be as little as $5 \mu$ in radial measurement. They have lignified walls with a single, or occasionally double, row of bordered pits on the radial walls, and the last two or three rows of summer wood have them also on the tangential walls.

(ii) Tannin-containing cells have the same form in transverse section as the tracheides. They have, however, cellulose walls with simple pits, and accurately transverse septa occur at distances of about $100 \mu$. The simple pits connect with the bordered pits of adjoining tracheides or with the simple pits of medullary ray parenchyma cells. Their contents give reactions for tannin and protein, but not for resin, at any rate in March. They probably correspond to resin cells in allied types.

(iii) Resin ducts occur scattered irregularly in the summer wood. They are always small, and are formed in the following way. Four cells, which correspond to tracheides, form an intercellular space between them, and, remaining thin walled and alive, secrete resin into this space. The intercellular space then becomes the duct, and the four cells correspond to the epithelium. The walls of the latter may become weakly lignified, though remaining thin, and the cells may divide so that there are ultimately six or eight epithelial cells surrounding a duct. About nine or ten ducts, but generally less, may be formed in the wood of the first year, and corresponding numbers in succeeding years. 
(iv) The medullary rays (vide fig. 67) are composed of two kinds of cells. Firstly, the medullary ray parenchyma cells with thickened cellulose, or slightly lignified, walls with 2-5 (generally 4) slit-shaped simple pits into each tracheide they cross. These cells contain protoplasm, nuclei, starch, and resin. And, secondly, modullary ray tracheides which are not present in all rays, but are present on the upper and lower sides of many of them, and occur as intermediate layers of some. These cells have thin lignified walls with small bordered pits, and contain only water.

Medulla. This is the star-shaped central portion, having usually five unequal points which are left by the tracks of leaf traces, and thus correspond to the five rows of leaves. The medullary cells have at first cellulose walls, but when secondary wood is formed they become lignified, though the cells may still contain starch. 


\section{CHAPTER II}

\section{THE LARCH CANKER}

General. Historical. The mycelium of Dasyscypha calycina and its effect on the tissues. The canker as a pathological structure.

General. The canker or blister of the larch is by far the best known of the diseases of this tree. It is exceedingly common and very destructive, and, since none of the methods which have been adopted with a view to preventing attack have met with success, the pest bids fair to become even more disastrous in the future than it has been in the past. In Germany it has already made larch growing so unprofitable that the tree has almost ceased to be planted except where sparingly mixed with other species, and a like fate must follow it in many parts of Britain unless a system of growing can be adopted which will to some extent obviate the evil.

The disease is due to a fungus which has been called by a variety of names, but is now generally known as Dasyscypha calycina $^{1}$ in Britain and D. Willkommii on the Continent. This fungus belongs to the class Ascomycetes, since it bears its spores in eights inside an enlarged hypha or ascus (fig. 18, A, p. 40), and it is placed in the sub-class Discomycetes since its fructification is in the form of an open cup or apothecium (fig. 17, p. 38), which is lined on the upper concave side by the asci arranged at right angles to the surface.

D. calycina is almost universal on recently dead branches of larch trees. Its fructifications are very small, being seldom more than one-eighth of an inch in diameter, of bright orange or yellow colour above and white below, and each

1 The synonymy of Dasyscypha calycina is discussed in a note at the end of Chapter IV. 
apothecium has a short white stalk. When growing in this way (i. e. saprophytically) it does no damage to the tree. It is only when it begins to live parasitically and to prey on the living tissues that a canker is formed.

When it has penetrated the cork protection of a tree, the mycelium of the fungus kills the cortex and phloem (the soft tissues which surround the wood) and causes them to turn brown. Next it attacks the cambium, and since this is the tissue which gives rise to new layers of wood and phloem, its death renders the tree incapable of further growth in thickness at this point. The fungus spreads very slowly into the surrounding living tissues, and gradually kills a wider and wider area of cambium, so that a larger patch of the tree each year fails to keep up with the growth of the rest. In this way a flattened cavity is formed at the point where the cambium has been killed, the dead bark becomes blackened, resin oozes out and streams down the tree, and the whole presents the ugly appearance of a black blister or running sore. This is the canker.

On the blister may often be found the fungus fructifications, which are generally larger than the similar apothecia on the dead branches. When fresh these are orange-red in colour, but later they become bleached to a dirty white or yellow, and in this state may be preserved for many years in a stream of resin.

The effect which canker has on a tree depends on the age at which the attack occurs. To young trees it is often fatal, for the trunks grow but slowly during their first five or six years, and may consequently be entirely girdled by the fungus. This very frequently happens when grass and weeds are allowed to grow long among recently planted-out trees, producing humid conditions which encourage canker formation. When a tree is girdled in this way the upper part continues to grow for some time, for it still obtains water and mineral food from the soil and carbon from the air ; but organic compounds which it sends down towards the roots are checked at the point of girdling, causing increased growth and bulging just above it, and the roots 1888 
are starved. Thus the roots die before the upper part of the tree, and the tree subsequently has all the appearance of having died from a root disease. Similar girdling may be seen in the side-branches of older trees, since these also grow very slowly in thickness. But when a main trunk is attacked in a portion which is more than four or five years old, the annual growth in girth is usually sufficient to confine the canker to one side. Also the healthy cambium at the back of a canker is more active than it is above or below, and the annual rings are consequently especially broad, so that a swelling is formed at the back of a canker which prevents the water-current of the tree being appreciably interrupted at this point (see figs. 1 and 9). There is thus no reason why the top of such a tree should not go on growing just as vigorously as one which has no canker ; and such is the case, for often in a twenty-year-old plantation the tallest and strongest-growing trees are found to be cankered near the base.

One canker in an otherwise sound tree may not prove a very serious blemish; but when, as is not infrequent, we find as many as six or eight cankers on the main trunks of nearly every tree in a young plantation, then the value of each tree is reduced to a very small figure, and the wood is certain to prove a financial failure. It is against these attacks in which canker becomes epidemic that we have to protect our forests. The disease would not be so notorious were it not so extraordinarily hard to prevent. Only the forester, who, over acres of otherwise healthy larch plantations, sees canker after canker appearing, on his best trees as well as on his worst, can know what a curse this pest has become to European forestry.

Sometimes a tree apparently recovers from a canker (fig. 8 and fig. 25). This only happens when the cork layers, by which the tree always tries to prevent the spread of the fungus, have been successful, and failing to find new feeding grounds the fungus has died of starvation. The surrounding tissues then grow over and occlude the canker just as they occlude the wound formed by the fall of a branch. It may 


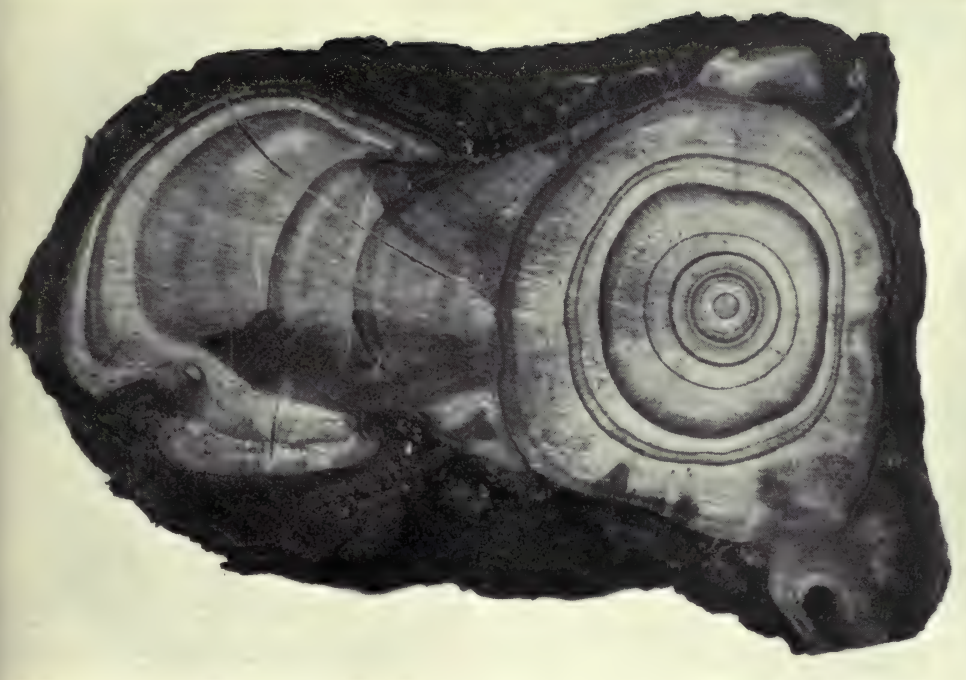

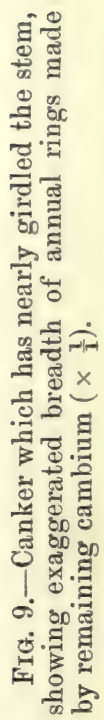

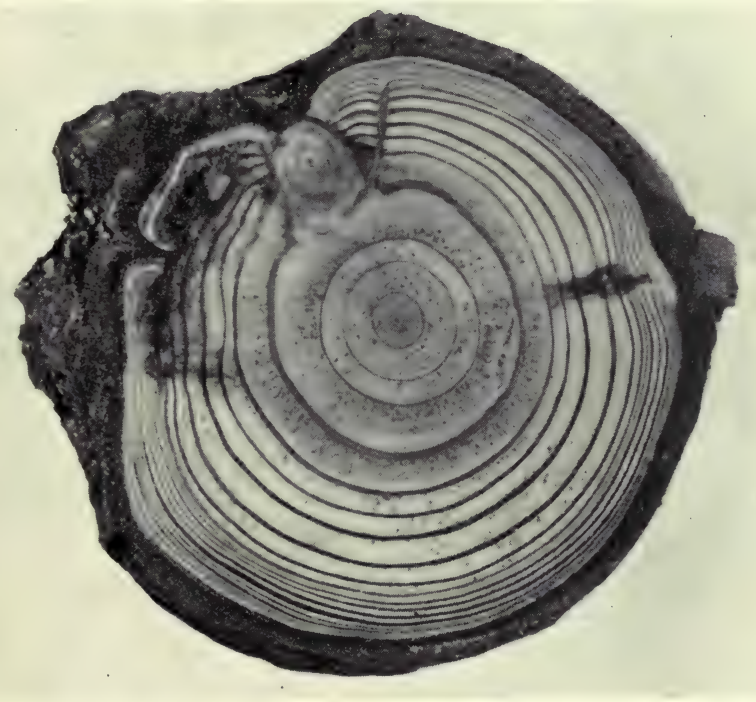

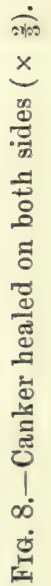



eventually be impossible to detect from the outside where the canker has been, but though the tree is to all appearances sound, there remains inside the blemish which the canker has left.

At present larch canker is prevalent only in Europe. It has been recorded from Britain (until twenty years ago it was rarely found in Ireland, but has now become common), France, Holland and Belgium, Scandinavia, Russia, Germany, Austria, Hungary, Italy and the Balkans, and probably its boundaries here are coterminous with those of larch cultivation. Australian and American text-books do not include the disease among their own pests, but care will be needed to prevent its introduction to these countries with seedlings from Europe. Indeed it has already been reported from Newfoundland, so that the danger to America is imminent.

Historical. It would be hard to say when or how the canker fungus was first introduced to Britain. According to Booth (1904) it was known to the Duke of Atholl at the beginning of the nineteenth century, ${ }^{1}$ and Loudon (1838, p. 2384) quotes as follows from de Candolle: 'Sometimes, also, we see the larches having a wound of resinous cancer ; but this seems to proceed from some accidental cause, such as a blow or a knock, which the tree may have received when it was in full sap. All these observations incline me to think that the cause of the diseases which attack the British larches must be sought for in some difference existing in the physical nature or in the culture of your trees and ours.' From this quotation we learn not only that the canker was fairly common in Britain by 1838, but also that it was less frequent in France than here.

The suggestions offered by de Candolle on the etiology of the canker are not happy, and Loudon's volume had reached the conventional age of manhood before the true

1 I have been unable to find a copy of the Duke of Atholl's book (1832) to confirm this reference. Schotte's view (1917) that 'canker, as a rule, has always been found where the larch occurs ', may probably be accepted for Britain as well as Sweden. 
cause of canker was discovered by M. J. Berkeley, ${ }^{1}$ who published a short article on the diseases of the larch in the Gardener's Chronicle for 1859. The canker which he described was found in a specimen 'forwarded by Sir Walter C. Trevelyan in which mycelium has penetrated through the bark and produced its proper Fungus, under the form of . . . Peziza calycina. In a small plantation, most of the trees of which are young, nearly all are more or less attacked on stem or branch with the Peziza.'

Berkeley's observations were characteristically direct and accurate, and he demonstrated the following features of the disease. (i) In affected portions the cambium is first killed in winter, since inside the canker the year's wood is always complete. The cambium must thus have been destroyed after the formation of the summer wood and before that of the spring wood. (ii) The growth of the cambium in the spring and summer is sufficient to counteract that of the fungus, but each winter more and more of the cambium is destroyed, so that a section of the cankered portion shows a step-like arrangement of the wood, one step corresponding to each year; or, as Berkeley described it, the wood is like an amphitheatre with its seats raised one above another on each side of a central depression (see fig. 12). (iii) The actual wood inside is attacked, but 'it should seem that the disease does not originate from the wood, and that the fungus is introduced into the wood

1 Miles Joseph Berkeley was born April 1, 1803, near Oundle in Northants. He was educated at Rugby and Christ's College, Cambridge, and took Orders in 1826. In 1829 he went as curate to Margate, and found time to study the anatomy of molluscs, and later, seaweeds. From 1833 to 1868 he was perpetual curate at Apethorpe and Wood Newton and lived at King's Cliffe, Northants, and from 1868 till his death in 1889 he was vicar of Sibbertoft, near Market Harboro'. Berkeley wrote the volume on fungi in Simith's English Flora (1836), and described (with Broome) the fungi collected by Darwin during the voyage of the Bergle, as well as other collections. He also published a number of books, chiefly on fungi, and many articles from his pen appeared in the Gardener's Chronicle and elsewhere. His writings are characterized by extreme care and lucidity (vide Distimnar!l of Nrticnal Biofraphly, vol. xxii, 1901). 
from the bark'. (iv) The disease occurred most frequently in damp situations. (v) Berkeley observed that the Peziza also occurred on many dead branches and on branches that had been left on the ground after thinning.

Recent authors have commonly lost sight of the fact that canker was first attributed to its true cause by an Englishman, and Berkeley's article has often been ignored by writers who have taken their descriptions from the more detailed papers of the German professors Willkomm and Robert Hartig. Willkomm's ${ }^{1}$ treatise, published in 1867 , is, for the time at which it was written, a remarkably full account of the parasitology and pathology of the disease. But it is marred at the outset by an inaccuracy in nomenclature, which he would have avoided had he been acquainted with Berkeley's article. His description and figures leave no doubt that he was studying the fungus Dasyscypha calycina, but he confused this species with another fungus, Corticium amorphum, ${ }^{2}$ a Basidiomycete, belonging to an entirely different group of fungi, which has a superficial resemblance to Dasyscypha and may sometimes be found growing with it. If this error in nomenclature be corrected throughout the paper, the reader will find an accurate record of much that was not previously known about the

1 Moritz W. Willkomm was born June 29, 1821, at Hewigsdorf near Zittau. He studied medicine and science at Leipzig. He travelled over a great part of Europe, taking a special interest in field botany, and wrote extensively on the flora of Spain and Portugal. He took his Ph.D. at Leipzig in 1850 and remained there as a Privatdozent. In 1855 he was created extraordinary professor and custodian of the herbarium. Soon after he was appointed professor of biology in the Forstakademie at Tharandt, where he remained till 1868, when he proceeded to Dorpat as director of the botanic garden. In 1874 he went to the German university at Prague and stayed there till 1893, when he retired. He died in Bohemia in 1898. Willkomm is chiefly known for his writings on the flora and ecology of Spain and Portugal, but he published papers on many other botanical subjects. His Microscopischen Feinde is, as far as I am aware, his only contribution to pathology (vide Allg. Deutsche Biographie, Bd. 43, 1898).

2 Hoffman (1868) was the first to call attention to this error. He correctly named the fungus Peziza calycina. 
disease. Willkomm described the formation of a canker in great detail, and even grew cultures of the fungus and observed the germination of the spores. But he assumed, without experimental evidence, that spores of the fungus could germinate on larch stems and could give rise to cankers by piercing the unwounded bark with their germ tubes, a supposition which was subsequently shown by Hartig to be inaccurate. Also he never proved that the disease could be caused by the fungus acting alone, or indeed that the fungus was a cause at all. All he showed was that in every canker he examined mycelium, and generally apothecia, were present; but whether the fungus caused the disease or the diseased spots formed a suitable breeding-ground for the fungus was left undecided. Pathology, as we know it, was not then born.

Thirteen years later, Robert Hartig ${ }^{1}$ (1880), after working out numerous other tree-diseases, published his paper on larch canker, which has remained since then as the standard account of the disease. He states that the first complaints of the disease were made in Germany about 1850, and by 1870 it had become a source of danger throughout the whole of Germany and Scotland. It was especially prevalent in damp and foggy regions, and he thought it was largely encouraged by inhibition of transpiration. It occurred, however, in the Tyrol up to nearly 2,000 m., and in that region cankers nearly one hundred years old were

${ }^{1}$ Robert Hartig was born May 30, 1839, at Brunswick. Both his father and grandfather were distinguished foresters, and ho had an early training in scientific forestry, both under his father at Brunswick (1861-3) and at Berlin (1863-4). He served his time in the forests, and after taking his doctor's degree at the university of Marburg he filled various positions in the forest service. In 1869 he was appointed professor of botany at Eberswalde, and from here published some of his most important pathological papers, including 'Wichtige Krankheiten der Waddbäume' (1874) and the 'Zersetzungserscheinungen' (1878). In 1878 he was elected to the new chair of forest botany at Munich, and remained there till his death in 1901. His extraordinary energy is shown by the number and importance of his published works, which comprised 16 books and 130 other papers (vide Biographisches Jahrbuch u. Deutscher Nelorolog, Bd. vi, S. 93, and Zentralblatt für dis gesamte Forstwesen, 1902, pp. 37-46). 
found. Hartig noticed certain microdimensional differences between the canker fungus and the type Peziza calycina, and named the former Peziza Willkommii, but as these differences are not constant this name may be dropped. The synonomy of the fungus is difficult, and is discussed in a note at the end of Chapter IV.

The most important contribution which Hartig made to our knowledge of the disease was the result of his experiments on artificial infection. Previous experiments of this sort had been carried out by Fischer, a practical forester, in 1877 ; he cut pieces of bark and phloem out of a canker area and fitted them into suitably-shaped holes made in healthy trees; the latter became infected and ultimately showed all the features of canker. This proved that the canker was due to some transmissible cause, and was not entirely the result of unsuitable growth-conditions, as seems to have been generally supposed by English foresters even as late as 1895 ! But it did not establish a connexion between the disease and any one fungus, since a portion of infected tissue cannot be regarded as a pure culture of any particular parasite, and, as far as Fischer's experiments could testify, the Peziza might be a more or less constant concomitant of the canker without being its cause.

Hartig's experiments were of a more exact nature. He grew small larches one metre high in pots and infected them on September 29, 1879, with ascospores through small wounds. The pots were left in the open till the beginning of January, when they were placed in a room, and by the middle of January disease, accompanied by death of the bark, was noticed within a centimetre of the points of infec tion. By the middle of February normal fructifications were formed. Investigations showed that the mycelium had grown in October, but rested in November and December. All attempts at infection with uninjured trees failed, and it was only found possible to inoculate trees through wounds. On this rather slender evidence Hartig based his theory that the fungus could not gain admission to trees which were entirely uninjured. 
In addition to this experimental work Hartig added to Willkomm's description of the mycelium in the bark, phloem, and wood of the larch. In the wood it was distinguishable in the medullary rays, the resin ducts, and tracheides. In the sieve tubes he noticed that the hyphae bore short extensions, with or without a few branches.

He added little to our knowledge of macroscopic features of the disease, with the exception of some observations on the resin flow from the surface of the bark, but he provided some interesting measurements of the growth of canker in the longitudinal direction of the stem. They were taken from three isolated cankers from different altitudes, and though they were insufficient for a just comparison of the rates of growth at these levels, they nevertheless give some indication of the growth of a canker generally. The cankers were measured at-

1. Steinach (Tyrol), 1,300 m. (4,300 ft.) above sea-level.

2. Grafrath (near Munich), $700 \mathrm{~m}$. (2,300 ft.) above sealevel.

3. Brunswick Forest Garden, $170 \mathrm{~m}$. (550 ft.) above sealevel.

The results were as follows:

$\begin{array}{cccc}\begin{array}{c}\text { After } \\ \text { years }\end{array} & \text { Steinach. } & \text { Grafrath. } & \text { Brunswick. } \\ 1 & \text { cm. } & \mathrm{cm} . & \mathrm{cm} . \\ 2 & 1 \cdot 0 & 1 \cdot 2 & 1 \cdot 0 \\ 3 & 2 \cdot 2 & 3 \cdot 9 & 3 \cdot 3 \\ 4 & 7 \cdot 0 & 6 \cdot 5 & 8 \cdot 1 \\ 5 & 9 \cdot 4 & 9 \cdot 2 & 10 \cdot 5 \\ 6 & 11 \cdot 6 & 13 \cdot 1 & 13 \cdot 0 \\ 7 & 16 \cdot 8 & 17 \cdot 7 & 14 \cdot 7 \\ 8 & 20 \cdot 2 & 20 \cdot 6 & 16 \cdot 0 \\ 9 & 21 \cdot 8 & 24 \cdot 8 & 16 \cdot 9 \\ 10 & 24 \cdot 6 & 30 \cdot 5 & 19 \cdot 3 \\ & 27 \cdot 0 & - & 23 \cdot 0\end{array}$

The importance of-Hartig's work on tree pathology will be best appreciated when it is observed that reference has been made to contributions by this author under the head of nearly every disease mentioned in this book. The vast field of research covered by Hartig appears still more remarkable if we remember that when he started on his work the subject was in an entirely chaotic state, and it is 
chiefly through his untiring zeal that chaos has given place to order. The authority of Hartig's name had become so great that it has been thought scarcely worth while to reinvestigate diseases on which he had written, and consequently less is often known about parasites which he investigated than about others, of smaller importance, which were unknown in his time. The ground has been left as Hartig tilled it, and pathologists have sought new fields where the spirit of the pioneer has attracted them. Hartig's views were presented in English by Marshall Ward (1889), but without addition or correction.

Among subsequent papers the following may here be noticed :

Carruthers (1891) noted the blackening of the bark in the neighbourhood of the canker, which he attributed to the fungus Antennaria pithyophila, Fr., which looks like a covering of soot. As the result of observations on young cankered trees which showed no sign of having been wounded, he expressed the opinion that young trees might be attacked by the Dasyscypha while still unwounded, if the bark and air were damp.

Somerville (1895) published the results of an inquiry among foresters, instituted by the English Arboricultural Society, in pursuance of which a number of questions were put in relation to the causes and nature of larch canker. Forty answers were received, the chief value of which was to elicit evidence as to the kinds of soil and climate in which the disease was most to be feared. The majority agreed that damp situations are favourable to the canker, and many regarded larch aphis as a predisposing factor. Somerville suggests that this is due to the partial inhibition of transpiration caused by the aphis, and also that the aphis makes holes in the twigs and spurs, through which the spores of Dasyscypha may infect. A similar inquiry was held by the Scottish Society in 1905 (vide Richardson, Borthwick, and Mackenzie).

Massee (1902) performed experiments to demonstrate the connexion between the aphis, Chermes abietis, and the entry of the Dasyscypha, and found that canker spots resulted 
from placing spores in contact with the mucilaginous excreta of the Chermes in the spring.

A. P. Anderson (1902) gave an account of canker on Abies balsamea, which is caused by an allied species, Dasyscypha resinaria. This canker resembles, in most respects, that of the larch, and the further details which he provides, especially in connexion with resin flow, are for the most part equally true for the larch canker.

Münch (1909) carried out some interesting experiments on the relation between the rate of growth of a canker and (i) the air-content of the tissues, (ii) the temperature. $\mathrm{He}$ cut young shoots $(5 \mathrm{~cm}$. broad), which, though cankered, were still living, into strips $20-30 \mathrm{~cm}$. long, each with a canker. These he dried to varying extents, and found that the canker spread much more rapidly in the drier than the moister stems. He attributes this to greater air-content, but it may also be accounted for by the lessened vitality of the tissues induced by drying. He also found that the minimum temperature for the growth of the fungus is above $0^{\circ} \mathrm{C}$., so that it must be incapable of spreading during an Alpine winter.

is:?

The mycelium of Dasyscypha calycina in the larch stem and its effect on the tissues. The hyphae of $D$ yscypha calycina have been found in the outer cortex of the leaf cushions, the inner cortex, the phloem and xylem, and the medullary ray portions of the cambium.

Its presence in the leaf cushions of uninjured larch stems is of no practical importance. No great development of Dasyscypha hyphae has been observed in this region; but that there is sufficient nutriment for fungal sustenance in these cushions, even when they have been cut off by a cork layer, is demonstrated by the fact that fungal pycnidia may not infrequently be found growing in them. If the hyphae of Dasyscyplua obtained a firm hold on the cushion, any weak points in the cork armour would be liable to discovery, which would put the plant in danger of infection without previous wounding; but there is no direct evidence for this ever having taken place. 
The most marked development of the mycelium is located in the inner cortex and outer phloem. The hyphae grow freely in the intercellular spaces (which, as shown in Chapter I, are especially large and frequent in the outer phloem) and the resin cysts, and send branches through the walls into the cells, and these branches ramify and pass from cell to cell. The hyphae are usually rather small in the intercellular spaces, and the branches which enter cells are broader.

These larger hyphae have often a wavy outline, and contain numerous small oil drops. As the hyphae use up the food contained in the cells of the cortex and phloem, these cells contract and leave large spaces which become tightly packed with the mycelium of the fungus, and it is from the more superficial of these close masses of hyphae that the fructifications arise.

Except in cases of advanced disease, the hyphae do not grow luxuriantly in the inner phloem, cambium, or wood; this is probably due to there being few intercellular spaces, and consequently insufficient aeration. When they do enter the

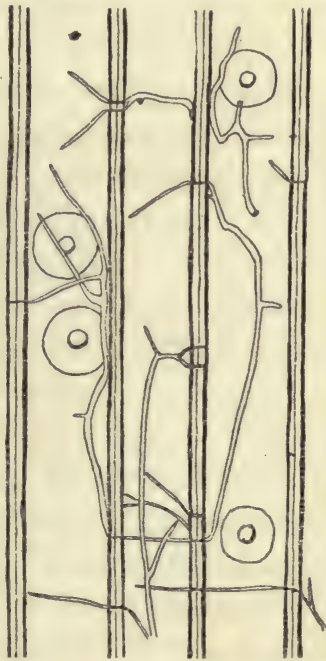

FrG. 10.-Mycelium of Dasyscypha in the wood of the larch. Radial section $(\times 630)$. wood they are at first nearly confined to the medullary ray parenchyma; only a few branches enter the tracheides, and these do not grow freely. But as the disease advances the air-content of the wood becomes relatively much higher, and the mycelium enters the tracheides and changes the wood from the normal yellow to a reddish-brown colour. Gradually in this way the mycelium may penetrate to the centre of the stem and attack the heart-wood, which, having a higher air-content, provides a more suitable substratum than the sap-wood; and, as the heart-wood increases, the fungus can flourish in it and fill many of the tracheides with 
an anastomosing mass of hyphae. In this case a red-brown stain is formed in the centre of the stem, irregularly starshaped in section and continuous on one side with the canker, but spreading for a short distance above and below it in the heart-wood.

The hyphae are colourless and of markedly varying width; they pass through the tracheide walls by very fine bore-holes, which are usually accurately transverse, but may be somewhat oblique or may even be transverse on one side of the middle lamella and oblique on the other. The whole mycelium in this region is evanescent and does little damage to the wood.

An interesting phenomenon in connexion with this attack is the formation of a gum by the infected wood. This gum has been worked out more in detail in connexion with the larch heart-rot which also stimulates its formation.

Under the influence of fungal attack the tissues show certain changes which must be described in detail.

(i) The walls of all the cells in the neighbourhood of the mycelium turn brownish yellow in colour; frequently their contents are modified; the protoplasm becomes markedly vacuolated, and the nuclei lose their rounded outline. Large accumulations of crystals of calcium oxalate, both of the mono- and tri-hydrated form, appear in the cortex, and crystals of the trihydrated form become much more frequent in the phloem parenchyma, and may also occur in the medullary ray cells. Large quantities of resin are formed in all cells, much more than can be contained in the resin cysts, so that all the tissues become saturated with it. The tannin content is also increased. Tannin and resin are probably products of excessive katabolism, showing that the protoplasm of the cells has respired to an abnormal extent, only ending in death. The calcium oxalate may arise partly in this way, though as shown below it is also excreted from the fungus.

These phenomena are not confined to the cells which either contain hyphae or have hyphae touching them; but all the cortical and phloem tissue, for a thickness of about 
three cells round the penetrated area, becomes yellow, and cells at a considerably greater distance contain more crystals than normally. The contents of the medullary ray parenchyma become brown, and the nuclei appear irregular, through two or three annual rings of xylem before the hyphae can be observed to have reached the cambium.

There is thus evidence that some poisonous substance is transmitted from the hyphae to surrounding cells (especially along the medullary rays), which first stimulates excessive. respiration in the cells, and ultimately causes death. It is not clear whether this substance is actually secreted by the hyphae, or whether it is some product of decomposition of the attacked cells, but there are certain reasons for favouring the former view. A phenomenon which is of interest in this connexion was observed in artificial cultures of Dasyscypha calycina on nutrient agar. ${ }^{1}$ Streak cultures were grown in Petri dishes, and all round the mycelium a kind of halo was noticed, which proved to be due to numerous crystals of monohydrated calcium oxalate extending to a distance of $1 \mathrm{~cm}$. from the mycelium. Presumably oxalic acid was secreted by the hyphae, and was converted into calcium oxalate by the calcium in the substratum.

This phenomenon is not confined to cultures of Dasyscypha calycina; but it has a particular interest in this case, as it suggests that oxalic acid may be the actual substance secreted by the fungus which kills the cells of the host; for probably the same process takes place in the tissues of the larch. At first the cells in the neighbourhood of the hyphae are able to render the acid harmless by means of the calcium at their disposal, which accounts for the accumulation of calcium oxalate in the affected tissues. But when this is used up the concentration of acid gradually kills the cells. By this means the fungus is able to spread through living tissues without being a true parasite ; that is to say, it kills the cells by secretions and enters them when they are dead. This kind of false parasitism has been investigated

1 Agar-agar 10 grm., malt extract 30 grm., meat extract 3 grm., and citric acid $0 \cdot 3 \mathrm{grm}$. in 1,000 c.c. distilled water. 
by de Bary (1886), and later by Kissling (1889), Smith (1902), and Brooks (1908), in the case of Botrytis cinerea. Various views have been entertained as to the substance which Botrytis secretes, but recent work by Blackman and Welsford (1916) and W. Brown (1915, 1917) has shown that oxalic acid plays no significant part in the parasitism of this fungus. Thesn authors have further demonstrated that the only active substance secreted by the germ tubes of the fungus is an enzyme which destroys the cellulose walls of the host. Whether or no oxalic acid plays a part in the parasitism of Dasyscypha, there seems to be little doubt that the fungus should be regarded rather as a plant poisoner than a true parasite. It first kills the cells in its neighbourhood and then grows into them.

(ii) The tissues in the proximity of the fungus grow faster than usual, causing a swelling which is noticeable in young cankers. A specialized form of this activity is the formation of new cork layers. These may surround an infected area and inhibit further advance of the fungus. Cases have been observed where the mycelium has been successfully prevented from reaching the phloem by such a cork layer, and probably this frequently happens, though it easily escapes observation, as the general healthy appearance of the stem is so little disturbed. The tree always tries to isolate the fungus, and when the mycelium has penetrated the phloem and killed the cambinum at any point, phellogen layers are instituted, which cross the cortex radially and then traverse the phloem in an oblique direction, and this phellogen forms a ring of cork which tends to prevent the canker spreading in a lateral direction. The cork layer formed by such a phellogen for a time completely prevents the further growth of the mycelium, and in some sections I have seen the tissues on one side of a cork layer healthy and apparently normal, whereas on the other side the colls were brown and had contracted, leaving large intercellular spaces filled with hyphae: Often, however, such cork layers may be found embedded in the brown attacked tissues, showing that the fungus has succeeded in passing 
them. The hyphal development in the wood never seems to be of a nature that can cause reinfection of the phloem, so that probably the hyphae get round the cork layer in the cambium just outside the wood, and spread from that point. Cork formed in the vicinity of the fungus is apt to become red. This is due to infiltration with resin, and cork cut fresh from a healthy tree may be made to assume this red colour by boiling in resin.

(iii) The character of the secondary wood which is made in the neighbourhood of the canker is also profoundly affected.

Where the cambium is killed, of course no more wood can be formed; but the cambium which is still living on the flanks of this dead patch cuts off wood elements which are essentially different from normal xylem (fig. 4 and fig. 11). The cells which are first differentiated in the spring wood remain thin walled and show no tendency towards sliding growth. Their walls become lignified and have numerous simple pits. Sometimes the living contents remain, but not infrequently they become disorganized and are replaced by water. Thus in many ways they resemble medullary ray parenchyma, except that they are extended longitudinally instead of radially. Irregular intercellular spaces are formed between them, and these often become filled with resin. Normal resin. ducts are also formed, besides such irregular abnormal ones (fig. 4, p. 8).

As the summer advances tracheides are formed. These, however, have an irregular wavy outline, which gives a truly longitudinal section the appearance of being oblique, although entire tracheides may be included in it. Subsequently formed tracheides are normal except for the frequency of a tertiary spiral thickening of the walls. Tannin cells are frequent throughout this portion.

The significance of this abnormal wood is difficult to define. In many respects it resembles the wound-wood described by Vöchting (1892) and Kuster (1903); but Hartig (1892) figures a very similar development in spruce after defoliation by the nun moth, and Harper (1913) has 
found a similar formation of resin ducts in larch which has been attacked by the sawfly. These comparisons do not support the contention of de Vries (1876) that such wood is the result of reduced tangential pressure produced by a wound, since in two cases the tree was not wounded

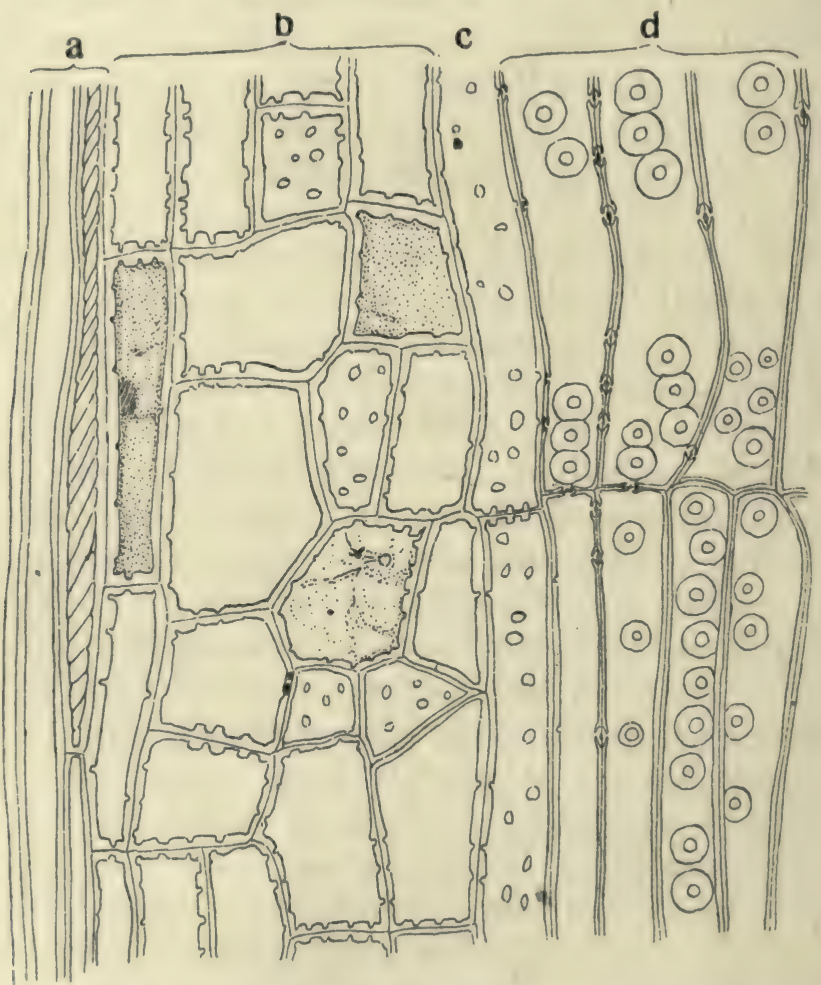

Fro. 11.-Radial longitudinal section of abnormal wood: $a$, summer wood of previous year, abnormal one cell shows tertiary thickening; $b$, short sclerenchymatous elements; $c$, long sclerenchymatous elements; $d$, nearly normal xylem.

except in its crown. We have rather to look for the cause in the reduction of food supply which may be brought about, either by defoliation, or by the death of the phloem in the neighbourhood of the developing wood.

In the canker the formation of normal wood is resumed only when new phloem has been made outside, which forms 
efficient channels for the conduction of organized food material sent down from the leaves.

The canker as a pathological structure. The type of structure known as a canker is the outcome of the action of a fungus on a stem. The same general result may be produced in different trees by different fungi (cf. canker of apple and ash caused by Nectria ditissima). But fungi which are capable of jroducing cankers must have four properties which, together, distinguish them from most other parasites. These features may be summed up as follows:

(i) They must be capable of killing living tissues, i. e. either they must be parasites in the ordinary significance of the word, or they must be capable of secreting some substance which kills the cells in their vicinity so that the fungus can penetrate them.

(ii) They must be essentially 'rind fungi', i. e. fungi whose mycelia flourish in the cortex and phloem of the stem and kill the cambium; and if the hyphae enter the wood at all, they must be incapable of spreading extensively in this part of the stem, or reinfecting the phloem; otherwise the hyphae would soon spread right through the tree and kill an entire section of the stem.

(iii) The mycelium must be perennial in the tissues of the cortex and phloem.

(iv) The mycelium must spread from cell to cell extremely slowly, so that its rate of tangential extension is approximately equal to the rate of increase in girth of the stem. If the mycelium spread too fast, it would soon extend the whole way round the stem, whereas a canker can only be produced as the result of continued growth of the stem whilst being attacked. And if the mycelium spread too slowly it would never get through the phloem and reach the cambium. When a fungus with these four characteristics attacks a host, a canker is the necessary result.

The canker of the larch usually obtains its hold on the stem within the first six years of its growth. The fungus gains admission-in what way will be shown later-and flourishes in the cortex and outer phloem, where there are 
large intercellular spaces. All the cells in the neighbourhood of the fungus are killed by secretions, and the fungus follows these secretions and feeds on the cells which have been killed by them. The further development of the canker can best be followed by reference to the accompanying diagrams.
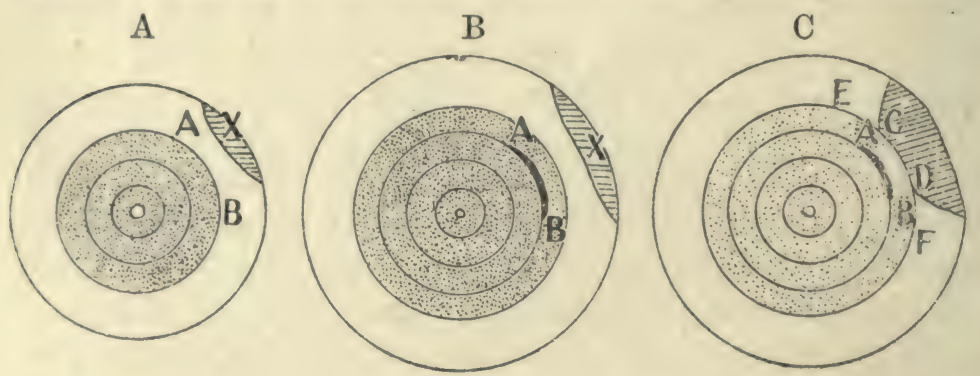

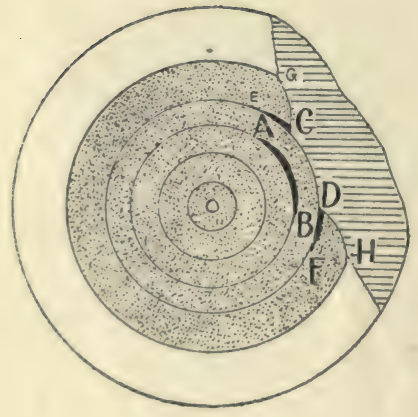

D

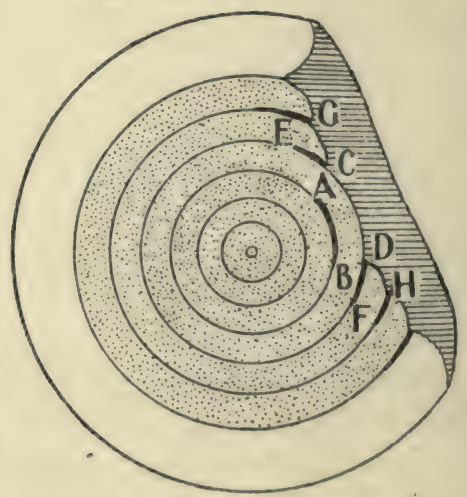

E

Fro. 12.-Diagrams showing stages in the development of a canker: A, first spring; B, first autumn; C, second spring; D, third spring ; E, fourth spring. For description, see text.

Fig. 12, A, shows a transverse section of a three-yearold stem in which' a portion ' $\mathrm{x}$ ' has been attacked and killed by Dasyscypha. In the spring of the first year the fungus has not reached the cambium, but is near enough to the section $\mathbf{A B}$ of the cambium to have affected it and caused it to make the abnormal wood $\mathbf{A B}$ of fig. 12, B. This latter figure shows the state of affairs at the end of 
the first year; the formation of the phloem outside $A B$ has kept the mycelium away from the cambium, though the mycelium has spread, especially in a tangential direction. Fig. 12, c, shows the position in the following spring. The section CD of the cambium has been killed by the inward growth of the fungus, which has also come sufficiently near the segments $\mathrm{EC}$, DF to affect them in the same way as $\mathbf{A B}$ had been affected a year earlier. By the next spring the canker has grown to the stage seen in fig. 12, D; CD has made no wood, EC, DF have made abnormal wood similar to $\mathbf{A B}$, and during the winter the mycelium has killed the further stretches of cambium GC and DH. Fig. 12, E, shows the canker after developing one more year on the same system. It is thus seen how the amphitheatre-like canker is formed, and also how the abnormal wood is related to it.

The step-like configuration of the sides of the amphitheatre clearly shows that the fungus makes greater inroads on the host in the winter than in the summer months. This can be accounted for most simply by the winter cessation of growth on the part of the tree, and it is quite unnecessary to assume with Hartig that the fungus grows more actively in winter than in summer. Hartig suggested that in the summer the tree tissues contain a larger percentage of air than during the winter (since in summer the soil and air are drier and the transpiration pull is greater), and that the reduction in water content inhibited the mycelial development of the fungus. But Münch (see p. 26) has shown that a high air-content stimulates, rather than retards, the growth of the fungus, so that Hartig's explanation is not in keeping with the experimental evidence. Further, Münch's discovery that the lower limit of temperature for fungal growth is above freezing-point precludes the possibility of fungal development during an Alpine winter. It is sufficient for our purpose to observe that during the winter the dormant cambium is more exposed to attack by the hyphal secretions, whereas during the summer it is protected by a constantly, thickening layer of new and active phloem. 
When part of the cambium has been destroyed, the rest makes up for the loss by greater activity, and opposite a canker the wood is abnormally thick, and the whole stem may bulge in a curious fashion. The same may happen at the sides as well, so that when one looks the canker full in the face it appears to be set in an especially broadened part of the stem (figs. 13 and 14).

All the cells in the neighbourhood of a canker form large quantities of resin, which permeates all the tissues. This gradually oozes out through the shrivelled cortex and phloem, and losing its more volatile constituents on exposure to the air, hardens into large whitish drops. Such large quantities are often formed that it runs down a stem in streams, covering the bark for several feet. 


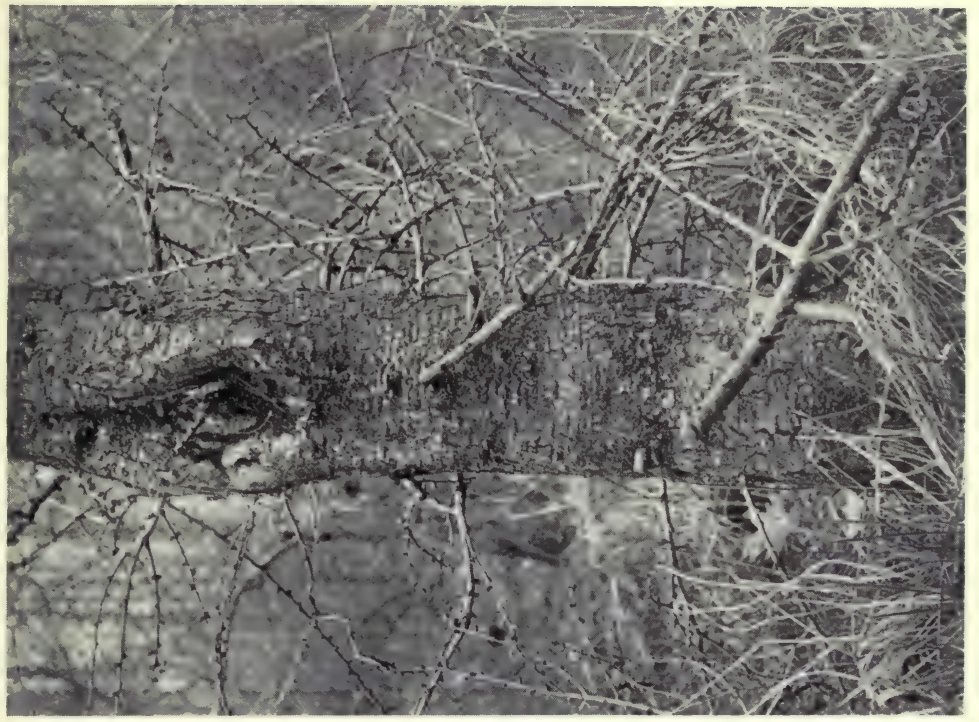


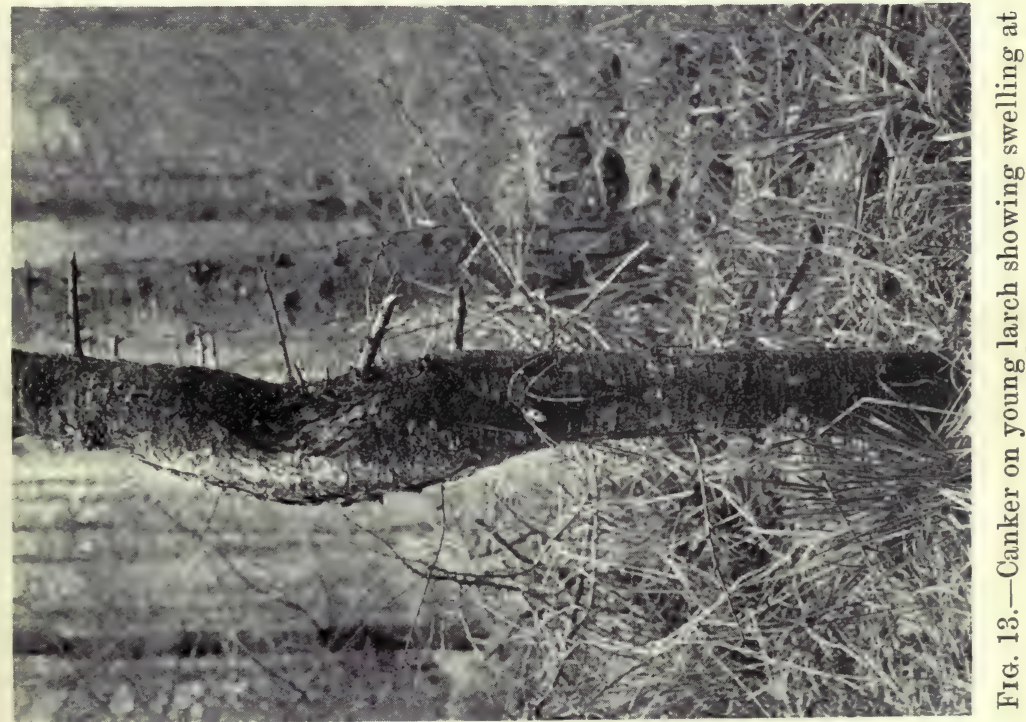



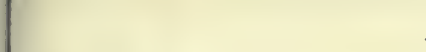

$-$ 


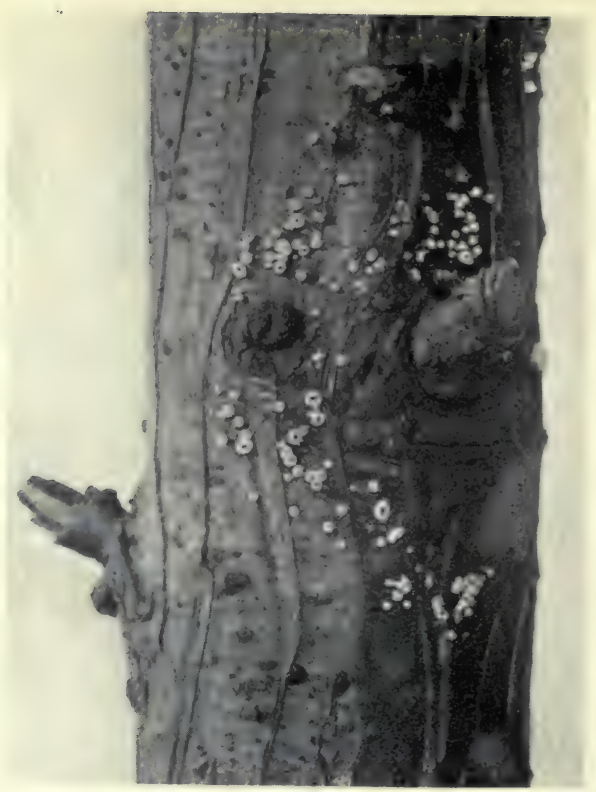

FIG. 15.-Apothecia of Dasyscypha calycina on dead larch stem $\left(\times \frac{5}{4}\right)$. Closed in dry weather.

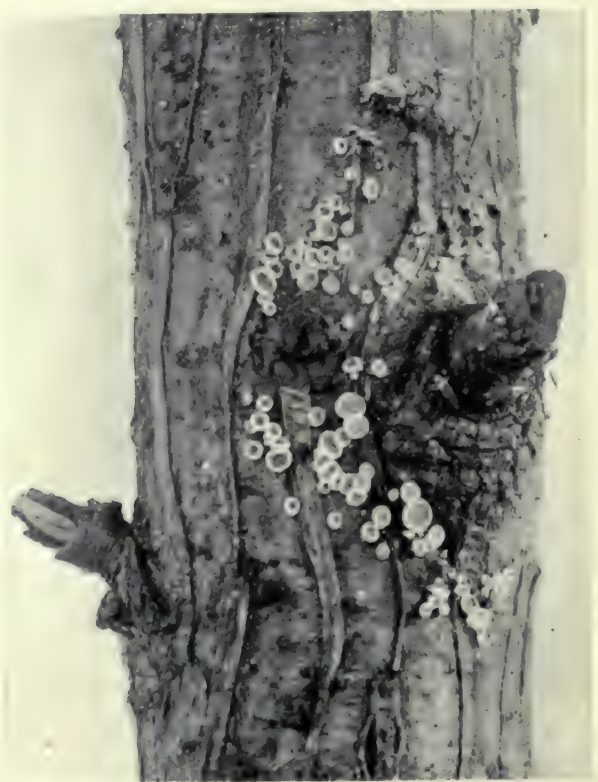

Fra. 16. - Same apothecia as in Fig. 15, open in wet weather. 


\section{CHAPTER III}

\section{THE LARCH CANKER (continued)}

The reproductive organs of the fungus. Germination of spores. Pure cultures on nutrient media. Artificial infection with canker.

The reproductive organs of the fungus. The reproductive organs are of two kinds :

1. Apothecia.

2. Spermogonia or pycnidia, the name depending on the interpretation of their morphological nature.

When fructifications are about to be formed there first appear on the surface of the bark a number of white or pale yellow felt-like mycelial outgrowths. These may give rise to both apothecia and spermogonia, the latter being generally mature just at the time when the former are initiated.

Apothecia. The youngest stage which I have traced in the formation of apothecia consists in a group of hyphae standing out from a small portion of one of the mycelial masses on the surface of the stem. These hyphae are easily distinguished by numerous very fine wart-like outgrowths on their walls. The portion bearing them is circular in outline, and towards the centre the hyphae are bent inwards. Underneath these hyphae there next appears the first indication of a layer of hyphae directed at right angles to the surface. This layer, which is the young hymenium or ascus-bearing layer, becomes broadened by the interpolation of fresh hyphae, and the apex of the apothecium opens, leaving the warted hyphae as a broad fringe of hairs round the hymenium, which is orange in colour.

The apothecium grows for a long time, reaching a size of 2-4 mm., or in extreme cases $5 \mathrm{~mm}$. The hymenium becomes paler with age, and the margin and under-surface are white throughout. The whole is raised on a short stalk about $1 \mathrm{~mm}$. in height and rather less in thickness (fig. 17). 
A section through a ripe apothecium shows the lower portion, or excipulum, differentiated into two parts. The outer (lower) portion, or cortexx (fig. 17, c), is composed of a mass of closely interwoven and rather swollen hyphae of firm texture. The middle portion is made up of hyphae which are much less closely interwoven. The hard cortex not only prevents. loss of water from the apothecium, but also assists in closing it in dry weather. For on drying the central portion contracts more than the cortex, and this

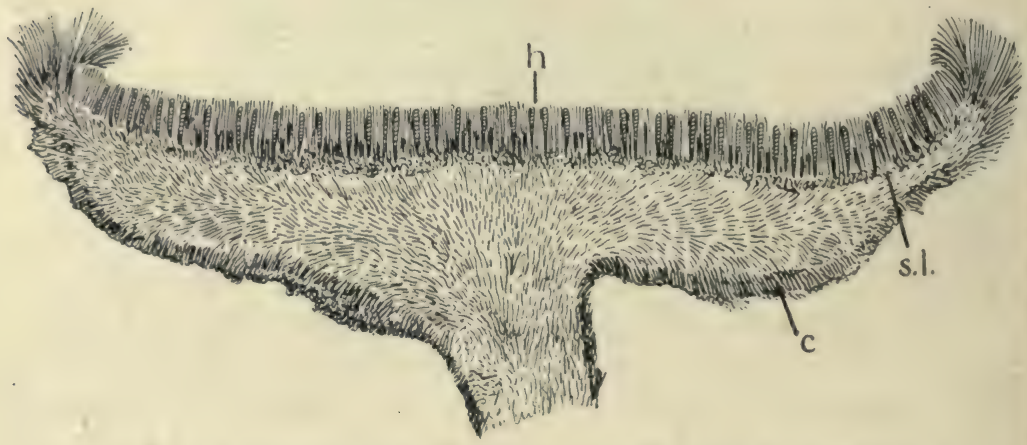

Fra. 17.-Section through apothecium of Dasyscypha calycina: c, cortex ; $h$, hymenial layer ; s.l., subhymenial layer.

causes the margin to fold over the hymenial layer (figs. 15 and 16).

The hymenium (fig. 17, $h$ ) is a layer composed of asci and paraphyses, and is borne by a dense subhymenial layer, s.l. The details of the hymenial layer are more clearly shown in fig. 18, A. The ascus, $a$, is the organ which produces and ejects the spores. The eight spores occur in a single row and fill the upper part of the ascus, whilst the lower part contains hyaline protoplasm. The length of the ascus is $150-200 \mu$, and the greatest breadth is $10-14 \mu$. It is nearly cylindrical, but somewhat swollen towards the upper end, and tapering at the lower end. The walls are sufficiently thick to show a double outline under a D objective, except at the extreme apex, and are quite smooth. The spores (fig. 20, A) are ellipsoidal, the long axis being 20-23 $\mu$, 
and the short axis 9-10 $\mu$. Each contains, when ripe, a single central nucleus and a large hyaline vacuole, containing glycogen, on each side of it, lying with it in the long axis of the spore. The wall is thin, but appears with a double contour under a D objective. The spores are ejected by a sudden squirt action to a height of about half an inch, and after ejection the top portion of the ascus can be seen to be bent back as in fig. 19 .

The apex of the ascus, at any rate in my specimens, does not turn blue with iodine. As some authors have described this as a feature of the fungus, it is apparently variable in the species.

The paraphyses (fig. 18, p) are thin hyphae which are found between the asci. They are unseptate and very fine, $1 \cdot 5-2 \mu$ in diameter, and about $30 \mu$ longer than the asci. The apices are scarcely perceptibly swollen, but they tend to bend over the asci and protect them. When kept in a saturated chamber the whole apothecium often becomes filled with a drop of water. This is probably secreted by the paraphyses, and as the secretion presumably continues in a dry atmosphere also, it may serve by evaporation to moisten the air round the asci and save them from drying up.

Fresh asci continue to be formed for a long time. They appear as short swollen hyphae growing up from the subhymenial layer, but ascospores cannot be traced in them until they are fully grown.

The margin of the apothecium is covered by stiff bristlelike hyphae, which, as described on p. 35, have numerous very fine warts on their walls. Anderson (1902) describes these warts as crystals of calcium oxalate. But I find that they do not dissolve in acetic acid or in dilute sulphuric or nitric acid. I am inclined to regard them, therefore, as outgrowths of the wall substance.

The same general description applies to the apothecia found on dead branches. These are, however, smaller, and ior their dimensions the reader is referred to p. 79 .

Spermogonia (fig. 18, B, C). The spermogonia are also formed on the mycelial cushions, and may be found on the 
same cushions as very young apothecia. They consist of a ramifying series of cavities nearly filled with hyphae
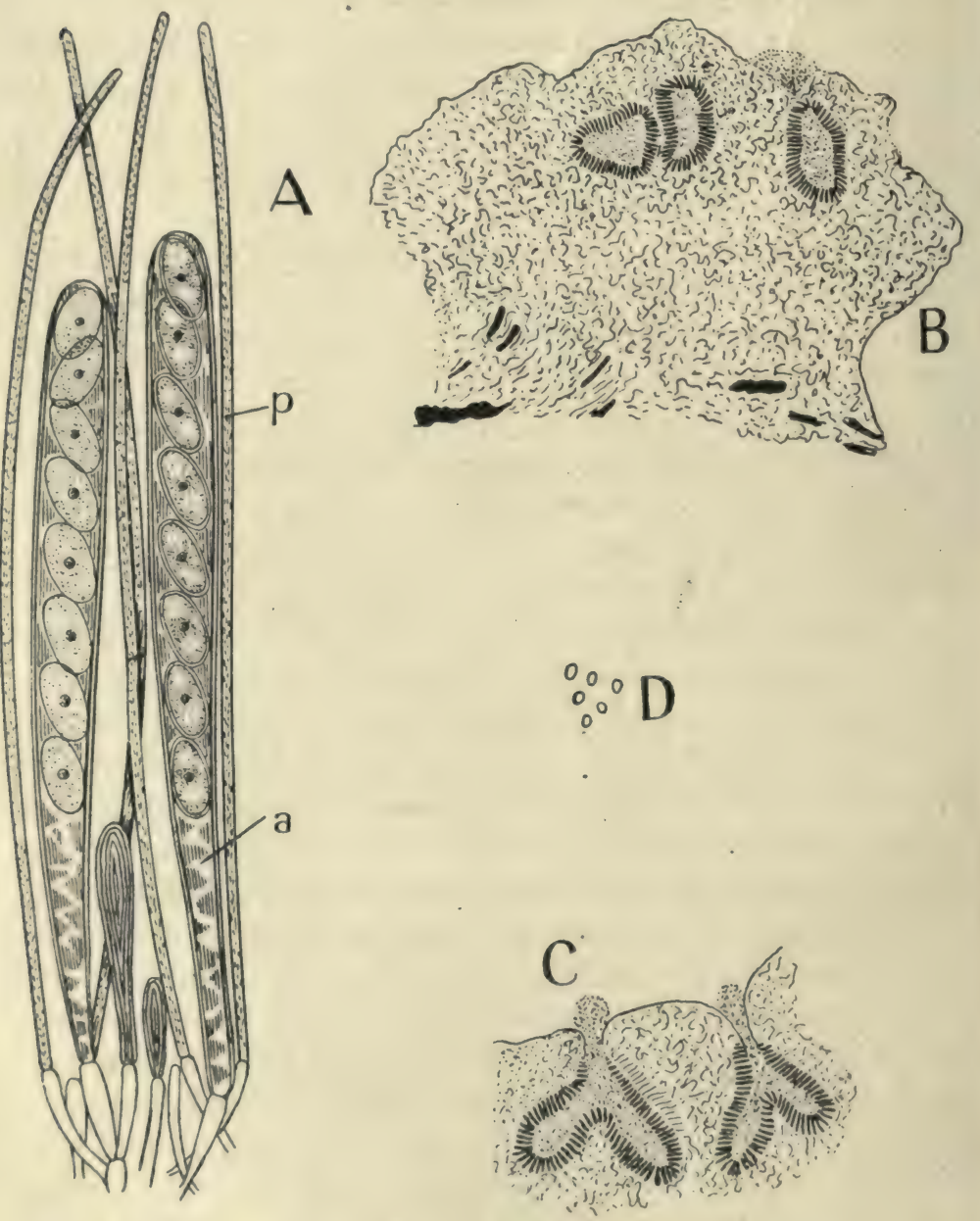

Fia. 18.-Dasyscypha calycina, reproductive organs: $A$, asci and puraphyses $(\times 430)$; $a$, ascus; $p$, paraphysis; B, spermogonia $(\times 430)$; , spermogonia, showing escape of spermatia $(\times 430) ; \mathrm{D}$, spermatia $(\times 1,000)$.

radiating towards the centre. These fine hyphae abstract from their apices numerous spermatia, small slightly elongated cells (about $1.5 \times 1 \mu$ ), which remain for a consider- 
able period in the cavities. The cavities usually, though so far as I can determine not invariably, connect with the outside air by irregular mouths, whieh are mere gaps in the mycelial cortex, and are not lined by specialized hyphae. Through these mouths the spermatia are forced out by the formation of numerous younger ones behind, and often remain in masses stuck together by a mucilaginous liquid which is exuded with them.

These spermatia are quite functionless, and, as the name implies, are regarded as vestigial male cells. Many botanists now consider them to be functionless conidia. The reasons against this view are shortly as follows.

Firstly, they will not germinate. Massee (1902) describes and figures cells, which he considers to be conidia, germinating by normal germ tubes in the presence of sections of larch bark. But the cells which he describes are round and larger than spermatia, and bear an intimate resemblance to conidia of Penicillium sp., which grows commonly on the apothecia of Dasyscypha. Brefeld (1891), who also

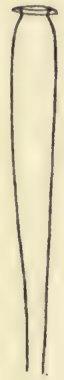

Fra. 19.-Ascus which has discharged its spores. regarded these cells as conidia, states that Dr. Möller, working in his laboratory, found. that they became slightly swollen when placed in a nutrient solution, but did not germinate. This incapacity for germination is normal in spermatia, whose only function is fertilization; but it is not easy to understand why conidia should ever become functionless in this way.

Secondly, we know from the researches of Baur (1898), Darbishire (1900), Thaxter, \&c., that in some Ascomycetes fertilization is still effected by means of spermatia. In other Ascomycetes fertilization by spermatia has been replaced by fecundation by a hypha in proximity with the female organ, or by the fusion in pairs of the nuclei in this organ. Probably one of these methods obtains in Dasyscypha, but the investigation of this point is outside the 
scope of the present inquiry. That spermogonia and spermatia can continue to be formed after they have become functionless is shown by the rusts, where first Blackman (1904) and later Christman (1905) and others have shown that fertilization occurs through the fusion of neighbouring hyphae just at the time when the spermatia are shed. The spermatia of Dasyscypha recall those of the rusts in many respects. They are small cells which do not germinate; they are set free just at the time when the young apothecia are appearing, and they are forced out in a mass of mucilaginous liquid. We are thus justified in calling these organs 'spermogonia' and 'spermatia' with de Bary and Willkomm, rather than 'pycnidia' and ' conidia' with Brefeld and Massee. In either case they appear to be entirely functionless, and only the vestigial remains of what was once part of the reproductive system.

Germination of the spores. If ascospores are required for germination, it is essential that they should be ripe and naturally ejected. They may be collected by placing apothecia on damp filter-paper on the bottom of a dropculture chamber. The spores are ejected in eights, and usually cling to the overlying cover-slip as a cluster; but not infrequently they are somewhat scattered, five or six appearing in one spot, whilst two or three separate spores hit neighbouring parts of the cover-slip at the same time. Sometimes it is impossible to trace more than six or seven of the eight spores of an ascus, probably because the last one or two spores to leave the ascus are not expelled with sufficient velocity to reach the cover-slip. In support of this view it has been observed that when the cover-slip is raised by another culture-ring placed on the top of the first one, it frequently happens that not more than four of the spores reach the cover-slip. If two rings are placed above the first, making three in all, none of the spores reach the cover-slip, though the apothecia be subsequently proved to be ejecting spores. The height of a culture-ring is $5 \mathrm{~mm}$., so that the maximum distance of ejection of 
spores from the ascus of this species is between 10 and $15 \mathrm{~mm}$. In a damp chamber such as that described, the spore-ejection may take place very rapidly, and from two small apothecia, measuring $1.25 \mathrm{~mm}$. and $1.5 \mathrm{~mm}$. respectively in diameter, 104 spores were found to have been ejected in 2 minutes. In a dry atmosphere the asci cease to shed their spores, a fact which is no doubt correlated with the closing of the apothecia in dry weather.

The spores may germinate in either of the two following ways: (i) The spores first divide by one, or less commonly

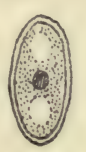

A

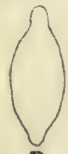

B

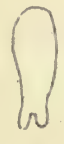

C

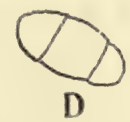

D
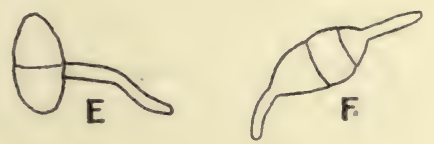

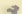

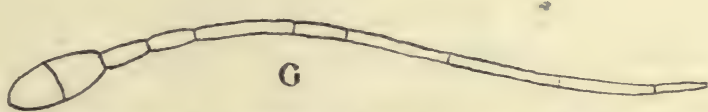

Fic. 20.-Spores and germination: A, spore, showing nucleus and vacuoles; $\mathrm{B}$, germinating at both ends ; $\mathrm{C}$, two germ tubes at one end ; D, segmentation; E, F, G, methods of germination.

more septa which are put in at right angles to the long axis of the spore (fig. 20, D, E). The first of these may be completed twenty hours after the ejection of the spore. When the spore becomes divided into three segments (fig. 20, F) these are usually unequal, one being nearly half the size of the whole spore; a third septum may then be formed in the larger cell. The germ tubes may arise in many different ways. Most commonly one grows out from each end of the spore, or one of them may originate near the middle septum, but cases in which three or four germ tubes arise from a single spore are not infrequent. (ii) The spore may give rise to germ tubes without first becoming 
septate, and in this case the germ tube is developed rather earlier than when the spore becomes segmented, and it may appear as soon as twenty hours after the ejection of the spore. This method of germination is less common than the last, but very many cases were observed, and the spores did not afterwards become septate. Either one germ tube grows out terminally, or one from each end; in one case two germ tubes appeared at the same end (fig. 20, c).

The germ tubes vary in size (the larger ones are about $4 \mu$ broad), and may grow to a considerable length without branching. One unbranched hypha attained a length of $140 \mu$ in less than twenty-six hours. But generally the germ tubes branch when they are much shorter than this and form a fairly densely interwoven mass, even in tap-water without any added nutriment. The walls of these hyphae are thin and colourless.

As the hyphae grow and use up the food at their disposal, they frequently fuse with each other. These fusions were observed by Willkomm, though his figures are misleading as to their method of formation. I have noticed three kinds of fusions. Firstly, when one hypha grows so as to meet another broadside, the apical wall of the one may be digested, and at the same time a hole be formed in the side of the other. In this case the former hypha does not continue its growth. Secondly, one hypha may grow over another and lie across it; a clamp connexion may then be made, in the form of a branch, which grows out from one hypha and fuses with the other. I have not observed from which hypha this branch usually arises. It does not generally connect points which have been in contact, but is usually bent, and connects the side of the upper hypha with the top of the lower hypha. Thirdly, two hyphae growing parallel with each other 5-20 $\mu$ apart may each send out a branch hypha, and these two branches fuse by their apices. Possibly their meeting in this way is merely accidental, though the large number of fusions of this kind suggests that some stimulus attracts the two growing apices 
to each other. Further evidence, however, would be necessary to substantiate this view.

For a fusion to take place it is of no consequence whether the two hyphae are branches of the same mycelium or not, and a number of spores germinating together form a close network in which it is impossible to determine from which

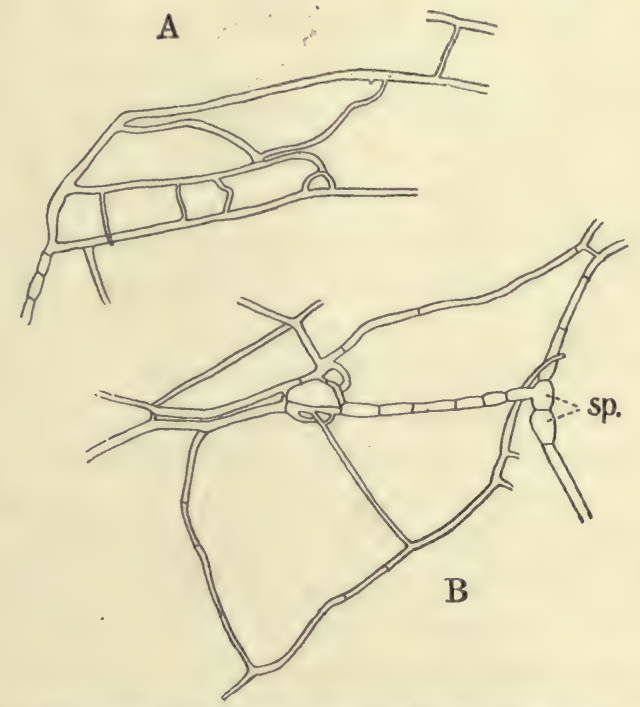

Fia. 21.-The growth of mycelium in drop cultures: sp., spore.

spore many parts of the mycelium have arisen. Such a network is best seen in cultures in distilled water, as until the hyphae become starved the fusions are not so frequently formed.

In such cultures the primary germ tubes become markedly septate (fig. $21, \mathrm{~B}$ ), the septa being usually $12-20 \bar{\mu}$ apart. But the branch hyphae which arise from these are often quite unseptate, and septa, when present, are far apart. As the available food supply is used up, drops of some liquid (probably an oily substance) appear, which become more numerous as the segments die. I have often noticed that some segments die before others and lose their turgidity, and then the more turgid ones are markedly refringent and 
show no such drops, or only a few very small ones, whereas the dead segments are not noticeably more refractive than the surrounding water, and contain numerous large drops. These drops often escape from the dead cells into the surrounding water, and may then cling to the outside of the hyphal walls. It was probably these drops which Willkomm (1867, p. 206) described as ' micrococcusschwärmer'. Occasionally movement can be traced in them, but this is not a necessary sign of life. The great variability in the size of the so-called ' micrococcusschwärmer' figured by Willkomm (Taf. xxiii, 24, $\mathrm{E}$ ) is against their being bacterial cells (cf. Hartig's criticism on p. 73).

Willkomm states that the hyphae in culture may bear lateral conidia, but though I have observed hyphae with laterally borne bodies, like those figured in Taf. xxii, $24 c$, these bodies never became separated from the hyphae, and they showed no inclination to germinate.

Hyphae of a Penicillium bearing conidiophores and conidia often turn up in drop cultures of the Dasyscypha. This Penicillium grows on old apothecia of the Dasyscypha, and it is often difficult to avoid collecting some of these conidia when the ascospores are obtained.

Pure cultures on nutrient media. The method of obtaining pure cultures of Dasyscypha calycina which I have found most successful is this. Portions of bark with vigorous apothecia of the fungus are placed on wet filter-paper in the bottom of a drop-culture chamber, as described on p. 42. A sterilized cover-slip is then placed over the top and fixed with vaseline. Almost immediately the underside of the cover-slip becomes cloudy with condensed vapour, and in the film of water so formed the spores ejected from the apothecium remain attached to the cover-slip. If the apsthecia are giving off spores at the time when they are put in the culture-chamber, these may be gathered in an hour or two, but generally the chambers have to be left till the next day, when sufficient spores will have accumulated.

Two culture-chamber rings are then placed on a slide 
and a few drops of water are allowed to lie between them. A cover-slip is then very carefully removed from one of the culture-chambers, and placed on the two rings, so that, resting above the drops of water, the moisture on its underside does not dry up. The whole can be put under the microscope and the spores removed by a sterilized needle or glass filament and transferred to culture media in Petri dishes or Cogit's flat glass bottles, the usual precautions being taken against the introduction of foreign spores.

A suitable medium was found to be either gelatine or agar-agar containing malt extract (3 per cent.), meat extract $\left(0^{\circ} 3\right.$ per cent.), and citric acid ( 0.03 per cent.).

There is at first some difference between the cultures obtained from the large spores of the parasitic form and the smaller spores of the saprophytic form. The germ tubes of the latter are smaller, and growth is at first rather slower, but after a day or two very little difference can be found, and older streak cultures are indistinguishable.

The mycelium is characterized by forming a very close felt-like mass, and it grows so evenly on all sides that a culture from a single spore becomes a circle (fig. 22) and a streak culture has the form of an even band. When growing on gelatine the mycelium puckers up the substratum into folds, but agar-agar remains flat.

Temperature has a considerable modifying influence on the growth of cultures, and the following table is instructive in this respect. Twelve streak cultures were grown on agaragar in Petri dishes. The first four, $\mathrm{A}_{1}-\mathrm{A}_{4}$, were grown at the temperature of the room $\left(13^{\circ}-14^{\circ} \mathrm{C}\right.$.), the next four, $\mathrm{A}_{5}-\mathrm{A}_{8}$, in an incubator at $22^{\circ}-23^{\circ} \mathrm{C}$, and the last four, $\mathrm{A}_{9}-\mathrm{A}_{12}$, in an incubator at $26^{\circ}-27^{\circ} \mathrm{C}$.

It can be seen from the following table that a temperature of $12^{\circ}-13^{\circ} \mathrm{C}$. is below the optimum for growth, and $26^{\circ}-27^{\circ} \mathrm{C}$. is above the optimum. It is interesting to note that the higher temperature encourages germination, which takes place very slowly at the lower temperature, but for subsequent growth the latter is more favourable. Also the high temperature encourages excessive branching. 
TABLE SHOWING RATES OF GROWTH OF

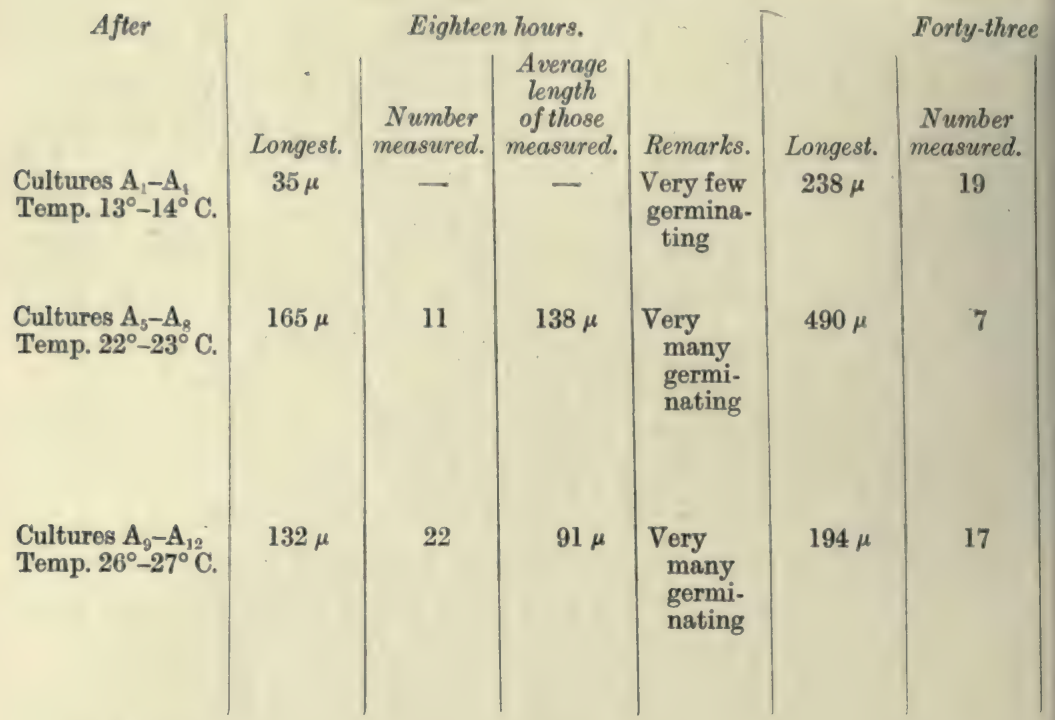

In agar-agar cultures numerous spermogonia were formed after a few months. These spermogonia were somewhat larger than those found on larch trees and, but for their apices, were sunk in the substratum. They produced normal spermatia which resisted all my efforts to germinate them. No such spermogonia were formed in gelatine cultures.

Cultures on other media may be obtained directly from spores, but on the whole it is easier to start from the mycelium growing on gelatine or agar-agar. In this way cultures have been grown on moistened sterilized bread cubes in Erlenmeyer flasks and on pieces of branches of European and Japanese larch which have been sterilized in steam. On these larch stems apothecia were developed completing the life-cycle from spore to spore (fig. 23) ; there is no difference between such cultures obtained from the parasitic or saprophytic form of the fungus.

Mycelial cultures were also grown successfully on sterilized 



\section{MYCELIUM AT DIFFERENT TEMPERATURES}

hours.

\begin{tabular}{|c|c|}
\hline $\begin{array}{c}\text { Average } \\
\text { length } \\
\text { of those } \\
\text { measured. }\end{array}$ & Remarks. \\
\hline $175 \mu$ & $\begin{array}{l}\text { Very } \\
\text { many } \\
\text { germi- } \\
\text { nated }\end{array}$ \\
\hline $346 \mu$ & $\begin{array}{l}\text { Very } \\
\text { many } \\
\text { germi- } \\
\text { nated }\end{array}$ \\
\hline $161 \mu^{\prime}$ & $\begin{array}{l}\text { Very } \\
\text { many } \\
\text { germi- } \\
\text { nated. } \\
\text { Very } \\
\text { much } \\
\text { branched }\end{array}$ \\
\hline
\end{tabular}

Three days.

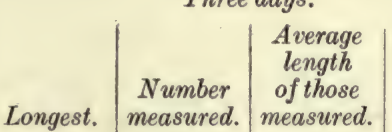

Longest. $650 \mu$

$240 \mu$ measured.

9

10
Fifteen days.

Remarks.

United into band $1.5-2 \mathrm{~mm}$. across. Very thin growth.

United into band $4 \cdot 5-7 \mathrm{~mm}$. across. Very close dense growth.

Temp. of incubator not constant, so statistics valueless.

twigs of other conifers in damp chambers. The conifers which I experimented with were spruce, silver fir, Scots pine, and Corsican pine. In all these the mycelium grew freely, and on silver fir apothecia were produced.

Cultures were also obtained on sterilized leaves of larch, spruce, and Scots pine. These showed no tendency to grow for several weeks; but ultimately masses of dead leaves became covered with mycelium, and on sectioning the needles hyphae were found to have ramified the mesophyll, though they had not penetrated into the vascular bundle region.

This shows that the mat of dead larch needles lying on the floor of larch plantations forms a suitable substratuin for the mycelium of Dasyscypha, and the mycelium which is commonly found growing on these needles may belong to this fungus. It is not suggested that the fungus can reinfect the trees by this means, since no fructifications are formed. But it may assist in the decomposition of the foliar débris.

Artificial infection with the canker fungus. The first 1888 
recorded artificial infection with larch canker was performed by a practical forester named Fischer, who caused canker in trees by inserting into a wound made in healthy bark a suitably shaped piece of bark and phloem from a canker on another tree. This experiment proved that canker was due to a transmissible cause and was not merely the result of unsuitable growth conditions. That the fungus Dasyscypha calycina is actually responsible for canker was first proved by Hartig when he induced the disease by infection with ascospores of the fungus. An account of his experiments has already been given on p. 23, and need not be repeated here.

Massee (1902) also produced canker by means of artificial infection, and obtained results which are important in two respects. Firstly he found that canker resulted when ascospores were placed on the mucilaginous excretion of Chermes abietis in the spring. This he attributed to the small holes which the insect makes in forcing its proboscis through the cork to the living tissues beneath; and he supposed that the fungal germ tubes grew down these holes and thus gained admission to the cortex and phloem below.

Massee attached great importance to this method of infection as a source of canker in nature, and considered that if the larch aphis could be destroyed, canker would cease to be a serious epidemic disease. As I shall show, however, the aphis can only assist in the infection of comparatively young stems, whereas the cankers which are important to foresters are mostly those which have been induced after the stems are three years old.

Secondly, Massee found that Dasyscypha calycina is capable of infecting other trees besides the European larch. From the spores of the fungus he produced canker on the Scots pine and on two other species of larch-the Siberian (Larix siberica) and the Japanese (Larix leptolepis).

In my own infection experiments, inoculation was obtained by inserting a small piece of agar-agar, with fungus mycelium in pure culture, in a slit made with a knife in the bark of young trees. Infections made in Munich in 
1914 with cultures grown from spores of the saprophytic form of Dasyscypha calycina developed so far as to produce the earlier apparent signs of canker, but no fructifications of the fungus had been formed before my departure in June. Subsequent infections, made in the same way with cultures grown from the parasitic form, at Oxford, produced normal cankers bearing fructifications, but no new features were demonstrated by these experiments. 


\section{CHAPTER IV}

\section{THE LARCH CANKER (concluded)}

On the mode of infection in nature. ${ }^{1}$ Importance of wounds as a source of canker. Contributory causes of canker. Methods of prevention. The synonymy of Dasyscypha calycina.

On the mode of infection in nature. After the examination of a large number of cankers I have arrived at the conclusion that the ordinarily accepted methods of infection by the disease are insufficient to account for the numerous cankers which occur on larch stems. I shall consequently give a summary of the theories that have been advanced, and then proceed to the consideration of a new one which may explain the occurrence of canker on main axes.

For the sake of clearness it will be well to divide infections into two classes : (i) those on young stems and small lateral shoots.; (ii) those on main trunks which occur when the latter are more than two years old.

The first class of canker is comparatively unimportant, since side branches die quickly whether they are attacked or not; and when a main shoot is affected early, it is generally killed and its place taken by a lateral.

(i) It is a matter of observation that a shoot does not become cankered till the end of its first year's growth. This is a necessary corollary of the view propounded by Berkeley and accepted by all subsequent writers that the annual ring is always complete at the base of a canker, so that the cambium must be killed in the winter. This does not, however, preclude the possibility of infection having occurred in the outer tissues during the summer, and it is only the failure to find any sign of fungal growth in shoots

1 I have already published a preliminary note on this subject in the Quarlerly Journal of Forestry, 1915. 
during their first growing season that justifies the conclusion that shoots do not become infected until the first year's growth is complete. This is in keeping with the theory already enunciated that Dasyscypha requires dead tissue to grow on while it is secreting those substances by which it kills the living cells in its vicinity.

By the end of the first year of growth a larch shoot has made a continuous cork layer, and as long as this remains unbroken it is quite impervious to the hyphae outside it. The only weak points in this armour are at the leaf bases (see p. 10), and though no artificial infections have proved successful at such points without wounding, yet it is just. possible that in an extremely small percentage of cases infection does actually occur here.

In addition, wounds of various kinds occur on young branches, which may all help in furthering infection. These wounds may be caused by :

1. Frost. The late frosts often cause ruptures in the cork protection of young shoots, presumably through the swelling of the saturated cortical cells inside. Such wounds are usually seen as whitish specks, the white colour being due to resin which is secreted through the wound. The mycelium will tolerate a considerable percentage of resin in its substratum, but an almost pure resin layer, such as is here formed, is impermeable to it. It is thus unlikely that infection will take place through these wounds, except immediately after their formation.

2. Hail. Hail-stones often make wounds on young stems and may even break off young shoots. These wounds also are quickly covered by resin, and after a very short interval they are protected against the canker fungus.

3. Chermes. Massee's infection experiments, which showed the possible connexion between canker and attacks of Chermes abietis, have been cited above, and the punctures made by the Chermes should be included among the list of wounds. Further evidence on this point may be looked for as a result of the experiments initiated by Burdon (1908), in which larches infected with Chermes were to be compared, 
as regards canker, with others which were sprayed with an insecticide.

Somerville's suggestion that Chermes may partially inhibit transpiration and so increase the growth of the fungus after infection is based on Hartig's theory of the connexion between mycelial growth and transpiration, which has a very insecure foundation. At present the evidence is not conclusive that Chermes does in any way encourage canker (vide Gardener's Chronicle, 1896, p. 435).

4. Other wounds may be caused by men or animals breaking off twigs, and perhaps by one twig rubbing against another.

We thus see that, if the fungus were able to enter the tree through any sort of wound, it would have many opportunities of infecting young twigs, and it is remarkable that cankers are not more frequent than they are on side branches. But branch cankers are of small practical importance to the forester. What he must try to prevent are cankers on the main stems of the trees.

(ii) Now the factors which bring about these important cankers are of a different nature, because such cankers are usually found to have been initiated when the portion of the stem is three or more years old. This is seen by observing the number of annual rings which are left intact in a transverse section of a canker. Cankers dating from the first or second year of growth are extremely rare on trunks, and probably when infections occur at this early age the leader is killed by the fungus and its place is taken by a side shoot.

But the predisposing factors that we have considered are not applicable to the main stems after three years of growth. The periderm layer is then sufficiently strong to prevent damage by frost (except in extreme cases), hail, or Chermes, and the central axis is not likely to be affected by abrasions caused by the rubbing of other branches. We have thus to seek fresh causes for the infection of the main axis.

Two sources of wounds have been suggested. The first is that in planting out the young trees the labourer may graze the bark of the trees when pressing down the earth 
with his foot. If this were so cankers should be especially frequent near the ground, which I have not found to be the case. It is true that in some woods cankers are apt to occur at rather definite levels; but this level may be near the ground, or $3 \mathrm{ft}$., $6 \mathrm{ft}$., or even $30 \mathrm{ft}$. above it. This probably means that in certain years the meteorological conditions have favoured the formation of cankers, which have then occurred at the level most susceptible to attack. On examination of a plantation in which attack had commonly occurred near the base one might be tempted to adopt such a theory as that suggested. But my own experience has not led me to attach much importance to this source of infection.

The second suggestion as to the source of wounds is based on the observation that on such main stems cankers nearly invariably occur at the base of branches which have died. On this account it has been thought that the swaying of branches in the wind, and their depression under snow, may cause cracks in the bark at the branch bases, through which infection may take place. This would further be encouraged by the fact that spores settling on the trunk would be washed down by the rain and often get lodged in the axils of the branches. Now if this were really a serious cause of canker we should expect to find cankers particularly frequent on the edge of plantations, where the side branches grow bigger and thus offer more surface to the wind and snow, and where also the wind is more pronounced and better able to sway the branches. But, as a matter of fact, the reverse is the case, and cankers are much more frequent inside a larch plantation than on its edges. Also it will not be found easy, by any ordinary swaying of a branch, to cause such ruptures as this theory requires.

In order to test the various theories that have been advanced to account for infection, I have examined a large number of cankers on main stems of larch. Most of the specimens were obtained from Bagley and Tubney woods near Oxford, and in all cases the cankers were taken from otherwise healthy trees which had full crowns and gave no 
indication of being suppressed. The trees were cut down and the parts containing the cankers were brought into the laboratory. Here the cankers were sawn through transversely and the surfaces planed or smoothed with a sharp knife until the section was reached where the cambium had first been killed.

The inspection of these cankers confirmed the two important observations that in the large bulk of cases :

(i) The cankers had been initiated at the bases of lateral branches.

(ii) The cankers were initiated when the sections of stem were from three (occasionally two) to eight (occasionally nine) years old.

We must thus consider in detail the condition of affairs which exists at the bases of lateral branches on those parts of the tree which are from two to nine years old.

In an ordinary ten-year-old larch plot planted at $3 \times$ $3 \mathrm{ft}$., the weaker shoots die off when two or three years old, the stronger shoots when five, six, or even eight years old. In younger plantations, before the branches have begun to shade each other, all of them may remain alive, but generally some small dead branches will be found at the base of the trunk, especially when they have been smothered by rank grass and weeds. Thus the part of the tree which is from two to eight years old, in which cankers are generally initiated, is also that part where some or all of the lateral branches have lately died. Further, in nearly all woods the lateral branches become infected with Dasyscypha calycina, which grows saprophytically on them as soon as they are dead, and continues to flourish on them for three or more years, filling all the dead bark with its mycelium.

When a dead branch is seen projecting from a canker it has generally been supposed that the canker has killed the branch, but it may equally be true that the fungus spreads from the dead branch and causes the canker. In order to determine this it was necessary to notice the relative times at which the branch died and the canker was initiated. The date of the death of the branch may readily be deter 


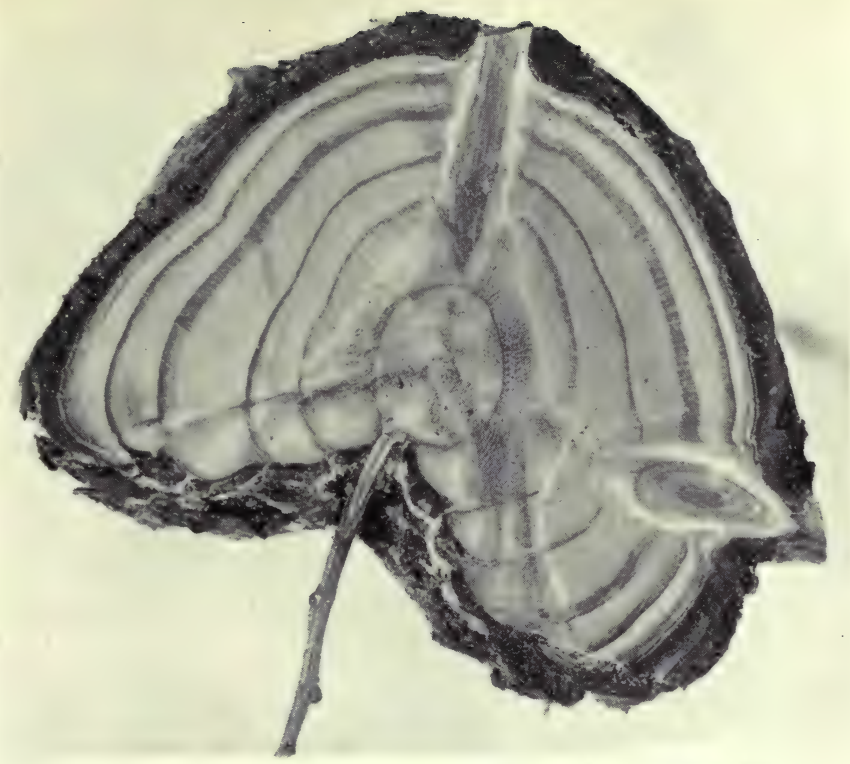

FIG. 24.-Canker showing origin from branch $\left(\times \frac{5}{6}\right)$.

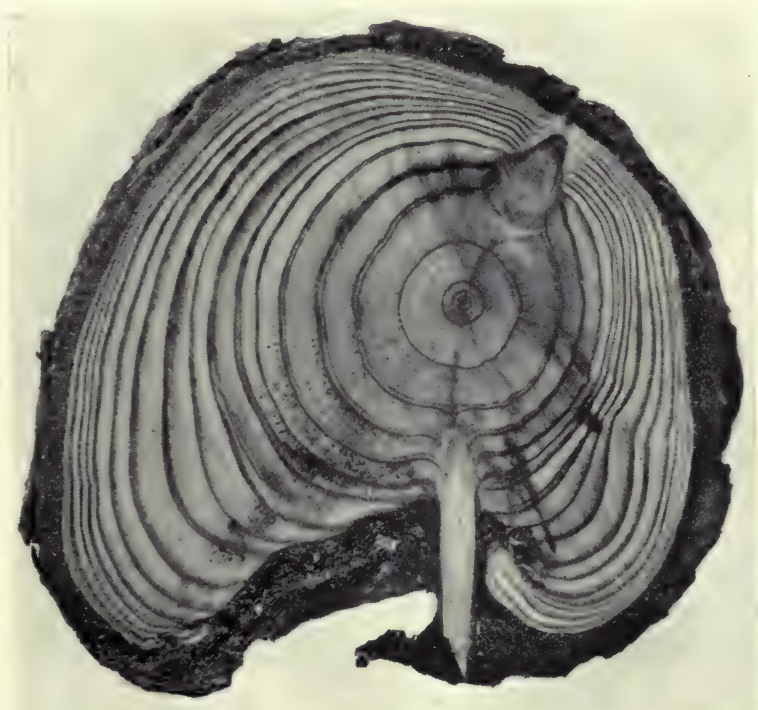

Fia. 25.-Canker showing origin from branch. Subsequently healed on one side. $\left(\times \frac{2}{3}\right)$. 

mined by observing the last annual ring of the trunk which is continuous with the wood of the branch.

In 30 cankers taken at random, in which this point could be precisely determined, it was found that in 5 cases the canker was initiated the same winter as the branch died, in 12 cases it began the year after the branch died, in 7 cases two years after, in 1 case three years after, in 3 cases four years after, and in 2 cases six years after.

In the following table the observations are set out at length :

Age of section

of tree in Number of years of which canker Agewhen Agewhen initiation of canker

Specimen. occurred. branch died. canker began. after death of branch.

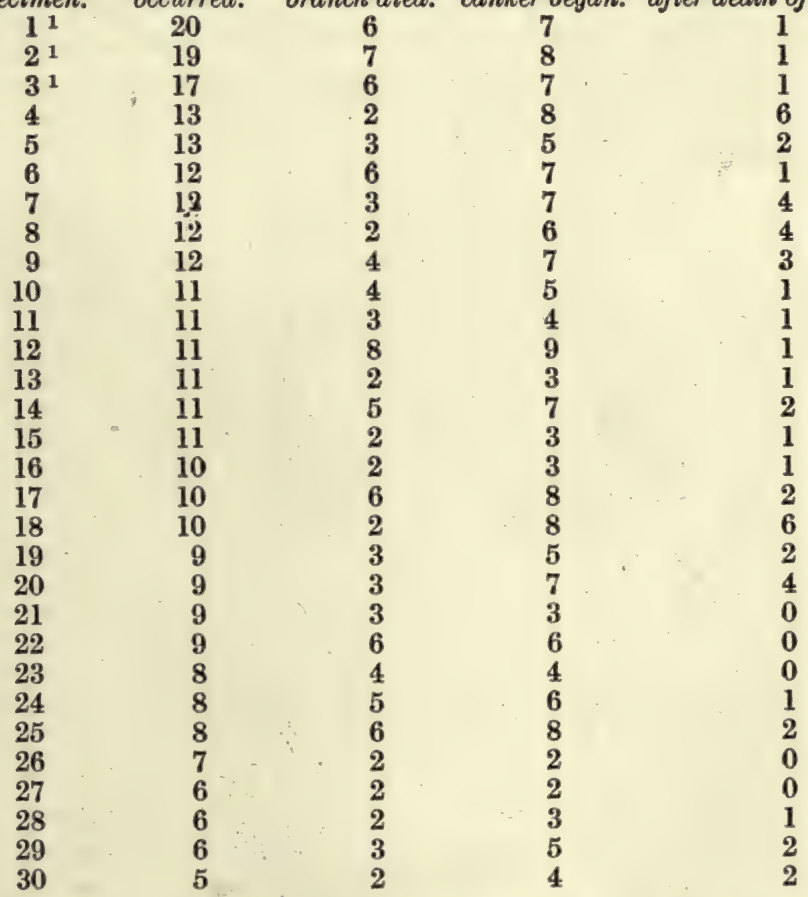

This shows that in the large majority of cases the canker begins at least a year after the death of the branch. In

1 These specimens were kindly sent me by Mr. Alex. Luttrell from Dunster Castle, Somerset. 
the other cases the branch probably died in the autumn and the canker was initiated in the spring. This cannot be proved from my specimens, but since the branches may become infected with Dasyscypha immediately after death, this seems the easiest explanation of the facts.

It is thus clear that the conception of a canker being initiated at the base of a living branch and killing the branch is erroneous, and in the majority of instances it can be definitely proved that infection takes place a year or more after the branch has died. Thus at the base of a branch, just at the time when it regularly contains mycelium of Dasyscypha calycina, the main trunk becomes infected by the fungus. It is scarcely possible to avoid the conclusion that the mycelium passes from the dead branch into the living trunk, and that this is commonly the source of infection of those cankers which are seen on the older trunks of the larch. ${ }^{1}$

There is, however, one important obstruction which the fungus has to pass before it can grow from the branch into the main stem. This is a cork layer which is always made across the cortex and phloem of a branch just before death, and which in the majority of cases is a sufficient obstacle to prevent the passage of the fungus. But in many instances, as in that shown in fig. 27 , the mycelium occurs on both sides of the cork layer, and must presumably have passed it. There are three possible ways in which this might occur. Either

(i) The mycelium obtains entrance to the trunk before the cork layer is completed, or

1 A similar conclusion has been reached independently by Mr. P. V. Laidlaw on an estate in Northumberland (vide Quart. Journ. Forestry, 1914, p. 216). Also, since the publication of my paper in 1915, Mr. A. C. Forbes has pointed out in the Gardener's Chronicle for February 6, 1915, that he suggested as early as November 15, 1902, in the same paper, that the canker fungus might attack a living twig, and, having killed it, grow down to the main stem and cause a canker there. As this article is not referred to in the index for the last six months of 1902, I may be forgiven for not having seen it earlier. The fact that two foresters have reached a similar conclusion by another route lends support to the correctness of the theory. 
(ii) It grows through the cork layer, or

(iii) It grows round the cork layer.

(i) This is impossible, for the formation of the cork layer is the last act of the living cortex at the base of the branch. The mycelium, however, does not spread till the branch is quite dead. So this alternative must be rejected, except in the case of trees whose vitality has become very much reduced before the death of the branch.

(ii) This also is apparently impossible. I have examined hundreds of cankers but have never found any mycelium growing through a cork layer-which in fact forms an impassable barrier to the hyphae, except when they attack it from the inside.

(iii) We are thus reduced to the third alternative. And since the cork layer is continuous with the peripheral cork layer of the tree, it is impossible for the mycelium to get round it on the outside. It can thus only get round it on the inner or wood side. Here again there are two possibilities-either

(a) It grows through the cambium, just outside the wood, the cork layer not having been welded sufficiently perfectly on to the wood, or

(b) It grows through the wood.

To discuss these alternatives the anatomy of the cork layer must be described. It will best be understood by following the accompanying diagrams (fig. 26). Fig. 26, A, shows the general arrangement of the tissues, at the point where a branch joins the main stem. A is the main axis, B the branch. Everywhere to the outside is a layer of cork $c c^{\prime}$, which becomes wrinkled at the point of junction by the continuous thickening of each member. Between $c$ and $d$ are the tissues known as the cortex and phloem; at $d$ is the cambium, inside which is the $\operatorname{wood} w$. On the death of the branch the dead tissue of the latter would come into direct contact with the living tissues of the main stem, were it not for the interpolation of a cork layer c.l. This layer is put in usually, not at the base of the branch, but about $1 \mathrm{~cm}$. above it. 
Fig. 26, B, which is an enlarged drawing of the top righthand corner of fig. 26, $\mathrm{A}$, shows in greater detail the formation of this new cork layer ; PH is here the normal phellogen or cork cambium which makes cork on its outside. The

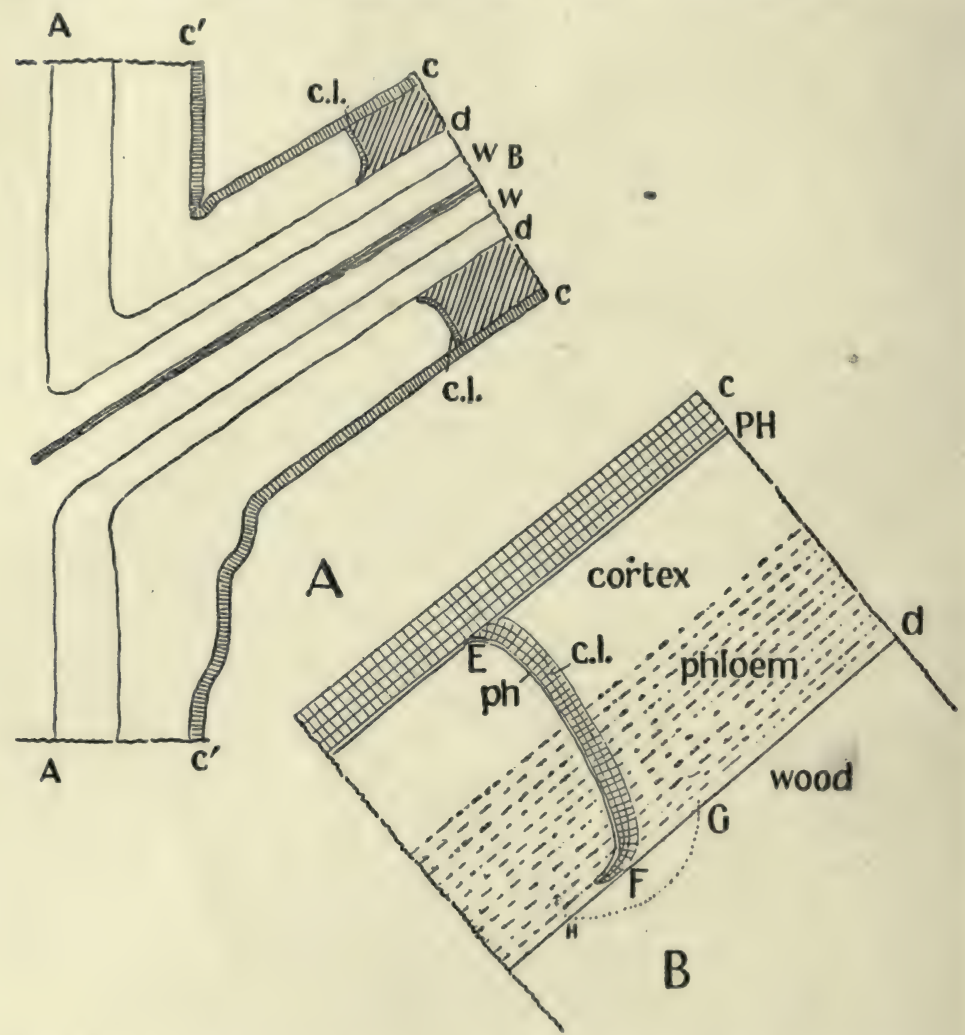

FIG. 26, A and B.-Cork layer across base of branch. For description, see text.

new cork is formed by a new phellogen $p h$, which is developed right across the cortex and phloem, and makes a downward turn as it approaches the cambium. It is in direct continuation with the outer phellogen at $\mathrm{E}$, and forms, as it were, a side branch of this phellogen. It passes usually transversely across the cortex and phloem (it may be oblique) until it reaches the layer outside the cambium, 


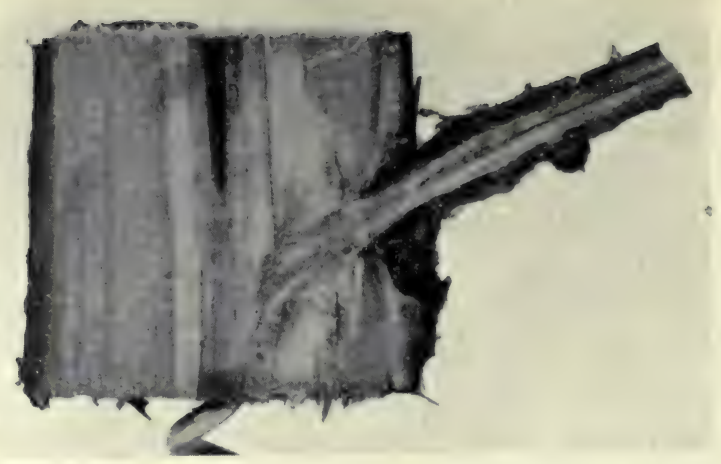

Frg. 27.-Canker fungus spreading down from a branch. This was photographed from a living specimen. The darkcoloured cortex near the branch is dead. The lighter coloured, above and below this, is alive.

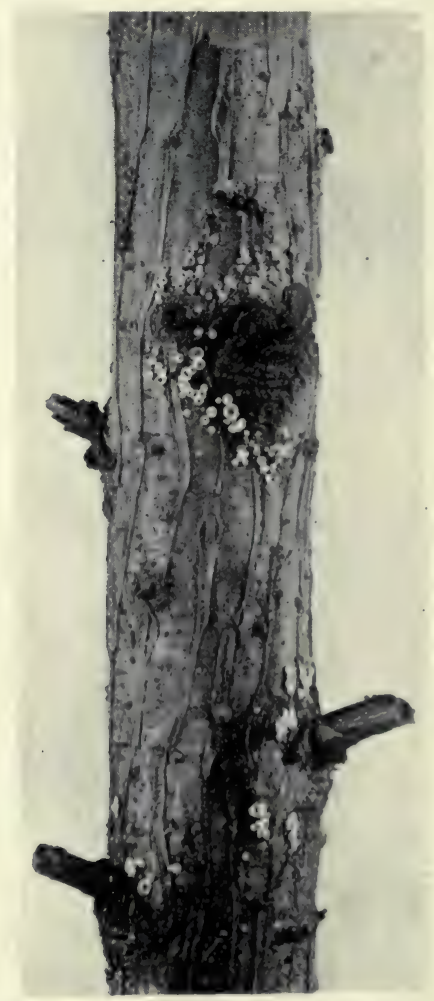

Fra. 28.- Spread of fungus down the branches. This stem was taken from a young tree which had been felled and allowed to lie in the wood for a few months. 
where it turns sharply down the stem at $\mathrm{F}$ and ends blindly. The cork made from this layer becomes welded perfectly with the outside cork layer, and is perfectly continuous across the cortex and phloem.

Thus the two alternatives $(a)$ and $(b)$ of p. 59 resolve themselves into these: either $(a)$ the mycelium grows through the gap between the cork layer and the wood at F, or $(b)$ it grows round through the wood by the route $\mathbf{G H}$. I think the course by $\mathrm{F}$ is the more probable. The space left here, though narrow, is not infrequently just large enough. And, though I have never been able to trace hyphae right through it, I have seen hyphae at each end of it. The mycelium of the fungus can under certain circumstances be found in the wood, but I have never observed it growing to any extent up or down the stem except when the wood is quite dead; when it occurs it is usually either in the wood just inside a canker, where fungal secretions have killed all the living cells, or else in the heart-wood. It is conceivable, however, that in some circumstances it might grow down through the wood from the branch to the main stem, and there attack the phloem. ${ }^{1}$

For the present the question must be left open whether the mycelium passes from a dead branch to the main axis through the wood or just outside it. That it can pass such a cork layer is shown by an ordinary canker. For this is surrounded each year by a cork layer in every way comparable with that at the base of a branch, yet in the majority of cases the mycelium successfully penetrates to the other side.

It is difficult to obtain experimental proof of this method of infection. But it may be somewhat strikingly demonstrated by cutting down a larch tree, 15-18 years old, which has on it numerous dead branches, bearing the canker

1 As the trunk grows in thickness, the cortex and phloem at the base of a side branch generally gets torn away from the wood, and frequently the bark of the trunk becomes corrugated round the branch bases. It is likely that the canker fungus may sometimes reach the trunk through ruptures caused in this way. 
fungus. After a time it will be found that at the base of nearly all these dead branches the fungus has spread on to the main trunk, and fructifications are duly made there (fig. 28). This shows that, when the resistance of the living tissues is reduced, the fungus finds no difficulty in growing down from the branches; and, under these conditions, there regularly occurs what only occasionally happens when the trees are alive and vigorous. It may be that when the tree is alive it can usually neutralize the secretion which the fungus pours into it through the gap, and thus prevent the mycelium from obtaining any foothold.

There is another way in which Dasyscypha may gain admission to living stems without previous wounding; this is through dormant buds which have died. There is always a large number of these dormant buds on a larch stem; they are surrounded by a number of dead brown scales, but in the middle is a growing apex with the living leaf primordia. Given light and food these may at any time develop into side shoots. As the tree gets older such buds on the lower part die, and they immediately become attacked by germ tubes of Dasyscypha spores. But in a healthy tree a cork layer is formed beneath the buds at the time of their death, so that there is very slight danger of the stem bearing them becoming infected. In trees, however, which from lack of light, or other causes, are growing poorly, such buds are responsible for a large number of cankers.

This source of canker, though of frequent occurrence, is of comparatively little importance to the forester, since it only affects the poorer trees in a plantation, which would be ordinarily removed in the first thinning.

The importance of wounds as a source of canker. In the foregoing section it has been shown that there are two ways in which the canker fungus can gain admission to trees without their previously being wounded, and it is probable that the importance of wounds as a source of infection has been greatly exaggerated. The dogma that trees can only become cankered through wounds is due to Hartig's infection experiments, for he was unable to infect 
trees artificially unless they were first wounded in some way. But infection experiments may be incapable of demonstrating a phenomenon which is almost ubiquitous in nature, and the case of larch canker is one in which it is exceedingly difficult to repeat in the culture house a process which we can observe in the forest. For every time the mycelium successfully grows from a dead branch to the trunk, it must fail at least a dozen times. But experiments which at the luckiest were only successful in 8 per cent. of the inoculations would not by themselves be conclusive, especially when we know that minute punctures, too small to be seen with a simple lens, may be sufficient to admit the fungus, and these might have been overlooked in the experiment. It is thus by no means easy to get satisfactory results with experiments set up to show that Dasyscypha can infect living trunks from dead branches, and if such experiments did apparently succeed, it is difficult to be quite certain that the fungus has not entered in some other way. It is for these reasons that the arguments in favour of this means of infection have been drawn, not from culture experiments, but from observation.

Conversely, wounds which have been found necessary for artificial inoculation are probably of much less importance in the forest. I have often seen billhook wounds which have healed naturally even in plantations where canker was epidemic. And where shooting rides have been cut in larch woods there is not generally any increase in the frequency of the fungus. Again, when larches are grown as nurses for other trees, the branches have regularly to be cut back to make room for the main crop, and yet, in such cases, cankers are often less numerous than in other plantations in which there has been no pruning; indeed, in a plot treated in this way in Bagley Wood near Oxford, where larch was grown as nurses for deodar, there was no canker at all on these nurse trees, whereas a larch plot less than 200 yds. away was attacked with moderate severity.

The reason why laboratory experiments give a false impression of the importance of wounds is by no means 
obscure. When a wound occurs in nature, it is covered in a very short time with a layer of resin, through which infection cannot take place, so that it is only a source of danger for a very brief period. But in an experiment, immediately a wound is made, spores or pieces of mycelium are thrust into it, and the resin which is secreted is poured outside the fungus, which can then attack the tissues inside.

Contributory causes of eanker. As has been known ever since Berkeley first investigated larch canker, the primary cause of the disease is Dasyscypha calycina. But there are many secondary or contributory causes, which while unable by themselves to bring about a canker, encourage the fungus, or in some way make the tree more susceptible to its attack. These factors are therefore of great importance, and the means adopted by foresters in their attempts to get rid of canker have been based much more on the mastery of secondary causes than of the primary cause, of which - they are often ignorant.

One class of contributory causes has already been dealt with in the section on 'the mode of infection in nature'. This included all the factors which may cause wounds. A great deal of attention has formerly been paid to this class, and probably its importance has been over-estimated.

Other contributory causes may be grouped under headings of climate (including altitude), soil, and mixtures of trees in plantations.

We have here chiefly to rely on the published opinions of practical foresters, which may be found in articles and letters from time to time in the Gardener's Chronicle and in answers to the English Arboricultural Society's inquiry into the causes of larch canker (Somerville, 1895), and to the similar Scottish inquiry (Richardson, Borthwick, and Mackenzie, 1905). The best and most critical survey of the whole question is given by Forbes (1904), and as there is much diversity of opinion among foresters as to the causes in question, Forbes's account is most valuable.

Altitude and climate. From the time of Hartig (1880) onwards it has always been a matter of speculation why 
canker should be more frequent in lowlands than in the larch's natural home in the Tyrol. Hartig adduced three reasons to account for this difference. The first is that when the larch is growing in its native home, where natural regeneration takes place freely, young trees are always springing up among the older ones, and forests are composed of trees of all ages. But canker, as an epidemic, is nearly confined to plantations under twenty years of age, and trees which are older than this are generally free from attack. So in the Tyrol the canker fungus can only pick out here and there the younger trees from among a much larger number of older ones. (This leaves out of account the frequency of canker on side branches of older trees which I have particularly noticed in the Tyrol.) The second reason is that in the mountains the trees are not often surrounded by damp stagnant air, which is conducive to the formation of fructifications of the fungus and to the germination of the spores. Lastly, the early spring in the lowlands causes a premature renewal of vigour. The twigs become full of sap and the needles begin to appear. But too often this is followed by May frosts, which cut back the shoots and make a number of frost-wounds on the young twigs, which reduces the vitality of the trees. In the Alps summer development does not begin so early, so that the trees are less likely to be cut back by frosts.

All these causes are no doubt operative to a limited extent, but their importance must not be over-estimated. Indeed, larch in its native habitat is by no means free from canker, and as high as 5,000 ft. in the south Tyrol I have found parts of trees almost riddled with the disease, though not so much on the main trunks as on the side branches. Boden (1904) also comments on the fact that trees may be cankered as high as 7,200 ft. in the Alps, whereas the disease is often absent from plantations in the plains. In parts of the Tyrol, which I have seen, the larches do not grow in dense formation, but are sufficiently scattered to allow the full development of the side branches. Of course many branches must die, but not, as a rule, till they have grown 
for many years, and probably snow accounts for the fall of most of them. At any rate the dense screen of small lateral dry branches so characteristic of our own woods is generally absent in the Alps; and since, as has been shown above, dead branches are one of the most important sources of canker, the absence of such branches in the Alps is a noteworthy factor in the suppression of the fungus.

In the case of British plantations it is questionable whether the altitude at which larch is planted is ever great enough materially to lessen the attack of the canker fungus. Trees may be as badly attacked at a height of 1,000 ft. as at sea-level, and where a mountain-side is immune from the disease this may be accounted for by the favourable soil conditions that such a slope provides.

Though altitude has little effect in restricting canker, low hollows seem to encourage it very markedly. Such hollows are peculiarly liable to late frosts, which have an adverse effect on the general health of the trees and render them more liable to infection, and frost-wounds may admit the fungus in some cases. Also the atmosphere is there more humid, and conditions are favourable for the formation of fructifications of the fungus.

No direct relation can be traced between the frequency of canker and the rainfall or the site exposure.

Soil. Though it is very difficult to determine exactly the soil conditions which favour canker and the reverse, nevertheless the edaphic factor seems to be of more importance than the climatic. Even in flat country neighbouring plots of larch may be very variously affected, and since this cannot be attributed to climatic differences, it seems a just inference that soil is responsible. On the whole we may say that soil conditions which favour larch-growing in other respects are generally least conducive to canker; a good, deep, wellaerated soil is better than one which is peaty or rendered shallow by a pan near the surface. Forbes (1904) lays great stress on the fact that young trees are often notched or slitted into the upper six inches of soil quite unsuited to their requirements. If it is composed of dry peat or débris 
of recently cleared coniferous woods, the superficial layer is poor in nutriment; and if the site is one where grass or heather has recently been growing, the roots of these plants will prevent a free interchange of gases between the soil and the air. Larch is peculiarly sensitive to the condition of the surface, for being in its youth a surface-rooter it cannot range through the deeper layers in search of the nutriment which it requires. For the same reason the subsoil is of secondary importance, i. e. for the normal growth of the tree. (The nature of the subsoil is an all-important factor in susceptibility to heart-rot.) So long as this is well drained a good thick surface-soil will grow satisfactory larch, and if the trees are growing vigorously there is a good chance of their remaining free from canker. Perhaps the safest situation is a mountain-side, where the porous, welldrained, gravelly soil derived from the rocks above provides all the factors favourable to larch culture.

Only in comparatively few cases can we say that a soil will or will not grow healthy larch until it has been tried. I have seen healthy woods grown on a clay subsoil and plantations riddled with canker on sand. Mitchie (1885) says that soil which is suitable for barley will generally prove successful with larch.

Conditions of culture. Pure larch-plantations are more liable to attack than trees which are mixed sparingly with hardwoods, such as hornbeam or beech. This is usually explained by supposing that the hardwoods act as a kind of screen, protecting the larch from fungal spores which are blown through the woods. Such a theory, however, cannot be entertained when, as is often the case even in mixed woods, the dead lateral branches of the larch become covered with the fructifications of Dasyscypha. For this shows that the spores have found out the larch trees, and the number of fructifications made on the dead branches would be sufficient to ensure infection of the trees, were they susceptible. Probably Forbes is right in accounting for the comparative immunity in mixed woods in quite another way. 
As he points out, finer larch trees are found in mixed woods than generally occur in pure plantations, even when these are free from canker. This is partly due to the fact that ' when mixed sparingly with deep-rooting or compactrooting trees, the larch-roots can spread without meeting much opposition, while their more rapid stem-growth gives them a lead over other species from the first'. Also the soil under mixed woods is maintained in a state more generally suitable to tree-growth than in pure coniferous plantations.

One result which we gain from the considerations of contributory causes is that the conditions which are favourable to the restriction of canker are in general identical with those that encourage the active growth of the tree. Keep the trees growing vigorously and canker is not so likely to become epidemic. The explanation of this may be sought in the nature of the struggle between the parasite and the host. Given an uninterrupted tissue of living cells, the fungus can push forward, killing the cells in advance of it by its secretions and itself growing into them. But the tree resists this progress by cork layers, which we may liken to a series of trench systems, each holding up the enemy for a time, and perhaps entirely preventing his advance. When the fungus grows down from a branch, the first trench it has to capture is the cork layer normally made at the base of a dying branch. If this is passed, fresh cork layers are made in the tissues of the tree, and it often happens that the first of these prevents the canker from spreading farther. If this fails, more and more cork layers are formed, and so the struggle progresses-purely offensive on the one hand, and purely defensive on the other. Fortunately the advance of the fungus through living tissue is very slow, especially in a tree which is healthy and fastgrowing, so that such a tree has time to make a fresh cork layer (or, to revert to the simile of war, it can complete new earthworks before they are reached by the advancing enemy), and the better and more thoroughly this layer is made the less chance the fungus has of passing it. Not infrequently trees which are growing strongly show a number 
of incipient cankers at the bases of their branches. Blackened bark and slight exudation of resin show that the fungus has penetrated to the cortex of the trunk, but, though they may develop into normal cankers, these spots frequently disappear as the tree grows older, and the fungus, held from further penetration by a cork layer, has died from lack of nutriment.

The greater susceptibility of weakly-growing trees may thus be associated with their enfeebled power of forming cork layers. The surprising rarity of canker on other conifers, such as spruce or Scots pine, which have been shown experimentally to be susceptible to infection, may be due to their possessing this power in a higher degree. In particular, isolated cankers have not infrequently been found on the Japanese larch, but in general this tree is surprisingly free from the disease, even when grown in close association with cankered European larch. It has yet to be demonstrated that Japanese larch has a more pronounced faculty for making cork layers than the European larch, but it is probably along these lines that the explanation for the comparative immunity of the former tree should be sought. And as it is now considered that nearly every species is composed of a number of 'races' which differ only in small particulars, it may be expected that some races of European larch are better able to make such cork layers than others, and the selection of such races may be the ultimate means of growing larch without canker. Selection of tree races is a slow affair, but it is clearly advisable, when collecting seed, to choose those trees which have grown free from canker, in the hope that their progeny may share their immunity.

Methods of prevention. The treatment of larch which has been recommended at various times for the prevention of canker has always been based on the current views as to the causes which lead to the disease. Thus Hartig insisted that every kind of wound must be, as far as possible, avoided, and he is particularly emphatic that branches must never be removed until they are dead. Somerville 
laid stress on preventing wounds when planting young trees; and Massee, on finding that infection could take place through the punctures made by Chermes abietis, declared that, if this insect could be suppressed, canker would cease to be an epidemic disease.

All these suggestions have proved useless in obviating the disease, and foresters have been forced to adopt other means for reducing the pecuniary loss for which canker is responsible. One doctrine is that larch-growing should be confined to situations and soils which have proved capable of bearing healthy plantations. But since this rules out the majority of districts in which larch is at present grown, it is a confession of failure except in a few favoured localities. Sir Donald Munro Ferguson has adopted, at Novar, a method of treating larch which was described by Somerville (1906) in the Journal of the Board of Agriculture. He plants pure larch at 3,500 to the acre, the vast majority of which become cankered. At the age of 16-20 years he cuts out all but $300-500$ of the best trees, and is able to sell the 3,000 or so thinnings for $£ 20$ to $£ 25$. The lateral dead branches are removed and the remaining larch are underplanted with beech, or preferably such conifers as Picea sitchensis, Pseudotsuga Douglasii, Tsuga albertiana, Thuja plicata, Cupressus lawsoniana, and Abies grandis.

In most plantations it will be possible to select 10 per cent. of healthy trees, and the 300-500 trees that are left may be exempt from canker during the remainder of their lives. But obviously the treatment will be impossible in woods where, as sometimes happens, even the best trees have three or four cankers apiece. Nisbet (1907) criticizes the system on the ground that the pure larch woods make an excellent breeding-ground for the fungus, and become a source of danger to all the intermixed larch woods in the district.

We need therefore some method by which canker can be prevented, and the method of infection which I have described as accounting for the greater number of dangerous cankers suggests a treatment which may possibly prove helpful in preventing the disease. Until successful experiments have 
proved its adequacy, it must be put forward somewhat tentatively.

If dead branches are the cause of infection, then dead branches must be removed, and, since branches are attacked by Dasyscypha almost immediately they die, they should be removed before they have any chance of being infected. To be on the safe side they might be pruned a year before they would naturally have died if allowed to remain on the tree. In a wood planted with pure larch at $3 \times 4 \mathrm{ft}$. lateral branches generally die when they are 5-6 years old, so that this is the age at which they should be cut. But cutting off branches will leave wounds, which Hartig has so strongly recommended us to prevent, and though, as has been shown on p. 62, the importance of wounds has been over-estimated, we may as well be on the safe side and cut the branches in dry weather, preferably in winter or early spring, when the spores of the fungus are not being liberated in large quantities. It may be objected that such a treatment is expensive, and that forestry is not sufficiently lucrative to allow of individual attention to the trees. But the expense of cutting off the small lateral branches would not be excessive so long as the woodman confined himself to plantations from 6 to 18 years old, since up to that age he can probably reach the still living branches without a ladder. Beyond this age the trees are much less liable to serious attacks of canker.

In districts where the canker is comparatively infrequent the treatment would be unprofitable; but where it has ravaged in the past, it may still prove to be possible to grow healthy plantations by this means, though it can only be determined empirically whether the increased value of the trees will repay the outlay.

An experimental plot in Bagley Wood, near Oxford, was pruned in the manner suggested during the winter of 1915-16. A large number of dead branches had to be removed from the lower $5 \mathrm{ft}$. of the stems, and living branches were cut for about a foot above this. Unfortunately, owing to the war, this experiment could not be 
continued, and the trees have now grown too tall to be suitable for further work of this kind. But it is observable that those parts of the stems from which living branches have been removed are much less attacked by canker than the remainder of the trunks, and none of the wounds that were made while the work was in progress have become a source of infection.

Since the cut branches form a suitable breeding-ground for the fungus, they should not be allowed to lie on the ground, but should be collected and burnt. This will reduce the number of fructifications in the neighbourhood of the trees, and will probably assist in lessening the chance of infection.

Special treatment of individual trees must nevertheless be avoided as far as possible. It involves labour which is now a serious expense, and this is incurred early in the rotation, so that, with compound interest, it must deplete the already slender profits of forests. The chief of prophylactic measures will always be the correct sylvicultural treatment of the tree. Maintain the general health of the trees and canker will not be a serious pest. The point of first importance is to plant larch in mixtures, which maintain the soil in better condition than pure larch woods and stimulate better development of roots. Forbes's views on this subject have already been quoted, and Schotte (1917), after a careful survey of the larch woods of Sweden, adopts a very similar standpoint. The most suitable tree for mixture with larch is probably the beech, but where beechgrowing is unprofitable other trees, such as hornbeam and chestnut, may be tried. Among conifers Scots pine can, according to Schotte, 'be unreservedly recommended'; but woods of larch and Scots pine in this country are apt to open out in later life and need to be underplanted either with beech or with that most promising of shade-bearers, the western hemlock. Spruce should be avoided in mixture with larch on account of Chermes abietis, which has alternate generations on the two species, and Schotte states that in Sweden spruce is apt to shade the larch overmuch, and 
thereby reduce its vitality and power of resistance to canker. Douglas fir grows well with larch up to twenty or thirty years, but on suitable soil for Douglas the larch is then suppressed. This mixture may be recommended where pure Douglas stands are ultimately required, and it is probably preferable to Douglas planted pure in the first instance, but mature larch can seldom be grown in this association.

The question of site is of less importance. Healthy trees can be grown at any reasonable altitude in Bitain, and woods in low-lying localities may be just as healthy as those on hills. Damp hollows, however, where there is danger of cold stagnant air collecting, should be avoided, as larch is here especially liable to damage by spring frosts. Very poor sandy soil is no doubt unsuitable for growing larch, and on heavy clay other trees are likely to be more profitable, but between these limits there is a wide range of soils in which larch can be satisfactorily grown, when mixed with other trees. A fuller account of the sylvicultural requirements of the larch will be found in Chapter $\mathrm{X}$.

\section{Summary of Chapters on Larch Canker}

Larch canker, which is one of the most virulent diseases of forest trees, has been known in this country since the early part of the nineteenth century, and has been described in detail by Berkeley, Willkomm, and Hartig. Subsequent writers have not added anything of first importance to our knowledge of the disease.

The canker is due to the mycelium of the fungus Dasyscypha calycina, which can live either as a saprophyte or as a parasite on the larch tree. Dead branches are usually filled with the mycelium of the fungus, which makes small cup-shaped fructifications on the surface of the bark.

Under suitable conditions the mycelium gains admission to the cortex and phloem of living parts of the tree, and can then cause canker. By killing the cambium at any spot it prevents further growth in thickness at that point, and each year it kills a larger and larger area of cambium, 
thus producing an amphitheatre-like appearance in the wood of a transverse section. The mycelium flourishes chiefly in the cortex and the phloem, but can also attack the wood to a limited extent.

It has been shown that this fungus is not a parasite in the sense in which the term is generally used. The mycelium does not directly attack the living cells of the host, but first kills them by secretions. The mycelium grows both in the cells of the host and in the intercellular spaces. Fructifications are borne on the dead bark in the canker region. These are larger than those on the dead branches in all their parts, but it has been shown that this difference is due to growth conditions, and the dimensional differences cannot be made the basis of specific or varietal separation.

Large quantities of resin are made by all attacked parts of the tree. This oozes out on to the surface of the canker, and often forms long streams down the trunk.

Pure cultures of the fungus have been grown on various media, including sterilized twigs of different conifers and dead needles of larch, spruce, and Scots pine. In a damp chamber larch needles may become matted together by the mycelium which ramifies the mesophyll. It is suggested that the matting of needles on the floor of larch plantations may be largely due to the mycelium of this fungus, a process which may help in the decomposition of the foliar débris. Pure cultures on sterilized larch stems were grown up to the stage of bearing apothecia, thus completing the cycle from spore to spore.

The fungus may gain admission to the living parts of the tree in three ways:

1. Through wounds, which may be caused by a varicty of agents.

2. By growing down from the dead branches into the living tissues of the trunk.

3. By means of buds which have been killed by the shading of the upper branches.

It has been shown that the second of these methods gives 
rise to most of the serious cankers on main trunks. The third is less important, since it only affects trees which are being killed out through lack of light. The importance of wounds has been over-estimated by most previous writers.

Contributory causes, rendering the tree more liable to canker, are any agencies which cause wounds, damp stagnant atmosphere, and poor badly-drained soil. Pure larch plantations are more liable-to the disease than those where the trees are intermixed with hardwoods. In general it may be said that any conditions which are prejudicial to the vigorous growth of larch are favourable to the spread of the disease.

Healthy plantations can best be grown by selecting sites where all the conditions are favourable to larch growth, but a treatment has been suggested whereby it may become possible to grow sound trees where canker has usually been epidemic. By the pruning of branches it is hoped that infection from these members may be prevented.

On the Synonymy of Dasyscypha calycina, (Schum.) Fuck.

The literature of larch canker has become much confused by the variety of names which have been applied to the fungus causing it.

Berkeley (1859) called it Peziza calycina; Willkomm (1867) confused it with a somewhat similar member of the Basidiomycetes, Corticium amorphum, and called it by that name; Hoffmann (1868) corrected this error, and adopted the same name as Berkeley; and Hartig (1880) said that the fungus showed microdimensional differences from $P$. calycina, and instituted a new name, Peziza Willkommii. Most English mycologists, however, have refused to adopt this new name, maintaining that the conventions of nomenclature demand that it should be called Dasyscypha calycina.

This confusion has arisen from the fact that there are three or four different species of Dasyscypha which are indistinguishable with the naked eye or a pocket lens, and 
these were consequently regarded as one species by earlier investigators. For clearness we will at present adopt the names given by Massee (1895) for four of these. They are :

1. Dasyscypha calycina, Fuck.

Spores 18-25 $\times 6-8 \mu$.

On larch and Scots pine.

2. D. subtilisima, Sacc.

Spores $8-10 \times 2 \mu$.

On firs (larch, silver fir, and spruce?).

3. D. abietis, Sacc.

Spores $12-14 \times 3 \mu$.

Paraphyses longer than the asci.

On silver fir.

4. D. resinaria, Rehm.

Spores $3 \times 1 \cdot 5-2 \mu$.

On spruce, pine, larch, and Pinus excelsa. (Massee, 1902.)

Though there is to-day a considerable difference of opinion as to the value of all these species, they will serve for purposes of argument.

Types which might include any or all of these were described by

1. Batsch (1786), p. 195. Description and figures of a species not more than $1 \mathrm{~mm}$. across, and rather longer than broad, under the name of Elvella calyciformis. The under-side of this fungus was grey-brown or flesh-coloured, so that Batsch was probably not describing the fungus which causes canker.

2. Hedwig (1789), ii, p. 64, Tab. xxii, described the same form under the name of Peziza calyciformis or Octospora calyciformis. He was the first to find the eight spores in the ascus.

3. Willdenow (1787), p. 404, gave a similar account of the fungus.

4. Schumacher (1803) first adopted the name Peziza calycina. He found his specimens ' in strobylo Pini abietis', 
but since no spore measurements were given, it is impossible to decide which species he was describing.

5. Fries (1822), p. 91 (and 1828) described three forms of Peziza calycina, viz. :

a. Pini sylvestris $=P$. calyciformis of Willd., Batsch, and Hedwig.

$\beta$. Abietis.

$\gamma$. Laricis_' albido-testacea'. 'In ramis pini Laricis, Chaillet. P. balsameae. Weinmann. (v.s.)'

It is a convention among mycologists ${ }^{1}$ to accept Fries's names for Ascomycetes where these are sufficiently distinctive; but where a species is omitted, or insufficiently described by Fries, to take the name given by the first investigator after him who gave a description on which a species can be based. What may be called the Continental contention is that $\gamma$ Laricis is the equivalent of the cankerproducing fungus, and, if this is going to be raised to specific rank, a new name [P. (Dasyscypha) Willkommii, Hart.] must be adopted for it, since ' $P$. calycina' is retained for a Pini silvestris.

It must be objected, however, that since each of the species of Dasyscypha under consideration grows on a variety of trees, and since D. calycina, D. subtilissima, and $D$. resinaria, as described on p. 76 , can each grow on the larch, it is very doubtful to which of these species $\gamma$ Laricis of Fries belongs; and it is also doubtful which form he intended by a Pini sylvestris. Certainly 'albido-testacea' is not peculiarly applicable to the canker-producing fungus.

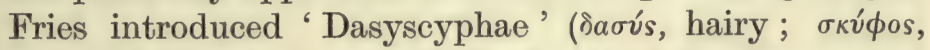
a cup) as tribe vi of series ii (Lachnea) of the large genus Peziza.

Passing over Corda (1837), v. 78, and Hornemann (1839), plate 1917, 1, whose species given under the name of Peziza calycina are both doubtful, we come to

6. Fuckel (1869), who is the first to give spore measurements. Raising Fries's name Dasyscyphae to generic rank, he

1 International Rules of Botanical Nomenclature, Brussels, art. 19, f. 
calls the fungus Dasyscypha calycina (Schum.), and gives the dimensions of the spores as $20 \times 8 \mu$. This, with the habitat of the fungus 'an dürren berindeten Aesten von Larix europaea nicht selten im Herbst', leaves no doubt that he was describing the canker fungus.

It is on this description that the name Dasyscypha calycina must be founded, since it is the first about which no doubt can be entertained. Fuckel does not mention any other species of Dasyscypha which grows on conifers.

Subsequent authors may be quoted in the usual way.

Dasyscypha calycina, (Schum.) Fuck.

Synon. : Peziza calycina (Schum.). Rehm (1876).

Peziza calycina (Schum.). Cooke (1876).

? Lachnea calycina (Schum.). Gillet (1879, p. 71).

Peziza Willkommii. Hartig (1880).

Lachnella calycina (Schum.). Phillips (1887, p. 241).

Helotium Willkommii (Hartig). Wettstein (1887).

Dasyscypha calycina (Fuck). Massee (1895).

Trichoscypha Willkommii (Hartig). Boudier (1907).

Dasyscypha Willkommii, (Hartig) Rehm. Lind (1913).

It is probably not the same as

Erinella calycina (Hedwig). Patouillard (1883).

Erinella calycina (Hedwig). Quélet (1886).

Dasyscypha calycina, (Fries) Fuck. Lind (1913).

Saccardo describes the species as follows:

Dasyscypha calycina, (Schum.) Fuck. Symb., p. 305. Pez. calycina, Schum. Sael., p. 424, saltem p.p. nec Nyl Karst. P. calycina var. Laricis Cooke Handb., p. 685. Peziza Willkommii, Hartig Lehrb. Gregaria v. sparsa, saepissime caespitosa, stipitata, albo-villulosa ; cupula expansa, sicca concava, disco aurantiaco-luteo $\mathrm{v}$. aurantiaco, concaviusculo v. planiusculo, 1-2 mm. lat.; stipite brevi crassiusculo, in cupulam dilitato; ascis subcylindraceis $120 \times 9$, octosporis ; sporidiis elongatis, obtusis, continuis, monostichis, 16-22x 6-7 hyalinis; paraphysibus filiformibus, hyalinis, sursum incrassatulis, pilis hyalinis $2.5 \mu$ crassis. Hab. in cortice Laricis et Pini sylvestris in Germania, Britannia, Italia, Gallia. 
It should here be noted that when growing saprophytically the fungus is generally smaller in all its parts than when taken from a canker spot. The saprophytic form is seldom more than $2 \mathrm{~mm}$. in diameter, whereas the parasitic one may be as much as $3 \mathrm{~mm}$., and the asci of the former are about 140-170 $\times 9-12 \mu$, and of the latter 160-200 $\times 10-15 \mu$; and the spores $17-20 \times 8-9 \mu$ in the one case and $20-23 \times$ $9-10 \mu$ in the other.

The spores are here measured in each case when ripe and ejected and placed in water. When measured inside the asci they are always somewhat smaller.

At first I was. inclined to regard these as two distinct varieties of the fungus, but that they are only different growth forms is shown by the following considerations:

1. A canker may be produced by inoculation with mycelium grown from the spores of the saprophytic form.

2. Mycelium grown from the spores of the parasitic form will grow readily on dead larch twigs, and produce apothecia.

3. When a young tree with canker dies the fungus spreads centrifugally from the canker and produces numerous fructifications of the saprophytic type.

4. All intermediate forms between the two types can be found.

The large apothecia of the parasitic form are probably the result of differences in the substratum, the most obvious of which is the presence of a vastly greater amount of resin in the canker than in the bark of a dead branch. 


\section{CHAPTER V}

\section{HEART-ROT. FOMES ANNOSUS}

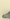

Various fungi which cause heart-rot. Fomes annosus : general ; historical. Secretions induced by Fomes annosus: turpentine and resin; soluble gum; insoluble gum. Decomposition of the wood.

HEART-ROT of trees is caused by fungi which grow saprophytically on the dead wood, but are either incapable of growing parasitically, or attack living tissues very feebly. The heart-wood of trees is dead, has lost all its protoplasm and with it much of its power of resisting fungi. Though it is more resistant than dead sap-wood, it is by far the most susceptible part of the trunk of a living tree, and is liable to become entirely decayed, leaving only a ring of healthy sap-wood which maintains the life of the tree. With the destruction of the heart-wood the tree may lose none of its vital activity, but it is nevertheless weakened in two respects. The central column of tough wood is lost and the tree is much more liable to be wind-blown, especially as the roots are often weakened in the same manner as the trunk, and if the central hollow has any communication with the outside air, a ready means of infection is provided for truly parasitic fungi.

One of the most familiar instances of heart-rot caused by a purely saprophytic fungus is afforded by the elm. This tree is usually grown in avenues or hedgerows where large lateral branches are allowed to develop which would be suppressed in closely-timbered woods. These branches are brittle, and frequent breakages result in numerous large scars which expose both sap-wood and heart-wood to fungal attack. In summer spores are nearly everywhere present to take advantage of these scars, and the trees become infected with such fungi as Fomes ulmarius, which is the chief, if not the only, cause of heart-rot and hollowness in 
elms. When attacked by this fungus the heart-wood assumes a reddish-brown colour, and ultimately falls to dust, leaving the centre of the tree hollow. Large woody fructifications are borne inside the hollow trunk, white or ashy grey above and salmon coloured beneath, which provide spores for further infection by the fungus. Often by the subsequent attack of other fungi the tree is killed, and then the mycelium of Fomes ulmarius spreads through to the bark and more fructifications are produced on the outside.

I have cited the instance of the elm as it is familiar to every one. The hollowness of the trunk is commonly discernible from the outside, and the fructifications can frequently be found. With conifers this is not so. The destructive work of the fungus is the more insidious by its very secrecy. The heart of the tree is eaten away, and the evil is betrayed by scarcely an external sign which would warn the forester to cut the trees before the damage has progressed so far that the base of the tree has become worthless, and most foresters must have experienced the disappointment of finding some of their finest specimens of larch or Scots pine rotted up to 10 or $20 \mathrm{ft}$. from the ground, when they had expected to obtain sound healthy butts.

It must be admitted at the outset that the cure of trees which are attacked by any of the heart-rotting species is impossible. It is thus of supreme importance that woods should be grown under conditions in which disease is not likely to occur, and the most essential part of our investigation of the pathology of the fungi will be that concerned. with the mode of infection of the pests. No detail which has any bearing on the problem of infection can be ignored, and since a fungus may become reproductive in any stage of its existence, we must familiarize ourselves with every part of its life-history. To prevent loss it is also necessary to keep a careful watch on all plantations and to adopt every means at our disposal of tracing the earlier symptoms of the rots. It may then be possible to thin out those trees which would afterwards have become reduced in value, and if whole woods are attacked it may be more profitable to 1888 
cut them down before they are mature than to leave them to be ravaged by disease.

It is possible to detect a tree which has become actually hollow by tapping it sharply with a stick. The peculiar sound emitted by a hollow tree can generally be recognized. But this only discloses the fact that damage has already been done, and to trace disease in an earlier stage a Pressler borer must be employed. By boring young trees with this instrument the presence of rot can be discovered before the tree has seriously depreciated in value. It is recommended that foresters should test their woods every few years by means of such a borer, picking out every tenth tree and boring it a foot or less from the ground to test its soundness. Where diseased trees are found all the trees in the immediate vicinity should also be tested, and those which are attacked should be removed, if possible, root and all. Holes made by the borer must be pegged by pieces of stick, which should be cut off at the level of the bark.

Heart-rot of the larch is caused by several different fungi, each of which has its own method of attack and causes its peculiar form of destruction in the wood. The most important of these fungi is Fomes annosus, which is destructive to nearly all species of conifers, and attacks both young and old trees, producing strikingly different results in the two cases. Wood destroyed by this fungus shows small black specks later associated with white patches which ultimately become holes. In this way the wood may become honeycombed and feel soft and spongy, and finally crumble into dust, or, if wet, it may become slimy. In either case it leaves the tree hollow.

Another very important cause of heart-rot is Polyporus Schweinitzii, which, though it does not make the tree hollow, converts the wood into a darkish cork-coloured substance which is light in weight, smells strongly of turpentine, and when dry crumbles to dust on being lightly rubbed between the fingers. The red-brown fructifications of this fungus may frequently be found growing either on the lower part of trunks themselves, or else on the roots, often at some 
distance from the trunk. The fungus is especially frequent in the south of England, and grows on the Scots pine and maritime pine as well as the larch.

Heart-rot of the larch is also caused by Polyporus sulphureus, a fungus which is easily recognized by its bright yellow, bracket-shaped fructifications which appear in July and August. It is most common on oak, in which tree it also produces heart-rot, but I have also a specimen of larch which has been rotted by this species. The rot is similar to that caused by $P$. Schweinitzii, but fractures occur especially in the first-formed elements of the spring wood, so that the annual rings become separated from each other. Also the turpentine smell is absent.

In Germany Poria vaporaria has also been frequently recorded as a cause of heart-rot in larch and other conifers. It is very doubtful whether the species which is alluded to in these records ever accurs in Britain. The name has been made to cover a large number of closely associated species, and though I have found a Poria growing on dead larch trunks and apparently causing a rot closely resembling that described by Hartig, I have never been able to determine its capacity to grow in living trees. This fungus also causes a rot which resembles that of Polyporus Schweinitzii.

Trametes Pini is another wound parasite which attacks the larch through branch stubs near the crown of large trees. It causes a very distinctive rot, which is described on p. 140.

There are thus four, or perhaps five, distinct species of fungi which attack the heart-wood of the larch, and each of these will be more fully described in the ensuing chapters. But before closing this general introduction to the heartrots, it should be noted that the first two differ from the remainder in one all-important respect. Fomes annosus and Polyporus Schweinitzii are essentially root fungi, that is to say, they attack the roots first, and always advance from the roots to the trunk. Polyporus sulphureus and Trametes Pini, on the other hand, gain admission in the same way as Fomes ulmarius on the elm. They attack the heart-wood which is exposed when branches fall off, and 
when the rot reaches the trunk it spreads both upwards and downwards. There is some doubt as to the method of infection adopted by Poria vaporaria, but probably, like Polyporus sulphureus, it can only reach the heart-wood through wounds.

Fomes annosus, (Fr.) Cooke : General. In Britain Fomes annosus attacks nearly all kinds of conifers. It has, however, two different modes of attack, and as the symptoms are very distinct in the two cases, they might easily be considered the work of two different fungi. In one case the fungus attacks the trees when young, usually about four to ten years, and kills them in a year or two. Frequently in young plantations individuals or groups may turn a brown or reddish-brown colour, lose their leaves and die, and on pulling these trees up it is generally found that the roots are attacked either by Armillaria mellea or Fomes annosus. The identity of Armillaria mellea can generally be detected by the presence of rhizomorphs and the large flaky masses of mycelium between the wood and the phloem and between the scales of the bark of the rootstock, as well as by the resin flow at the base of the trunk. Fomes annosus is not so easy to identify unless some of the perennial fructifications are present, but small pustules of mycelium on the roots and the very thin layers of mycelium in the bark, no thicker than the thinnest tissue paper, are usually sufficient evidence of its presence. The species that are most commonly attacked in this way are Douglas fir, Lawson's cypress, Weymouth pine, and sometimes the monkey-puzzle tree, but probably many other conifers are liable to this kind of attack. In such instances the fungus is a fairly rapid parasite, and death follows quickly on attack. Other species, such as the larch, ${ }^{1}$.spruce, and Scots pine, are not generally attacked by the Fomes until they are comparatively old and have made heart-wood. On these trees the fungus is a rather feeble parasite and kills living tissues very slowly. It flourishes, however, in the heart-wood which is dead, and

1 The death of some young larch trees in the manner described above is reported by Somerville (1898). 


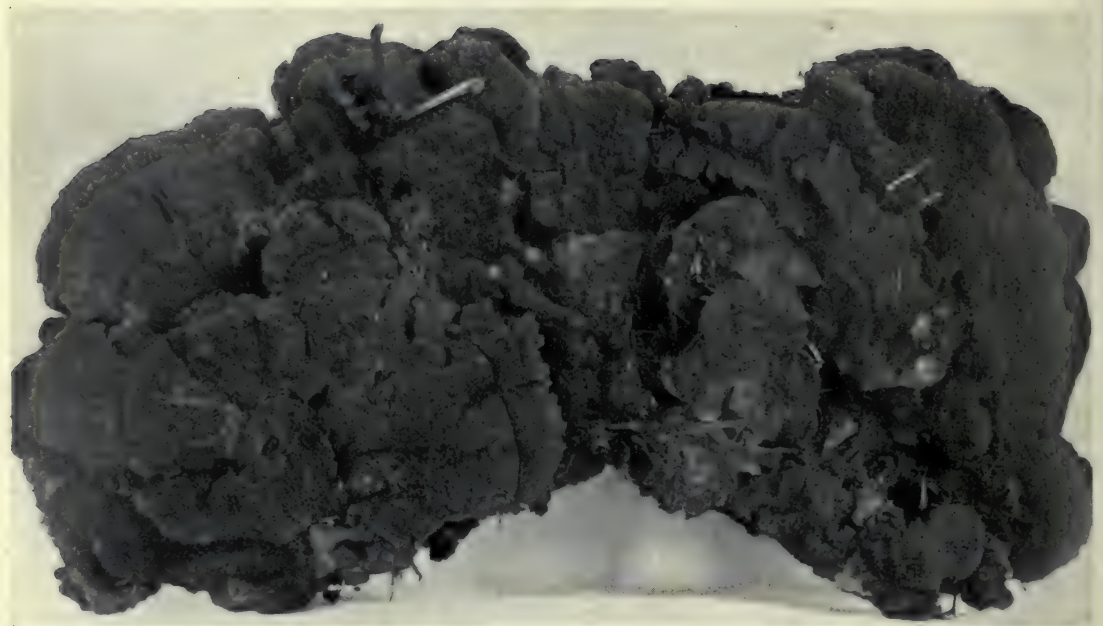

Fra. 29. - Single fructification of Fomes annosus found on a dead spruce. Upper surface.

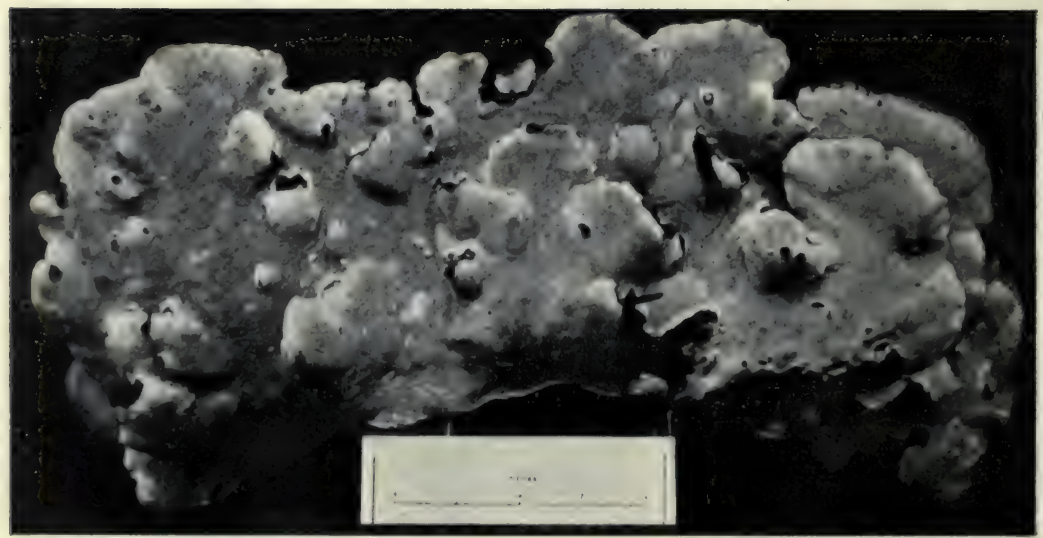

FIG. 30.-Lower surface of above $\left(\times \frac{2}{4}\right)$. 
rots the centres of the trees without destroying the vital tissues, so that the trees continue their growth and appear to be healthy until they are cut down, when the basal part of the tree is found to be valueless. The disease is sometimes accompanied by a swelling of the base of the trunk, known to foresters as 'goutiness', but it is by no means safe to diagnose the disease on the basis of this single feature.

Conifers are not so often killed by the fungus when attacked at this later period, but when the trees are weakened by the overshadowing of other trees, death may ensue. And larch is killed in this way less often than spruce or Scots pine. At the same time larch is more frequently heart-rotted than either spruce or pine, at any rate in the south of England. I have never seen silver fir rotted by this fungus, though instances are recorded on the Continent.

Since in pumped trees the fungus is confined to the heartwood, fructifications are not generally formed on living trees. But when the trees die the fungus penetrates to the bark, and often bears large fructifications such as those shown in figs. 29 and 30 . This accounts for the comparative infrequency of fructifications of Fomes annosus on larch trees, and consequently for the doubt that has often been expressed as to the connexion between this fungus and the rot. But I have twice found unmistakable fructifications of the fungus growing in direct connexion with the rot in living trees, once on the roots of a wind-blown larch near Tintern, and the other time on a tree which I had dug up at Terringham Wood in the Forest of Dean. Probably fructifications are frequently borne in this way on the roots, but being subterranean they remain unseen.

If further evidence is needed to confirm the connexion between Fomes annosus and the larch heart-rot, it is provided by series of cultures taken on the one hand from pieces of rotted wood, and on the other from spores of the fungus. These are identical in all respects, and agree in the possession of a peculiar type of conidiophore which is at present unknown in any other fungus. 
Historical. The history of our knowledge of the disease is briefly as follows. In 1878 Hartig published a detailed account of his investigations on the fungus (which he called Trametes radiciperda). His paper is chiefly concerned with details of timber rotted by the fungus and its mode of attack. He recognized two methods of infection, (i) by spores of the fungus and (ii) by the contact of diseased roots with living roots, and proposes combative measures which are suggested by the results of his researches. Apparently he never found Fomes annosus growing on larch, though he suspected that this tree might also be attacked. But Hartig did not clearly distinguish between the two forms of disease for which the fungus is responsible, and since larch trees are seldom killed by it, he may have overlooked the heartrot. He states that in Germany Pinus sylvestris, $P$. strobus, Picea excelsa, Abies pectinata, and Juniperus communis are the species which are most frequently attacked. It is commonest in young plantations, but trees as old as one hundred years may succumb to it. In 1889 Brefeld $^{1}$ carried out an exhaustive investigation of the fructifications, the germination of the spores, and artificial cultures. He was the first to discover the conidia, which are produced in great profusion in cultures but have rarely been found under natural conditions. On account of the similarity between the conidia and basidiospores, and between the organs which bear them, he renamed the fungus Heterobasidion annosum, thereby creating a new genus which has not been perpetuated. On questions of prophylaxis he was fundamentally opposed to Hartig's doctrines, and the divergence of opinion was not softened by the caustic style of Brefeld's

1 Oskar Brefeld was born in 1839 at Telgte, in Westphalia. He succeeded R. Hartig as professor of botany at Eberswalde in 1878, and proceeded in 1884 to Münster, and in 1898 to Breslau. His researches on fungi have included the cultivation in pure cultures of an immense number of different species, and he has thereby discovered conidial forms of reproduction in many species in which they were previously unknown. He has also brought methods of cultivation to a high degree of excellence, and was the first to introduce gelatine as a medium for cultures (New International Encyclopedia, iii, 1910). 
criticism. Certainly the discovery of conidia profoundly affected the value of the measures by means of which Hartig sought to combat the disease. A more general account of the fungus and its effects on trees may be found in the translation (1894) by Somerville and Marshall Ward of Hartig's Diseases of Trees.

Heart-rot is the cause of very serious financial loss to foresters. It occurs with alarming frequency in woods which are planted as a first rotation on land that has previously been arable or waste, and acres of plantations may be reduced through it to two-thirds their value or less. And since in Britain new land is frequently being converted into forest, a conversion which is likely to be much accelerated in the near future, the disease must be regarded as one of our most serious enemies. Plantations on old forest land, however, remain comparatively free from heart-rot, so that we may look forward with more confidence to the yield of later rotations on land which is at present being afforested.

Though Fomes annosus is found in North America, it does not appear to do so much damage there as other heartrotting fungi. Butler (1903) records its occurrence on deodar in India, but his description and figures suggest that, if this fungus was present, it was working in collaboration with Armillaria mellea.

In the following sections I shall describe in detail the various characteristics of the disease as it appears in the larch. Afterwards I shall deal with the methods by which the fungus attacks the trees, and with the means of combating it and minimizing its depredations.

Secretions induced by Fomes annosus. (i) Turpentine and resin. In the early stages of attack by the heart-rot fungus the wood assumes a reddish-brown appearance. This red region usually surrounds all parts which are actually rotted by the fungus, and advances in front of the heart-rot as it ascends the tree. At first it resembles a red duramen, but its tone is generally redder and deeper than that of normal duramen, and the outside limit of red coloration may cut 
across a number of annual rings and even reach the cambium when the attack is more marked on one side. This may specially be seen in a rootstock when the fungus has entered the tree through a lateral root.

Owing to this red colour the earlier stages of the disease are sometimes known by foresters under the name of 'red rot'.

The red colour is ascribed by Hartig to infiltration of the wood by turpentine and resin, which are secreted by the resin ducts and medullary rays. If shavings of the red wood are soaked for a considerable time in methylated spirit, the turpentine and resin are dissolved and the colour disappears, except in the medullary rays which retain a reddish-brown tinge. Osmic acid stains part of the contents of these medullary rays a deep black, and it is probably the proteins which both give this reaction and cause the red-brown colour in these cells. In the specimens that I have examined the medullary ray cells have been all dead and no nuclei could be traced. Stray hyphae were often found in the red rot region, and where hyphae could not be seen the occurrence of the empty bore-holes proved that they had formerly been present. Hyphae were even seen in the normal coloured wood outside the turpentine region.

(ii) Soluble gum. During the red rot and earlier stages of attack a large amount of soluble gum is present in the tracheides and medullary rays. It can easily be seen in microscopic sections mounted in alcohol, in which it takes the form of an emulsion in the tissues. On addition of water this vanishes. It may be extracted by soaking in water shavings of wood, which has reached the red rot stage. When the water is poured off and filtered, it is found to be slightly opalescent, and on adding an excess of alcohol the gum is thrown down as a flocculent precipitate. This may be collected by filtering; and on drying the filterpapers it remains as a yellowish mass. This is readily soluble in water, so that a strong and moderately pure solution may be obtained in this way. From $500 \mathrm{grm}$. of red rot shavings $I$ obtained 22 grm. of gum. When dry it 
is hard, but readily becomes soft on the addition of water, though the solution is not adhesive.

The gummy nature of this substance, its solubility in water and insolubility in alcohol, showed it to be either a gum or a dextrin. On hydrolysing for half an hour by boiling with dilute $\mathrm{H}_{2} \mathrm{SO}_{4}$, it gave large quantities of sugar which was capable of reducing Fehling's solution. This led me to suppose that the substance was a dextrin, but Dr. D. H. Vernon kindly tested it for me and identified it as a gum. The distinction was based on the readiness with which an aqueous solution is precipitated by alcohol, and on the detection of pentose sugars as a result of its hydrolysis. If alcohol to 51 per cent. be added to a 20 per cent. solution of the gum, a dark-brown gummy mass is thrown down and a moderate amount of white precipitate is retained in solution. If alcohol is added to the filtrate up to 64 per cent., a considerable further white precipitate is thrown down, while alcohol to 70 per cent. brings down a very copious white precipitate. No further precipitate results from adding more alcohol, so that we may conclude that an excess of alcohol to 70 per cent. precipitates all the gum. Dextrins, on the other hand, do not begin to be precipitated till the alcohol exceeds 70 per cent. If the solution be kept for some time the presence of pentose sugars may be detected by the phloroglucol and orsinol tests, which give very marked results. And since the gum was derived by precipitation by alcohol from a watery extract of the wood, it cannot be maintained that the pentose sugars were present from the first, as such impurities would not be precipitated by the alcohol.

Now it is known that in the process of delignification a number of pentose derivatives are removed from the cell walls, and we may here seek the source of the gum found in the early stages of rot. Very little is at present known about the chemical constitution of gums, and the term is applied rather vaguely by biochemists; but as far as I know this is the first occasion in which a member of this class of substance has been isolated from a conifer. In the trunks 
of broad-leaved trees, especially in the heart-wood, wood gum is not infrequent; this, however, is insoluble in water. A general account of the presence of gum in heart-wood, and as a result of wounding in Dicotyledons, is given by Temme (1885), and the reader is referred to this and to .a short account in Beilstein (1893).

A few solubility tests were carried out on the larch gum, and it was found to be soluble in water and nitric acid, but insoluble in alcohol, ether, chloroform, sulphuric acid, and caustic potash, and is doubtfully soluble in hydrochloric acid. It has a high power of attraction for water, even absorbing it from the air. When heated to $120^{\circ} \mathrm{C}$. in an oven it becomes somewhat changed, and does not dissolve so freely in water, though its adhesive power is much increased. In this respect, as also in its solubility, it resembles gum arabic.

In pure cultures of Fomes annosus in sterilized blocks of larch wood, the gum is formed in a few days after infection, and may be found at a distance of an inch from the nearest fungal hyphae, though none is present in similar blocks which have not been infected. We must suppose that enzymes, presumably including a lignase, are secreted by the fungus, and that these, or the products of their digestion or both, become diffused through the tissues of the wood blocks. It is curious that gum should appear at a time when the only delignification that is apparent is in the bore-holes, to be described hereafter, through which the hyphae grow from one tracheide to another. But it is possible that some slight delignification takes place through the whole region surrounding the hyphae.

As the rot advances this gum disappears. As shown in the next section it is probable that some of it becomes converted into an insoluble gum, but what happens to the rest is obscure. It does not seem in any way to impede the growth of the fungus, and it is possible that the fungus even feeds on it, either in its original state or after hydrolysis. I have examined a heart-rotted spruce tree for the presence of soluble gum and was unable to obtain any trace of it. 
(iii) Insoluble gum. As can be seen in figs. 32 and 36 , the larch is generally rotted in a very irregular manner. A transverse section of the trunk has often a curious figured appearance, the truly rotted wood being in more or less isolated patches, or the rot may be annular as in fig. 31, with a peg of sound wood in the middle. In every case the rotted wood is surrounded by a layer of very dark hard wood which appears to prevent the further progress of the rot. The colour and hardness of this layer are due to the precipitation of an insoluble gum which fills all the tracheides and medullary rays and forms a prominent object in all sections of the wood.

Though it imparts to the wood a red-brown colour, in microscopic sections it is yellowish, so that the red tinge is supplied by the wood itself. It is only found in close proximity with the fungus, and apparently only where air is present, for it occurs especially near the outside of infected blocks, and often appears surrounding a bubble in a tracheide.

The nature of this substance has not been ascertained. It is insoluble, but swells slightly in water, is insoluble in alcohol, ether, chloroform, acetic acid, $\mathrm{HNO}_{3}$; in 10 per cent. $\mathrm{HCl}$ or $\mathrm{H}_{2} \mathrm{SO}_{4}$ it is not dissolved after five days, though it then appears slightly corroded. It contracts markedly in a 5 per cent. oxalic acid solution in spirit, and appears somewhat discoloured. It dissolves entirely in 10 per cent. $\mathrm{KOH}$ solution after three days' immersion.

It thus differs from the 'wound gum' of Dicotyledons, which, according to Temme (1885), is insoluble in $\mathrm{KOH}$, but is soluble in warm $\mathrm{HNO}_{3}$. Also Temme states that if thin sections containing 'wound gum' be placed for a quarter of an hour in dilute $\mathrm{HCl}$ and potassium chloride, the gum, though still insoluble in water and ether, becomes soluble in alcohol. With the gummy substance in the larch this was not the case. This gummy substance has considerable pathological importance, for it is impermeable to hyphae of the fungus and acts as a screen; preventing the unlimited growth of the mycelium. It is deposited as a layer up to twenty tracheides thick, which entirely sur- 
rounds the rotted region in advanced stages of disease and definitely limits the scope of the fungus. In cases of annular attack in which a central pillar of wood is left unrotted, it is found that this is surrounded by a layer containing the gummy substance, so that here also it secures the central portion from attack. And when, as so often happens, the rot is confined to certain patches (as seen in a transverse cut), each patch is surrounded by a layer of this gum. How this layer is formed is obscure, but its protecting efficacy is clearly shown by the fact that on one side of it the wood may be entirely rotted, though on the other it is quite sound. This layer may thus help to account for the fact that larch trees are so seldom killed by Fomes annosus, for the young wood, being protected by this gummy layer, continues to function. In completely rotted, dead trunks, portions may often still be found which have been saved from rot by the preservative gummy layer, though in such cases they are usually not entirely free from fungi, and one must suppose that the gum is eventually decomposed. Woodmen have told me that they consider the part immediately surrounding the rot as stronger and more resistant to damp than ordinary larch wood. This is readily intelligible in the light of the above observations.

In spruce the heart-rot is sometimes surrounded by a darkbrown or grey layer. In this layer some of the tracheides are partially filled with a gum, but it is duller in colour and has a different appearance from the insoluble gum of larch.

Decomposition of the wood. The mycelium in the tracheides consists, in the first place, of septate hyphae which branch freely and have hyaline contents. These hyphae vary greatly in thickness, and although all intermediate sizes may be found, they are mostly either large $(3.5-5 \mu$ in diameter) or small $(1-2 \mu)$. The large ones grow somewhat irregularly, are often wavy in outline, and have thin walls. The fine ones usually grow very straight and arise from thick ones without themselves giving off many branches. In early stages of attack they usually grow from one tracheide to another through the bordered pits, but later 


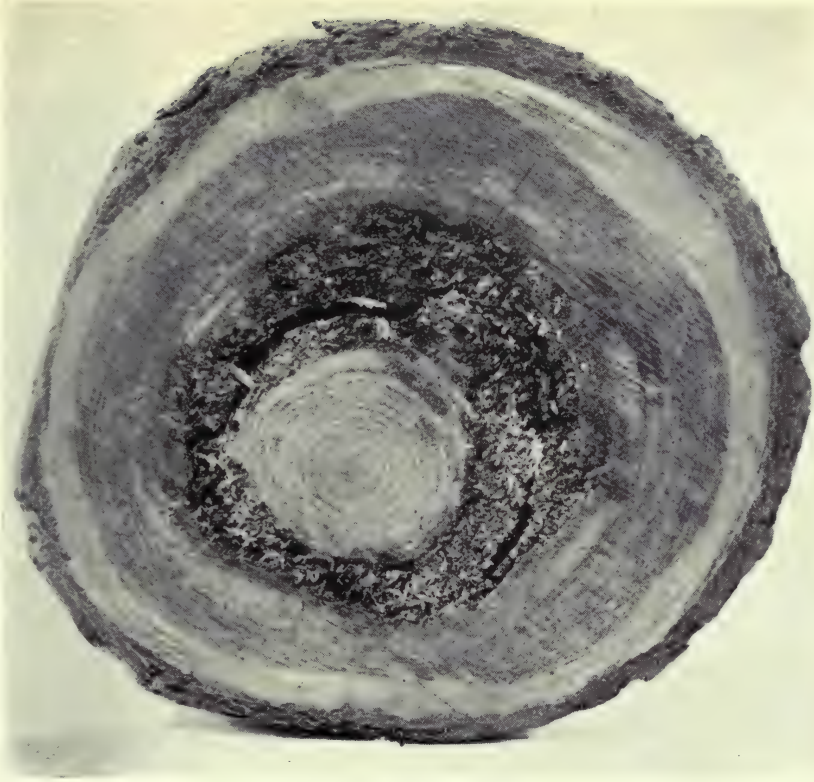

Fig. 31.-Fomes annosus. Annular rot with a central un rotted core $\left(\times \frac{3}{10}\right)$.

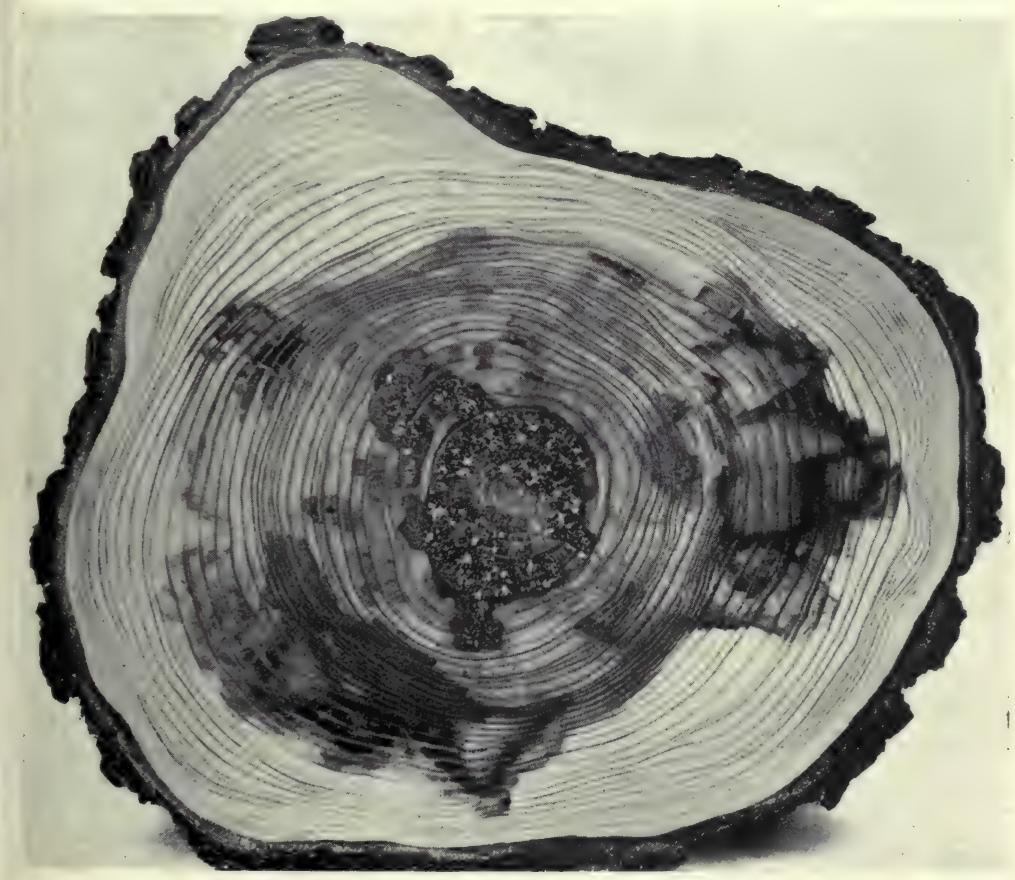

FIG. 32.-Fomes annosus. Figured rot; the central portion shows advanced rot with white specks. Farther out the rot has not reached this stage, but clearly shows layers of insoluble gum $\left(\times \frac{1}{3}\right)$. 

they make themselves bore-holes which are nearly circular and of the same size as the hyphae. These bore-holes are always exactly perpendicular to the surface of the walls, and thus follow the line of the shortest distance from the lumen of one tracheide to that of the next. To make these bore-holes the hyphal tips must excrete the necessary enzymes (presumably a lignase and a cytase). When once a hypha has gained a passage from one tracheide to the next, the hole which it occupies ceases to enlarge, and it may reasonably be deduced from this that the enzymes are only secreted by the apices of the hyphae, since, if they were also secreted by the sides of the hyphae, the holes would continue to enlarge when the hyphae had grown through. Bore-holes may be seen cut through the curved side-walls of a bordered pit while the actual pore of the pit is left intact. These bore-holes are often extremely numerous, and $I$ have counted as many as thirty-five in $0^{\circ} 002 \mathrm{sq} . \mathrm{mm}$. of tracheide wall.

The fungal hyphae may be seen in all kinds of elements of the wood-tracheides, resin ducts, resin cells, medullary ray tracheides and parenchyma. The hyphae in the tracheides are of all sizes, and generally run along the elements in a longitudinal direction and often clinging to the sides. Either large or small hyphae may bore through the tracheide walls; thus the bore-holes vary from 1 to $5 \mu$ in diameter (fig. 35, b).

The resin ducts often become entirely filled with a mass of hyphae which are nearly always fine : the broad hyphae do not commonly appear in the resin ducts. In the medullary ray parenchyma it is otherwise, for here only the coarser hyphae are found, and these run generally along the medullary rays, passing through the end walls of the ray cells by holes which they bore through the simple pits.

The decomposition of the wood by the hyphae in this stage is very slight, and, apart from the bore-holes, there is no apparent delignification. But in certain places an entirely different development of the hyphae occurs, which causes black specks in the wood. These black specks are 
always small and are more or less circular in cross-section, though they extend to greater length in the longitudinal direction. The cross-section has a diameter of $0^{\cdot} 1-0^{\circ} 4 \mathrm{~mm}$., and covers one to a dozen or more tracheides. The length is fairly regular, being $0 \cdot 5-1 \mathrm{~mm}$.

These black specks may occur in the spring or summer wood, and do not bear any definite relation to each other,

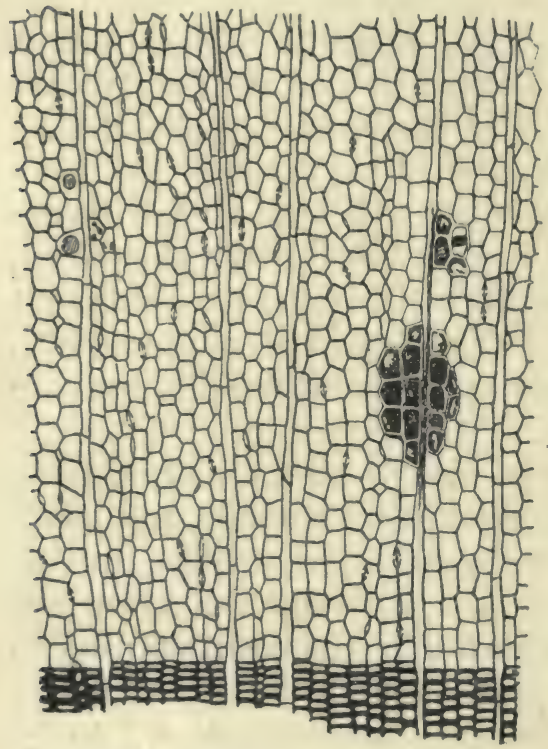

FIG. 33.-Black specks in the wood of the larch caused by Fomes annosus. Transverse section $(\times 85)$. except that they sometimes appear in longitudinal series, with a distance of $1 \mathrm{~mm}$. or so between them. Under the high power of the microscope they are seen to be composed of dense masses of hyphae, all of the broader kind, whose walls have become more than usually thick, and dyed with a deep brown or black colour similar to Brunswick black. The hyphae at these points branch very freely, and on the outskirts of the patch they are-seen with rounded ends and have a tendency to grow in fascicles. Sometimes, however, the brown hyphae may be seen continuing as colourless hyphae, and in such cases the coloration ceases somewhat abruptly at the limit of the black patch. These hyphae are presumably the original hyphae which were present before the black patch was formed, and which gave rise by branching to the rest of the hyphae forming that patch; but, in addition, hyaline branches are also sent to the neighbouring tracheides, and these may give rise to new black patches after the parent ones have disappeared. 
The centre of a fully formed patch is so deeply coloured that even in a thin section no details can be made out. But, as will be shown later, treatment with dilute $\mathrm{HCl}$ bleaches the whole patch, so that subsequent to this reaction the structure can be investigated.

The mode of development of these patches has been observed in detail in artificial infections on sterilized larch wood blocks. They originate a few weeks after infection at points where a large amount of soluble gum has collected, and the first sign of their formation is seen in one or two broad hyphae becoming light brown in colour. These hyphae are sometimes situated in the tracheides, but more generally in the medullary ray parenchyma. Thus Hartig's statement that the black specks originate in the medullary rays is in general right, though his contention that the blackness is due to substance diffusing from the medullary rays into the tracheides is certainly wrong. From the original brown hyphae other hyphae arise by branching, and they all become much darker in colour. The branch hyphae enter neighbouring tracheides and medullary rays so that the black patch increases in size.

The hyphae penetrate everywhere, making very numerous bore-holes and entering and filling the cavities of the bordered pits. Where three or four tracheides abut on to each other the middle lamella is sometimes digested, and an intercellular space is formed which becomes filled with hyphae. In the black state the hyphae delignify all the walls they touch, so that these walls cease to stain red with phloroglucol and hydrochloric acid, but give a blue reaction with chlorzinc-iodine. This shows that the lignone is absorbed and the cellulose substance left. Further, the fungus may destroy this cellulose substratum and whole walls may disappear, or half a wall may be absorbed, i. e. the part on one side of the middle lamella, and the other half remain. Thus it will be seen that the digestion of the cellulose is somewhat irregular. Probably some of the cellulose is digested from every wall, for the walls are always thinner after this kind. of attack than before. 
The dense blackness of the patches makes it impossible to observe the details of development in this stage until

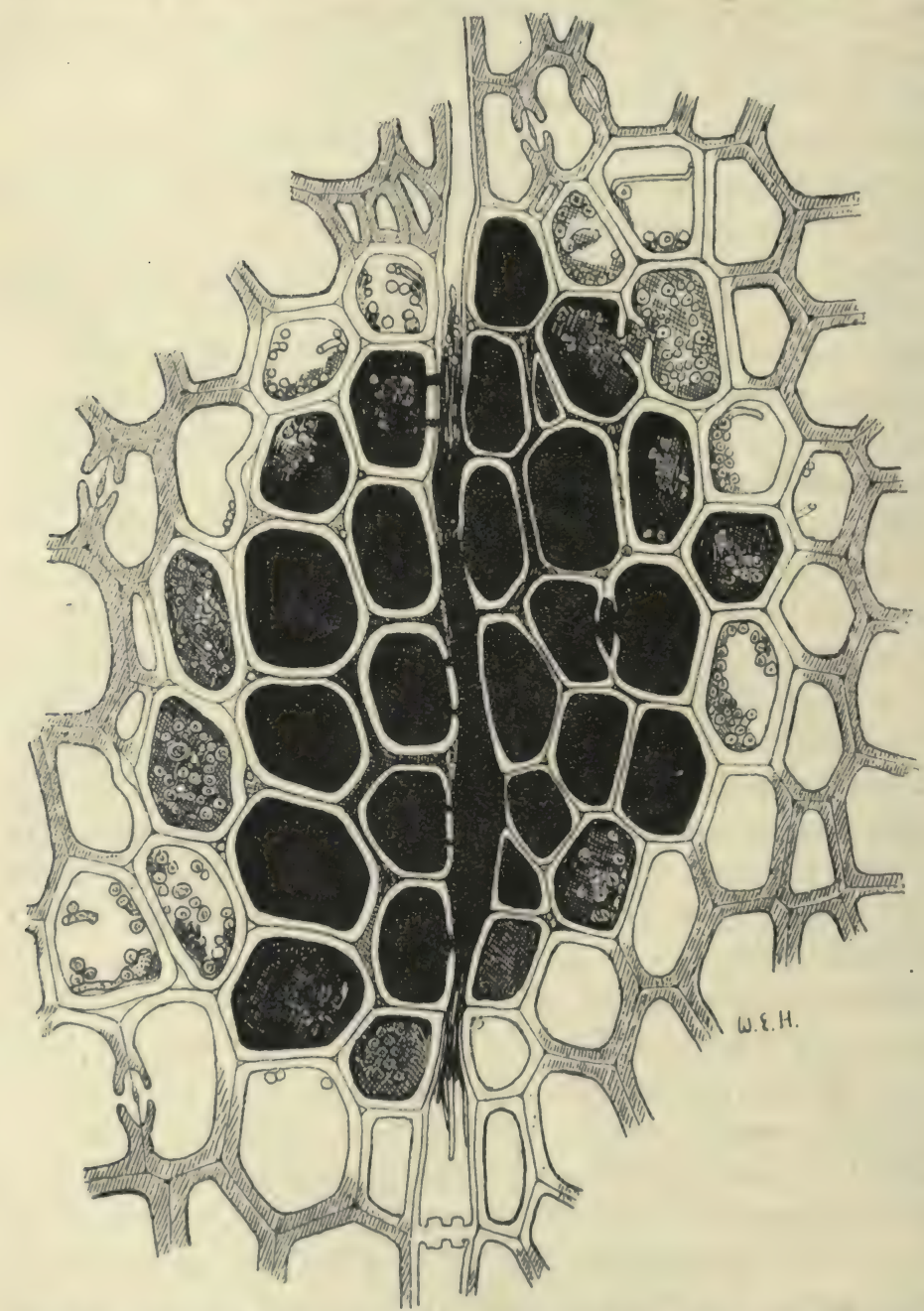

Fra. 34.-Black speck in the wood of the larch caused by Fomes annosus. Transverse section $(\times 600)$.

the black pigment has been removed. But the fact that these dark-walled hyphae are bleached by the action of almost any acid makes investigation possible. Convenient. 
preparations for making observations on these patches were obtained by first soaking sections in dilute $\mathrm{HCl}$ until bleached, then staining with safranin and mounting in Canada balsam. The hyphal walls, which were previously dark brown, readily absorb the safranin, whilst those which were formerly colourless remain so. In sections mounted in this way the following details may be observed.

As shown in fig. 35, the hyphae at the edge of the dark patch are easily distinguishable, though frequently two or three may be seen growing side by side in fascicles and touching for their whole length. They grow in this way up and down the tracheides and along the. medullary rays. Nearer the middle of the black patch the hyphae are very irregular, with swellings here and there; and where two hyphae are touching, the intermediate walls have often been partially or wholly

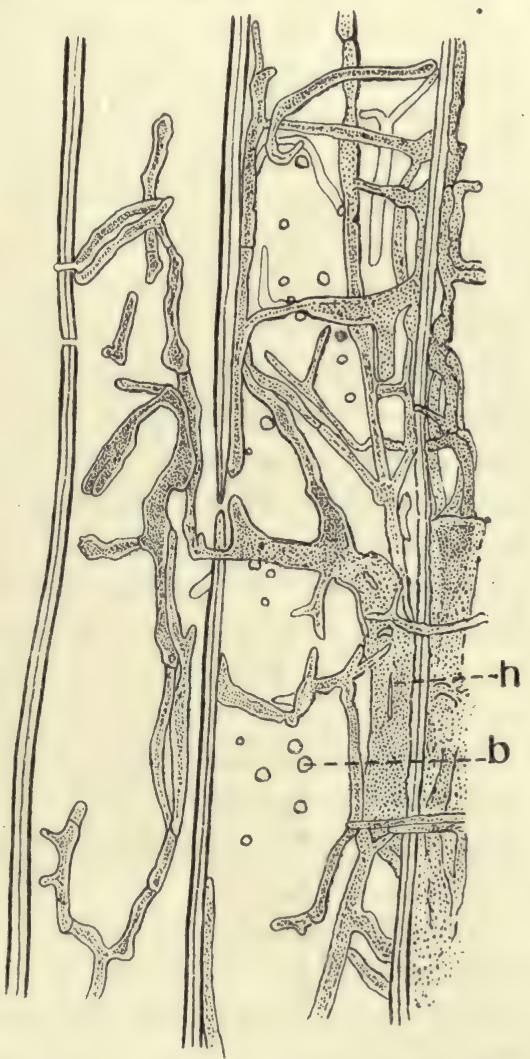

Fra. 35.-Longitudinal section near the edge of a black speck, after bleaching in dilute hydrochloric acid: $b$, borehole; $h$, two hyphae joined by the dissolution of their adjoining walls $(\times 800)$. digested, so that several adjoining hyphae come to have the appearance of one very large hypha (fig. $35, h$ ).

In the centre of the patch still further disorganization is found. The walls of some hyphae break down entirely, setting free a jet black liquid which stains all the contents 1888 
of the tracheide. In this way many tracheides become plugged by a more or less consistent black mass, composed of the disorganized walls and contents of the hyphae. In slightly older patches the viscid black liquid in the centre is absorbed by the surrounding hyphae, leaving only the thin white delignified walls of the tracheides, pierced and torn by innumerable bore-holes, and with scarcely sufficient strength to maintain their structure. A touch is often enough to tear them away, and then nothing is left but a small hole in the wood.

Sometimes it is found that by the side of a white patch of delignified tracheides left by a black speck as described, another black patch is formed, and in rare instances a black patch has been seen entirely surrounding a white one. By this means holes which were originally small become large, and eventually all the wood in an attacked region becomes honeycombed. Black patches are also found in the middle of white ones. How this occurs has not been determined, but Hartig, who describes this state as typical, says that the hyphae in a black patch delignify the tracheide walls around them, though the black patch remains intact. Wood that has become rotted in this way is dry, very light, and has the colour of cork. It contains many holes and white delignified patches, and almost always some black specks as well.

The ultimate state of rotted wood is very variable. When a trunk, or more commonly a single root, is killed and rotted right through to the cambium, the affected wood dries as it rots, and becomes pale yellow, and at the same time spongy and fibrous. On rubbing between the two hands, it crumbles into a mass of fibres, which remain more or less stringy and are too weak to stand much strain. Inside a trunk which has not been killed the gummy layer prevents drying, so that the rot advances a stage farther. The wood then resembles coarse sawdust of the consistency of coco-nut fibre, such as is used for growing bulbs. Fairly large pieces of wood may still remain intact, though these are always partly rotted and riddled with bore-holes. 


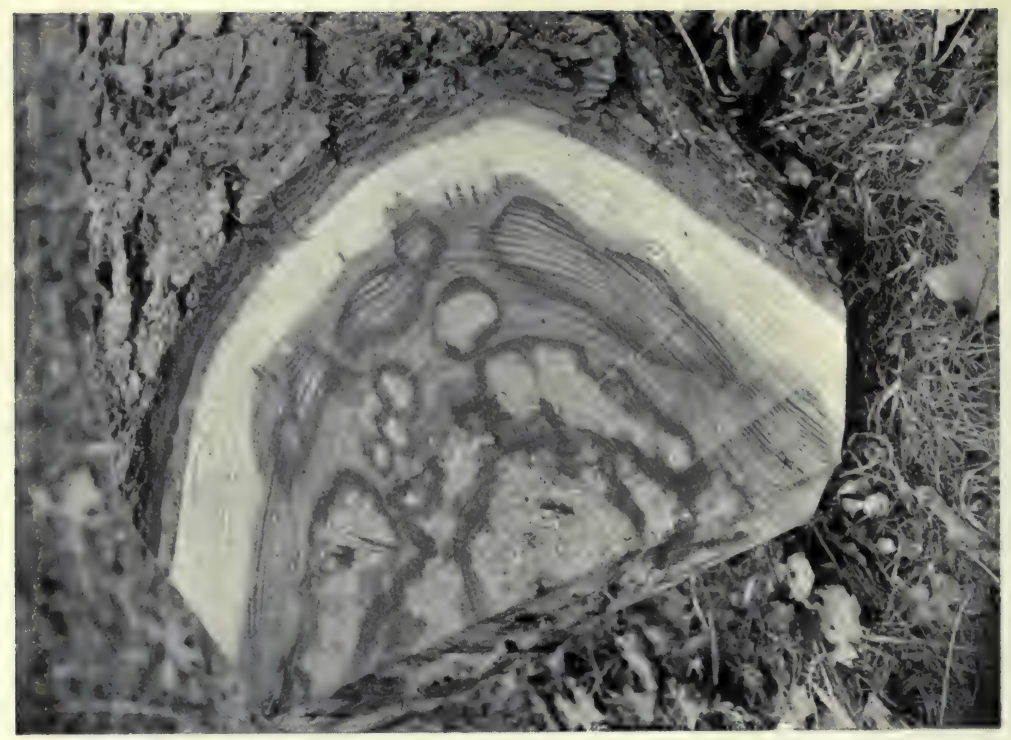

Fia. 36.-Fomes annosus. Base of a rotted trunk showing the figured arrangement of the rot. The white delignified specks can be seen in the rotted portions.

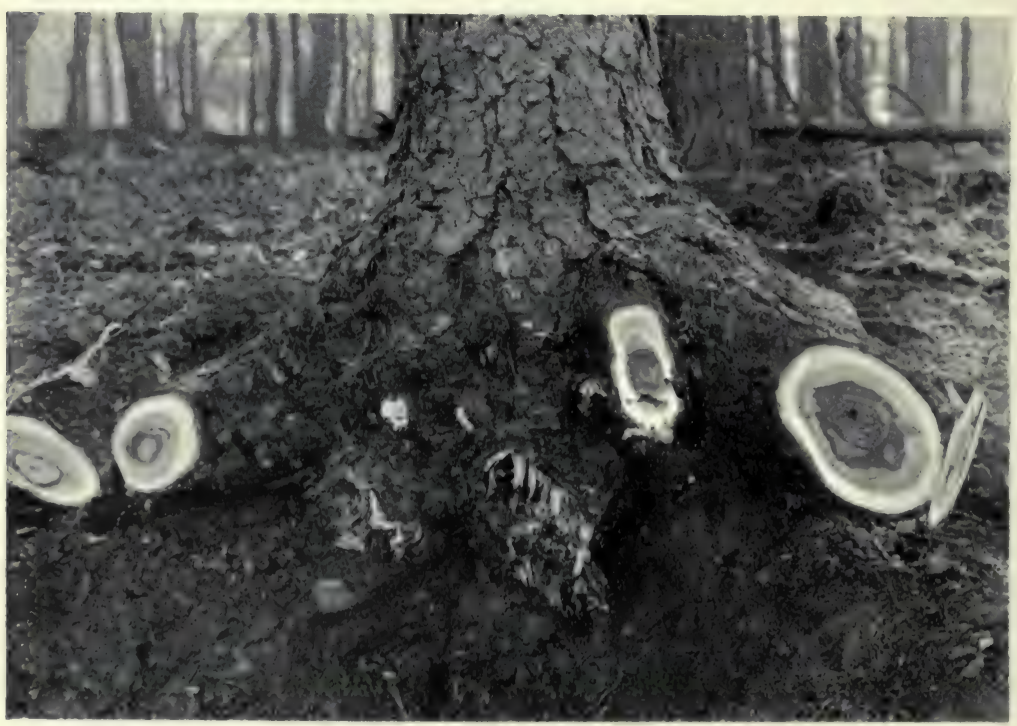

FIG. 37.-Fomes cinnosus. Base of a larch trunk which has been excavated underneath. The lateral roots show figured rot, whilst the tap-root and an anchor-root are completely rotted. 
If the rotted wood remains wet (and it is often saturated with water), it may become sodden and still more decomposed. It is very probable that bacteria assist in this final stage, and the large amount of cellulose present would be suited to bacterial action if enough moisture were present.

The mycelium grows up the trunks much more rapidly than it spreads transversely, since the gum layer limits lateral expansion. The affected part of the wood may be less than half an inch in diameter, but up to 4 or $5 \mathrm{ft}$. in length. If the rotted portion could be dissected out it would then appear as a long spike. Later the fungus grows up from other basal points, making fresh spikes, and when a number of these are cut across in a transverse section, a beautiful pattern is often produced. Fig. 36 is a photo. graph of such a section, cut somewhat obliquely with an axe. In the rotted portions the white cellulose patches can be seen, and the dark gum layers round the individual ' spikes' of rotted wood are also visible. Another common type of rot is shown in fig. 31. Here an annular portion is rotted and a central peg of sound wood remains, which is of course protected by a layer of insoluble gum. This central peg is often present, and may be no thicker than a pencil, though as much as $5 \mathrm{ft}$. long. 


\section{CHAPTER VI}

\section{HEART-ROT. FOMES ANNOSUS (Concluded)}

Reproductive organs: fructifications; conidiophores. Pure cultures on artificial media. Cultures on natural media. Infection experiments. Mode of attack in nature. The frequency of heart-rot in plantations which form the first rotation on cultivated soil. Methods of prevention.

Reproductive organs. Fomes annosus has two kinds of reproductive organs. These are (1) fructifications, usually large, of Polyporus form, which may occasionally be found associated with larch heart-rot, but which are much commoner on young trees of other coniferous species when they have been killed by the fungus; and (2) conidia on somewhat specialized conidiophores, which occur regularly in all cultures, but have been found, so far, only very rarely in a truly wild state. They are apparently formed only in a saturated atmosphere, such as is provided under usual cultural conditions, but which cannot be relied upon in nature.

The morphology and life-history of the fungus have been carefully worked out by Brefeld (1889) under the name of Heterobasidion annosum, (Fries) Brefeld, and I have made free use of his description in the following account.

1. Typical fructifications are shown in figs. 29, 30, 39, 40. They are of two kinds-bracket-shaped, borne usually on the sides of trunks and above ground, and 'resupinate', which grow on the under-sides of roots and have the whole or nearly the whole of the upper side attached to the root. The latter form is generally subterranean, and has its lower, spore-bearing side exposed in some hole in the ground, such as those made by rabbits and mice.

The fructifications first arise as small white masses of hyphae, often no bigger than a pin's head. These break through the bark of the roots and broaden on the surface 
(1) 


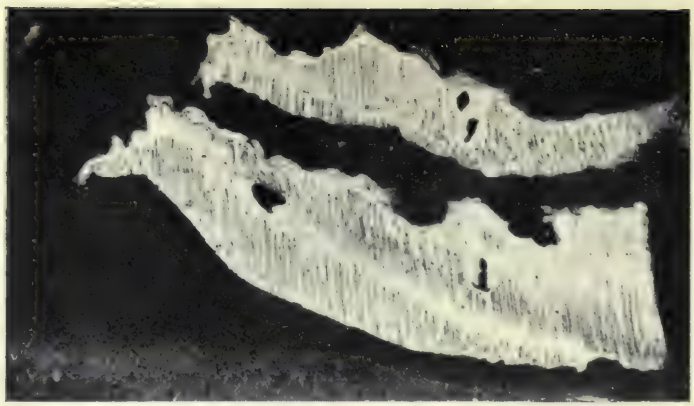

Frg. 38.-Fomes annosus. Fructification cut across showing pores in longitudinal section $\left(x \frac{4}{3}\right)$.

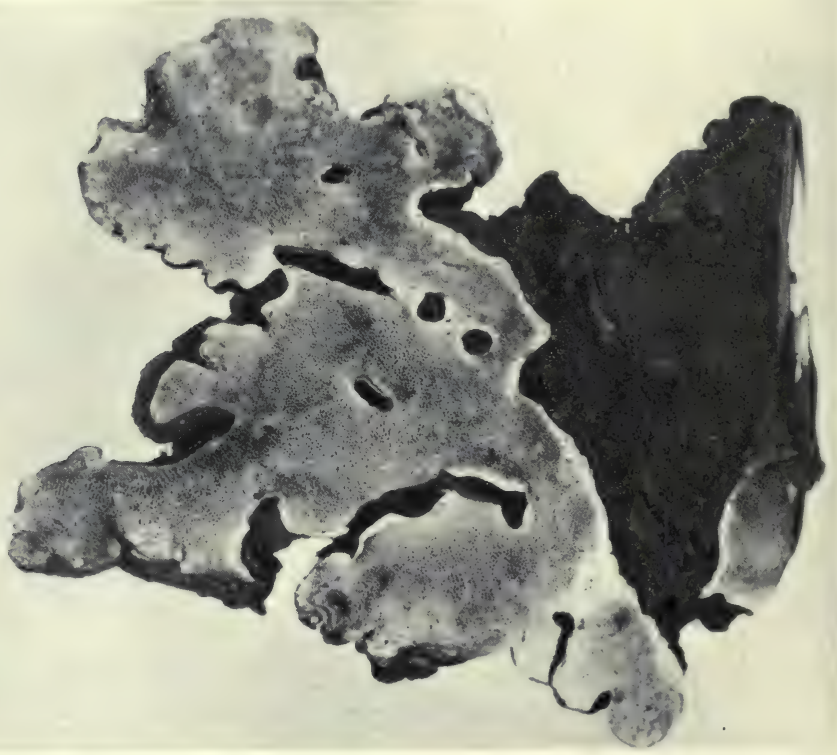

Frg. 39.-Fomes annosus. Under surface of small fructification showing mouths of pores $\left(\times \frac{1}{1}\right)$.

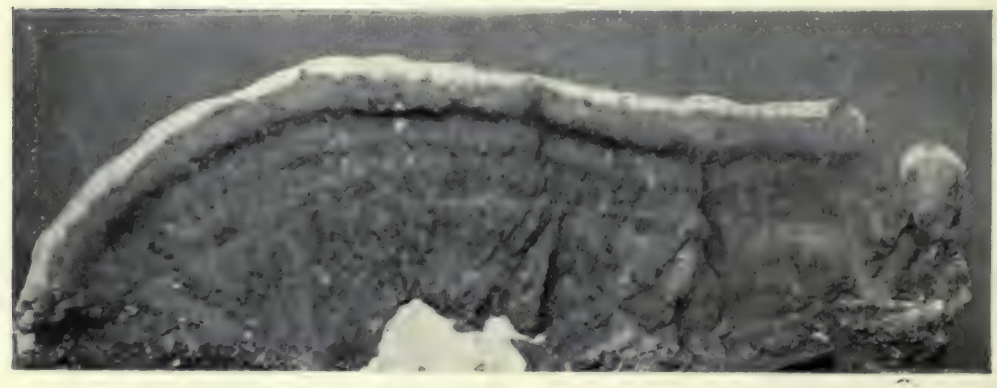

Fra. 40.--Upper surface of fructification showing concentric furrows and white margin. The white at the bottom edge of the photograph is a flint included in the fungus $\left(x \frac{1}{1}\right)$. 
without at first becoming much thicker. If they are growing on the under-surface of a root they cling to the root until their width becomes greater than that of the root, when they grow beyond it in the shape of a bracket. If they are growing on the side of the trunk (always near the base) they develop the bracket form quite early. When these fructifications reach the size of a penny, and sometimes much earlier, pores or slight depressions appear on the lower surface. These are the beginnings of the tubes inside which develops the hymenial surface. The fructification is then composed of a continuous layer, of hyphae on the upper side, about 1-2 mm. thick, and a layer of vertical tubes on the lower side, which may be more than double this thickness. The upper surface is at first pale brown; in resupinate fructifications it remains pale, but in bracket fructifications it becomes darker, until it attains a dark reddish-brown colour. As long as the fructification is growing laterally the margin is white (fig. 40), but when lateral extension ceases the margin generally becomes dark brown like the rest (fig. 29). This surface is concentrically furrowed (at any rate in bracket forms), and the furrows are striated radially. The lower surface is at first white, and may also be pure white in older fructifications, but it often becomes biscuit coloured and even slightly reddish, especially at times when it is not growing actively.

The fructifications grow in size (i) by the tubes becoming longer, thus increasing the thickness, and (ii) by marginal growth, which makes the fructification broader. The new parts bear pores very nearly up to the margin, and the youngest portion is always the whitest. Fructifications may reach a considerable size, and the largest $I$ have seen is 17.5 by $8.5 \mathrm{in}$. and 5 in. thick. This specimen, which is shown in figs. 29 and 30 , was found by my wife on a dead spruce. Growth is most active in summer, but $I$ have found fructifications growing vigorously and bearing spores in March. When growing, the marginal extension keeps somewhat ahead of the pore-formation, so that the margin is sterile, but as soon as marginal growth ceases, pores are 
made very nearly up to the margin, so that in the resting stage the fungus has the appearance shown in fig. 39 .

A very constant feature of the fructifications of this species is the holes in the sporophores. When the latter encounter a small root or stick, or even a blade of grass, they grow round it, leaving a hole such as those seen in fig. 39. These holes differ from those made under similar circumstances by most other fungi, by being surrounded by

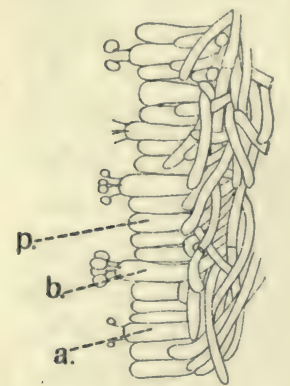

A

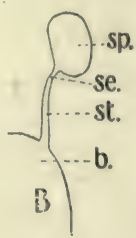

$\sigma \stackrel{D}{D} C$

FIG. 41.-Fomes annosus: A, hymenial layer inside a pore; $a .$, a young basidium with two spores; b., older basidium with four spores; p., paraphysis $(\times 200)$; $\mathrm{B}$, single spore showing attachment to basidium ; b., basidium ; st., sterigma ; se., septum ; sp., basidiospore ( $X$ $1000)$; c, ripe spores after shedding.

a reddish-brown ridge of sterile tissue. This ridge forms one of the most useful features for identification. Fig. 39 shows the appearance of the lower surface of the pores. It will be seen that they vary from circular to irregularly oval or elliptical. Their width is usually about $0.25 \mathrm{~mm}$. ( $=\frac{1}{10} \overline{0}$ in.), but may be anything from $0 \cdot 15$ to $0 \cdot 6 \mathrm{~mm}$.

The pores are not fertile through their whole length at the same time. As a fructification grows older the upper part of each pore becomes filled with hyphae, and only the lowermost 1 to $2 \mathrm{~cm}$., i.e. the part nearest the openings, bears spores. During the summer the pores lengthen and the fertile zone moves downwards. Fig. 38 shows the pores in longitudinal section; two pieces of the fungus are here cut through, in each of which two years' growth can be distinguished.

In the fertile region each pore is lined with the hymenium, a layer made up of basidia and paraphyses. Fig. 41, A, shows this layer as seen in a longitudinal section of the pores. The basidia are $30-40 \mu$ long and $8-10 \mu$ broad. Normally each bears four spores $(b$.$) , but basidia with two$ spores are frequent $(a$.$) , and basidia with three or five spores$ 
have occasionally been found. Each spore is attached to the basidium by a very thin extension of the latter called a sterigma (fig. $41, \mathrm{~B}$, st.), and when ripe the spore which develops at its extremity is cut off from the sterigma by a transverse septum. The mature spores are hyaline, measure $5 \cdot 5-7 \times 4 \cdot 5-5 \mu$, and have a slight projection at one side, where they are attached to the sterigmata. The

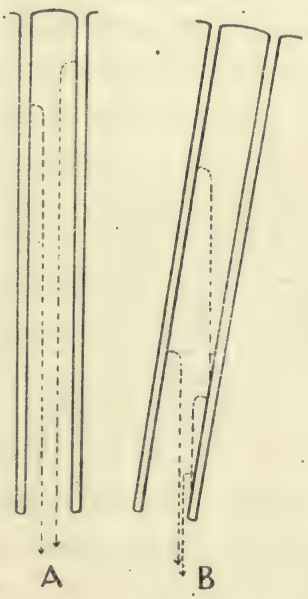

Fic. 42.-Diagram showing the necessity for the pores to be vertical. In $\mathbf{A}$, in which the orientation is correct, all the spores escape. In B, which is tilted, only a small proportion of the spores escape from the pores and the rest stick to the sides. For the sake of clearness the pores are shown as much wider in proportion to their length than is the case in Fomus annosus. For correct proportions the pores should be eight times as long as in the diagram. The loss of spores through tilting would then be much greater than that shown in the diagram.

paraphyses are similar to the basidia in shape, but remain sterile, and serve to keep the basidia at appropriate distances.

The spores, like those of most Hymenomycetes, are slightly sticky, so that if they come in contact, during their fall, with the sides of the pores, they adhere and fail to escape. To prevent this it is necessary for the pores to be exactly vertical, and the fungus, by some means not as yet understood, has the power of making them grow in the 
desired direction. It is expressed botanically by saying that the pores are positively geotropic, i. e. they grow towards the centre of the earth. The necessity for exactitude in this orientation is demonstrated by the following calculation. If a tube is $0.25 \mathrm{~mm}$. across and bears spores for a distance of $2 \mathrm{~cm}$. from the orifice, a displacement from the vertical of $\tan ^{-1} \frac{2}{2} \frac{5}{0}-\left(=\frac{1}{80}\right)$, i. e. a displacement of less than $1^{\circ}$, will prevent any spores growing as ${ }_{\text {, far }}^{\prime}$ as $2 \mathrm{~cm}$. from the orifice from escaping (fig. 42). Actually the accuracy has to be far greater than is shown in this calculation, since the spores do not simply fall from the basidia but are shot off to a distance of rather less than $0.1 \mathrm{~mm}$. (vide Buller). The ejection mechanism for the Polyporeae has been investigated by Buller, and, as is shown in the accompanying diagram (fig. 41, B), the ejection is accomplished by the splitting of the septum between the spore and the sterigma. The force of propulsion is provided by the turgidity of the basidium and the spore, each of which tends to bulge out the septum which separates them. The fineness of the mechanism is due to the thinness of the sterigma and the consequent small cross-section of the septum that crosses it.

The spores, being very small, present a large surface in proportion to their weight, so that once they have escaped from the pores they are easily carried away by the wind. They germinate at once, either in pure water or damp air, or in nutrient solution, and under suitable conditions every spore germinates. The germ tube may emerge from any part of the wall, even, occasionally, from the small point where the spore was attached to the sterigma.

2. Conidiophores arise in all cultures. They are borne on especially broad hyphae, which occur in groups in the mycelium, and have the form shown in fig. 43. They may be simple or branched, and have a few cross septa, and the whole conidiophore is somewhat reminiscent of that of Aspergillus. The conidiophore is rather swollen at its apex, and the conidia closely resemble the basidiospores. When the conidia have been ejected the conidiophores are left 
with a number of pointed sterigmata, and even in this state they are easily recognized.

These conidiophores and conidia were first discovered by Brefeld, who sought in them support for his theory that basidia and basidiospores are modified conidiophores and conidia. He found instances in which the conidiophores bore three or four large conidia instead of a large number of smaller ones. But, even so, it is unlikely that they are homologous with basidia. The formation of basidiospores is generally, if not invariably, preceded by a nuclear fusion; but if these conidia are homologous with the conidia of types whose cytology has been investigated, the nuclei which enter them are not derived at all directly from a fusion nucleus. This distinction between conidia and basidiospores has been drawn subsequently to Brefeld's work on Fomes annosus, and it is sufficient to justify the disfavour with which his synonym 'Heterobasidion annosum' has been received.

As stated above, these conidio-

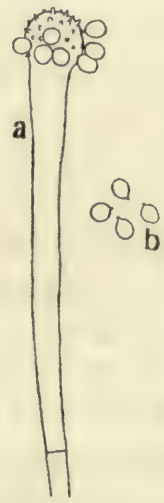

Fig. 43.-Fomes annosus: $a$, conidiophore from which some conidia have fallen, leaving the pointed sterigmata ; $b$, conidia $(\times 400)$. phores occur regularly in cultures, not only on bread and gelatine, but also on diseased wood and even on fructifications if kept in a damp chamber. They are usually simple or slightly branched, but under certain circumstances, as when a culture is grown on bread soaked in a solution * of dung and given plenty of room, the conidiophores may appear in large bundles. A single conidiophore of such a bundle is exactly like one of the simple conidiophores and has the same dimensions, but the whole bundle may be a quarter of an inch high.

As these conidiophores are of such frequent occurrence in artificial cultures it is extraordinary that they should be so rarely met with in nature. No doubt the conditions which 
favour their formation are not always present, but probably the chief reason is that owing to their insignificance they are generally overlooked. Olsen (Brefeld, 1889, p. 177) has, however, found layers of the conidiophores on fallen trees in Norway, growing in such a way as to have a superficial resemblance to a species of Corticium. He does not state the time of the year at which they were found. This is important, as it is possible that climate plays an important part in their formation.

Brefeld, who has had unrivalled success in producing the fructifications of this higher fungi in the laboratory, was unable to stimulate their growth in the case of Fomes annosus, and suggested that under pure-culture conditions a conidial race is produced which becomes incapable of bearing fructifications. In one of my own cultures, however, a sterilized larch block, which was infected with conidia, produced normal, though small, fructifications (fig. 44), and it must be presumed that Brefeld did not experiment with the most suitable medium.

The germination of conidia is in every way similar to that of basidiospores. They germinate at once, and with great regularity, both in pure water and in nutrient solutions. The possibility of making inoculations from old, apparently dried up, cultures of more than a year's standing testifies to the longevity of the conidia.

Pure cultures on artificial media. Cultures of the fungus grow readily in 15 per cent. gelatine or 3 per cent. agar-agar when appropriate food-stuffs are added. I have found that meat extract $0 \cdot 3$ per cent., malt extract 3 per cent., give suitable nutriment. If the medium is at all alkaline it may be neutralized with citric acid. Cultures were first obtained from rotted portions of pumped trees. Small lumps of wood were sterilized externally by holding for a few seconds in a weak flame. The central portions were then cut out with a sterilized knife and placed on the gelatine in culture flasks, which had been suitably sterilized prior to inoculation. Cultures grew slowly at first and then fairly rapidly, and were similar on gelatine and agar. The mycelium is 
white, and does not grow out much from the substratum, and appears finely granular. Conidiophores are produced in six to ten days, and may constantly be found afterwards.

Cultures obtained from basidiospores or conidia differ in no way from those grown from diseased wood, but the risk of including impurities is reduced. Cultures will also grow on moistened sterilized bread, but they are not very vigorous on this medium.

\section{Cultures on natural media. Cultures were grown on}

1. Sterilized larch twigs with bark.

2. Sterilized blocks of larch wood, composed of heartwood or sap-wood or both.

3. Sterilized roots of $(a)$ larch, (b) Weymouth pine.

4. Soils from various localities.

Unless otherwise stated, inoculations were made by placing small pieces of gelatine or agar-agar containing mycelium on the substratum which was to be infected.

1. Larch twigs $2-3$ in. long and $\frac{1}{2}$ in. in diameter were placed on damp cotton-wool in Erlenmeyer flasks and testtubes. On sterilizing in the autoclave the cotton-wool became slightly stained by liquid running down from the twigs. Mycelium placed on these twigs grew fairly rapidly, and at room temperature completely covered them in about six weeks, and even spread on to the cotton-wool at the bottom of the flasks. A much more woolly mycelium was produced on larch twigs than in gelatine or agar-agar cultures, and conidiophores were everywhere abundant. Mycelium penetrated the periderm, cortex, phloem, and wood.

2. Cultures on larch blocks were very similar. The mycelium grew much more rapidly on the surface of the blocks than inside, especially when the air was thoroughly damp. When the cotton-wool at the base of the test-tube was only slightly moistened, the external growth was scarcely noticeable, though on addition of more water it became quite normal. It is much greater on blocks of alburnum than on duramen.

The formation of soluble and insoluble gum and the 
process of wood destruction in these cultures are described in the sections dealing with these phenomena. In one of these cultures two fructifications have now been growing for more than four years (fig. 44).

3. On small sterilized roots of larch and Weymouth pine growth was rapid, especially at a temperature of $20^{\circ}-22^{\circ} \mathrm{C}$. Small bunches of such roots in test-tubes became smothered in mycelium to a distance of an inch in fifteen days.

4. Altogether over 220 cultures were attempted on soils. Special care was taken with these because, on discovering that mycelium would grow readily on sterilized soil, I thought I might find that it preferred some soil to others, and in this way immunity and susceptibility to heart-rot might be in some measure explained. Some results of value have been obtained from these experiments, but the problem of immunity and susceptibility has certainly not been solved by them. No growth was obtained on unsterilized soil, and growth on autoclaved soil was much more abundant than on dry sterilized soil, so that the method of treating soil prior to infection is a matter of great importance.

After some preliminary trials my procedure was as follows : For each sample of soil twelve or more test-tubes were prepared. A plug of cotton-wool was placed in the bottom of each and dry soil poured in to a depth of about 2 in. The test-tubes were plugged in the usual way. Plo four of them sterilized water was added without further treatment till infection. Four more were moistened with sterilized water and autoclaved for twenty minutes at 2 atm. pressure. Yet another four were sterilized in the hot-air sterilizer for twenty-five minutes at $140^{\circ} \mathrm{C}$., and sterilized water was added when they were cold. Soils were inoculated sometimes from mycelium, but generally by pouring in a drop or two of water containing conidia. The soils on which such sets of cultures were made are shown in the following table. 


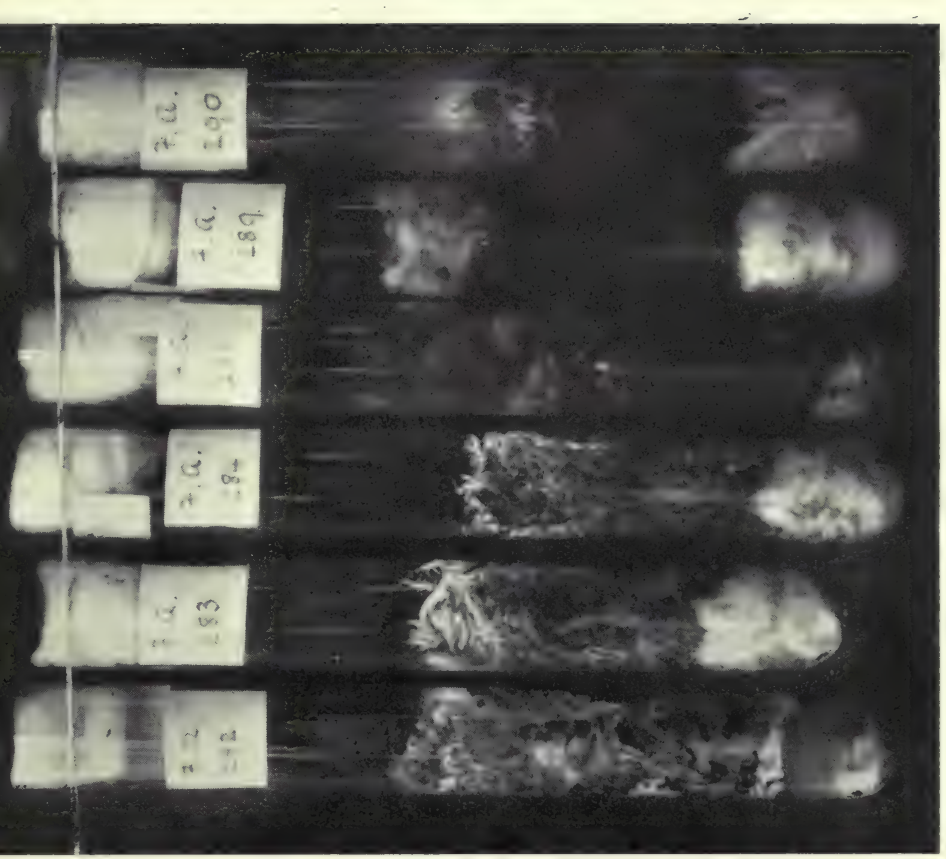

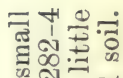

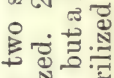

$8 x \div \cdots$

हैं है

范。

की कै है

낭 क

응 유욜

요요

ฉอุ

* त्ञ

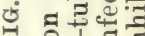

(I)

$Ð \Phi$

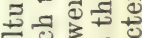

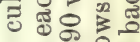

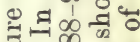

N

|

过完

풍ㅇㅇ

ชั รีำำ

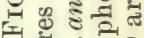

퐁ㅇㅇ

.चे है

उं 1 .

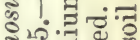

समำ क्ष

₹

近啫

हิ -

i $7=\frac{\pi}{5}$

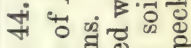

ญ्

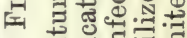

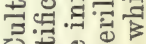
인 氙苞苛 



\section{Soil.}

(a) From pot in which young larch had been grown: acid : humus and numerous dead roots of larch no lime : markedly acid : deep black colour

(e) Beech humus : little lime: some roots : brown colour

(d) Soil from beneath spruce containing needles and roots: much lime: brown colour

(e) Clay with flints, from above chalk: beech humus

(f) Well-manured lightarable sand

(g) Moderately manured heavy arable sand

(h) Sycamore humus

(k) Sandy loam from Douglas plantation which had been attacked by Fomes annosus

(l) Same wood as (k), but where Douglas was healthy

(m) Same wood as (l), but) another part

(n) From larch and beech wood near a fructification of Fomes annosus: loam above chalk

(o) From near spruce at-) tacked by Polyporus Schweinitzii: oak above: loam above chalk

(p) From near spruce killed) by Polyporus Schweinitzii: very open wood: loam above chalk sandy loam: slightly

(b) Sand with oak humus :)

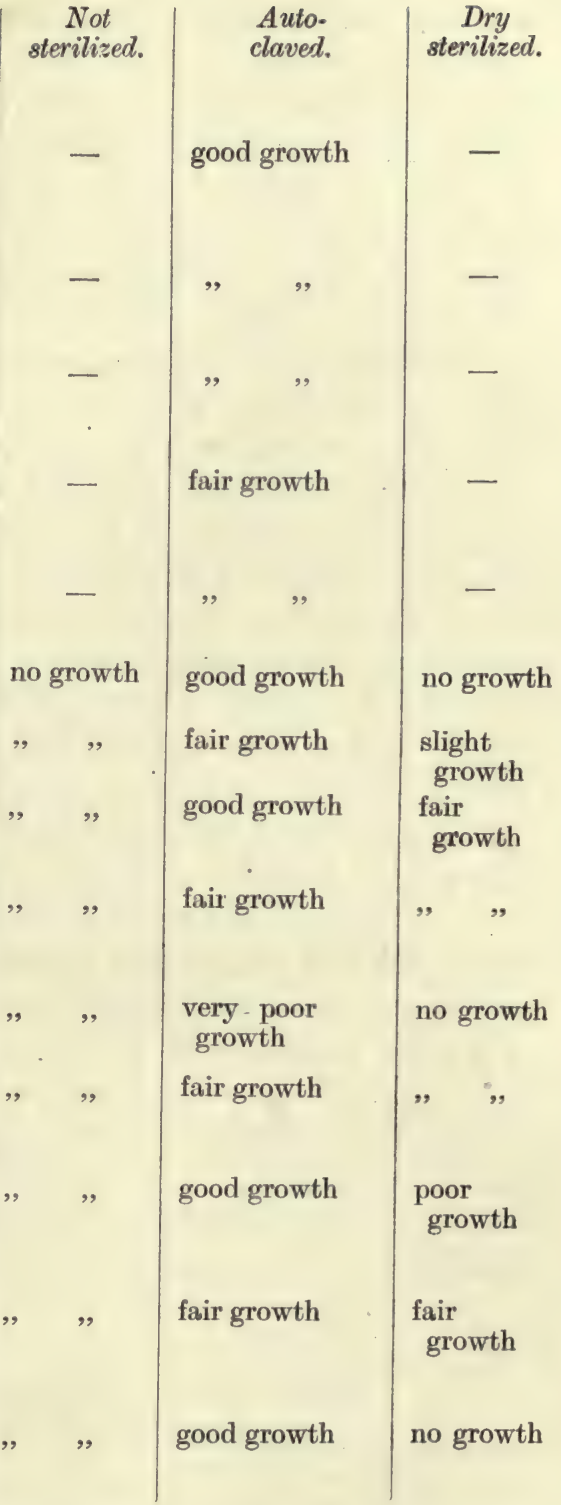

The test for the growth of Fomes annosus in each case was the appearance of conidiophores, and if these were not 
present the mycelium was not considered as definitely belonging to the fungus. This precaution was especially necessary with cultures on soils which had not been sterilized, since many saprophytic fungi (especially Penicillium spp.) as well as bacteria made their appearance. The most striking feature of this table is the failure of the fungus to grow on any unsterilized soil and its growth on all soils when autoclaved.

The changes in the substratum, induced by antoclaving, which might account for this are :

1. Destruction of rival organisms.

2. Chemical changes induced by boiling.

Both these effects are probably of importance, and they must be considered separately.

1. Destruction of rival organisms. In cultures on unsterilized soil other fungi sometimes appeared, but they were not constant. A certain species of bacterium, however, nearly always grew abundantly and formed a white covering over part of the soil. It seemed possible that this bacterium was destructive to the mycelium of Fomes annosus, and to prove this a series of cultures was made in the following way. Eighteen test-tubes were filled in the usual way with sand and oak humus (soil $b$ ). Twelve were autoclaved and six were not. They were then treated according to the following table :

Cultures No.

276-78. Autoclaved 279-81. Not sterilized 282-84. Autoclaved 285-87. Not sterilized 288-90. Autoclaved 291-93. Autoclaved

\section{Infected with}

conidia.

conidia.

mycelium.

mycelium.

mycelium and a little unsterilized soil. conidia and a little unsterilized soil.

The results were :

276-78. Very good growth.

279-81. Bacteria only.

282-84. Very good growth.

285-87. Bacteria only.

288-90. (Fair growth at first of mycelium of vas ious fungi, but later 291-93. restricted to mycelium above the soil and bacteria in the soil itself. 
The effect of the addition of bacteria is clearly shown in fig. 45. It is thus proved that the unsterilized soil contains some factor which is very strongly inhibitive to the growth of the mycelium of Fomes annosus, and this factor appears to be bacterial.

2. It is evident that chemical changes are induced by boiling humus soils containing roots and other plant remains which have not been completely disorganized. When twigs and wood blocks are autoclaved in test-tubes, a brown stain nearly always runs down on to the cotton-wool at the bottom of the test-tube. When infected with Fomes annosus the latter grows down on to the cotton-wool and flourishes on the stained portion. No doubt a similar liquid escapes from roots into the soil containing them when the whole is boiled, and this probably assists the growth of fungus mycelium. (This, however, cannot apply to such arable soils as $f$ and $g$, which contained no organized remains.) There is also a physical change, for soil which is autoclaved becomes very evenly moistened, whereas soils which have been dry sterilized and subsequently wetted are very difficult to moisten evenly, and this may partially account for the poor growth of mycelium on dry-sterilized soils.

From the foregoing experiments it is clear that the mycelium of Fomes annosus will grow on soils under certain conditions. One condition is the absence of a certain bacterium which is so frequently present in the soil as to inhibit the mycelial growth in all my cultures on unsterilized soils. These experiments were all performed in the summer, when bacterial activity is at its greatest. It is possible that in the spring, when bacterial growth is less active, more auspicious conditions for Fomes mycelium may obtain.

Infection experiments. A series of infections was made on two-year-old potted plants of larch and spruce.

These were designed to answer the following questions :

1. Can unwounded roots become infected with the fungus ?

2. Can infection take place through slight wounds?

3. Can infection take place through dead roots ? 
4. Can trees be infected through growing on infected soil ?

In order to infect the trees they were lifted from the ground and their roots were washed in running water. Pieces of infected roots, or lumps of infected soil, taken from pure cultures were tied to roots of the trees by means of bast. Infection points were tied round with sterilized moss, and the trees were carefully potted in suitable soil. On March 30, 1915, twenty-four infections were made without wounding, eighteen with slight scalpel wounds into the phloem, eighteen on roots still attached to the trees which had been placed in nearly boiling water for one minute in order to kill them, whilst the other roots of the trees remained alive, and twelve on roots which were both boiled and wounded.

None of the infections were effective where there was no wound, whereas all those where the fungus had touched a wound were successful. In these successful infections the mycelium grew into the wood and usually reached the centre of the root. The hyphae grew both upwards and downwards in the wood and bark, killing and browning the tissues on their way. Growth was very slow, but rather more rapid in the wood than in the phloem, where it was always hindered by cork layers which were made across the phloem and cortex as an obstruction. The extreme slowness of growth is shown by the fact that in most cases the mycelium had only spread 5-6 $\mathrm{mm}$. upwards and downwards in the wood and about $1 \mathrm{~mm}$. less in the phloem in six months.

Infections on killed roots were invariably successful. In five weeks the mycelium had spread to one and a half inches in the wood, and since infections were mostly made on the larger roots the hyphae soon spread to the stem and killed the tree. With some of the trees, whose experimental roots had been killed, I was doubtful whether enough healthy roots had been left to supply water during the summer months. On this account I cannot be certain that death was always brought about by the fungus. But some were examined as soon as the trees began to look unhealthy, 
and in these it was found that the hyphae had penetrated to the stem.

Thus question 1 can be answered in the negative, questions 2, 3, and 4 in the affirmative. Infection does not take place through unwounded roots, at any rate under the circumstances of the experiments (too much confidence must not he placed in a negative result), but can take place through a living wounded root or through a dead root.

Mode of attack in nature. The habit of the fungus leaves no doubt as to the part of the tree which is first attacked. It is always the roots which first become infected, and in every case that has been recorded the disease has spread from the roots to the stem, and not vice versa. Infection then, must be subterranean, or immediately on the surface of the soil.

Hartig (1878), who at that time was unaware of the existence of conidia, recognized two possible means of infection. One was by the spores of the fungus reaching the roots of healthy trees, and the other by living roots coming into contact with roots which contained the fungus. These two methods will be discussed in turn, and as they do not seem adequate to account for all the infections which occur in nature, a third method will be suggested.

(i) Infection by means of spores. The fructifications of the fungus are usually subterranean, or if they grow above ground they bear their spores so near to the soil that wind can play but a small part in the dispersal of the spores. Often fructifications which begin to develop subaerially become covered by fallen leaves and shoots of ivy, but this seems rather to encourage than retard their development. Thus it is presumed that spores are carried by other means than air currents, and, as Hartig suggested, rabbits, voles, and other burrowing animals are probably the chief agency in dispersal. The fructifications require some open space for development, and burrows, made by animals under the trees, afford the kind of station in which they flourish. So there is reason to think that such animals catch the spores in their fur or pick them up on their feet, and they may 1888 
rub them off on to other roots which they pass. As roots are often broken by rabbits while making their burrows, it appears likely that such spores may occasionally come in contact with wounds by which they can infect the trees. Hartig attached little importance to this mode of infection, as he found a very low percentage of germination in the spores which he examined, but Brefeld found subsequently that, when ripe, the spores germinate almost invariably.

(ii) Infection by means of healthy roots coming into contact. with diseased roots. This might happen when a healthy root grows so as to meet a diseased root, or two roots might be touching and the disease might spread down one and cross to the other. In order to discuss this theory it is essential to know whether a root can become infected whilst still undamaged. Unfortunately, Hartig's experiments leave this question unsolved. To demonstrate the possibility of such infection he placed diseased roots in contact with living roots after removing the outer bark scales from parts of the latter. It is not clear whether by this treatment the living tissues of the roots were exposed, i. e. whether the roots were wounded or not. In my own experiments, infection did not take place unless the roots were definitely wounded, and it may be regarded as extremely unlikely that living roots can be infected except through wounds. If this is so, this theory of infection demands not only that a diseased root should be in contact with a living root, but that it should actually touch a wounded portion of a living root. This must greatly reduce the frequency of opportunities for such infection, and it no longer appears reasonable to account for the infection of groups of trees, which undoubtedly takes place, by this means. The following theory, though difficult to demonstrate in the woods, seems to have a wider application.

(iii) Infection through dead roots. My infection experiments have shown that trees can become infected when attached dead roots are brought into contact with diseased roots or soil infected with the fungus. These experiments may, however, be criticized on the ground that natural 
conditions were not accurately reproduced, that by steaming a portion of a root and allowing it to become infected immediately time was not allowed for the plant to develop its normal power of resistance against fungal attack. For when a portion of a root dies, the plant to which it belongs inserts a screen between the living and the dead parts which is made as far as possible impermeable to fungal hyphae. This criticism is valid up to a point. The screen which the root makes is of two kinds : firstly, a layer of cork across the phloem and cortex, i. e. all the tissues outside the cambium ; and secondly, various devices in the wood, which, having non-living as well as living elements, is less able to make a protective layer. In conifers the protection of this region is chiefly, if not entirely, limited to plugging the tracheides with resin, and even this amount of protection is confined to the sap-wood, which contains living cells. The heart-wood can adopt no such measure, and in consequence the heart-wood remains as a free channel for the growth of any fungus which can live in it. It thus appears that dead roots, if they are small and contain no heart-wood, may be safely delimited from the living portions of the tree; whereas large roots, when dead, present an open path by which any of the heart-rotting fungi can gain admission to the trunk.

Dead roots may become infected in a variety of waysby spores or conidia, by contact with diseased roots, and, what is probably more important than either of these methods, by mycelium growing in the soil. Pure cultures of the fungus only proved successful on soils when the latter had been sterilized, and it was shown that other organisms, which were present in unsterilized soils, were sufficient to prevent the growth of Fomes annosus. But in spite of being unable to produce a rigid demonstration, I think it is probable that under suitable conditions the fungus may grow in forest soil and bear conidia, which, being washed down by rain, will reach the lower strata, where, as shown in the next section, dead roots most commonly occur. 


\section{The frequeney of heart-rot in plantations which form the} first rotation on cultivated soil. A large number of observations have shown that heart-rot is especially to be apprehended in coniferous woods when they are planted as the first forest rotation on land which has been previously cultivated. The same applies, though in a lesser degree, to first plantations on commons and heaths. I have personally seen plantations of larch damaged in this way on the Tintern estate, at Terringham Wood near Cinderford, in the Forest of Dean, on two separate plantations on the Duke of Bedford's estate at Endsleigh, near Tavistock, and two or three more near Brentor in Devon, where in every case the larch was a first forest crop. Other instances have been reported in Britain, and Sir William Schlich tells me that in Germany heart-rot commonly affects the spruce, which is planted as a pioneer rotation, though the second rotation is usually free from it. As no adequate explanation has been advanced ${ }^{1}$ for this phenomenon, I made a special study of a number of trees at Terringham Wood. Thirteen trees were uprooted with the object of finding out through what part of the root system the fungus entered. It was found possible to locate the path of infection, for, although all the roots of diseased trees were rotted to a certain extent, the rotted roots could be divided into two markedly distinct classes. Those which had what I shall term 'primary rot' were rotted equally from the centre to the cambium; the bark was dead and the wood had reached the pale yellow spongy stage, or had in some cases been destroyed by worms, the cavity surrounded by the hollow bark being filled with the wormcasts. Others showed only 'secondary rot', i. e. they were rotted only in the centre, like the trunk; the rot was in an earlier stage, and the rotted wood was surrounded by a layer of gum: Outside this the young wood and phloem were living and active. It is reasonable to suppose that the roots which show the primary rot are those through

1 Mathes (1911) correctly ascribed root-rot to the presence of dead roots and dead roots to poor nutrition and soil aeration. See also Ieslie (1915) and Ribbentrop (1908). 
which the trees have been attacked, whilst those with secondary rot have been attacked in a reverse direction, i. e. from the trunk. For the rot on entering the trunk will spread in all directions in the heart-wood, and will grow as much down the roots as it does up the stem. The fact that secondary rot occurs in this way was established by finding that in such roots the rot at no point reaches the surface, so that it is clear that the disease cannot have entered by them (see fig. 37).

It is among the roots with primary rot, then, that we must look for the source of infection. And these roots show a very marked localization. In all the roots of the pumped trees I only found one superficial root which showed primary rot; all the other roots in this stage had grown more or less vertically downwards into the subsoil, and were situated almost directly underneath the trunk itself. In eight of the trees a tap-root, or other root which had early taken its place, could be distinguished, and in every. case but one this root showed primary rot. In two of these trees no other root was in the same state, in one tree one other root was, in three two other roots, in one four others, and in one six others. In the tree in which the tap-root did not show primary rot, two others did, and two trees in which no tap-root could be found had respectively six and seven roots showing primary rot. Thus in all thirty-four roots were found with primary rot, and only one of these could possibly be called a superficial root. When the trees were uprooted the surface roots were firm and spread out from the tree in the usual way, though most of them were rotted in the core, and the wholly rotted roots had to be sought on the under-side, where they were usually broken off short. Their position could generally be located in the soil from which the trees had been raised, and they could be seen to continue in their vertical or nearly vertical course. The conclusion is unavoidable that the trees were rotted either through their tap-roots or through their deepgoing 'anchor' roots and not through the spreading superficial roots. Similar evidence has been forthcoming in trees 
from other woods. A rootstock sent me from Tintern showed the same phenomenon, and a wind-blown larch on the Endsleigh estate had been rotted solely through its tap-root.

We are thus confronted with the fact that the disease enters the trees through roots-either the tap-root or ' anchor' roots--which grow more or less vertically downwards and penetrate the subsoil. With this in view I had a trench cut $3 \mathrm{ft}$. deep in order to ascertain the state of the roots in the subsoil. The superficial 9 in. of soil was composed of blackish-brown humus and loam. For the next 14 in. there was a fairly loose sand with broken 'greystone', and it contained numerous healthy roots of larch and oak. Below this to the lowest point reached in digging the sand was tenacious, and bound as though with an admixture of clay, and contained numerous stones. There were few roots in this layer, and many of those which I picked out were dead. In fact I estimated that in the hard subsoil 60 per cent. of the larch roots and 25 per cent. of the oak roots had been killed, though a few of them were rotted. This wood-a mixture of larch and oak-was 54 years old. For comparison I had a similar trench cut in a pure oak wood alongside which was 105 years old. The soil was here composed of a superficial $3 \mathrm{in}$. of black leaf-mould and $18 \mathrm{in}$. of a sandy loam with a few stones and very many healthy oak roots. At 21 in. (the same depth as in the former trench) the sand became much more compact, but not nearly so hard as in the younger wood. There were a few oak roots, all of which were vigorous.

The points that chiefly interest us in comparing the two trenches are, firstly, that in the older wood the subsoil is much looser and more broken up than in the younger wood, and, secondly, that many of the subsoil roots were dead in the younger wood, whereas all were alive in the older wood. The cause of death in the former case is almost certainly lack of air, for, like all other parts of plants, roots must have access to a supply of free oxygen in order to maintain their vitality. 
The discussion must thus be carried back a step farther, viz. to a consideration of the agencies which facilitate the aeration of the subsoil in the cases of cultivated land and woodland.

These agencies are notably divergent in the two cases. In arable land the surface soil is very thoroughly aerated tó a depth of 5 to 7 in. by ploughing, and somewhat more where a steam plough is used, but below this there is very little disturbance of the soil particles. Three factors may, however, assist, though slightly, in bringing fresh supplies of oxygen to the subsoil. These are-(1) worms, which burrow deep in cold winters and in dry summers (a depth of $5 \mathrm{ft}$. is recorded as not uncommon in Darwin's Vegetable Mould and Earthworms, p. 112) ; (2) rain, which percolates through to the subsoil carrying with it a small amount of dissolved oxygen, and allowing room for more air when it drains away; and (3) frost, which very rarely affects the subsoil in our climate. The combined action of these three factors is very slight in most soils, and only in those with very deep drainage is the subsoil at all effectively aerated.

In woels, worms are comparatively infrequent, and frost is entirely negligible. But there is a new factor which is incomparably more efficient than any in arable land, viz. roots, which act in a multiplicity of ways. By boring their way into the subsoil and by their secondary growth in thickness they force apart the soil particles, and if they die and rot the space which the root formerly occupied must become filled again. Also the organic remains will improve the soil. Still more important than all these mechanical disturbances is the absorption of water by the roots. For when roots draw in water from between the particles immediately surrounding them the equilibrium in the soil is disturbed and water is attracted by capillarity from the more distant, moister soil into that which has been dried through its propinquity to the roots. This system by which roots obtain water from a distance is depicted in the well-known diagram in Sachs's Physiology of Plants, which has been copied into most subsequent text- 
books. In this way a large volume of soil is partially dried by each root, and during a drought water is drawn from all the subsoil which is penetrated by the root system of the trees. The rigidity of the roots prevents a wholesale subsidence of the soil, and consequently air must be drawn in from the outside. When rain comes again, the water slowly percolates through the interstices of the soil and drives out the air, and the same cycle begins anew. This process, carried on through a number of years, has an important loosening effect on the soil, and the living conditions of the roots improve as the forest becomes older. This explains the fact which is well known to foresters that the subsoil in woods is more porous than in open ground.

Sufficient evidence has now been advanced on which to base a theory accounting for the frequency of heart-rot in the first rotation of larch on land that has previously been cultivated. The argument for this theory may be given under three headings:

1. The subsoil in arable or pasture land is very poorly aerated, and the tree roots which grow more or less vertically downwards into this soil not infrequently die from lack of oxygen.

2. It is shown by experiments described on pp. 111 and 113 that larch trees readily become infected through dead roots which are still attached to living trees.

3. The pioneer roots which penetrate the subsoil, and later die from lack of aeration, form suitable infection points for heart-rotting fungi. Such dead roots are found especially in the first rotation of trees on new forest land.

This theory may be accepted as a working hypothesis. Much experience will be needed to prove or disprove it, and the following points immediately present themselves for elucidation. First, it would be interesting to know whether plantations on arable or meadow land, in which the subsoil was for some reason well aerated before planting, are less liable to heart-rot than new plantations on soil which is otherwise conditioned. Next, in old woods in which heart-rot has occurred are there any other causes 
operating which might account for the death of some of the roots before they became attacked by the fungus? Also what is the frequency of heart-rot in conifers planted on heaths? Where the soil is peaty the aeration of the sub-soil must be very poor, and heart-rot might be expected. I have had no opportunity of investigating these points, and foresters' notes on the subject would be of great value.

Extreme caution is necessary when attempting to prophesy the effect of different types of subsoil on the frequency of heart-rot. In one part of Terringham Wood the subsoil is a hard strong clay, which must be far inferior in porosity to that in other parts of the wood. And yet in this portion several of the larch trees were sound. I thought that this must be a case in which the theory failed, until I had one of the trees grubbed up and found that the roots were all superficial. The subsoil had proved too hard for them, and consequently the tree had been saved from infection.

Two points of interest are involved in this theory of the method of infection. First, the roots which grow vertically downwards are not those which are most likely to come in contact with the diseased roots of other trees, so that Hartig's contact theory can hardly apply. It seems much more probable that the roots become infected either directly by spores and conidia or through the soil being penetrated by mycelium. The other point is the depth of the soil at which infection takes place. When a root is killed because its lower extremities lack sufficient oxygen, it does not necessarily follow that only those lower extremities die. Unless the upper part of the root has sufficient vigour to send out branch roots into the upper layer of soil (and I have never noticed such branches in roots with primary rot), the upper part will cease to receive the full supply of water and nutriment, and will probably die. In one case I found a layer of resin across the wood of a vertical root with primary rot at a point less than a foot below the surface of the soil, in fact quite near the rootstock, and this probably represented the upper limit of death before infection. 
I sought for a similar line of resin in other roots, but they were too far rotted to show any trace of it. Thus, though these roots are killed because they grow deeply, it is not necessary that their point of infection is deep.

The statement that larch is more liable to heart-rot in pioneer stands than in subsequent rotations is not accepted by all writers on the subject. In particular, Elwes (Elwes and Henry, 1907, vol. ii, p. 363) holds that the rot is more often found in the second rotation. This runs directly counter to my experience, and the issue can only be settled by the counting of woods in which the incidence of heartrot has favoured Elwes's view or mine. In discussing the question, Elwes does not say which of the heart-rots he was referring to, whereas my observations are only concerned with Fomes annosus. Ribbentrop (1908) shows that in Germany the first rotation has given most trouble with root-rots generally.

Methods of prevention. The only preventive measure which, as far as I know, has been recommended for defence against Fomes annosus, is digging a trench round all the infected trees. This method was adopted by Hartig in the forests near Eberswalde, and the trenches were apparently dug with the object of cutting off all the roots so that infection should not pass from root to root from infected trees to other parts of the forest. Kienitz found that, in one of the trenches that Hartig had cut, fructifications developed on the cut and exposed roots, so that in this case the remedial measure proved to be a source of danger. He referred to the treatment as 'waldverderblich', an expression which Brefeld quotes with relish. Hartig replied that a trench could easily be watched for fructifications which could be removed, and persisted in his recommendation. But the conidia discovered by Brefeld present a fresh difficulty. These cannot be removed, for they cannot generally be seen. And now that we know that the mycelium can grow in the humus itself, a trench does not seem a likely method of preventing its further expansion. I have found, however, that when 10 per cent. of lime is added to humus soil, the 
mycelium is incapable of growing in it. Thus a trench filled to the surface with lime might prove to be an effective barrier. But conidia and spore infection through the air is probably too common to make such a trench worth the labour of digging. Vigilance and forethought will help us much more than trenches. Heart-rot is a particularly insidious disease because its presence is not generally discovered till the trees are cut, so that not only have the trunks been getting more and more rotted, but they have been filling for many years a plot that might have been earning a useful rent. A skilled woodman can generally distinguish pumped trees by the hollow sound they emit when struck with the back of an axe or a stick, and by this time they are often 'gouty' at the base. But these means do not aid in the discovery of the disease till much damage has been done. Testing a tree with an increment borer, however, will disclose the presence of heart-rot as soon as the trunk is affected, and it is recommended that foresters should test their larch plantations from time to time with this instrument. It should be remembered that trees usually become pumped in groups, and if every tenth tree is bored every other year, an epidemic will be discovered before the loss or value becomes serious. Where one tree is found to be attacked, others in the immediate vicinity must be bored, and all the trees that are diseased should be cut out. They will only be wasting themselves and the land on which they are growing. Sometimes it may be necessary to clear fell, and in this case it is safer to grow a rotation of broad-leaved trees before replanting with larch or other conifer.

Land which is being afforested for the first time presents a special case. Here pumping must be anticipated, and yet the exclusion of larch and spruce, and to a less extent Scots pine, would prove a serious obstacle in afforesting new land. Either the conifers may be grown in a mixture with hard woods and the former removed in the earlier thinnings, or, where it is thought advisable to plant pure coniferous woods, the forester must watch them carefully 
with the increment borer, and be prepared to clear fell as soon as they reach a remunerative size. The poles can then be sold for pit props, for which purpose a little heart-rot is not a serious blemish.

No means of artificially aerating the subsoil is economically possible. I have seen larch plantations on land that was previously common, where the ground was said to have been double-dug before planting. Heart-rot was not very serious, but it was unmistakably present. Double-digging will at most affect the top 16 in., and aeration must go down much deeper than this in order to prevent pumping. Natural aeration may, however, be encouraged by planting deeprooting trees such as oak or false acacia. In Germany, lupin is also used on heaths for this purpose, and is allowed to grow for a few years before planting trees.

Destroying all fructifications will no doubt have a palliative effect, especially in woods where Fomes annosus is not yet abundant. It removes, at any rate, one of the sources of infection, and we know that spores are made in great quantities where fructifications are allowed to appear. In looking for them it should be remembered that they are borne particularly on the trunks of dead conifers. They are always formed near the base, and are often quite hidden in the débris of leaves, twigs, and weeds that surround the trunk. By treading lightly all round the tree their presence can often be discovered.

The remains of rotted trees should be burnt whenever it is possible, but grubbing up stumps is so expensive that woods can seldom be effectively cleared in this way. In some cases, however, such trouble will be well repaid. There is one wood which I have kept under observation for many years without ever finding Fomes annosus. The wood is a fairly large one, and in the last twenty years conifers have been widely planted in it. Previously it was almost exclusively composed of broad-leaved trees. This year (1919) a Corsican pine was found dead and fallen down, and from its roots I picked the fructification shown in fig. 40. This pine is almost surrounded by larch trees. 
In a case like this it is well worth while to dig up all the roots that can be reached and to cut off as much of the rootstock as is found to be rotted and to burn the whole with the utmost care. Such time and trouble spent now may protect the wood for many years against attack by the fungus. 


\section{CHAPTER VII}

\section{HEART-ROT CAUSED BY OTHER FUNGI}

Polyporus Schweinitzii, Poria vaporaria, Polyporus sulphureus, Trametes Pini.

Heart-rot caused by Polyporus Schweinitzii, Fr. Next to Fomes annosus this fungus is the most frequent cause of heart-rot. Though in many respects resembling the two following diseases, this rot may easily be distinguished from that caused by the Fomes by the rotted wood being very dry, light, and friable, and not spongy or fibrous. It has marked cleavage surfaces which are at right angles to each other, so that the wood breaks up easily into more or less cubical blocks, and, owing to shrinkage, the cracks often open before the tree is felled and the interstices become filled with white mycelium which frequently becomes embedded in resin and assumes a chalky consistency. When the rot is far advanced the wood is usually light or dark brown and reeks strongly of turpentine.

The fungus enters by the roots and grows up the stem, and is in the vast majority of cases confined to the heartwood. But dead trees are occasionally found in which all the wood up to $20 \mathrm{ft}$. or more from the ground is rotted.

The disease is reported as fairly common on the Continent, especially on Scots pine, Weymouth pine, and larch. There are frequent notices of it in the United States of America on Weymouth pine, balsam fir, white and red spruce, and arbor vitae, and in New England it is considered one of the most destructive diseases (Schrenk, 1900). In Scotland, Murray (1916) reports it as occurring on Douglas, spruce, and Scots pine. My own observations have been made in the south of England, where I have found it on Scots pine, cluster pine, and larch, chiefly in Sussex, Surrey, Berkshire, and Devonshire, but I have no 


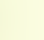




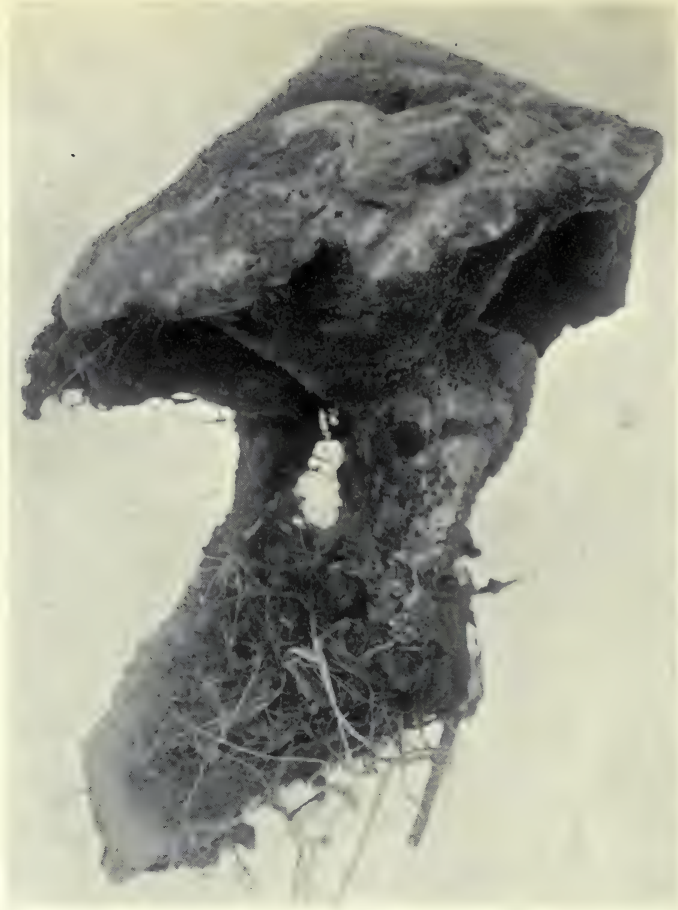

FIG. 46.-Polyporus Schweinitzii. Stipitate fructification.

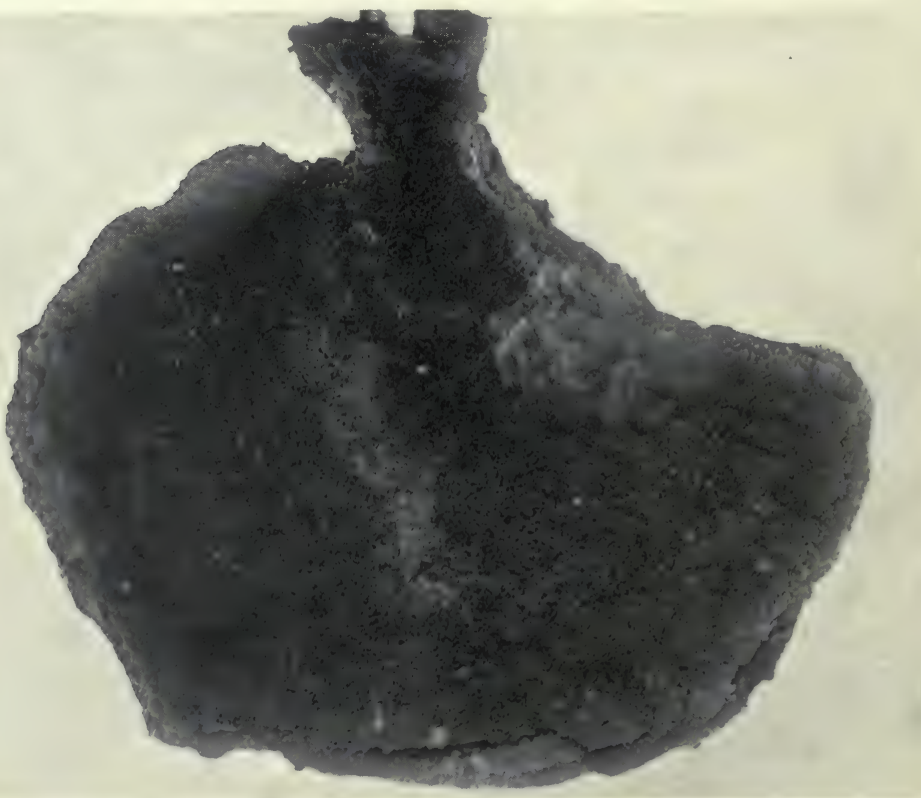

Frg. 47.-Polyporus Schweinizii. Bracket-shaped fructification, showing pore arrangement on lower surface. The fructification has a distinct stalk. 
reason to suppose it is confined to those counties. The parasitology and method of attack of the fungus have not been worked out. The best papers on the disease are by Hartig (1878), who described it under the name of Polyporus mollis, Fr., and gave an account of two hundred-year-old Scots pines which had been attacked by the fungus, and by Schrenk (1900), who described the rot on American trees and made interesting observations on the fructification.

Fructification. This may arise either from the roots, often at some distance from the trunk, or on the trunk itself up to 10 or $12 \mathrm{ft}$. When growing on roots that are buried its connexion with the tree may not be observed until the roots are bared of earth, but in other cases it may arise from parts of roots that are exposed to the surface. In either case it is stipitate, i.e. has a stalk with an expanded pileus as in fig. 46. Sometimes, as in the figure, two or more stalks may grow up side by side and their respective pilei grow into each other, or become congruent. The pores are borne on the lower side of the pileus, and the upper swollen part of the stipe also becomes pore-bearing, so that there is no sharp line of demarcation between the pileus and the stipe. When growing on the trunk the fructification has a totally different form. It is then bracket-shaped, as in fig. 47, with a more or less distinct stalk; and often the brackets are imbricated, borne closely one above another, in which case there is usually no stalk visible. The fruitbodies are generally about 6 in. across, but specimens up to 16 in. have been measured.

Though the two forms of 'fructification are so different in their general shape, the details of structure are identical. The upper surface is dark, reddish brown in colour, and rough with excrescences. The pore-bearing under-surface is greenish when young, but changes to red on being touched, and during the period of active growth it exudes numerous drops of liquid. Unlike Fomes annosus, the fructification is not woody, but soft and fairly light. It hardens somewhat with age and dries up and dies in the autumn. It generally falls from the tree in late winter unless it has been 


\section{HEART-ROT CAUSED BY OTHER FUNGI}

already eaten and destroyed by insect larvae. It is never perennial.

The inner part of the fructification is mainly composed of masses of parallel, very tender, richly septate, red brown hyphae, filled with protoplasm. On the upper side many of the masses run up into the scales that project from the upper surface; those on the lower side run down into the

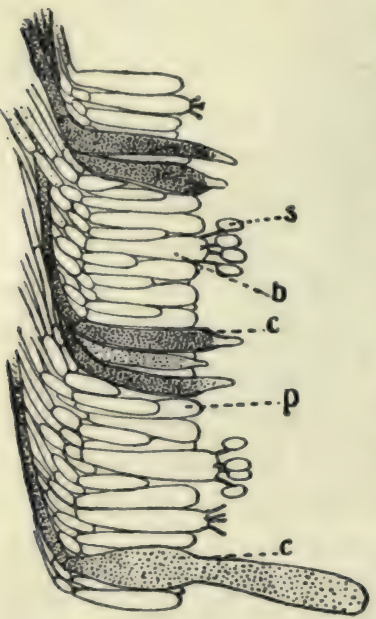

FiG. 48.-Hymenial layer of Polyporus Schweinitzii, showing basidia $(b)$, basidiospores $(s)$, paraphyses $(p)$, and cystidia $(c)(\times 300)$. trama between the pores, and according to Hartig it is the escape of the contents from these hyphae that gives the red colour on bruising. The pores are irregular in shape (fig. 47), and from 0.5 to $2 \mathrm{~mm}$. in diameter. Their depth is about $5 \mathrm{~mm}$. Near the stipe the pores are long and labyrinthine, but the margin is barren until marginal growth has ceased, when pores are formed out to the edge. Inside, the pores are lined by the hymenium, which is composed of basidia and various forms of paraphyses. The basidia are colourless or very pale yellow, 30-40 $\times 5-8 \mu$. The spores are about $4 \times 6 \mu$ (fig. 48 ). In addition to the basidia there are numerous thin-walled paraphyses and larger specialized thick-walled paraphyses (cystidia). As shown in this figure the cystidia are very variable in shape and size. They have deep brown contents, and the large brown hyphae which carry them can often be traced for some distance back into the trama. The cystidia project into the pores beyond the basidia, and often bear drops of liquid at their extremities to which spores adhere. Thus it appears that the cystidia obstruct the normal dispersal of the spores.

When the fructifications are growing actively the spores fall from them in clouds, dense enough to be seen with the 


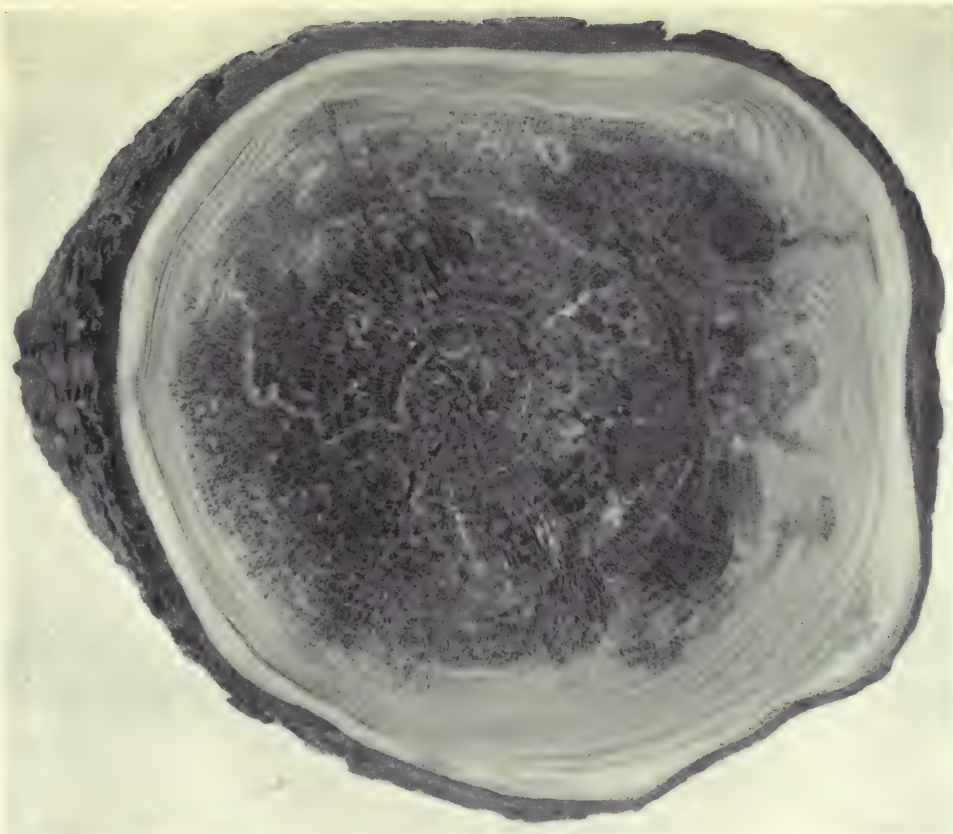

FIG. 49.- Section across base of larch-tree showing rot caused by Polyporus Schweinitzii. $\left(\times \frac{1}{3}\right)$.

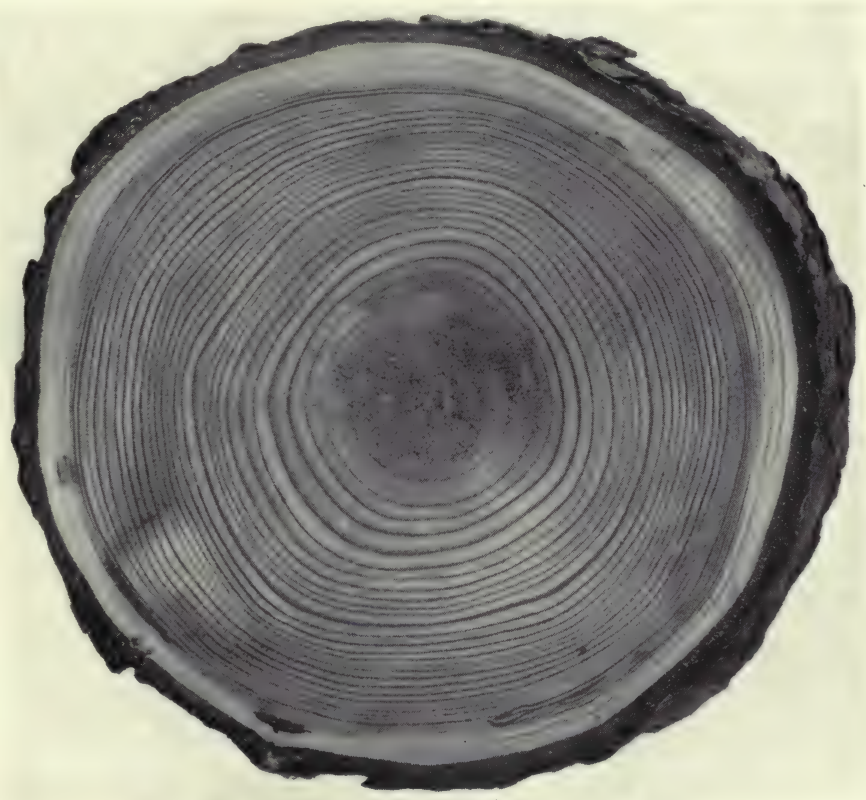

Frg. 50.-Section across larch-tree, $15 \mathrm{ft}$. above the ground, showing rot eaused by Polyporus Schweinitzii $\left(\times \frac{1}{2}\right)$. 

naked eye. With respect to the secretion of liquid which occurs at the time of spore dispersal, the following quotation from Schrenk (1900) is of interest:

'At the time of ripening of the spores it was noticed that hundreds of drops of a yellowish liquid were hanging from the hymenial surfaces every morning when the fungus in question was visited. Some of these drops were carefully collected and were examined. In them floated a number of spores and flocculent yellowish-brown masses, which stained yellow with nitric acid. These were present for several days. Thereafter the liquid was almost clear except for numberless spores which were in every drop. For three weeks the drops were collected with a pipette during the day, and during the night a plate, carefully protected against dew and rain, was placed under the fungus. In this way about three-fifths of a pint (300 c.c.) of liquid were collected. This was poured into an open dish and put in a cool place, where the water was allowed to evaporate. A thick brown syrup was left after some weeks, which had the odour of very impure molasses. The syrup was transferred to a vial, which was corked and placed in a warm place. In a few days delicate needle-shaped crystals shot out, which on examination proved to be melezitose and mycose, sugars sometimes found in fungi.

At the same time that this secretion appeared on the hymenium, or rather shortly afterwards, a number of small beetles began to devour the hymenium with great avidity. So active were they that within three weeks of their appearance the hymenium was entirely destroyed, and of course with it whatever spores had remained. It is suggested that the secretion of this sugar and the destruction of the hymenium by the beetles may have some meaning in connexion with the dispersal of the spores. It is a point worthy of further observations by local observers in future years.'

Rot in the wood. In all sections of living trunks which I have obtained, showing rot with this fungus, the rot is entirely confined to the heart-wood. Consequently in the Scots pine with its narrow heart-wood the rot is much 1888 
more confined than in the larch (compare fig. 49 with fig. 52). This suggests that the fungus is purely saprophytic. At the same time dead trees are not infrequently found which have become rotted through to the bark, and it is only then that fructifications are borne on the trunk, except when large branches have fallen away so as to expose the heart-wood. For the present it must remain an open question whether such dead trees are killed by other causes, or whether $P$. Schweinitzii can kill the roots, taking advantage of the more moist conditions in the soil, and thus, secondarily, produce suitable conditions for growth in the sap-wood of the stem.

In the earliest stages of rot, the heart-wood has a rather deeper red colour than normally, but it soon loses its reddish tinge and takes on more the colour of cork (fig. 50). It also becomes very much lighter in weight. Further decomposition is generally attended by deepening of the colour (fig. 49), in which case the wood becomes dark walnut brown, and has a strong smell of turpentine. It cracks along transverse, radial, and tangential planes, producing wedge-shaped or cubical blocks which can be picked out with the fingers. The cracks are often filled with mycelium of the fungus, bound together with resin and of cheesy consistency. If a section of a trunk cut in this stage is kept in a dry laboratory the rotted wood contracts on drying to such an extent that small pieces fall away by their own weight, and the section is eventually left with a hollow centre. The wood is then so far reduced in weight that, according to Hartig, its specific gravity is only $0 \cdot 19$, as compared with 0.57 for normal wood.

With the help of a microscope mycelium can be found in the wood from the earliest stages of rot. But dense agglomerations of hyphae, such as occupy the regions of most intense wood destruction in Fomes annosus and Armillaria mellea, are nowhere present in wood rotted by this fungus, except in the cracks as mentioned above. Consequently, decomposition is less localized and more evenly distributed. The hyphae present in the wood are mostly colourless and 


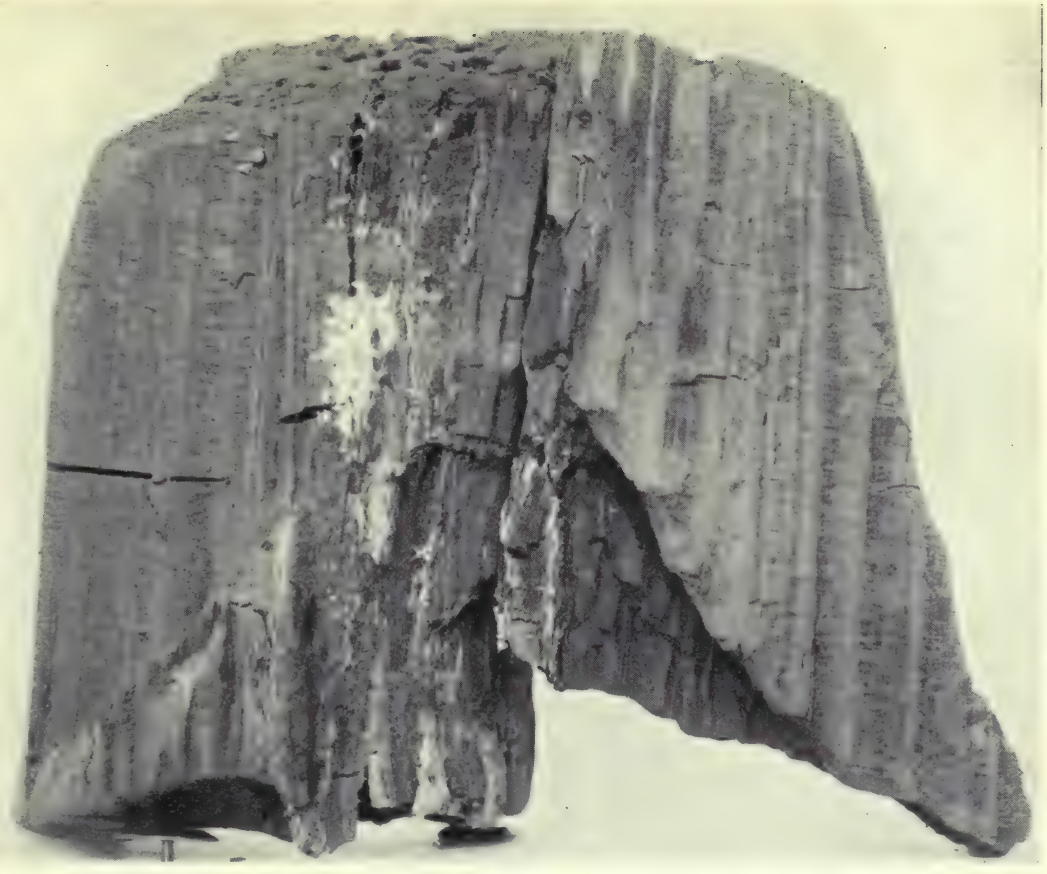

FrG. 51.-Piece of larch wood rotted by Polyporus Schweinitzii, showing crevices and patches of white mycelium.

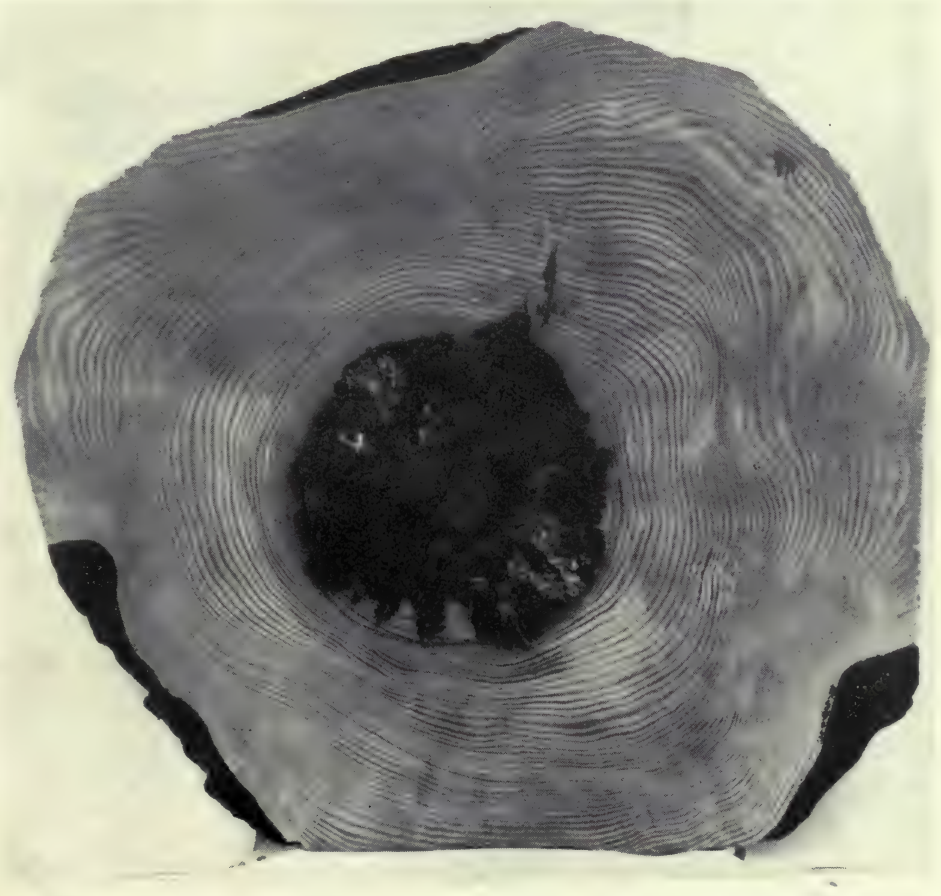

FIG. 52.-Section at base of Scots pine stem with rot caused by Polyporus Schweinitzii. 

of all degrees of thickness from $6 \mu$ downward, but some of the largest, in the earlier stages of rot, have brown contents. These thicker, brown hyphae generally run either vertically along the tracheides, or horizontally, boring through the tracheide walls and markedly constricted in the bore-holes. The finer hyphae, which are much more numerous, branch frequently and spread in all directions, though the boreholes are nearly always transverse to the tracheide walls. Hyphae may also grow up between the tracheides. As decomposition proceeds fewer hyphae are found, but even in advanced stages of rot a few colourless hyphae are generally present. The same variation in size and colour of the hyphae is also a feature of the felted mycelium which fills up the cracks in the rotted wood.

Although the mycelium in the wood lacks those special features of interest which characterize the growth of Fomes annosus and Armillaria mellea, the effects produced in the wood are peculiar and distinctive. In the first place the wood is never quite delignified, and to the last will give a slight

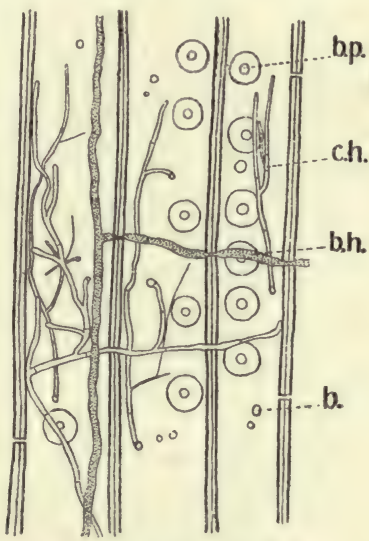

Fig. 53. - Mycelium of Polyporus Schweinitzii in the wood of the larch: $b$, hyphal bore-hole; b.h., brown hypha; b.p., bordered pit; c.h., colourless hypha. reaction with phloroglucol and hydrochloric acid. At the same time the cellulose, which, though present in normal wood, fails to give normal reactions without special treatment, is so far freed from lignone that rotted wood gives a blue or purplish colour with chlor-zinc-iodine. Thus the presence of lignone and the presence of cellulose may be demonstrated, without special treatment, in the same cell wall. During the process of decomposition the wood also undergoes contraction to a very marked extent. In the final stages this is apparent to the naked eye by the large cracks and crevices, but before these appear evidences 


\section{HEART-ROT CAUSED BY OTHER FUNGI}

of a state of tension can be observed in the cell walls themselves. The general form of the tracheides is unaffected, but cracks appear in the walls, always rising from right to left, as shown in fig. 54, and usually in tiers, one above another. These cracks appear first in the summer wood, and in all stages are more conspicuous in the summer wood than the spring wood. They do not rupture the complete

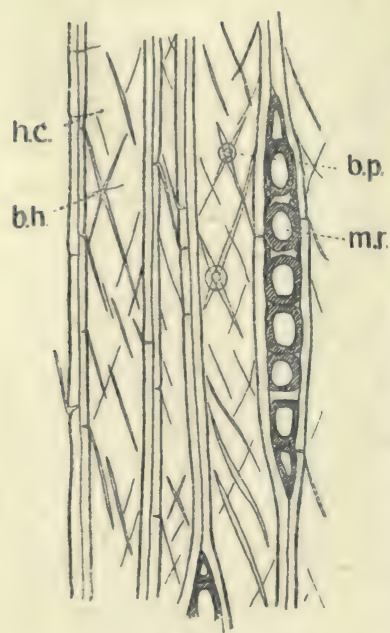

Fra. 54.- Tangential longitudinal section of larch wood after attack by Polyporus Schweinitzii, showing cracks in the walls: $b . h$, hyphal borehole; b.p., bordered pit; .h.c., horizontal crack ; m.r., medullary ray.

a trunk with a rotten core is allowed to dry, further irregular cracks occur in all directions in the wood, so that in such wood the microscopic details are apt to become obscured.

General remarks on Polyporus Schweinitzii. We know very little indeed about the mode of infection of this fungus. In fact the text-books give all the information which is available on the subject when they say that the fungus first attacks the roots of a tree and grows up from the roots 
into the stem. This appears to be invariably the case, as no instances have been reported in which the fungus has attacked the tree through sub-aerial wounds. The mode of growth of the fungus in the tree suggests that, if it is a parasite at all, it is a very feeble one, and it is extremely improbable that the fungus can attack a living root, even when it is wounded, unless some of the dead wood is exposed. Very likely its habit is to gain entrance to the tree through dead roots, but by what means it reaches dead roots is at present entirely unknown.

-Cure of the disease is, of course, impossible. The forester must remember that he has a sixth sense in his Pressler borer, a sense which he should use with enthusiasm and discernment. If he watches carefully for the incidence of heart-rot caused by Fomes annosus (see p. 122) he will be equally guarded against this other heart-rot; at any rate he will not receive his first intimation of it when the woods are cut, but being warned beforehand, he will be able to use his discretion as to whether the woods should be cut before normal financial maturity is reached. But apart from the borer, the presence of $P$. Schweinitzii can generally be detected by its fructifications. It fructifies much more freely than Fomes annosus in the early stage of rot, and as the fructifications are sub-aerial they can always be seen. A special look-out should be maintained for the upright fructifications, like that in fig. 46, which grow from the roots, and may have no obvious connexion with the tree on which they are feeding. These may be formed before the trunk is appreciably affected, whereas fructifications are not borne on the trunk itself until it is either dead or very severely damaged. August is the best month in which to look for these growths, and when they are found they should be picked and destroyed in order to restrict the further distribution of the fungus. Of course the removal of the fructification will not help the tree that is actually attacked, and an investigation of the roots of the tree is advisable, as if the attack is not far advanced it may be possible to remove all the diseased roots, which are very probably 


\section{HEART-ROT CAUSED BY OTHER FUNGI}

already dead, and thus save the tree, or it may be found desirable to remove the tree with as many roots as possible, and thereby save surrounding trees.

These precautions are likely to repay the time spent on them, as the disease is not yet very common in Britain, and if taken in time epidemics may be prevented. But it is essential that all attacked portions of trees should be burnt, and not allowed to lie about in the forest, for the fungus fructifies with great regularity on all exposed surfaces of rotted wood.

Poria vaporaria, (Pers.) Cooke. This fungus is reported-as a wound parasite on various conifers both in Germany and the United States, ${ }^{1}$ and it probably occurs on the larch. But as it is probable that many species of fungi are included under this name, and as I have had no opportunity of studying the fungus on the larch, only a very brief account of the disease will be given. The information is derived from Hartig (1878), who found the rot which he attributed to this fungus several times on the Scots pine and once on the spruce. The rot so closely resembles that due to Polyporus Schweinitzii that the two may frequently have been confused.

The fungus fructification is resupinate, i. e. it does not form a bracket, but is confined to the under-side of the wood or tree on which it is growing, and does not extend beyond it. Its upper surface everywhere touches the tree and is hidden, and its lower surface is covered with small pores which bear the hymenial surface, as in the genus Polyporus. The two genera Poria and Polyporus are so closely allied that they were formerly included in one, and Hartig describes the fungus under the name of Polyporus vaporarius. The fructification is white, thin, and fragile.

The trees which Hartig investigated were mostly 50 to 100 years old. The rotted wood is at first light brown, but later it becomes dark brown, and at the same time shrinks so as to cause vertical and horizontal crevices, as in wood rotted by Polyporus Schweinitzii. Also the crevices become

\footnotetext{
${ }^{1} \mathrm{H}$. von Schrenk (1900).
} 
filled up with mycelium as with the latter fungus. But wood rotted by Poria vaporaria may be distinguished by the following features:

(i) The rotted wood has the consistency of charcoal, for which it might be mistaken but for its redbrown colour.

(ii) It has not the turpentine smell which is so charac-teristic of wood rotted by Polyporus Schweinitzii.

(iii) The mycelium in the crevices is not chalky, but woolly, and the mycelium is partly composed of white mycelial veins, which are made up of numerous parallel, thick-walled, slightly branched and sparsely septate hyphae. These veins grow not only in the crevices, but also on the outside of blocks of wood, where they are kept damp, and between the wood and bark of dead trees.

The microscopic features are also similar to those of Polyporus Schweinitzii. The hyphae, which are not numerous in the tracheides, are some thick-walled and some thinwalled, are poor in branches, and are constricted where they bore through the tracheide walls. But the bore-holes are characteristic in that the hyphae digest the middle lamella across a greater breadth than the rest of the wall, as shown in fig. 55, B, so that the bore-holes are somewhat lens-shaped and in surface view appear to be surrounded by one or more nearly concentric circles. In the summer wood there are numerous cracks in the tracheide walls similar to those caused by Polyporus Schweinitzii, but not as a rule so long. The hyphae frequently have 'buckle connexions' at the points where septa are formed (fig. 55, A).

This rot may either spread up from the roots or may be initiated above ground where the heart-wood is exposed by the fall of a branch.

As stated above, there are many varieties of this fungus, the distinctive features of which are only partially known. 


\section{6}

One form causes a 'dry rot' on structural timber not unlike that produced by the dreaded Merulius lacrymans. Both occur in houses, especially in cellars and other damp or ill-ventilated situations, and rot the woodwork to such an extent that it collapses under any strain that may be put upon it. Surfaces of the rotting wood are often covered by a thickish layer of felty mycelium traversed by veins of denser conducting hyphae. Such layers are made by Merulius lacrymans as well as Poria vaporaria, but with increasing age the two fungi may be readily distinguished by the fact that with Merulius they become grey and silky

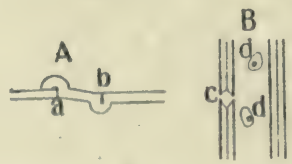

FIa. 55.-Poria vaporaria: A, hypha, showing buckle connexions; $a$, early stage showing how the connexion grows out from one side of the septum; $b$, later stage, in which the wall between the connexions and the part of the hypha on the other side of the septum has been absorbed. $\mathrm{B}$, hyphal bore-hole; $c$, in section ; $d$, in surface view.

on the surface, whereas with Poria they remain white and felt-like. These mycelial layers are very like those found in the open on trees attacked by Poria. But the humid conditions and large area of wood surface afforded by the under-side of an ill-ventilated floor, or similar situation in a building, allow of a much more massive mycelium than is generally found in the forest.

Polyporus sulphureus, Fr. We now come to two fungi which, though they cause heart-rot in the larch, are definitely wound parasites, and infect the tree through sub-aerial wounds or dead branch snags left by the fall of the larger branches. These two fungi are Polyporus sulphureus and Trametes Pini.

Neither of these fungi has yet proved very destructive to the larch in Britain, and with the former, at any rate, little fear need be entertained as to its power for evil in well-regulated woods. The sulphur polypore has been found in Europe on oak, locust (Robinia pseudacacia), 
alder, willow, poplar, walnut, pear, and larch (Hartig, 1894); in America it is recorded on a similar range of broad-leaved trees, but appears to be much more general on conifers, and is reported as a parasite on pine, spruce, hemlock spruce, \&c. (Schrenk, 1900 ; Atkinson, 1901). It is not uncommon in England, where it is most frequent on the oak, but also attacks the larch, yew, and other trees. Infection generally takes place through wounds left by the pruning or breaking of large branches, so that single trees grown in the open are much more liable to attack than plantations in which side branches are killed before they attain sufficiently large size. Branches which die naturally through being shaded by the crown are less likely to introduce the fungus, but Atkinson observed one case in the American white oak in which the fungus had apparently entered through a dead leader which had become included in the gradually thickening trunk. This, however, is exceptional, and the occurrence of the disease in larch woods may be regarded as evidence of an open canopy which has allowed undue development of side branches. In parks, where such development is normal, the snow-break, or wind-break, of large branches will furnish 'infection courts' for the fungus, unless the timely treatment of such wounds is resorted to.

The fungus makes large annual bracket-shaped fructifications which are usually imbricated, i. e. a number grow together, one above another, and are generally found on wound surfaces between May and September. They are easily recognized from all other polypores by their colour, being bright orange above and sulphur yellow below. The soft flesh of young fructifications is full of a clear yellow fluid, and the upper surface particularly is very moist and turns brown when bruised. This surface is somewhat hairy and when mature becomes hard and brittle. Drops of water containing melezitose (Schrenk) collect on the lower side, which is marked by very fine pores. The whole fructification develops very quickly, and soon after maturity is destroyed by grubs. 
The fungus produces a red rot in the duramen of the larch, which spreads indefinitely both upwards and downwards from the point of infection. My own observations of the rotted wood have been confined to a section from the base of a large trunk in the School of Forestry Museum at Oxford. This section (fig. 66, p. 155), which came from Windsor Park, is hollow, and only small fragments of rotted wood remain attached to the uninjured wood surrounding it. These fragments are in many respects similar to wood rotted by Polyporus Schweinitzii. They differ, however, in showing more regular tangential and transverse cracks, so that portions broken away are more nearly cubical. These blocks are heavier and firmer than wood rotted by $P$. Schweinitzii, and have a darker and richer chestnut colour. The process of decomposition does not appear to have been described in the larch, though the fungus was carefully investigated by Hartig (1878) on the oak. Schrenk's observations on the spruce (1900), although they cannot be applieable to the larch in all details, should be briefly noted in this connexion.

First the wood turns slightly red brown, but in longitudinal cuts it is seen that this colour is confined to irregular patches. Then small transverse cracks appear which never cross from one annual ring to the next, but extend part way across a ring either from the side of the summer or spring wood. At this stage microscopic sections show numerous small breaks and fissures, which are evidence of much shrinkage having occurred in the wood. Slanting fissures in the tracheide walls, similar to those shown in fig. 54, were also observed in the spruce, but they are said to rise from left to right at an angle of about $45^{\circ}$. The medullary rays are often absorbed, so that the tracheides appear distorted in tangential sections. Later the annual rings separate from each other, presumably owing to the destruction of the first-formed spring wood in each ring, and the radial fissures become complete, so that the wood becomes divided into a number of long flat slabs, each the width of an annual ring. There is very little mycelial development in the 
wood at any time. In this respect the spruce apparently differs from the oak, in which Hartig noted that the mycelium almost completely fills some of the tracheides and vessels.

I find it very difficult to distinguish microscopically between old rotted wood of larch decomposed by $P$. sulphureus and $P$. Schweinitzii. The oblique fissures in the tracheide walls are very similar in the two cases, though with each fungus the range of variation in this respect is considerable. Transverse cracks crossing one or two tracheides are, however, more frequently associated with $P$. sulphureus than $P$. Schweinitzii. It should be easier to control this fungus than any of the root-rotting species. Infection is sub-aerial, and fructifications when made are easily seen. Destruction of fructifications as soon as they are spore-bearing will do much to prevent the spread of the fungus, but as they can grow again after being removed early in the season, a constant watch has to be kept, and it is better to cut down infected trees and, after utilizing undamaged portions, to burn the remainder. Hartig found that in the vessels and tracheides of oak wood a form of conidium was often produced, apparently by the mycelium of this fungus; but its connexion with the fungus was not proved by culture experiments, and the conidia may have belonged to a saprophytic fungus which gained admission to the wood subsequently to its destruction by $P$. sulphureus. If it is found that these conidia belong to the parasite and can carry infection, stringent measures would be necessary to localize the disease in districts where the oak is attacked by the fungus. For such oaks become hollow and often open at the side, and the powdered decomposed wood can be blown about by the wind, and with it the conidia. Consequently all these hollowed old oaks, which are common in parks, would be a source of infection for other trees, quite apart from the production of visible fructifications. But, as yet, the relation between these conidia and $P$. sulphureus is conjectural. Schrenk found no trace of them in the wood of the spruce, and Brefeld (1889), who grew pure cultures of the fungus, states that no conidia were borne 
by the mycelium. I have found similar conidia in larch wood, rotted by $P$. Schweinitzii, which has been allowed to lie about in the laboratory for some years, but have so far been unable to induce the conidia to germinate. I hope in the future to carry out further experiments with them to ascertain their relationship with the fungus that rotted the wood.

Trametes Pini, (Thore) Fr. This is another wound parasite of the conifers which rots the heart-wood, and, to a limited extent, the sap-wood as well. According to Hartig it only gains admission to the tree through wounds caused by the fall of live branches. Unlike Polyporus sulphureus, it is by no means confined to trees growing in the open, but has proved destructive in plantations of forty years old and upwards. In woods of this age, owing to thinning, more space is given for the development of the crowns of individual trees, and consequently the branches reach a greater size. They are then more liable to be broken by wind or snow, especially on the more exposed edges of plantations, and it is in such exposed positions that the fungus is most prevalent. Hartig (1878) has noted that the frequency of the disease on its four European hosts, Scots pine, larch, spruce, and silver fir, is in the order given, being greatest in the Scots pine and least on the silver fir, and that the frequency of broken branches follows the same order. Wounds left by the breaking off of small branches do not admit the fungus, as they are almost immediately protected by a layer of turpentine and resin. But when a large branch breaks the broader core of heart-wood, which does not secrete these substances, is not so easily protected, and it is in the central portion of such a wound that the fungus first begins to grow. Thus inception of the disease generally occurs at some height above the ground.

The disease affects the same genera of conifers in America as in Europe, with the addition of Tsuga, the hemlock spruce. It has also been reported as growing on willow (Stevens, 1913). In Britain, at any rate in the south of England, it is fortunately uncommon, so that it cannot be included as one of the more dangerous pests of larch cultiva- 
tion in this country. Rostrup (1902) does not include it among Danish fungal diseases. In India it occurs on Pinus excelsa (Mayes, 1905).

The fructification of the fungus is of Polyporus form, and may be composed of either a single large bracket (up to 9 in. wide), numerous imbricated small brackets, or 'resupinate' incrustations which may spread for $10 \mathrm{ft}$. or more on the under-side of branches or fallen trunks. It is hard, woody, and perennial, and is most easily distinguished by the light red-brown colour of the lower surface, which is pierced by small pores. The pores are round, but appear elongated where the surface is not horizontal, a feature, however, which the fungus has in common with many allied species. Brackets are produced freely on dead trees, and the spread of the fungus is chiefly secured by these post-mortem growths. The hymenial surface which lines the pores bears basidiospores which are 5-6 $\times 3-4 \mu$, and is characterized by elongated, brown, pointed, thick-walled, spine-like paraphyses or 'cystidia' not unlike those figured in Polyporus Schweinitzii. They persist in the pores for a long time after the region bearing them has ceased to produce spores.

The process of decomposition induced in the wood by the fungus has been described by Hartig (1878) and Schrenk (1900). From the infected branch narrow red-brown streaks spread both upwards and downwards in the trunk. Though these streaks scarcely spread at all in a radial direction, they may become tangentially extended in the annual ring or rings in which they were initiated, and in this way produce a kind of ring-shake in the tree. Several partial rings of this nature may arise before the centre of the tree is appreciably affected. The wood outside the red-brown area becomes suffused with turpentine and resin, which to a considerable extent limit the spread of the mycelium. White flecks then appear in the red rot portions, which are occasionally, but by no means always, preceded by black spots similar to those caused by Fomes annosus. These flecks are much larger than those produced by $F$. annosus, 


\section{2}

and are usually the entire width of an annual ring. The subsequent stages of rot are somewhat variable. The delignified walls of the white flecks may crumble away, owing to the digestion of the middle lamellae, leaving holes arranged in layers associated with definite annual rings, and if many adjacent annual rings are attacked the wood becomes honeycombed. This is general in the pine and spruce and sometimes occurs in the larch. In the Tamarack (Larix americana) it generally happens that the flecks become joined, first longitudinally and later tangentially, so that entire tangential sheets become rotted and intermediate plates can readily be separated out. In the larch and pine the mycelium is said not to destroy the sap-wood, so that the water-supply of the upper part of the tree is not materially reduced; if a tree is killed by the fungus it is generally through wind-break at the weakened portion. For the same reason fructifications are not borne except on or near the branch stubs. In the spruce and silver fir, which are poorer in resin, the mycelium can penetrate to the cortex, and where this occurs brackets may grow from the bark without any special relation to the branches.

The only remedial measure is to cut down the trees and destroy infected portions. As the rot is generally confined to the upper portions of nearly mature trees, the lower part of the trunk can be utilized, and it is to the forester's interest to secure this timber at the earliest possible moment; as the longer he leaves the tree the greater will be his loss through the downward spread of the rot. But what is much more important than his own interest is his clear duty to British forestry. The fungus is as yet uncommon in Britain, and we should do all in our power to prevent it from spreading. Wherever any sign of its presence becomes apparent, infected trees should be immediately cut down, and every part of a tree that shows the least trace of rot should be burnt. To remove the brackets and incrustations is not enough, as they grow again even from felled logs in the forest, and it is impossible to maintain a sufficiently careful scrutiny to prevent the dissemination of the fungus. 


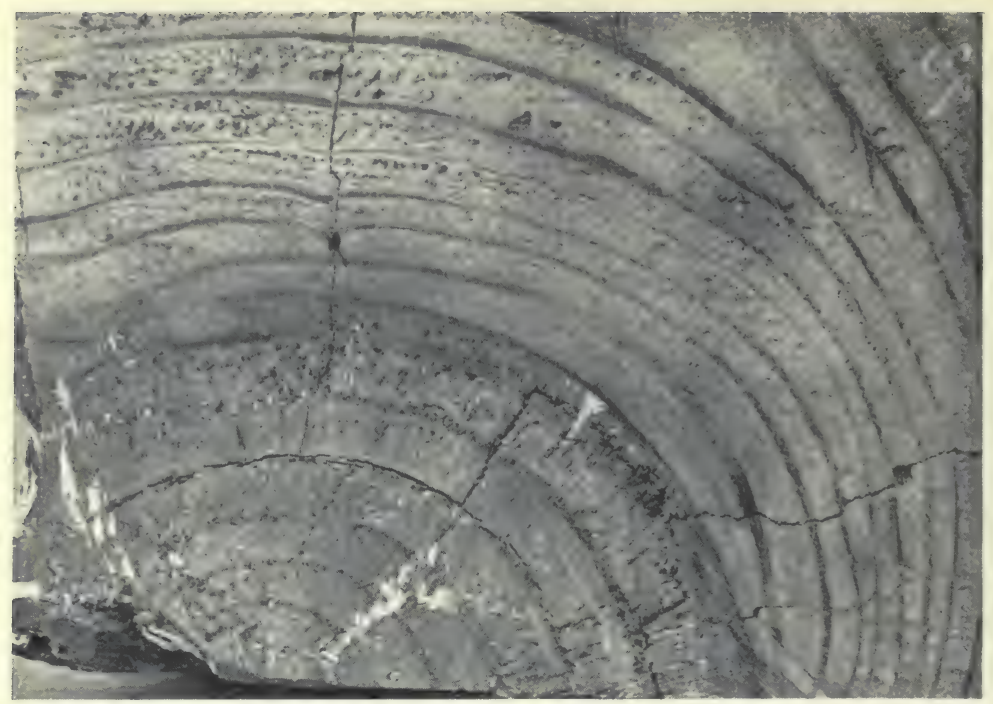

FIG. 56.--Transverse section of larch wood rotted at the centre by Trametes Pini $\left(\times \frac{1}{1}\right)$.

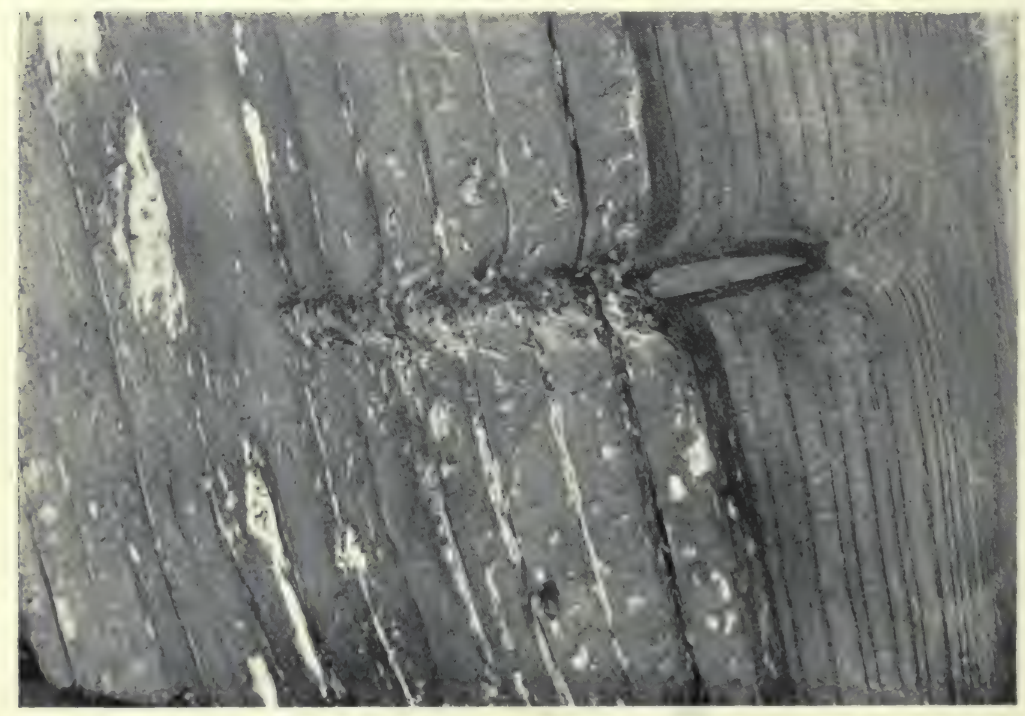

FIG. 57.--Radial longitudinal section of larch wood rotted at the centre by Trametes Pini $\left(\times \frac{1}{1}\right)$. 
Note.-Since writing the above I have found a larch near Oxford in which part of the crown is heart-rotted, apparently by this fungus. The rot had not advanced very far and no fructifications were present. The rotted portion shows incipient ring-shake through the partial decomposition of the junctions of the annual rings. The holes described at the junctions occur chiefly in the last-formed elements of the summer wood, but the first-formed spring wood of the next year is in places affected. In each annual ring there is also a number of radially extended delignified patches and holes. The rotted portion, which occupies the centre of the stem, is surrounded by a layer of insoluble gum which resembles that described in connexion with Fomes annosus. Photographs of the specimen are shown in figs. 56 and 57. 


\section{CHAPTER VIII}

\section{ARMILLARIA MELLEA, THE HONEY FUNGUS}

General. Microscopic details of the fructification. Rhizomorphs. Effect on the host. The black line and resin flow. The method of infection. Means of prevention.

Armillaria mellea, (Vahl) Sace., ${ }^{1}$ belongs to the large group of toadstools. There are about a thousand British species of these toadstools, or Agaricaceae, as the mycologists have it, a group distinguished from the rest of the higher fungi by having gills running radially on the under-surface, as in the mushroom ; and the very large majority of them are purely saprophytic, living either on the humus in the soil or on decaying timber or leaves. But a very few can also live parasitically, deriving their nutriment from the tissues of the host plants, and thereby causing them damage which may be more or less fatal. Of these Armillaria mellea is by far the most destructive. Indeed more trees die, in Europe at any rate, from attack by this fungus than through any

1 The name Agaricus melleus dates back to 1777, and is apparently due to Vahl (Florae Danicae, fasc. 12, plate 1013). No doubt the specific name refers to the honey-coloured pileus. Bulliard (Histoire des champignons, 1791, plate 377) calls it Ag. annularius, and J. Sowerby (English Fungi, vol. i, 1797, plate 101) Ag. stipitis. Fries (Systema Mycologicum, 1821, vol. i, p. 26) fixes Vahl's name, and places the species in his section Armillaria (L. armilla, a ring), characterized by its clothed stipe and partial veil which persists as an annulus, by which points the section is distinguished from other white-spored agarics. Saccardo (Sylloge Fungorum, vol. v, p. 80) was apparently the first to raise Armillaria to generic rank as applied to this species, so that the full title of the fungus is Armillaria mellea, (Vahl) Sacc. Innumerable figures of the fungus have been published, of which Vahl's, though uncoloured, is one of the best. The Flora Batava contains two figures, viz. vol. x (1849), plate 775, and vol. xi (1853), plate 815, the latter under the name Ag. mutabilis. Cooke's coloured drawing (Illustrations of British Fungi, vol. i, plate 32) is not quite characteristic. 


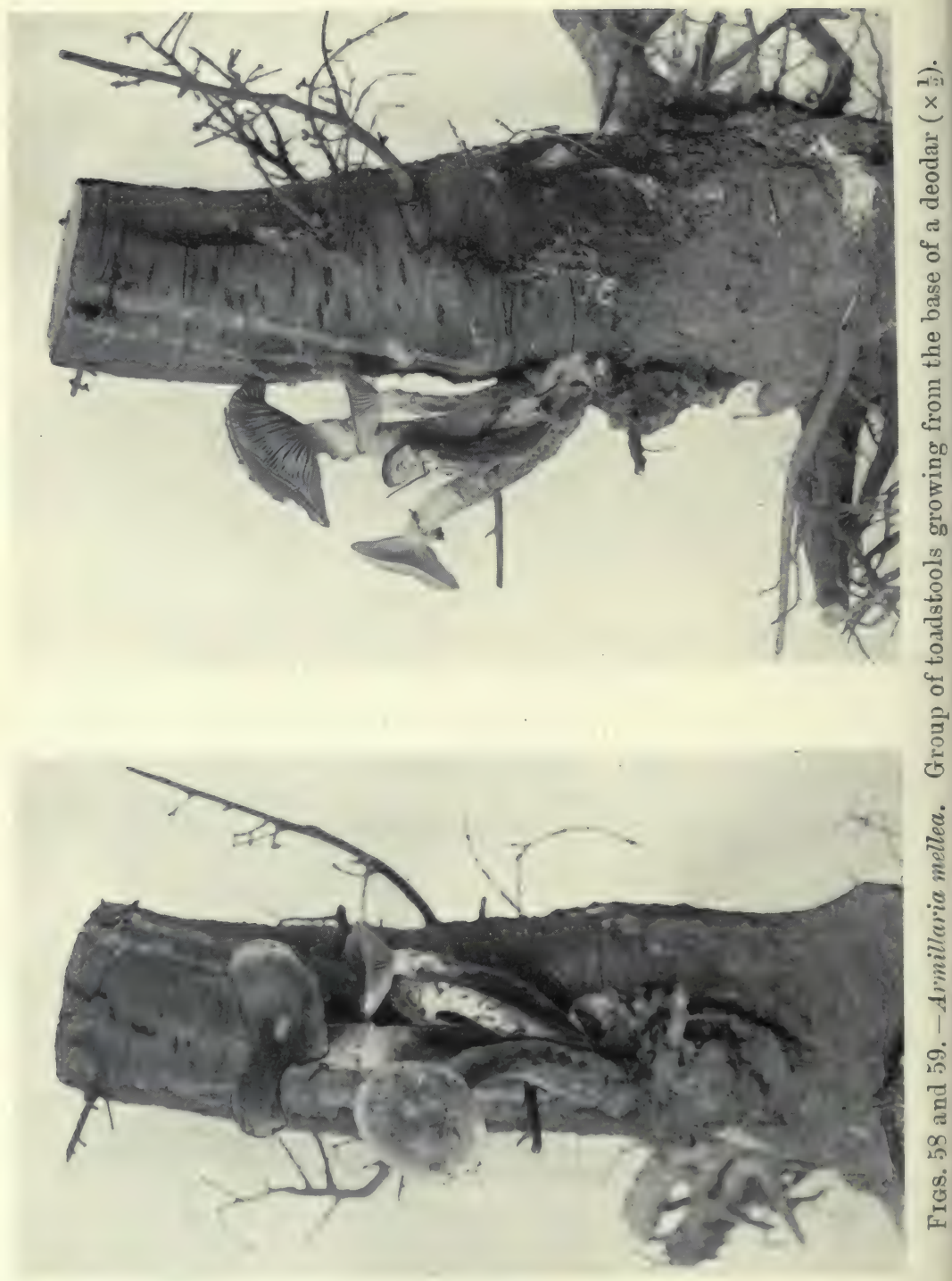


other parasitic agent. It attacks not only the larch but all other species of conifers, and several species of broadleaved trees become subject to it, especially when weakened by other causes. It is thus of exceptional interest to foresters, and its life-history has been studied in considerable detail. This chapter contains most of what is known about the fungus, and enough has been discovered to give us a pretty clear idea of the way in which the parasite grows and spreads. But before going into the details of the disease I shall give in this first section a summary of the external features of the fungus and the means by which it may be recognized.

The toadstool itself is the only part which grows above ground, and it is thus the most familiar portion of the fungus. Its sole function is reproduction, and in every detail it is constructed so as to advance the formation and dissemination of the spores. At the same time it is an ephemeral growth, found only in one or two months of the year, whereas the vegetative part of the fungus grows on through all the months underground, visible only in its effects. This toadstool has much the same size and shape as a mushroom : rather larger, though, at times and always slimmer in stipe and pileus, and honey yellow in colour. The stipe or stalk is 3 to $8 \mathrm{in}$. long, of dull orange or brown, but varying much in tone. At the base it is usually very dark brown or even black, and about three-quarters of the way up is an annulus which is white and rather thick, though in old specimens it often shrinks to a few whitish scales. Below the annulus the stipe is roughly. grooved, but above it is smooth and pale in colour. In the button state the annulus is continuous from the stipe to the margin of the pileus, as in the mushroom, but it soon becomes ruptured at its circle of attachment to the pileus.

The upper expanded portion is known as the pileus. This is honey coloured above, with dark-brown scales which are clustered near the swollen centre but more scattered farther out. They are particularly conspicuous in young fructifications, but with age they become more 1888 
obscure. The margin is radially striated. The under-side of the pileus is beset with whitish gills which run radially from the stipe to the margin. Those which reach the stipe are decurrent, i. e. are continued for a short distance, often a very short distance, down the stipe; but others start farther out and fill up the broadening spaces between the rays. These gills bear on their surface millions of minute white spores, the formation of which is the sole function of the toadstool, for each spore is capable under suitable circumstances of reproducing the whole fungus. They begin to be formed while the toadstool is still a button, they ripen as the pileus expands, and, when mature, fall from between the gills and are carried away by the air currents which pass along the ground surface. It is on account of these spores that the toadstool is called a fructification or sporophore.

The fungus is very variable, but is not difficult to distinguish. The scaly pileus, the decurrent gills, and the persistent annulus, together with the general colour and shape, render it one of the easiest of the toadstools to identify.

It is found from the end of September up to the first frosts of winter, and generally in woods where the growth is not too dense. In dark coniferous woods the fungus will readily grow and spread underground, but it seldom makes fructifications. On this account it generally remains unnoticed in such places until its presence is evinced by the trees it has victimized.

The details of the toadstools are shown in figs. 58-61.

The fructifications are usually found on stumps or growing on the ground near by. If a bit of the earth is dug up beneath a fructification, it will be found to contain one or more black strands, which resemble leather boot-laces; and if the earth is pulled away with care the fructifications will be seen to be attached to one of the branches of these strands, as shown in figs. 60 and 61 . These strands are called rhizomorphs, owing to their superficial resemblance to the roots of higher plants, and they are composed entirely of 


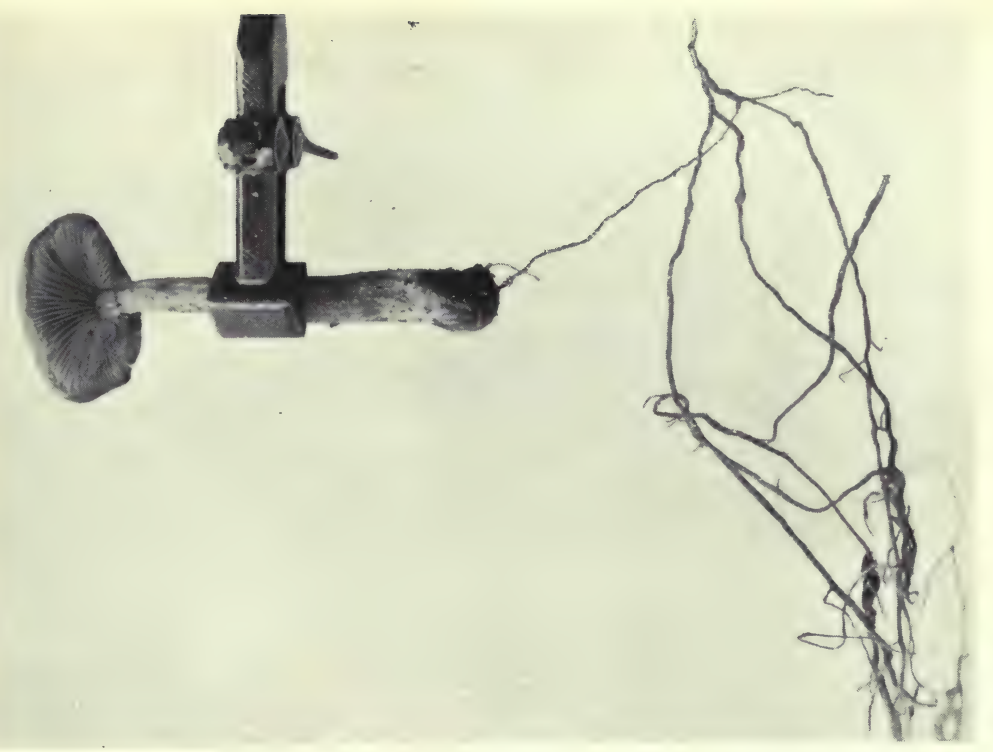

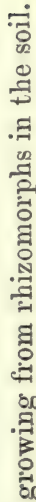

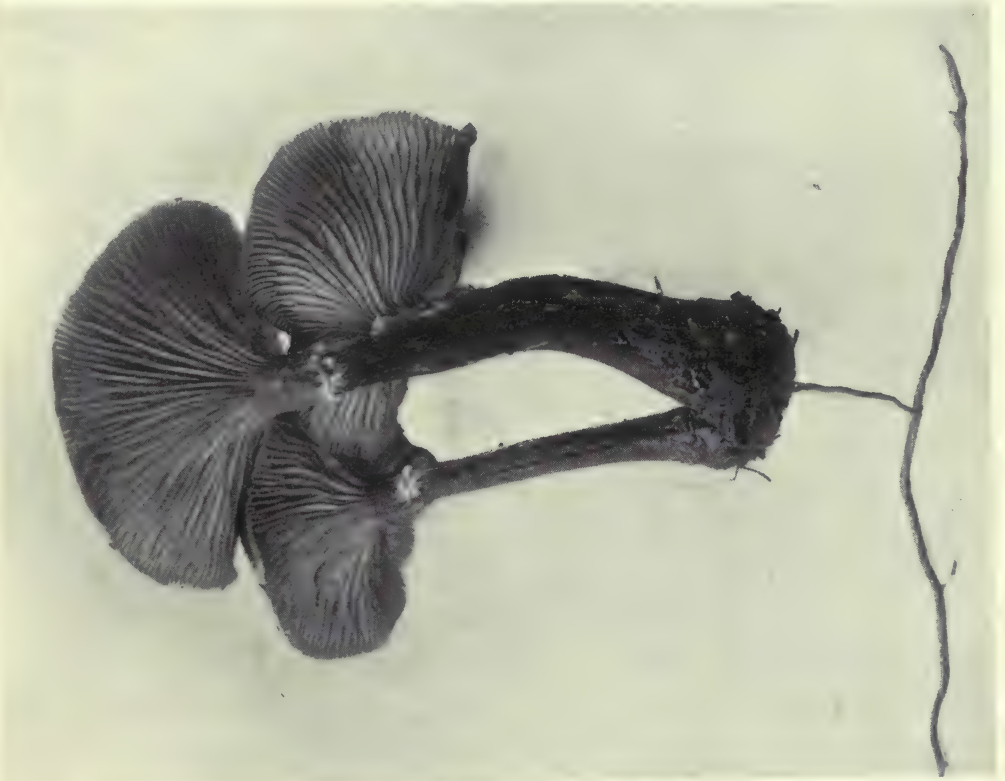

을

İ 

hyphae woven together into a dense mycelium. But in function they are entirely different from roots, for they are incapable of obtaining moisture or nutriment from the soil in which they are growing. If they are traced back to their base they will be found to originate in a stump, and though they may grow to a considerable length, all their food supplies are drawn from the stump. One of their uses is obvious, viz. to bear fructifications at a distance from the stump; but they have a still more important function, for when they come into contact with the root of a living tree under favourable circumstances, they penetrate it and infect the new host with the disease.

It is these rhizomorphs which make Armillaria so difficult to eradicate, for they spread far and wide in the soil, and all the trees in the neighbourhood of an infected stump are liable to attack.

In addition to the fructifications and the rhizomorphs, there is the mycelium in the tree itself. In the wood the mycelium is too fine to be seen by the naked eye, except for the black line (fig. 65), which can be found in any sections across the base of a trunk during the more advanced stages of attack. In conifers this line is always fine, but in broad-leafed trees it sometimes becomes fairly broad, and is very marked in stumps which are thoroughly rotted. Between the scales of the bark and in the cambium dense layers of white mycelium are formed which are the surest means of diagnosis in the earlier stages of the disease. They are much thicker than the layers formed by Fomes annosus, and are usually veined. This felted mycelium grows up through the cambium to a considerable height, but when the tree is dead and the bark has become loosened, it is replaced by a tangled mass of flattened rhizomorphs (figs. 63 and 64). These were at one time regarded as a separate species of fungus under the name of Rhizomorpha subcorticalis, distinguished from the rhizomorph in the soil, which was called Rh. subterranea.

Though the fungus attacks all kinds of conifers, it favours some more than others. Scots pine is probably the most 
frequent victim, and after that, according to my experience, Sitka spruce, Weymouth pine, and Corsican pine. Larch is not usually attacked till it is more than fifteen years old, but is then frequently killed by the honey fungus. I have also seen trees of deodar, Douglas fir, monkey puzzle, and common spruce all killed by it, and probably no species of conifer is immune from attack. Among broad-leafed trees, oak, beech, chestnut, laburnum, and alder are not infrequently destroyed, and I have found a street-planted elm and other trees killed by it. Wagner (1899) has found the fungus on twenty-nine species of broad-leaved trees in Germany, including pear and apple, and in America ${ }^{1}$ many fruit trees are fatally attacked. It has generally been held that broadleafed trees do not succumb to the fungus unless previously weakened in some way, but this is always difficult to prove. Death does not follow on attack so quickly as in the case of conifers, and the early symptoms of the disease may be mistaken for inherent weakness in the trees. Certainly oaks are attacked in Britain as much in the open as in woods, and there can here be no question of suppression by other trees. At the same time park trees are especially liable to all types of root disease, as for instance beech by Fomes australis and F. resinaceus. This is probably due to grazing animals damaging the surface roots, and also to the inferior quality of the subsoil in parks as compared with woods, for reasons mentioned in the discussion on Fomes annosus.

Larch trees are not usually killed until many years after infection. The external signs of advanced attack are the death and fall of the needles and generally a flow of resin at the base of the trunk. If a portion of the bark is removed from the tree at a point near the roots, thick white layers of mycelium are disclosed, and on digging the soil away from the roots rhizomorphs are almost invariably found. In woods which have an open canopy the toadstools of the fungus may be found growing from the roots of the trees for many years in succession before the trees show any external symptoms of ill health.

1 Panmel (1911), Horne (1912 and 1914), Hey (1914), Long (1914). 
Microscopic details of the fructification. The general appearance of fructifications has been described in the previous section. A few details of mycological interest may here be added. The young sporophores arise singly, or in clumps, as masses of whitish hyphae, either growing from the extremity of a rhizomorphic branch or from the white mycelial sheets which lie hidden beneath the bark of diseased trees. They are most commonly found on or near the ground, but may arise $6 \mathrm{ft}$. or more up a trunk, this position being especially frequent on Scots or Austrian pine. The pileus is early delimited from the stipe by an annular furrow, on each side of which the young toadstools become swollen. The more pronounced swelling on the upper side becomes the pileus; the lesser swelling on the lower side forms the veil. Hartig's drawing of this stage is reproduced in the translation of de Bary's Comparative Morphology, fig. 133. The young veil soon becomes congruent with the margin of the pileus, and the latter by greater growth on the upper side becomes curved so that the annulus is not unduly stretched. Inside the ring-shaped cavity between the veil and the stipe the gills develop, and when they are sufficiently mature to bear ripe spores, the veil is suptured by increased growth on the lower side of the pileus.

The rupture occurs near the margin of the pileus, so that the veil remains attached to the stipe and forms the annulus, which when fresh may be as much as a centimetre in breadth. In the early stages the pileus is completely covered by a skin which is continuous with the veil, but with the final expansion of the former this skin is ruptured in many places and remains in the form of scales on the upper surface.

The arrangement of the gills is shown in figs. 60 and 61 . Each gill is entirely covered by the hymenium, a layer composed of basidia and paraphyses (fig. 62). Each basidium commonly bears four spores on sterigmata, not unlike those of Fomes annosus, but basidia with two or three spores are occasionally found. The dispersal mechanism of the spores is like that of Fomes annosus, i. e. the spores are thrown 
horizontally for a short distance and then dropped by their own weight between the gills. For this purpose it is necessary that the gills should be vertical, and this orientation is secured by a triple action (Buller, 1909). The stipe is vertical, the pileus adjusts itself to a horizontal position, and finally the gills place themselves vertically.

A section of the gills stained with iodine disclose some interesting facts with regard to the distribution of glycogen,

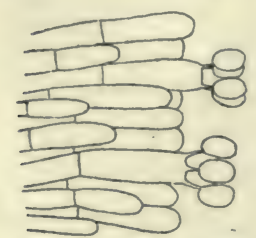

Frc. 62.-Hymenial layer of Armillaria mellea $(\times 420)$. the principal reserve carbohydrate of the fungus. In young basidia glycogen is fairly generally distributed; but, as they get older, part of the glycogen is passed into the spores, and the rest is left as a drop at the upper end of the basidium. Basidia which have lost all their spores still contain this drop of glycogen, and its function is probably to provide the osmotic pressure necessary for the discharge of the spores (see p. 104). The ripe spores measure about $9 \times 6 \mu$, and are somewhat reniform.

Rhizomorphs. Armillaria mellea has a more specialized vegetative system than any other known fungus. In a nutrient medium such as a rotten stump, and especially in the space between the wood and the bark of dead trees, it makes a reticulated mass of somewhat thick strands or rhizomorphs, each flattened thread of which resembles a black leather boot-lace (figs. 63 and 64). From points beneath the soil these rhizomorphs send out branches into the earth, which are of a somewhat different type, being round in section instead of flat, and having fewer branches. Both types of rhizomorphs were known long before they were associated with any particular fructifications, and they long went by the name Rhizomorpha subcorticalis and Rh. subterranea, ${ }^{1}$ Persoon, respectively. It was not even determined that the two forms belonged to the same species

1 Sowerby, vol. iii, 1803, figures five species of Rhizomorpha, two of which are certainly $R h$. subterranea. The others are doubtful, but none resembles $R h$. subcorticalis. 


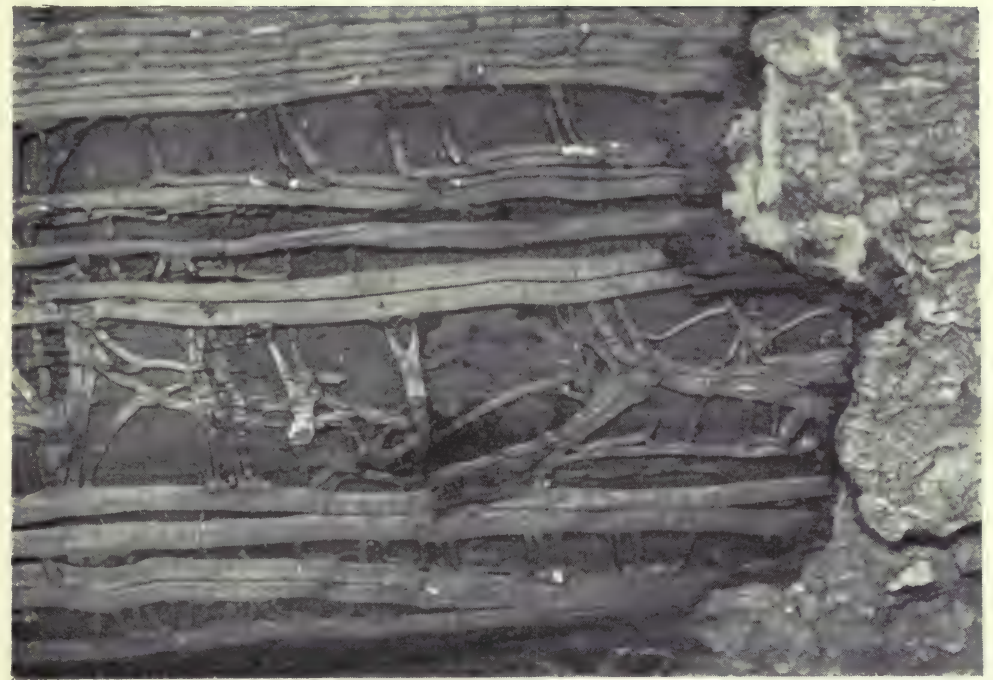

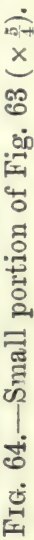

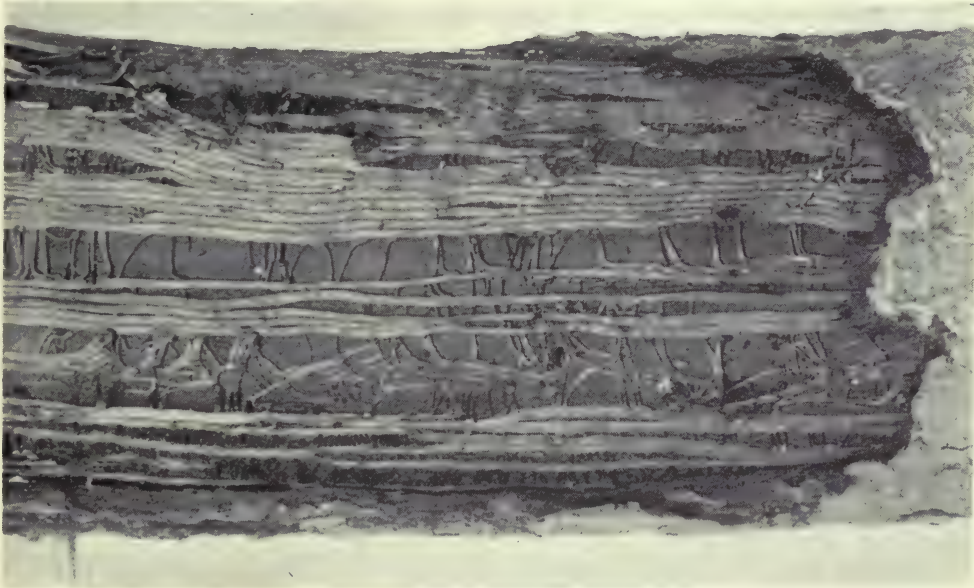

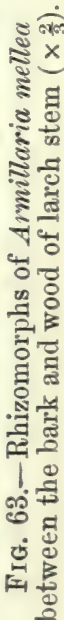



They were described by Jos. Schmitz, whose account with some additions was included by de Bary in the first edition of his Morphologie der Pilze (1866), and at that time several different fungi which grew as parasites on the rhizomorphs were regarded as their fructifications by various authors.

It was not until 1874 that Hartig discovered that both forms of rhizomorphs are mycelial growths of the fungus Armillaria mellea, or as it was then called Agaricus melleus. Brefeld in 1877 obtained rhizomorphs in pure cultures grown from spores of the fungus, and thereby confirmed. the association. The following account is derived chiefly from de Bary, Hartig, and Brefeld, who worked out the development and morphology of the rhizomorphs in great detail.

It will be best to begin with the germination of the spores. These germinate in a nutrient solution in a few days, though germination does not take place in pure water. On a decoction of plums they produce circular masses of white mycelium which grow slowly, reaching a diameter of little more than $5 \mathrm{~cm}$. in about eight days, and then stop. Next, closelywoven masses of hyphae appear near the centre, which are at first light in colour, but later dark brown. These dense clumps of mycelium resemble the sclerotia (hard mycelial growths which function as perennating organs) of many fungi, and we may follow Brefeld in regarding the rhizomorphs as sclerotia which have developed growing points by which unlimited extension and branching are rendered possible.

Of a number of such sclerotium-like bodies only one or two develop into rhizomorphs; the rest cease to grow and become covered with white hyphae. The growing points only become operative on the lower side of the sclerotia, not on the upper side where they lie free of the culture substratum. Once growing points are formed the rhizomorphs quickly grow parallel to the bottom of the dish, and only cease to lengthen when the nutrient material is used up. By removing them to a fresh decoction Brefeld obtained renewed growth and profuse adventitious branching, and by further 
removal to very large culture dishes the cultures grew into more or less compact masses of rhizomorphs. So far, in development and form, the rhizomorphs agreed with the subcortical type. They were eovered with hyaline hyphae, which stood out at right angles to the surface. The rind was white where submerged in the substratum, but brown or blackish where it rose above it. And each rhizomorph gave rise to frequent branches. But after a rest of some months a mass of the Rhizomorpha subcorticalis made branches which grew out into the damp air and assumed the form of Rhizomorpha subterranea.

All the authorities cited depict the apical growing points of the rhizomorphs. Three fairly distinct layers can be observed in this region. On the outside a fairly loose weft of thin hyphae which send branches out into the air. Next is a cortex of longitudinally running hyphae, which are so closely welded together that they have no intercellular spaces between them, and appear polygonal, not circular, in section. They have frequent septa, and near the apex the segments are not much longer than they are broad. The centre is occupied by the medulla, in which the hyphae are much broader (up to $20 \mu$ ). These hyphae are thin walled and full of hyaline sap, and are arranged in marked longitudinal rows with numerous intercellular spaces between them. Farther from the apex the cortex increases its periphery through the branching of the hyphae that compose it, so that more room is left for the medulla. And since the medullary hyphae do not branch, they are drawn more apart and large air spaces are left between them. Usually a large central cavity is formed which becomes the main aerating system of the inner part of the rhizomorph.

This type of structure only occurs near the growing point, and in tracing successive stages of maturation from the apex of the rhizomorph it is found that each of these layers undergoes modification. The outermost layer, which is at first slimy, owing to the secretion of gelatinous liquid from the hyphae, becomes firmer through desiccation. The outstanding branches disappear, and then the layer becomes 
nothing but a firm gelatinous covering to the rhizomorph. Eventually even this becomes indistinguishable. The most noticeable change in the cortex, which becomes the rind of the mature rhizomorph, is the coloration of its outer layers, which begins a few millimetres from the apex. The coloration, which is associated with a hardening and thickening of the outer walls, gradually spreads inwards until it involves all the cortex and also a part, if not the whole, of the primary medulla. By the formation of a central cavity the primary medulla has been restricted to half a dozen or more layers of hyphae lining the inner side of the cortex. But a secondary medulla is formed by branch hyphae, which grow from the primary medulla or inner cortex and finally fill up the central cavity.

This description applies to the subterranean form. In the subcortical rhizomorph the outermost gelatinous layer does not dry up in the same way, and the branch hyphae, which arise not only from the superficial hyphae but also from those more deeply rooted, penetrate the surrounding tissue of the host, especially through the medullary rays, and, while destroying the tissues, serve to nourish the rhizomorphs. Subcortical strands usually remain colourless until the severance of the bark from the wood lets in air, when the cortical walls of the rhizomorphs become thickened and pigmented, though not so intensely as in the subterranean form. When bark, already loose, is first pulled off them the rhizomorphs are frequently red, but this colour gives place to a dull black within a few hours.

Branches arise through a new growing apex being formed in the inner layer of the cortex, which, in a few days, breaks through the rind and emerges from the parent strand. The birthplace of every new branch is indicated, some days prior to its emergence, by a floccose tuft of hyphae, $\frac{1}{2}-1 \mathrm{~mm}$. in diameter, which appears on the surface. The hyphae forming this tuft arise partly from the surface of the rhizomorph and partly from the hyphae more deeply seated.

The effects of the honey fungus on its host. As soon as a rhizomorph of Armillaria has entered a larch tree, it forms 
a thick white flaky mass of mycelium which usually spreads in the region occupied by the cambium. Compared with the very thin layers of mycelium produced by Fomes annosus the mycelium of Armillaria is almost leathery in consistency. Like the rhizomorphs it is composed of a central loose medulla and a denser cortex. The cortex is composed of hyphae running longitudinally and cut up into almost isodiametric segments by very numerous septa. Branches are given off by these hyphae, and these branch hyphae grow out into the surrounding tissues, attacking the phloem on one side and the wood on the other, chiefly by way of the medullary rays. It has been stated that the felty mycelial layer generally grows in the region of the cambium ; sometimes, however, it is outside the phloem in the inner cortex, or among the outer phloem cells. In either case, further felty mycelial layers are subsequently made, so that in pulling off the cortex and phloem of a root or stem in an advanced state of attack, several layers of white mycelium are found, one inside another. These layers are veined, and at the upper limit present an irregular outline.

The cambium and phloem are usually attacked in the larch to a height of 3 to $5 \mathrm{ft}$. In rough-barked pines, such as Scots and Corsican, mycelium is often found at a higher level, whilst in Weymouth pine it is usually confined to the lowermost $2 \mathrm{ft}$. On the death of the tree the mycelium continues to grow as long as there is sufficient moisture. When the bark contracts away from the wood, leaving an air cavity, the mycelium takes the form of Rhizomorpha subcorticalis, the structure of which has already been described.

In the wood the hyphae spread at first chiefly through the medullary rays, and they often grow sufficiently fast to reach to the centre of the tree from one side whilst the tree is still living on the other. From the medullary rays the hyphae grow into the tracheides and spread from tracheide to tracheide through fine bore-holes made in the tracheide walls. The hyphae naturally grow along the tracheides much more rapidly than across them, so that the rot spreads 



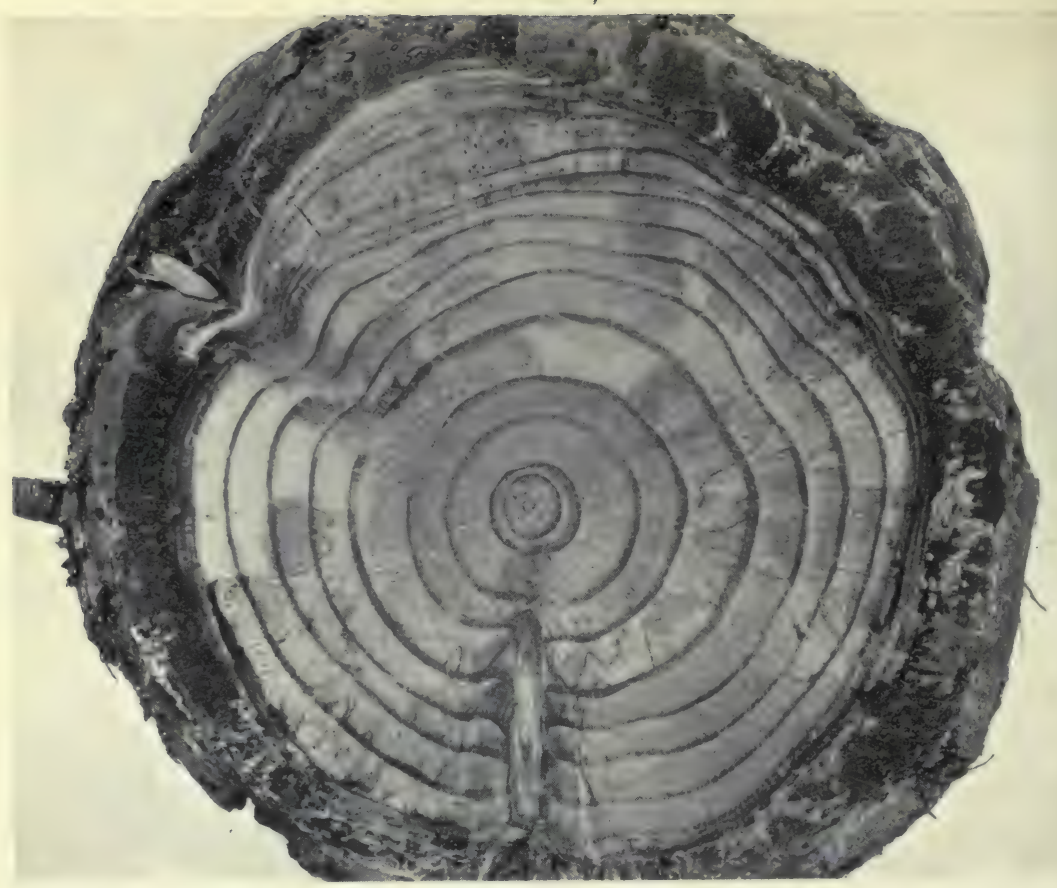

FiG. 65.-Section of a larch stem attacked by Armillaria m:llea. The black lines can be seen, especially on the right-hand side of the photograph $(\times\{$ )

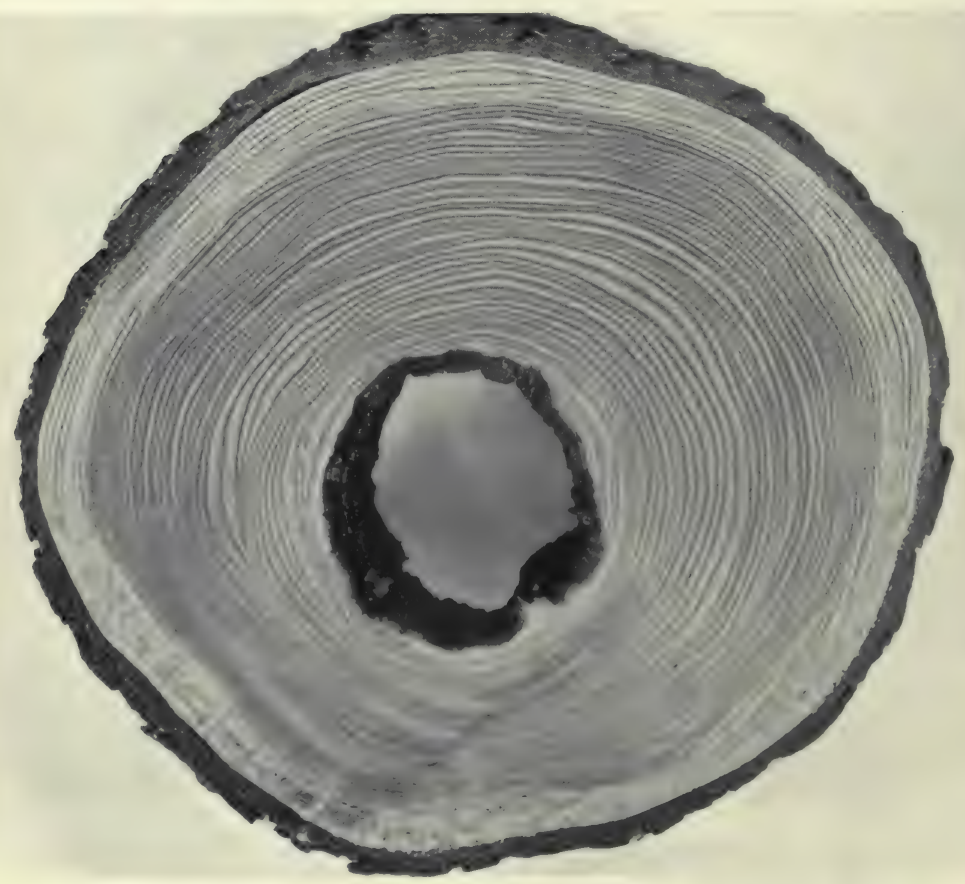

Fig. 66.- Hollow larch stem rotted by T'olyporus sulphureus $\left(\times \frac{1}{4}\right)$. 
up a trunk more quickly than transversely. In this first state of rot the wood is very little affected.

The black line. The second state of rot is distinguished by black layers in the wood. These layers start from the cambium and gradually spread inwards, remaining very thin

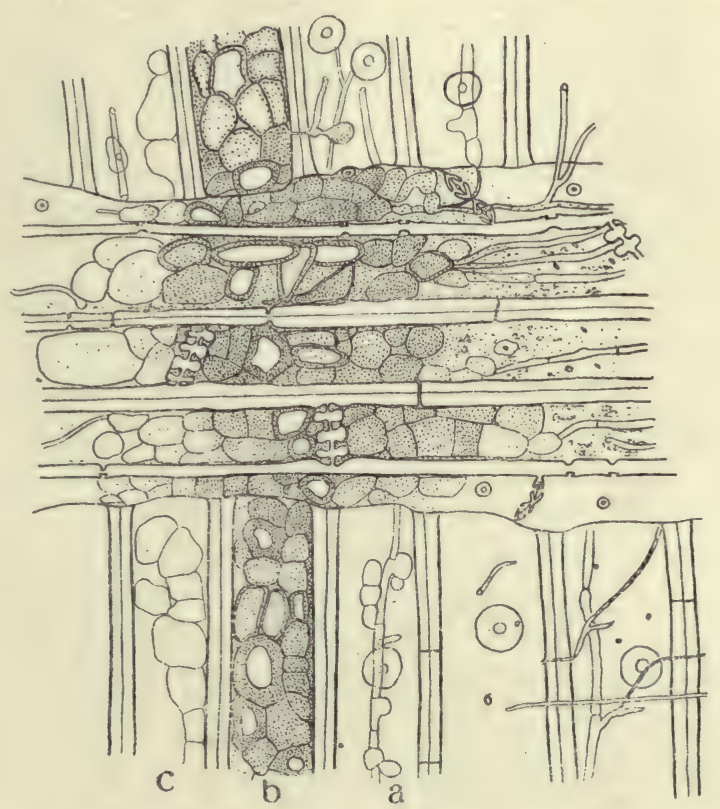

FIG. 67.-Armillaria mellea. Radial longitudinal section of larch wood showing the 'black line', where it crosses a medullary ray $(\times 400)$. For description, see text.

all the while, so that in a transverse section of the trunk they appear as lines forming the sides of triangles with the cambium as base (fig. 65). They also spread upwards in the wood, forming cone-shaped surfaces, and a section through a somewhat higher part of the trunk shows them as irregular circles.

A black layer, or black line as it appears in section, is entirely made up of hyphae. For when the rot has reached a certain stage in the wood, the hyphae become much more frequently septate and bear special short branches. Both 
the branches and some of the original segments swell up into bladder-shaped bodies and their walls become tinted with a pale brown pigment. This stage is seen in tracheide $a$ in fig. 67. The branching continues and more segments swell up into bladders, so that whole tracheides become tightly packed with them. At the same time their walls become thickened, often to such an extent that the lumen is nearly obliterated, and the pigmentation becomes much more marked.

Some of the swollen cells collapse, and their contents fill the interstices between the other bladders and stain the walls of the tracheides. This stage is seen in tracheide $b$ of fig. 67 and also in fig. 68. Next the swollen hyphae become bleached and empty, their walls again become thin, and finally they disappear (fig. $67, c$ ). In a radial section of the larch these three stages can usually be seen in three successive tracheides, and the black line itself generally covers only a single tracheide. It is clear that this series of changes will secure the forward movement of the line. When a section of a trunk containing a black line is looked at with the naked eye, the wood behind the line is found to be different in colour from that in front of it. The purplish red colour of the wood in the first stage of rot has given place to a dull yellowish-brown tinge, and the wood takes a polish with less brilliance. But when looked at with a microscope it is remarkable how little difference can be seen in the wood on the two sides of the black line. No more bore-holes are seen; the tracheide walls stain red with phloroglucol and hydrochloric acid and do not stain with the chlor-zinc-iodine reagent; the walls are not appreciably thinner, and even the tori of the bordered pits remain intact. (Hartig says that after the passage of the black line the walls stain blue with chlor-zinc-iodine, but in the larch this is certainly not the case.) Nevertheless, at some distance behind the black line marked delignification does take place. Comparatively few scattered filamentous hyphae are found in this third state of rot, but in it the most marked changes occur. Whole tracheide walls 
are delignified from the outside towards the middle lamella, leaving a layer of cellulose. Then the cellulose also is digested so that often whole walls disappear. The walls of the bordered pits are digested gradually and they often

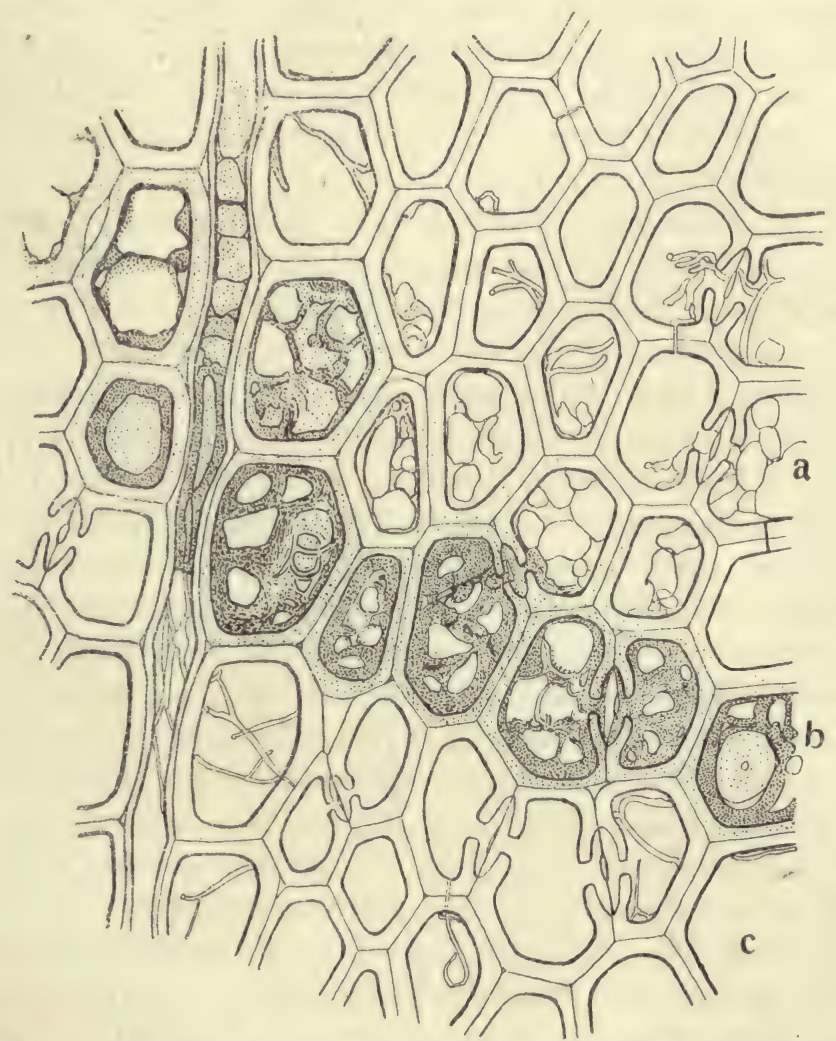

Fig. 68.-Armillaria mellea. Transverse section of larch wood showing the 'black line' $(\dot{\times} 450)$.

crack through shrinkage in the process, and present various curious figures, some of which Hartig has drawn (1879). The wood never becomes honeycombed as it does with Fomes annosus or as crumbly as with Polyporus Schweinitzii, but it is much too weak to be of any use for structural purposes.

The significance of the black line is obscure. It seems 
to indicate a stage of excessive vigour in the mycelium, and though it does not directly cause marked changes in the character of the wood, it appears in some way to transform the wood into a state in which it is easily acted on by the hyphae behind.

The dark-brown pigment differs from that found in the black specks of wood rotted by Fomes annosus in being unaffected by hydrochloric acid, though it is bleached by concentrated nitric acid.

When two black lines approach each other they seldom unite, but cease to move when about 1 to $5 \mathrm{~mm}$. apart. This causes the frequent phenomenon of a pair of black lines running parallel to each other. In some parts a black line is replaced by a much broader band of colourless, bladder-like hyphae. These resemble the black-line hyphae in all respects except their colour and the thickness of their walls, and apparently are much more slowly decomposed. They may cover a width of as much as 6 to 10 tracheides.

Resin flow. The disease is generally accompanied by an external flow of resin, and sometimes the quantity of this substance excreted is so great that the fallen needles, twigs, and soil round the base of the trunk become compacted into a hard adherent crust. The resin arises in two ways. Firstly, the living cells lining the resin ducts in the cortex and wood are killed so that the contained resin escapes, and, taking advantage of the cracks formed by the drying of the bark, runs down the outside of the trunk. Secondly, the living tissues in the neighbourhood of the fungus excrete an abnormal amount of resin, and wood which is formed after some part of the tree has been attacked is characterized by containing a large number of irregular resin ducts, so that in this respect the wood resembles the abnormal wood made in the region of a canker. On account of this escape of resin the disease is sometimes known under the name of 'resin flow' or 'resin glut', and though the flow of resin is commonly not so great in the larch as in the Scots or Austrian pine, it is often the first external symptom of the disease. 
The method of infection. Parasite and host are constantly at war. At one stage in the contest the parasite has the advantage, at another the host. And it is the business of the pathologist to find out the line of defence where the host has the best chance of success against its aggressor, as assistance may there be of greatest advantage. Now, it is generally in the opening stages of the conflict that the plant is at its strongest. It is the obstacles it presents to the entrance of fungi, its cuticle and bark, which şave it from what would otherwise be universal defeat and destruction. At the same time, parasites have become adapted so as to overcome these obstacles in a variety of ways.

The spores of a few fungi can, on germinating, actually pierce the cuticle of leaves and stems; many germ tubes have acquired the power of finding stomata and entering the plant through them, and spores of other fungi germinate on the stigmas of flowers and grow down into the ovaries by the same route as the pollen tubes. But those fungi which attack the trunks of trees have a much more formidable barrier to pass, since in the older parts of stems the epidermis is replaced by the bark, which is composed of many layers of cork cells, which are almost impermeable to fungi.

Though the earlier pathologists seem commonly to have accepted the theory that fungi pierce the sound bark of trees, no authenticated instance of this has ever been recorded, and the trend of recent opinion has been more and more in the direction of admitting the possibility of infection only by wounds or by outflanking the bark protection. Willkomm, for instance, thought that the larch canker fungus gained admission to the cortex through undamaged bark, a view that was disproved by Hartig. But Hartig, in his turn, thought that Fomes annosus could attack healthy unwounded roots, which now appears extremely improbable.

The mode of infection employed by Armillaria mellea has never been very critically examined. The question is a difficult one, and exceptional care and subtlety will be 
required in devising experiments to elucidate the problems connected with it which require solution. But there are some general considerations which may lead to the adoption of a reasonable view, in keeping with the present state of our knowledge.

No conidial form of reproduction occurs anywhere in the life-history of Armillaria, so that the fungus is confined to two methods of attack-by spores and by rhizomorphs. In my opinion the rôle of these two organs is quite distinct, as will be shown by the following analysis. In the discussion the fungus will be regarded as an enemy whose sole object is to attack living trees. Actually, this is not quite true to fact, as no doubt the fungus is just as happy living saprophytically on dead stumps as when sapping the life of growing trees; but if it confined its attention to a saprophytic existence, we should have no quarrel with it, and it is only in its career of depredation that we, as pathologists, are interested in it.

Infection by spores has never, to my knowledge, been experimentally demonstrated, but it is safe to formulate the following postulates with respect to spore-infection :

(i) Spores are incapable of infecting a tree through healthy bark of root or stem.

(ii) Infection is not known to take place through stems or roots which are so young as not to have developed a bark.

(iii) Consequently infection can only be effected through wounds or dead roots or dead stems.

Further, dead branches are not a suitable medium for infection by a root-attacking fungus like Armillaria, probably because the surface is not kept sufficiently damp for the germination of the spores. And dead roots can only very occasionally become exposed to the air-borne spores. Thus it is fairly safe to assume that spores can only attack a living tree through wounds in the rootstock just at the surface of the soil. Owing to mice and other rodents such wounds are not uncommon, but, as they soon become 
covered by resin, they are only open to infection for a very short period.

Evidence from observation confirms the deduction that infection by spores is unusual, for when attacked trees are rooted up it is almost always found that the soil in their vicinity is infested with rhizomorphs, which can generally be traced to a neighbouring stump. In such cases the evidence for infection by rhizomorphs as against infection by spores is overwhelming.

What then is the use of spores? Spores are the common means by which the fungus attacks dead, but uninfected, stumps. As will be shown later, a stump is employed as a base from which the fungus attacks living trees, so that spores are the medium by which it forms new bases from which the fungus proceeds on a career of penetration in limited tracts of forest.

Infection by rhizomorphs, on the other hand, is a matter of common observation, and it is no doubt the general means employed by the fungus in attacking living trees. It is through the rootstocks or larger roots that the rhizomorphs enter, but it is still a question whether an entrance is effected (i) through healthy, uninjured bark, (ii) through wounds, or (iii) through dead roots.

Most of the experimental evidence bearing on the subject of infection by rhizomorphs is concerned with broad-leaved trees. Hartig (1894 and 1901) experimented on the oak and Cieslar (1896) used a variety of dicotyledons. Wagner (1899) planted 43 small trees of various broad-leaved species in a garden in which the soil was infected with rhizomorphs. Of these, 17 had been intentionally wounded on roots or rootstocks. Eight of the wounded trees became infected and none of the unwounded. This result is in general agreement with the conclusions of the other authors.

A better known experiment of Brefeld's, designed to show that Rhizomorpha subterranea could give rise to Rh. subcorticalis, should also be mentioned. It was not intended to demonstrate any pathological principle, so that for the present purpose it is of very limited value. 
Brefeld found that his older cultures produced a profusion of aerial rhizomorphs of the subterranean type. When these were growing strongly he dug up some thick roots of Scots pine and brought them undamaged and fresh into close contact with the apices of the rhizomorphs (" Ich grub sie aus und brachte sie unverletzt und frisch mit den Rhizomorphenspitzen in innige Berührung '). His figures show that the pieces of root were only about 4 in. long. Brefeld found that the rhizomorph apices grew into the roots very quickly, both through the cut ends and through the undamaged bark. The time that they took to penetrate by each route is not stated.

Now, when digging up fairly thick pieces of root it is very difficult not to damage the bark, so that in this experiment the rhizomorphs may have grown in through wounds. Also cut pieces of roots, especially of coniferous roots, quickly lose their vitality and even after a very short time cannot be described as healthy roots. Brefeld says that the rhizomorphs grew in at once (" sofort'), but the possibility is not excluded that the first rhizomorphs to enter gained admission through the cut end, whereas the others may have taken some days about it. It should not be taken, then, as proved that rhizomorphs can force their way into a healthy root through undamaged bark.

The evidence gained from my own observation supports the view that the rhizomorphs can only attack through damaged or dead roots. Take the following instance. In Bagley Wood, near Oxford, a series of quarter-acre experimental plots were planted in 1907. Various species of conifers were used, and my observations, which date from 1913, show that most of the area is infected with Armillaria. At certain points there are large stumps from which rhizomorphs radiate in all directions, and some thousands of the toadstools appear annually on and around these stumps. The fungus was found in plots containing each of the following species: Corsican pine, Weymouth pine, Norway and Sitka spruce, larch, and deodar, and yet, with the exception of some fifteen Weymouth pines and a number of Sitkas, 
only one tree, a Corsican pine, has so far been attacked. (There is no plot of Scots pine.) Not a single larch, deodar, ${ }^{1}$ or Norway spruce has been affected, though from other woods I have obtained specimens of each of these species killed by the fungus. If perfectly healthy roots were liable to be penetrated by the rhizomorphs, I do not think that such immunity could have been expected.

In a larch tree in a neighbouring plantation, about eighteen years old, which showed only the early stages of attack, I found that the rhizomorphs had entered through a wound in the bark at the base of the trunk. In this case the roots and rootstock presented more than a square foot of undamaged bark, and yet the fungus found out the square inch of wound. Further instances might be quoted from other observations, but enough has been said to show the improbability of infection through healthy bark.

From Brefeld's experiment we know that rhizomorphs can enter dead roots, and it is probable that this faculty is commonly employed by the fungus. The importance of dead roots has been fully discussed in the chapter on Fomes annosus, and need not be reiterated; and though this method of attack by Armillaria raises some further questions, these have not yet been investigated. Infection through dead roots may account for a phenomenon that is frequently observed-I refer to the case of larch woods which remain practically free from infection by Armillaria until they reach an age of more than fifteen years, after which many trees succumb within a short time. The presence of the fungus may have been detected many years previously, but it had to wait until the death of some of the tree roots afforded a means of entrance into the living trees.

Means of prevention. The forester is too often taken unawares by the honey fungus, but generally a surprise is due to lack of previous observation. When oak or becch woods are cut down the fungus must be expected, and any coniferous plantations on a site which has previously been occupied by such trees are especially liable to attack.

1 One deodar was killed this year (1919). 
Consequently, they must be carefully watched. During September and October it is wise to search through all woods for the fructifications, and to mark on a map the localities where they are found. Armed with the knowledge as to which parts of the woods are infected by the fungus and which are free, a forester knows what risks he runs in planting, and he should refrain from planting the more susceptible species, such as Scots pine, Sitka spruce, and Weymouth pine, in or near infected areas. Where it is necessary to plant conifers in infected land it will probably be a remunerative expenditure to grub up and burn all the infected stumps. The fungus spreads by its rhizomorphs and bears fructifications at some considerable distance from these stumps; but it must be remembered that the fungus in an area round a stump is actually living on it, and when the latter is removed the fungus will cease to spread unless it has already found other feeding grounds.

Where, through shortage of labour or other causes, it is impossible to grub up the stumps, some good may be done by boring holes in them and filling them with commercial sulphuric acid, though this may kill a few trees in the immediate vicinity.

Stumps which are not yet attacked are nevertheless liable to form centres of infection in the future, so that all means which hasten their decomposition are of service. Decomposition may be brought about by the honey fungus itself, or by one of several other species of fungi; but it is seldom that we find two species of the higher fungi growing simultaneously on the same part of a stump. Consequently encouragement should be afforded to other fungi, so that by getting their mycelia well into the tissues of the stumps they may render them at any rate partially immune to the honey fungus. It is well to look for other stumps which are already attacked by harmless fungi and to infect newly-cut stools with these fungi. This is best done by cutting off the fresh fructifications, and laying them with their naturally lower side downwards on unrotted stools. See that all parts of a stool are brought into touch with the fungi and 
cover them with a few handfuls of grass or bracken to preserve the moisture round the stools and maintain suitable conditions for the germination of the spores.

Perhaps the most convenient fungi for this purpose are Daedalea quercina, a bracket-shaped fungus with large labyrinthine pores on the lower surface: Hypholoma fascicularis, a toadstool not very unlike the honey fungus, but smaller, scaleless, and with greenish-brown gills : and Collybia velutipes, another tufted yellow toadstool with a black velvety base to the stipe. But there are many other species which by their commonness will commend themselves to the intelligent sylviculturist.

Hartig recommends that attacked trees should be at once rooted out and all infected parts burned, and also that an isolation trench should be dug round such trees to prevent the spread of the rhizomorphs. This advice is ill-conceived. An isolation trench round an infected tree can never be actually harmful, but it is generally so much labour wasted. Symptoms of the disease are usually evinced in spring or summer, when transpiration is greatest and the needles die and shrivel up through lack of water. But steps cannot be effectively taken against the fungus till autumn, when the toadstools appear and show the extent to which the fungus has spread. It is then nearly always discovered that some stump near the dead tree is acting as a base of attack.

A trench dug round the affected tree which does not also include this stump is about as much use as the isolation of a single cow with foot-and-mouth disease on a farm which is devastated by the complaint. The correct procedure is to dig up and burn the roots of an infected tree as soon as the attack is discovered, and to mark the place for treatment in the autumn. At the end of September further action should be taken. The first essential is to be able to recognize the fructifications of the fungus; it is thought that with the help of the description and photographs in this chapter any one unacquainted with it may familiarize himself with its distinctive features. Armed with this knowledge the area infected with the fungus can be surveyed, and all the 
stumps within the area must be examined for signs of rot. Infected stumps break apart fairly easily and show plates of deep black tissue. Further procedure will depend on the extent of the area to be treated. If this is not too large the infected stumps should be grubbed up, a process which is far easier when the stumps are rotted than when they are fresh, and all parts burned. If this involves too much labour, isolation trenches should be dug round the stumps, and cut to a depth at which no more rhizomorphs are encountered.

By this means the chance of infection of neighbouring trees will be greatly reduced, as the rhizomorphs outside the trench, being cut off from their chief base of supplies, will be greatly weakened. But it may be found that some living trees, which in the summer showed no sign of attack, already have Armillaria growing from their roots, as in figs. 69 and 70. From the base of these trees the soil should be removed, and if it is found that only a few roots are infected, these roots must be cut through above the points of attack and grubbed up. If, however, the fungus has grown into the trunk, as shown by plates of white mycelium, it is better to grub up the whole trees, utilize the upper part for what it is worth, and burn the remainder, otherwise the trees will die shortly and become fresh bases for fungal invasion. Those who pin their faith to isolation trenches should remember that these are of no value unless they are kept open for a long time, for the fungus is long-lived and may grow on a single oak or beech stump ten years or more. If, on the other hand, an infected stump is removed, a trench is unnecessary, as the rhizomorphs still in the ground are incapable of growth when they have been severed from their base, unless they have already penetrated the roots of other trees.

The success of the measures adopted can only be tested in the following autumn. If the toadstools come up again next year, it is a sure sign that undiscovered bases had been left, and further treatment along the same line is necessary. It may take several years to eradicate a well-established 

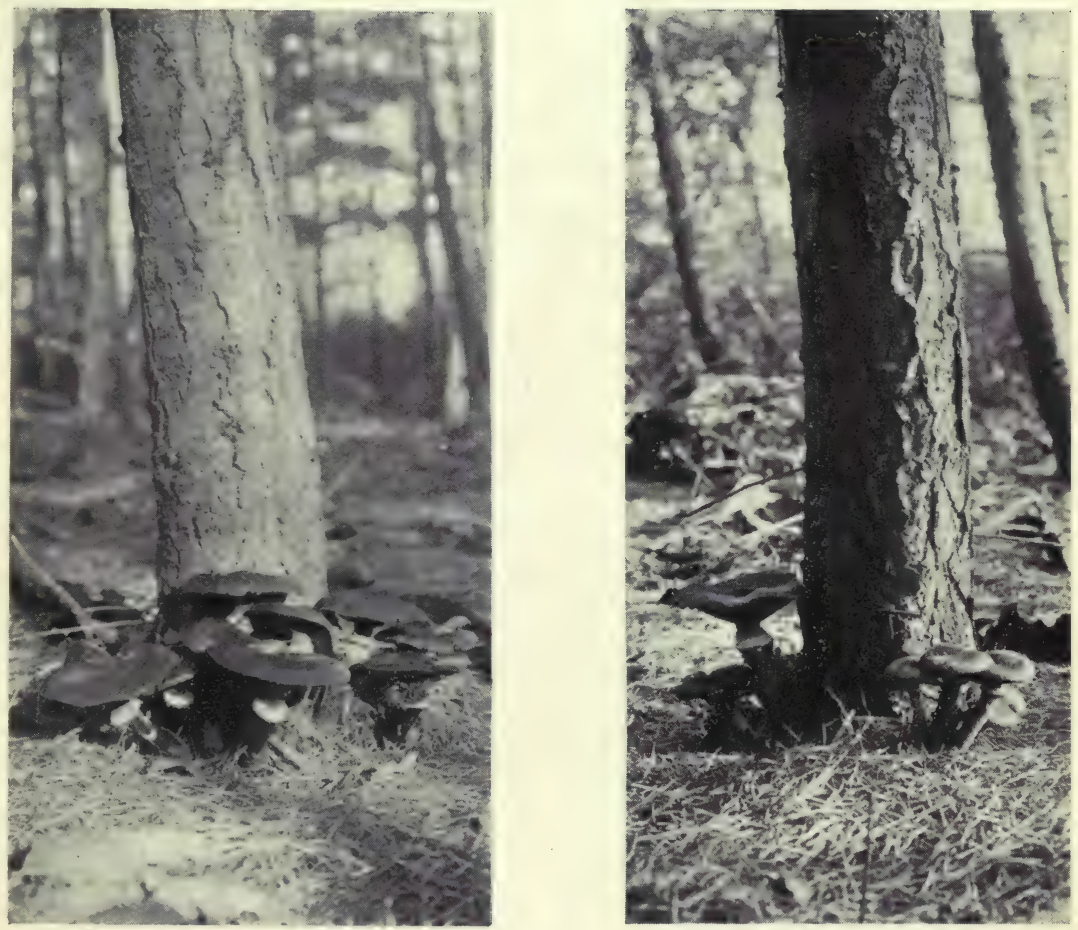

FIGS. 69 and 70.-Living larch-trees with the honey fungus growing from their roots. 

fungal colony, and where the fungus is widespread it may be impossible.

Where the fungus occurs only in one or two isolated patches, it is also worth while to destroy the toadstools. This is most easily accomplished with a scythe or sickle, with which the pilei can be cut off, after which they will soon die. But the process has to be repeated frequently, as fresh toadstools will come up through the autumn. Of course this precaution does not replace grubbing and ditching, and does not prevent the further expansion of the patch. Its purpose is solely to discourage the formation of new colonies, which would otherwise be initiated by the spores blowing on to dead stumps in other parts of the wood. 


\section{CHAPTER IX}

\section{LEAF AND SEEDLING DISEASES}

The larch needle-cast (Sphaerella laricina). Meria laricis. Hypodermella laricis. The larch needle-rusts: Melampsoridium betulinum, Melampsora tremulae, \&c. Damping-off diseases: Phytophthora omnivora; Fusoma parasiticum.

LEAF diseases of the larch are less harmful than the needle diseases of other conifers on account of its deciduous habit. In pines and spruces, in which the leaves function for several years, defoliation is a very serious matter, and in consequence the pine leaf-cast is one of the most dreaded diseases that infect trees. Not so with the larch, and a comparison of the bulk of literature published on the needle-casts of the larch and pine respectively justifies the supposition that Hartig's assessment of the importance of the former was pessimistic. Furthermore, those diseases which have been described as frequent and dangerous on larch needles in Germany and other continental countries are very infrequent in Britain. Indeed, some of them have never been recorded here, and their inclusion in this book is justified only as a warning to foresters of diseases which may spread to us from across the North Sea. There is no reason to think that our insular climate will render us immune from any of these pests, and it may be noted that Chrysomyxa abietis has already spread to the spruce needles of Scotland ${ }^{1}$ and the north of England, ${ }^{2}$ although until recent years our woods were entirely free from this fungus.

The larch needle-cast: Sphaerella laricina ( $R$. Hartig). This fungus causes the most serious larch-needle disease that is known in Europe. It was described by Hartig in a very interesting article published in 1895, and the following account is derived entirely from this source. The needle-cast was first

${ }^{2}$ Somerville (1911, 1915, 1917), Cowan (1915).

2 Hiley (1917). 
noted in 1883, and was then attributed to damp atmosphere inhibiting transpiration. Subsequently the disease became much more frequent, and in some woods, especially in Upper Bavaria, the greater part of the needles have been known to fall by the beginning of August, and in September many trees have become entirely defoliated. The disease is much less destructive at altitudes above $3,000 \mathrm{ft}$.

The first evidence of the disease is the appearance of small or large brown patches on the leaves in July. The leaves remain on the trees for a time, and on the brown patches there appear small black conidia-bearing pustules. The pustules are very small, only $0 \cdot 1$ to $0 \cdot 3 \mathrm{~mm}$. across, but arise in groups. The leaves begin to fall in the latter part of July, especially from the lower part of the crown where the air is moister.

Diseased needles contain much colourless mycelium, both in and between the cells. The protoplasm of the cells contracts away from the walls, but in the inner part of the leaf the green colour remains and is actually persistent till winter or the following spring, though it is masked by the brown pigment in the outer parts of the needle. The mycelium gives rise to the conidial pustules which are formed below the epidermis and break through it in circles. The conidia are of two sorts, each borne on the ends of very fine hyphae. First there are very small conidia, $3 \times 1 \mu$; which do not germinate in culture solutions. These have been described under the name of Leptostroma laricinum and also as spermogonia of Lophodermium laricinum. Next there are elongated needle-shaped conidia, $30 \mu$ long, which are borne on larger basidia near the outside of the pustules. They are at first non-septate, but later divide up into four segments. They break off easily, and are distributed either by wind or by being washed off by rain, when they fall on to the lower branches and leaves. The latter are readily infected, as germination takes place in a few hours, and new pustules appear on these leaves in about three weeks. Thus when once the fungus has appeared there is always a tendency for it to infect the lower branches rather than the upper. Also wet years and wet places are especially 
favourable to the disease, and long summers assist in its wide distribution.

The mycelium lives.through the winter in the infected needles lying on the ground. By the spring it is found to be composed of brown thick-walled hyphae, which in April and May give rise to perithecia - spherical, ascus-bearing fructifications, with a small aperture at the apex-which break through the epidermis like the conidial pustules. By the beginning of June these perithecia are the same colour as the conidial pustules, but are somewhat smaller $(0 \cdot 1$ to $0.15 \mathrm{~mm}$. in diameter). Some are half submerged in the leaf tissue, some are nearly superficial. The pore at the apex is obscure and difficult to find until ascospores, or entire asci, are seen emerging from it. The asci are clubshaped, 50 to $60 \mu$ long, and each contains eight ascospores, 15-17 $\mu$ long, which are at first one-celled, but later twocelled and colourless. They are forced out of the asci in a single mass.

The ascospores germinate in water in twenty-four hours from both ends, and sometimes also from the middle. Pure cultures have been grown from the spores, and such cultures bear four-celled conidia, exactly like those in the conidial pustules, after twenty days. Hartig observed a red coloration at the border of the mycelium in gelatine cultures, and presumed that this was due to the same cause as the redbrown discoloration of the needles. In the forest the ascospores are lifted by the wind, and are capable of infecting the young leaves of the larch. Thus the life-cycle of the fungus is completed.

It has been noticed that the disease is particularly severe in larch woods mixed with spruce. The explanation of this is that the dead needles fall on to the spruce shoots and remain there all the winter, and next year, as they are near the level of the fresh larch needles, reinfection is facilitated. Comparative immunity of larch woods at high altitudes is attributed to the shortness of the season, which restricts the number of conidial generations which can be produced during the summer.

When larch woods are heavily attacked by the leaf-cast 
it is recommended that they should be underplanted with beech, after sufficient thinning has been made to enable the beech to grow. As the beech is deciduous, the diseased needles fall through it and winter on the ground. In the following spring the young beech foliage acts as a screen, which prevents the free circulation of the ascospores to the larch above. This treatment has proved very effective in some woods at Freising near Munich.

Meria laricis (Vuillemin). This is another fungus which causes the browning and fall of the needles. The disease was first described by Émile Mer (1895), who noted it in 1890 in a nursery near Nancy. The attacked plants were two or three years old, and in June many of the leaves, especially on the lower branches, turned yellow. Later the yellow colour slowly gave way to brown, beginning at the tip. The disease spreads all through the summer and attacked leaves may fall as early as July, though they generally remain attached to the trees until within one or two months of the normal leaf-fall. This disease is particularly frequent in nurseries, but may be found in plantations, especially on small trees 6 to $10 \mathrm{ft}$. high. Such trees are generally attacked on their lower branches, and the comparative immunity of larger trees is probably due to their branches being too far from the ground to be attacked by the conidia.

The fungus was worked out by Vuillemin (1896), who created the new genus Meria to receive this single species. Together with Hypostomum Flichianum (another new fungus, which he described, on the needles of Pinus austriaca and P. montana) he placed Meria laricis in a new family, the Hypostomaceae, which he considers to be closely related to the Ustilagineae, or smuts. The hyphae which grow in the larch needles are septate, branched, and have mucilaginous sheaths. Conidiophores, which arise very soon after infection, grow from mycelial masses just inside the stomata, and emerging through the stomatal pores, divide by three septa into four segments. Each segment bears a single sterigma, at the end of which a colourless conidium is developed, $8-10 \times 2 \cdot 6-2 \cdot 7 \mu$. This conidiophore closely 
resembles the promycelium of the rusts or smuts, and, as in the latter group, it may give rise directly to hyphae, instead of conidia, under suitable cultural conditions. Infection of trees in the spring is brought about by conidia borne by similar conidiophores on needles which have lain on the ground during the winter.

As a remedial measure Mer suggests picking off the dead needles a short time before the normal leaf-fall in the autumn. It is not impossible to treat nursery plants in this way, as the diseased needles. are readily detached by drawing the hand along the branches. Needles which have already fallen form small heaps on the ground, which can be cleared up.

This fungus is apparently the same as that described by Hartig (1899) under the name of Allescheria laricis ( $\mathrm{R}$. Hartig) (=Hartigiella laricis, Lindau, in Engler and Prantl, Die natürlichen Pfanzenfamilien). According to Hartig, the disease is common in Germany, and may attack the needles of larch trees, especially in nurseries, as early in the season as May and June.

Hypodermella laricis (Tubeuf). This needle disease, which was described by Tubeuf in 1895, is found chiefly in Bavaria and the Tyrol, but has not, as far as I know, been reported from elsewhere. When attacked by this fungus, some or all of the needles of a dwarf shoot turn pale brown, but remain attached to the tree. Entirely brown dwarf shoots are often quite a conspicuous object on twigs whose needles are otherwise green. Bright black apothecia appear on the upper side of the needles, forming a single line of elongated dots. The apothecia contain asci, which are about $110 \mu$ long and contain four hyaline, unicellular, club-shaped spores, $66 \times 6 \mu$, with a gelatinous membrane. Interspersed among the asci, but shorter than these, are simple hyaline filamentous paraphyses. The disease is found particularly on the lower branches, and does not seriously interfere with the growth of the trees.

The larch needle-rusts. There are two genera of rusts which grow on larch needles, both of which have been found in Britain, though they are much more common on 
the Continent. The rusts are, for the most part, characterized by a very complex life-cycle, and many of them grow at different periods of the year on two different hosts and bear four different kinds of spores in the course of their life-cycle. Species which migrate from one host to another and back again are called heteroecious, to distinguish them from autoecious species, which live always on one host or on the ground.

.The discovery of heteroecism is one of the landmarks in the history of plant pathology. The first rust in which it was demonstrated is the black rust of wheat (Puccinia graminis), a fungus which has caused a great deal of damage to wheat crops all over the world. It had long been suspected that wheat rust was encouraged by the presence of plants of barberry, and a decree was promulgated in Rouen as early as $1660,{ }^{1}$ ordering the destruction of barberry in the vicinity of wheat fields. But it was not till 1865 that de Bary showed that this rust actually infects barberry plants in spring, and that wheat leaves are again infected in early summer by spores produced on the barberry plant.

The life-cycle of a typical heteroecious,rust will be better understood by following the accompanying diagram (fig. 71).

Starting from the bottom left-hand corner we have the mycelium in the tissues of the host A (e. g. the wheat plant). This mycelium bears red or rust-coloured pustules on the surface, called uredosori, which contain numerous spores called uredospores. These spores again infect the host A, sending their germ-tubes through the stomata, and giving rise to fresh mycelium which bears more uredospores, and so on through the summer. Towards the end of the season mycelium on the same host produces another kind. of spore (dark brown or blackish in the case of the black rust of wheat), called the teleutospore. The teleutospores may appear in special pustules (teleutosori) or side by side with, and in the same sori as, the uredospores. These teleutospores, which are thick walled, are the perennating organs of the fungus. They fall on the ground and remain there during the winter. They contain enough food reserve

${ }^{1}$ Whetzel, 1918. 
to live till the spring and then to send out a small germ tube of limited growth, called the promycelium, and this bears a few, generally four, very small spores, which are known as sporidia. The sporidia are very light, and being lifted by the wind settle on the leaves of neighbouring plants. But, though they may germinate, they inevitably perish unless they happen to come in contact with a plant

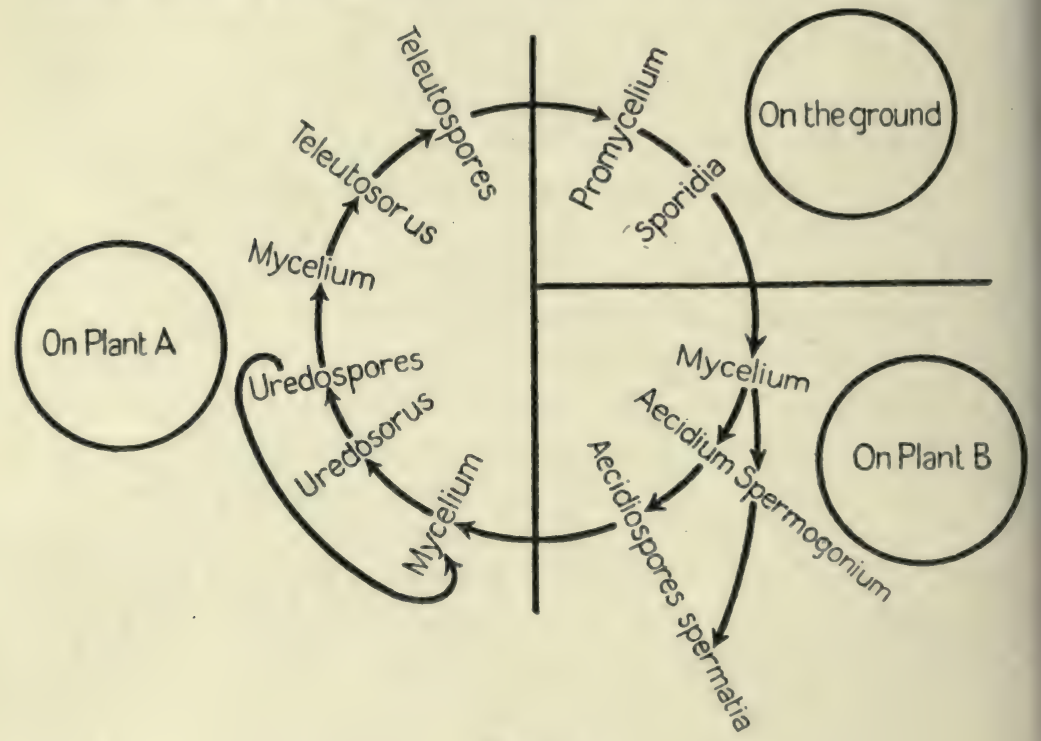

Fig. 71.

of some definite species, the host $B$. In the case of the black rust of wheat, this plant is the barberry. The germtube which grows from a sporidium pierces the cuticle and enters an epidermal cell of the host $B$, and develops into a mycelium which fills the tissues, and gives rise to another special type of pustule, also usually rust-red in colour, which is called the aecidium. The aecidium pustules contain spores, known as aecidiospores, which are incapable of infecting plant $\mathbf{B}$, but infect plant $\mathbf{A}$ by sending their germtubes through the stomata of the epidermis.

The mycelium on plant B generally produces, in addition to aecidia, other pustules, known as spermogonia (or pycnidia), which bear minute spore-like bodies, which are generally 
considered to be vestigial male cells (spermatia) though by some authors they are thought to be conidia or spores (pycnopores). They have never been known to germinate, and in any case they are now functionless.

This very brief description of the life-history of a heteroecious rust is only intended to assist those unacquainted with the group to follow the account of the two rusts which infect the larch. A more comprehensive account will be found in any botanical text-book or in Grove (1913).

Melampsoridium betulinum, Kleb. (=Peridermium laricis). Aș the heteroecious rusts have frequently been known as different fungi on their two hosts, they have commonly been designated by two names. For instance, Peridermium laricis is an aecidial form which is found on larch needles. The uredo- and teleuto-form which occurs on the birch has also been called Melampsoridium betulinum (or formerly Melampsora betulina, Desm.). As it is cumbrous to keep two different names for one fungus, it has become the accepted practice to designate a rust whose complete life-history is known by the name applied to the uredo-form. Consequently the name Peridermium laricis, by which this rust is most generally known to foresters, has to give place to Melampsoridium betulinum.

Fig. 72 shows the general appearance of this rust on the larch. The aecidia are very conspicuous by reason of the large white sheath which surrounds each pustule. This sheath, which is called a peridium, is one cell in thickness, and is shown enlarged in fig. 72, 4, and fig. 72, 7 shows the arrangement of the cells of the peridium when a portion of it is placed flat on a slide under the microscope. The

\section{Description of Fig. 72.}

-1. Photograph of twig of Larix Europea with diseased leaves: (a) pseudoperidium with lacerate margin; (b) unopened pseudoperidium $(\times 4)$.

2. Photogrnph of twig of ditto, with fused pseudoperidia $(\times 4)$.

3. Photograph of twigs of ditto (about natural size).

4. A pseudoperidium showing lacerate margin $(\times$ about 50$)$.

5. Spore in surface view $(\times 1000)$.

6. Spore in optical median section $(\times 1000)$.

7. Part of pseudoperidium; the lower cells show the verrucose marking on the walls $(\times 220)$.

(After A. W. Borthwick and Malcolm Wilson.) 
peridium is white, but the yellow or orange spores show through it and impart a dull yellow colour. When ruptured the peridium has a lacerated margin. The aecidia are very like those of Peridermium pini acicola (or, as it is now called, Coleosporium Senecionis, Fr.) on the needles of Scots pine, which being more common is far better known. The aecidiospores borne on the larch are orange-yellow, 14-21 $\times 11-16 \mu$, and rather irregular in shape (fig. 72). The spore wall is finely verrucose, except on a small area which is smooth, and is rather thick (fig. 72,5 and 6). The spores are borne in chains from the base of the aecidium. The aecidiospores are incapable of infecting another larch needle, but infect the leaves of the birch (Betula verrucosa and B. pubescens). The mycelium to which they give rise bears uredosori and teleutosori on the under-surface of the leaf, and causes yellow discoloration on the upper side. As this is the only rust known in this country on the birch, its identification is not difficult. The uredosori differ from those of Melampsora by being covered when young by a layer of fungal cells, which expand into a kind of peridium when the sorus is ruptured. The uredospores are abstricted singly. and, carried away by the wind, infect more birch leaves. The teleutospores are produced late in the season, and are borne in a single layer under the epidermis of the birch leaf. They pass the winter on the ground and in the spring give rise to promycelia, which bear sporidia. These are ready to attack the larch needles as soon as they open.

The identity of the forms on the larch and the birch was first demonstrated in 1890 by Plowright, who obtained cross infections from an infected larch, which he found at King's Lynn, to the birch and vice versa. It has been subsequently noted near Oxford by Jones (1911), and was identified by Borthwick and Wilson (1913) in specimens from Fersit in Inverness-shire. As the rust on birch is common nearly everywhere, it is remarkable that the form on the larch is not more frequent, but.it is probably often overlooked.

The damage caused by this fungus is very slight. It is fortunate for the larch-grower that his crop is attacked, not 
by the uredo-stage, which can spread from leaf to leaf throughout the summer, but by the aecidial stage, which cannot spread by itself. Some sporidia will blow up from the ground and infect a few larch needles, and these needles, which bear spores as early as three weeks after expanding, soon wither and die. But that is the end of it as far as the larch is concerned. Once the aecidiospores have attacked the birch, the fungus can spread from birch to birch as long as the summer lasts, and no limit is set to its distribution. Probably this is the reason why the fungus is found so much more commonly on the birch than on the larch. The disease on the larch is only serious when seedlings are attacked. Massee (1903) reports a case where rows of larch seedlings were severely damaged by this rust. The owner, believing in mixed planting as a panacea for plant diseases, put in rows of birch seedlings between the larch, with the result that any one familiar with the life-history of the fungus would have anticipated. Of course birch is the worst conceivable tree to bring into the neighbourhood of this rust, and where the disease is troublesome in a nursery it is advisable to destroy the birch as far as possible in the immediate vicinity. As the mycelium spreads entirely inside the leaf and not on the surface, spraying can only be effective if the mixture is on the leaf at the time of infection, so as to prevent the germination of the sporidia. This requires such thorough and constant application to be successful that it is outside the scope of practical sylviculture.

Melampsora tremulae, Tul, \&c. (=Coeoma laricis). Coeoma is another aecidial form which closely. resembles Peridermium, except that it possesses no peridium, and is consequently far less conspicuous. The small red spots or cracks which it produces in the epidermis of larch needles and cotyledons are no doubt often overlooked. The uredostage is borne on species of willow and poplar, and four distinct species, as well as many sub-species, are recognized in the uredo- and teleuto-forms, though there are no features by which these species can be distinguished in the coeoma 1888 
or aecidial stage. The following account is chiefly taken from the work of Klebahn, who has made a very special study of the genus Melampsora, and in nearly every case he has been the first to determine the identity of the coeoma with specifically distinct uredo-forms. The identification of the different species is often difficult, even in the uredostage, and a large number of biological races have arisen. Thus species which have their uredo-stage on Salix Caprea may have their aecidial stage on larch or spindle-tree, and those with uredo-stage on aspen may have their aecidial stage on larch, Scots pine, or dog's mercury. For the features by which these species may be distinguished, the reader is referred to Klebahn (1904) or Grove (1913), and only points of biological interest are mentioned here.

Melampsora Larici-Caprearum, Kleb. Uredo-and teleutosori on Salix Caprea, less frequently on Salix aurita and other species.

Melampsora Larici-epitea, Kleb. Uredo- and teleuto-sori on many species of Salix. There appear to be many biological races of this species, all with their coeomata on the larch, but with uredo-stage on different willows. These races are indistinguishable morphologically, and it is only by infecting the larch with the rust obtained from a particular species of willow and then reinfecting various species of willow that their validity can be determined. For instance, it is found that the rust of this species taken from Salix Caprea will, after its generation on the larch, infect $S$. fragilis or $S$. viminalis, but not $S$. purpurea, while the race which grows on $S$. purpurea will not infect the other species.

Melampsora Larici-populina, Kleb. Uredo- and teleutosori on Populus balsamifera, $P$. canadensis, $P$. nigra, and $P$. pyramidalis (italica). The association of this species with the coeoma on the larch was first demonstrated by Hartig in 1889.

Melampsora Larici-tremulae, Kleb. Uredo- and teleutosori on Populus alba, $P$. tremula, and rarely $P$. balsamifera .

The aecidial stage of all these species grows on the larch, and produces what is described as Coeoma laricis. On the 
willows and poplars the rust is generally very conspicuous. Microscopically members of the genus are distinguished by the large club-shaped paraphyses which grow among the uredospores. The uredosorus has no peridium such as is found in Melampsoridium.

Like Melampsoridium, Melampsora causes very little damage to the larch, except where it becomes epidemic in a nursery (see W. G. Smith, 1886). When found it will be difficult to identify, and if the disease is sufficiently harmful to justify special measures, it will be well, as far as possible, to remove poplars and willows from the neighbourhood of the nursery.

The damping-off of larch seedlings. There are two known fungi which cause the damping-oft of larch seedlings. It is not easy to distinguish between the two diseases with the unaided eye, but the conidiophores which grow from the diseased portions are readily identified under the microscope. Fig. 73 shows the conidia of the two species side by side.

Phytophthora omnivora, de Bary (=Ph. fagi, R. Hartig), attacks the seedlings of all conifers and of the beech. It is very closely allied to Phytophthora infestans, the fungus that causes the best known potato disease. The life-history of the fungus is somewhat complex, and will only be briefly described. The conidia shown in fig. 73, $\mathrm{A}$, are borne on conidiophores which either grow through the stomata of attacked portions of the seedling or break through the epidermal wall and cuticle. The conidia fall on to the ground and, instead of germinating in the usual way, the contents divide up into a number of parts, each of which becomes a swarm-cell, which escapes and swims about in the films of water contained in the soil. For a cell which produces these swarm-cells the word 'conidium' is a misnomer, and the term sporangium is generally used, and will be employed below. As the swarm-spore is known to botanists as a zoospore or zooconidium, the sporangium is also called a zoosporangium or zooconidangium. If a swarm-spore, while swimming about, comes into contact 
with a suitable seedling, it settles down and germinates with a germ tube which forces its way into the seedling at some point where two epidermal cells touch each other. The germt ube then branches and quickly forms a mycelium which may spread through a considerable part of the host. Sporangiophores and sporangia are produced in a few days

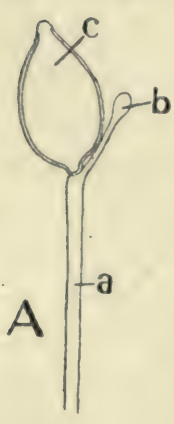

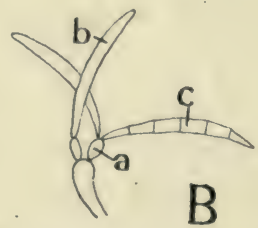

Fic. 73.-A, Sporangiophore of Phytophthora omnivora: $a$, stalk ; $b$, young sporangium; $c$, sporangium ready to fall. B, Conidiophore of Fusoma parasiticum: $a$, short hyphae bearing conidia: $b$, young, unseptate conidium; $c$, mature, septate conidium. and new cycle is commenced. In this way the disease may spread very quickly and whole seed-beds may be completely exterminated in a very short time.

The fungus has a special means of perennation, i. e. living over the winter. Certain hyphae inside the seedling. become swollen at the ends and form female organs. Other hyphae by the side of these become converted into male organs. A fusion takes place, and a large spore, called the oospore, is formed inside the female organ. This oospore puts on a very thick wall, and contains sufficient food material to live through the winter. In the spring it divides up into a number of swarm-spores like those which are set free from the sporangium.

Attacked seedlings show dark patches, especially near the surface of the ground, and quickly collapse. Remedial measures will be considered after the other damping-off fungus has been described.

Fusoma parasiticum, Tub., also attacks the seedlings of nearly all species of conifers. Like the last fungus, it causes dark patches and the collapse of the seedlings. In damp weather a greyish mycelium appears on the outside of attacked parts, and this mycelium bears slightly curved septate conidia (fig. 73, B). These are genuine conidia, and 
germinate directly by means of germ-tubes which infect healthy seedlings.

An excess of moisture is conducive to both these diseases. Consequently good drainage is the most important inhibiting factor. When seed-beds are attacked it is advisable to allow the free play of air currents over the beds and to remove any obstructing objects. Spaulding (1908) has. carried out trials with various powders and sprays. The most satisfactory powder was either $(a)$ a finely powdered sulphur (that known as ' washed sulphur' is apparently the best), or (b) a mixture of powdered sulphate of copper (one part) and slowly slaked, very finely powdered lime (ten parts), the two being very thoroughly mixed together. The powders should be applied three or four days after the seedlings have come up, and from then onwards, after each shower, for about two weeks. A weak solution of sulphuric acid ( $1 \mathrm{oz}$. to 1 gallon of water) was found to be the most efficient spray. This solution may be applied with an ordinary sprinkling-can before the seeds are sown. 


\section{CHAPTER $\mathrm{X}$}

\section{GENERAL SUMMARY}

Whetzen in his History of Phytopathology (1918) says that ' modern pathologists may be divided, for the most part, into two philosophic schools, the pathogenetists and the predispositionists'. Most of us object to being labelled, and, for our part, we do not call ourselves either pathogenetist or predispositionist. Nevertheless the terms have their value. Every disease described in this book is caused by some specific fungus, and this fungus is considered as the primary factor in the etiology of the disease. With some of the diseases secondary factors have also to be taken into account, such as sylvicultural conditions, which make for the good or bad health of the tree as a whole. The pathogenetist emphasizes the primary factors, the predispositionist the secondary factors. But whether we are to be one or the other depends entirely on the disease which we are considering. The general health or tone of the tree plays no part in the incidence of diseases caused by the rusts described in the last chapter. If sporidia of a suitable species of Melampsora or Melampsoridium blow on to leaves of larch under suitable conditions for germination, infection is almost certain, however healthy or unhealthy the larch may be. The canker fungus, on the other hand, is largely dependent on finding trees which are not growing with full vigour. This fungus is always with us on the dead branches of healthy trees as much as on those of unhealthy trees. Whether or no it is to become parasitic depends on its opportunities for infection, and this is chiefly determined by the vigour of the trees. With the rust diseases, then, we are pathogenetist; with the canker, predispositionist. With most other diseases we are somewhere betwixt and between. 
The bulky literature of the larch canker is almost entirely the product of predispositionists. About ten papers or notes have been published in English on larch canker for every one on heart-rot or the honey fungus, though the latter diseases are very nearly as destructive as canker, and the honey fungus, when the catholicity of its taste in forest trees is taken into account, is probably by far the most destructive of all forest pests. The explanation of this anomaly appears to be that many foresters will dilate on the general sylvicultural conditions which make for the health or sickness of a tree, whereas few are prepared to discuss the more directly pathological factors which control attack by a fungus which is just as prepared to parasitize healthy trees as sickly ones. We will follow this bent and consider first the general sylvicultural requirements of the tree.

In the literature of larch culture with relation to canker, great stress has been laid on the alpine habit of the tree, which is repeatedly dragged in to explain failures of cultivation at lower elevations. Cieslar (1904), in a reasoned paper, shows that too much importance has been attached to this feature. In the Alps the present natural distribution of the tree is confined to high altitudes, but in Silesia it comes down to 1,000 ft., and near Sokol it grows naturally and healthily, with silver fir, oak, \&c., at an altitude of 600 to $800 \mathrm{ft}$. Probably in the lowlands between the Carpathians and Russian Poland the larch has only been destroyed by cultivation, and in earlier days the alpine nature of its distribution may have been much less clearly marked. There are, also, many lowland places where cultivated larch grows extremely well, and in many parts of its natural home canker is very prevalent.

Be this as it may, the larch has certain alpine characteristics which must be taken into account in cultivation. Chief of these are its faculty for bearing extreme cold in the winter and its susceptibility to spring frosts. Alpine plants have to contend with a short growing season and waste no time in getting about summer work as soon as the snows melt. On this account the bursting of the buds is generally 
precocious in our climate, and late frosts take their toll of the young needles. South slopes of hills encourage early sprouting more than north slopes, but south slopes are not so injurious to the larch as frost hollows in which young larch often die outright as the result of late frosts. Next, the larch is extremely sensitive to shade, and whether we regard this as an alpine characteristic or not, it is the feature which more than any other determines its sylvicultural treatment. Where grown pure the larch must be early and thoroughly thinned, and it is best to underplant it with shade bearers. When grown in mixture the other trees should be so chosen as to allow plenty of space for the larch crowns, and they should be soil-improving species, to compensate for the larch's deficiency in this respect.

The soil requirements of the larch are more physical than chemical, and good aeration is the most important consideration. The soil in which it is to be grown should have :

(i) A deep, porous subsoil.

(ii) A surface that does not cake, but allows at all times a free interchange of gases.

(i) Unlike the spruce the larch has a tap-root, which, under favourable conditions, remains alive and penetrates the subsoil to a considerable depth. In addition to this, lateral roots send down 'anchor' roots, which not only fix the tree firmly in the ground, but maintain the requisite water-supply during a dry period. If the subsoil is hard or lacking in porosity these roots penetrate for a short distance, but then languish and die, and, besides adversely affecting the general health of the trees, allow the entrance of the chief heart-rotting fungus, Fomes annosus. Tree growth is the chief agency in promoting subsoil porosity, and in old oak woods or beech woods little difficulty should be experienced in this respect. The subsoil of agricultural land, however, is nearly always inferior, and, where possible, larch should be avoided as a first rotation on such land. The roots of most coniferous crops suffer in the first rotation on agricultural land, and in Germany special commissions 
have been appointed to inquire into the causes of root failure under such circumstances. The lupin has been found to have a beneficial effect on soil about to be afforested, and still better results have been obtained with the false acacia planted in alternate lines with conifers. This tree is unsuitable for mixing with larch, as it does little to improve the soil surface, but it mixes well with any of the shadegiving pines, such as Scots, Corsican, or cluster (maritime) pine. The false acacia is not a popular tree in British forestry, as it does not mature well here, but it apparently does its work on the subsoil quickly, and it may be thinned. out as soon as it fails to maintain its vigour. Besides improving the soil physically, the false acacia adds to the nitrogen content of the soil through the agency of the bacteria, which cause nodules to develop in its roots.

These comments all tend to show that larch is not suitable for a first rotation on agricultural land. Where, however, it is grown it should be sparingly mixed with other trees which improve the subsoil, and if the intermixture of three different species is not objected to, it would be as well to mix the tree with Scots pine and false acacia, by which means it is possible that an ultimate crop of healthy larch might be obtained.

(ii) Trees which are enumerated in the text-books under the heading of soil improvers are mostly those which keep the soil surface in good condition by producing a mass of leaves which rot slowly on the soil and maintain a layer of porous humus. The chemical composition of the humus is not particularly favourable to trees, as is shown by the poor natural regeneration which occurs where deep humus is present; but it remains open and porous in the sunniest weather, and besides allowing free access of oxygen to the soil below, in which the roots grow, prevents excessive loss of moisture through evaporation. These soil-improving trees also keep out the sunlight which stimulates the quick decomposition of the humus, and prevent the growth of weeds which mat the upper soil layers, and may have, as well, a toxic effect on tree roots. 
The soil improvement considered under (i) may be compared with deep and thorough digging in the garden, whereas (ii) has its horticultural parallel in surface hoeing, which removes weeds and prevents the caking of the top layer. Formerly the continental literature which dealt with the sylvicultural aspect of soils has given great prominence to the maintenance of a good surface, and it is only recently that the subsoil has received the attention which it deserves. Beech, which has been planted so enthusiastically in Germany as a soil improver, is chiefly good for the surface, but it is a moderately deep rooter, and no doubt assists in opening the subsoil to some extent.

If the chief trouble in planting agricultural land is the preparation of the subsoil, in the afforestation of heaths the first difficulty is the soil surface. The layer of peat which commonly collects on the surface of heather or heath moor is all but impenetrable to gases in any form, and the death of roots which is frequently observed in the first rotation on moors is probably chiefly due to this cause. The special treatment required in planting heaths is a subject outside the scope of the present book, but the susceptibility of larch to poor soil aeration makes the tree an unsuitable crop for planting where the layer of peat is sufficient to prevent a free circulation of gases. For such country Scots pine is probably the best crop, and the good results reported from Norway by Schotte (1917), which have been obtained with a mixture of larch and Scots pine, may be largely due to the improving influence exerted by the latter on heather peat.

In the north of England larch is often mixed with spruce. This mixture is in keeping with the principle of growing a light demander with a shade bearer, but otherwise has little to recommend it. Spruce does little to improve the soil surface, and being a surface rooter does not work the subsoil. Consequently, the larch gains next to nothing from the mixture. The encouragement which spruce gives to the larch aphis and the needle-cast fungus (see p. 170) renders the mixture undesirable. 
Some soils are unsuitable for tree growth owing to the presence of a pan or hard stony layer, which sometimes forms in sandy soils. When a pan is near the surface it has to be broken through, in planting, to allow free development for the roots. When at a depth of 12 in. or more it may not be discovered during planting operations, but it is none the less detrimental to tree growth, as it interferes with the normal flow of water. In wet weather it allows water to stagnate round the tree roots, and in times of drought it prevents water rising by capillary attraction from the lower levels where moisture is still present. One of the worst cases of canker that I have met with can only be adequately explained by the trees being weakened through shortage of water caused by such a pan in dry weather.

It has been found that the correct choice of site, soil, and mixture does much to restrict attack by the canker fungus. This is not because under these circumstances the canker fungus is less common, for, wherever larch is grown, it is present on the dead branches in sufficient profusion to infect all the trees. It is the direct outcome of the greater vigour of the trees. The larch normally protects itself against the canker, first by its original layer of cork, which covers the whole tree and extends across the phloem and cortex of newly dead branches, and, if the fungus has passed this, by new layers of cork which are put in to prevent its further penetration. If the tree is vigorous these layers are made quickly and made thick, so that the fungus has much more difficulty in reaching the cambium. By such means the tree throws off attacks and cankers are prevented; but if the trees are weakly, the fungus has things too much its own way, and has little difficulty in reaching the cambium and forming cankers.

It has been shown that the most frequent way in which the main stems of larch trees become infected with canker is by the fungus, which lives saprophytically on the branches, growing down, past the cork layers at the branch-bases, into the trunk. It is suggested that when larch woods are 
becoming severely attacked, pruning off the side branches during dry weather in the early months of the year (January to March) is calculated to prevent infection to a large extent. Fuller instructions for this pruning are given in Chapter IV. This treatment is necessarily expensive, and should be regarded as a last resort in woods which give sufficient promise to render it worth while. The side branches should be removed while still alive, but at an age when they would normally die through the shading by the crowns. If these cut branches are removed and burnt there will remain very little opportunity for the saprophytic development of the fungus, and fewer spores will be produced for reinfection. This treatment thus lessens the chance of canker in two ways: it prevents direct mycelial infection from the branches into the trunk, and it reduces the number of spores which might cause infection through wounds, aphis pricks, and the like. The latter reason for the restriction of canker is, however, relatively unimportant, since the fungus produces spores in such enormous quantities that neighbouring woods which have passed beyond the pruning age will provide sufficient spores for infection. The fungus is so widely distributed and so common that no hopes can be entertained of stamping it out.

The view of the predispositionist has been largely adopted in the consideration of larch canker. It so happens that as we recapitulate the larch diseases in the order in which they have been described in this book we are forced to take up more and more the attitude of the pathogenetist. Fomes annosus almost certainly enters trees largely through dead roots, and any treatment of the larch which discourages the death of roots will also discourage the fungus, so that remarks offered on the relation of larch to the soil in this chapter will be more especially applicable to this fungus. But it is also possible to combat the fungus by direct action, by searching woods thoroughly for fructifications and by destroying all diseased parts of trees. Such work can only be profitable in woods in which the fungus is as yet uncommon, and there are many such in the south of England. 
Where the Fomes has obtained a thorough hold, the only means by which it can be combated is by sylvicultural methods which improve the soil, especially the subsoil. Probably the same recommendations apply to Polyporus Schweinitzii, but so little is known about the pathology of this fungus that it would be unwise to dogmatize.

Polyporus sulphureus and Trametes Pini, which also cause heart-rot, begin near the top of the tree instead of at the roots. They enter chiefly through wounds left when large living branches are broken by the wind or other means, and the fungi are consequently most common in open places or near the edge of plantations. As soon as these diseases are discovered by the presence of fructifications the trees should be cut down and diseased portions, as well as the fructifications, burnt.

The honey fungus, Armillaria mellea, is probably the most destructive pest with which British forestry has to contend. It can kill all species of conifers and a great many broad-leaved trees as well, and in many woods it is so common that its eradication is wellnigh impossible. By means of spores the fungus attacks the dead stumps of trees, chiefly broad-leaved species such as oak and beech. On large stumps it may feed for a great number of years, and it sends rhizomorphs out into the soil, which grow into the roots of conifers, with which they come into contact, and in a few years kill the trees. From such conifers fresh rhizomorphs arise until the ground may become infested with the fungus and the pathologist comes to wonder, not why so many trees are killed, but why so many escape. Probably therhizomorphs are incapable of infecting a healthy, living root, and can only enter through wounds or dead roots, so that dead roots predispose the trees to attack, and thus far correct soil treatment may minimize the incidence of attack. But old trees must generally have some dead roots, and when the fungus is present a large percentage of deaths must be anticipated. Eradication of the fungus, though difficult, is well worth attempting where it is not very widespread. The means to be adopted have been described 
in Chapter VIII, and may be briefly summarized here. First, the forester should do all in his power to destroy old stumps. This may be achieved to some extent by cutting off the fructifications of fungi, other than parasitic species such as Armillaria or Fomes annosus, which he finds growing on stumps, and placing them, right way up, on stumps that are not yet rotted. It is found that a stump which is thoroughly penetrated by another fungus is not generally attacked by Armillaria, as many of the wood-rotting fungi are toxic to each other. This may be done at any time of the year when fructifications can be found. The next precaution is to make a careful search for the fructifications of the honey fungus during the autumn-from the end of September onwards. Spots where they are found should be marked for action during slack seasons; and, in particular, dead stumps, from which fructifications are growing, should be carefully noted. Action should be directed first against these stumps. If they are well rotted by the fungus it is often not difficult to break them up, when they may be removed in pieces and burned. Where it is found that the removal of a stump involves too much labour, a trench $1 \mathrm{ft}$. deep should be dug round it, so that the spread of rhizomorphs from it may be prevented and rhizomorphs outside the trench will be cut off from their chief source of food supply. Constant attention, however, is necessary to see that the trench is kept open as long as the fungus is growing on the stump. When a large number of stumps in close proximity are found to be attacked it may save time to dig a trench round the lot. When a living conifer or other tree is found to be attacked it should be either removed or surrounded by a trench. But it is often found that the affected tree is near a stump which is rotted by the fungus, and in this case the trench should surround the stump as well.

The fungus requires a certain intensity of light if it is to form fructifications. Consequently, in dark woods fructifications are seldom formed, even where the fungus is present, and in such woods infected regions may be overlooked during the autumnal survey. On this account 
special attention should be given to the survey of recently felled areas, as in such situations infected localities can be more exactly determined, and may be dealt with more successfully. Lastly, where fructifications are abundant, it is worth while to cut them down with a scythe or sickle, as once they are cut through they have little chance of spreading their spores.

About needle diseases the predispositionist can have little to say, since there is no reason to believe that the needles borne by robust trees are in any way less liable to attack than their weaker fellows. The only needle disease which need be seriously feared, outside the nursery, is the needle-cast, Sphaerella laricina, which may become epidemic, especially where larch is mixed with spruce or other evergreen. Where such mixed woods are attacked by this disease for many years in succession it is worth while to thin them out and to remove one or other species entirely. If it is decided to keep the larch, underplanting with beech is calculated still further to lessen the damage inflicted by the disease.

The fungi that attack nursery lines of larch are chiefly rusts and the damping-off fungi. Rusts may be prevented if it is possible to remove the alternative hosts. Damping-off should be met first of all by good cultivation of the soil, and secondly by spraying or powdering as recommended in the section on these pests.

The long list of diseases to which the larch is liable must produce a depressing effect, especially when set out in a single story, as in this book. Many of these diseases are . unimportant, and many are shared by other conifers which, in addition, present pathological difficulties unknown to the larch. None the less, the larch is more prone to disease than any other conifer commonly grown in British woods, and the advisability of planting other trees in the place of larch has been carefully considered by most foresters. The variety of trees introduced from Western America has added greatly to the list of species at the planter's disposal, and Douglas fir and Sitka spruce have already been widely 
employed in situations which would formerly have been occupied by larch. Both these trees are faster growing than the larch, and good returns may be expected from them on suitable soils; but with neither of them is there such a ready sale for thinnings of all ages as there is with the larch, so that the cost of planting is not so quickly repaid. Japanese larch and western larch are nearly, though not quite, immune from canker, and grow slightly faster than the common larch during their early years, ${ }^{\circ}$ and where grown in a short rotation they are safer and at least as remunerative as the common larch. For all this, the common larch will continue to be grown, and with reasonable care, that will be ungrudgingly bestowed by the lover of trees, as good larch may still be produced as any that have been raised in Britain. 


\section{BIBLIOGRAPHY}

Abdul Hafiz Khan (1910), Root Infection of Trametes Pini, (Bul.) Fr. Indian Forester, xxxvi, p. 559.

Anderson, A. P. (1902), Dasyscypha resinaria causing Canker Growth on Abies balsamea in Minnesota. Bull. of the Torrey Bot. Club, xxix, p. 23.

Anderson, R. (1891), The Canker of the Larch. Journ. R. Agric. Soc., London, 3rd ser., ii, p. 643.

Anon. (1908), Experimental Study of Larch Canker. Trans. Roy. Scot. Arb. Soc., xxi, p. 234.

Atholl, John, Duke of (1832), Account of the Larch Plantations on the Estates of Atholl and Dunkeld.

Atkinson, A. F. (1901), Studies of some Shade-tree and Timber-destroying Fungi. N.Y. (Cornell) Univ. Agric. Exp. Stat., Bull. No. 193.

Batsch, A. J. G. (1786), Elenchus Fungorum. Continuatio prima.

Baur, E. (1898), Zur Fıage nach der Sexualität der Collemaceen. Ber. d. Deutschen bot. Gesellsch., xvi, p. 363.

Beilstein, E. (1893), Handbuch der organischen Chemie. Dritte Auflage. Hamburg $\mathbf{u}$. Leipzig.

Berkeley, M. J. (1859), Gard. Chron., 1859, p. 1015.

Blackman, V. H. (1904), On Fertilization, Alternation of Generations, and General Cytology of the Uredineae. Ann. Bot., xviii, p. 323.

Blackman, V.H., and Welsford, E. J. (1916), Studies in the Physiology of -Parasitism. II. Infection of Botrytis cinerea. Ann. Bot., xxx, p. 389.

Boden, F. (1904), The Larch in German Forests. Trans. Roy. Scot. Arb. Soc., xvii, p. 47.

Booth, J. (1904), John, Duke of Atholl, his Larch Plantations (1774-1830) and the Larch Disease. Trans. Roy. Scot. Arb. Soc., xvii, p. 232.

Borthwick, A. W. (1909), Peziza Willkommii on Larix occidentalis (Nutt) and L. leptolepis. Notes from the Roy. Bot. Gard., Edinburgh, xxi, p. 23.

Borthwick, A. W., and Malcolm Wilson (1913), A New Disease on Larch in Scotland. Trans. Roy. Scot. Arb. Soc., xxvii, p. 192.

" The Canker of Scots Pine caused by Dasyscypha subtilissima (Cooke). Trans. Roy. Scot. Arb. Soc., xxix, p. 184.

Boudier, M. (1885), Bull. Soc. Myc., i, p. 117. , 
Brefeld, O. (1877), Botanische Untersuchungen über Schimmelpilze. III. Heft. Basidiomyceten I. Leipzig.

, (1889) Untersuchungen aus dem Gesammtgebiete der Mykologie. VIII. Heft. Basidiomyceten III. Leipzig.

, (1891), do. IX. u. X. Heft. Ascomyceten. Münster.

Brooks, F. T. (1908), Observations on the Biology of Botrytis cinerea. Ann. Bot., xxii, p. 479.

Brown, W. (1915), Studies in the Physiology of Parasitism. I. The Action of Botrytis cinerea. Ann. Bot., xxix, p. 313.

" (1917), Studies in the Physiology of Parasitism. IV. On the Distribution of Cytase in Cultures of Botrytis cinerea. Ann. Bot., xxxi, p. 489.

Buller, A. H. R. (1909), Researches on Fungi. An Account of the Production, Liberation, and Dispersion of the Spores of Hymenomycetes, treated botanically and physically. Longmans.

Burdon, E. R. (1908), Experimental Study of Larch Canker. Trans. Roy. Scot. Arb. Soc., xxi, p. 234.

Butler, E. J. (1903), A Deodar disease in Jaunsar. Indian Forester, Appendix Ser., Nov. 1903, p. 1.

Carruthers, J. B. (1891), The Canker of the Larch. Journ. R. Agric. Soc., London, 3rd Ser. ii, p. 299.

Caputh, L. (1896), The Larch Disease. Gard. Chron., 3rd, ser., xx, p. 93. Christman, A. H. (1905), Sexual Reproduction in the Rusts: Bot. Gaz., xxxix, p. 267.

Cieslar, A. (1896), Ueber das Auftreten des Hallimasch (Agaricus melleus) in Laubholzwaldungen. Centralbl. f. d. gesammte Forstwesen, xxii, p. 19.

, (1904) Waldbauliche Studien über die Lärche. Centralbl. f. d. gesammte Forstwesen, $\mathrm{xxx}, \mathrm{p} .1$.

Cooke, M. C. (1875), British Fungi. Grevillea, iii, p. 121.

, (1876), Observations on Peziza calycina. Grevillea, iv, p. 169.

Corda, A. C. J. (1837), Ioones Fungorum, v.

Coupar, R. (1884), On the Disease in Larch Plantations known as 'the Blister'. Trans. Roy. Scot. Arb. Soc., x, p. 119.

Cowan, J. M. (1915), Chrysomyxa Abietis. Quart. Journ. Forestry, ix, p. 325 .

Cross, C. F., and Bevan, E. J. (1905-10), Researches on Cellulose.

Darbishire, O. V. (1900). Ueber die Apothecienentwickelung der Flechte Physcia pulverulenta, (Schrb.) Nyl. Jahrb. f. wissenschaftl. Bot. xxxiv, p. 329.

de Bary, A. (1865). Neue Untersuchungen über die Uredineen, insbesondere die Entwickelung der Puccinia graminis und den Zusammen- 
hang derselben mit Aecidium Berberidis. Monatsher. d. kön. Preuss. Akad. der Wissensch. aus dem Jahre 1865, p. 15, Berlin, 1866.

de Bary, A. (1884), Comp. Anat. of the Vegetative Organs of the Phanerogams and Ferns. Engl. Trans. by F. O. Bower and D. H. Scott. Oxford.

, (1886), Ueber einige Sclerotien und Sclerotienkrankheiten. Bot. Zeit., 1886, p. 378, \&c.

, (1887), Comp. Morphology of the Fungi, Mycetozoa, and Bacteria. Engl. Trans. by H. E. F. Garnsey. Oxford.

de Vries, H. (1876), Ueber Wundholz. Flora (N.R.), xxxiv, p. 2.

Elwes, H. J., and Henry, A. (1907), The Trees of Great Britain and Ireland, vol. ii.

Forbes, A. C. (1896), Our Timber Trees. Gard. Chron., 3rd ser., xix, p. 167.

", (1902), Recent Experiments on the Larch Disease. Gard. Chron.,

3rd ser., xxxii, p. 352.

(1904), English Estate Forestry. London.

Fries, E. M. (1822), Systema Mycologicum, Vol. II.

, - (1828), Elenchus Fungorum.

Frömbling (1902), Ein Beitrag zur Lärchenfrage. Zeitschr. f. Forst- und Jagdwesen, xxxiv, p. 279.

Fuckel, L. (1869), Symbolae Mycologicae. Beiträge zur Kenntniss der rheinischen Pilze. Jahr. d. Nassauischen Ver. f. Naturk., xxiii.

Galloway, B. T., and Woods, A. F. (1896), Diseases of Shade and Ornamental Trees. Yearbook of the Dept. of Agr., U.S., p. 237.

Gardeners' Chronicle, Controversy on Larch Canker in (1896), 3rd ser., xix, A. C. Forbes, pp. 167, 361 ; J. S. W., pp. 243, 335, 398, 466, 528; Sir C. W. Strickland, pp. 304, 528 ; A. D. Webster, p. 368 ; C. Y. Mitchie, pp. 434, 494, 560 ; L. Caputh, xx, p. 93.

Gillet, C. C. (1879), Les Discomycètes. (Champignons de France.)

Grove, W. B. (1913). The British Rust Fungi. Cambridge.

Hall, A. D. (1901), The Soil. London.

Harper, A. G. (1913), Defoliation : its Effects upon the Growth and Structure of the Wood of Larix. Ann. Bot., xxvii, p. 621.

Hartig, R. (1870), Zur Lärchenkrankheit. Zeitschr. f. Forst- u. Jagdwesen, ii, p. 356 .

, (1874), Wichtige Krankheiten der Waldbäume. Berlin.

, (1878), Zersetzungserscheinungen des Holzes. Berlin.

, - (1880), Die Lärchenkrankheiten, insbesondere der Lärchenkrebs-

pilz. Untersuch. aus d. Forstbotan. Inst. zu München.

(1885), Bot. Centralblatt, xxxviii, p. 32.

", (1889), Zur Kenntnis von Trametes radiciperda. Zeitschr. f. Forst-

u. Jagdwesen, Juli, 1889. 
Hartig, R. (1892), Das Erkranken und das Absterben der Fichte nach der Entnadelung durch die Nonne (Liparis monacha). Forstl.naturw. Zeitschr. i, p. 56.

„ (1894), Diseases of Trees. Engl. transl. by W. Somerville and H. Marshall Ward. London.

„ (1894), Die Ausschlagfähigkeit der Eichenstöcke und deren Infection durch Agaricus melleus. Forstl.-naturw. Zeitschr., iii, ‘ p. 428.

, (1895), Der Nadelschüttepilz der Lärche, Sphaerella laricina n. sp. Forstl.-naturw. Zeitschr., iv, p. 445.

„ (1899), Die Lärchennadelbräune, erzeugt durch Allescheria laricis n. sp. Centralbl. f. d. gesammte Forstwesen, xxv, p. 423.

„ (1901), Agaricus melleus, ein echter Parasit des Ahorn. Centralbl. f. d. gesammte Forstwesen, xxvii, p. 193.

Hedwig, D. J. (1789), "Muscorum Frondosorum ", ii. Leipzig.

Hey (1914), Zeitschr. f. Forst- u. Jagdwesen, p. 595.

Hiley, W. E. (1915), On the Mode of Infection of Larch Canker and the Possible Means of preventing it. Quart. Journ. Forestry, ix, p. 7.

" (1917), Chrysomyxa Abietis. Quart. Journ. Forestry, xi, p. 191.

Hill, A. W. (1901), The Histology of the Sieve-tubes of Pinus. Ann. Bot., $\mathrm{xv}, \mathrm{p.} 575$.

Hoffmann, (1868), Forst- u. Jagdzeitung.

Hopkinson, A. D. (1913), The Occurrence of Larch Canker (Dasyscypha Willkommii) on Corsican Pine. Quart. Journ. Forestry, vii, p. 287.

Horne, W. T. (1912), Mo. Bul. Corn. Hort. Col., i, p. 216.

, (1914), do., iii, p. 275.

Hornemann, J. W. (1839), Icones Plantarum Florae Danicae.

Jones, W. S. (1911), Melampsoridium betulinum. Quart. Journ. Forestry, v, p. 137.

Kissling, E. (1889), Zur Biologie der Botrylis cineren. Hedwigia, xxviii, p. 227.

Klebahn, H. (1904), Die Wirtswechselden Rostpilze. Berlin.

Küster, E. (1903), Pathologische Pflanzenanatomie. Jena.

Laslett, T., and Marshall Ward, H. (1894), Timber and Timber Trees. London.

Leslie, P. (1915), The Planting of the Sand Dunes at Culbin. Trans. Roy. Scot. Arb. Soc., xxix, p. 19.

Lind, J. (1913), Danish Fungi, as represented in the Herbarium of E. Rostrup. Copenhagen.

Lindau, G., et Sydow, P. (1908-15), Thesaurus litt. mycologicae et lichenologicae. Leipzig. 
Lindemann, C.(1882), Tomicus typographus und Agaricus melleus als Verbündete im Kampfe mit der Fichte. Bull. Soc. Imp. Natur. Moscou, lvii, pt. 2, p. 189.

Long, W. H. (1914), U.S. Dept. of Agric., Bul. 89, p. 9.

Loudon, J. C. (1838), Arboretum et Fructicetum Britannicum. London.

McAlpine, D. (1895), Systematic Arrangement of Australian Fungi. Melbourne.

MacIntosh, C. (1860), The Larch Disease and the Present Condition of Larch Plantations in Great Britain. London.

Marshall Ward, H. (1889), Timber and some of its Diseases. London.

Massee, G. (1892-95), British Fungous Flora. London.

" (1902), Larch and Spruce Fir Canker. Journ. Bd. Agric., London, ix, p. 176.

, (1903), Diseases of Seedling Conifers. Gard. Chron., 3rd ser., xxiv, p. 347.

Masters, M. T. (1891), Larch Canker. Gard. Chron., 3rd ser., x, p. 160.

Mathes, - (1911), Mitteilungen über Bau und Leben der Fichtenwurzeln und Untersuchungen über die Beeinflussung des Wurzelwachstums durch wirtschaftliche Einwirkungen. Allg. Forst- u. Jagdzeitung, 1911 , p. 1.

Mayes, W. (1905), Note on the Occurrence of a Parasitic Fungus on Pinus excelsa. Indian Forester, xxxi, p. 369.

Mer, Émile (1895), Une nouvelle maladie des feuilles de Mélèze. Comptes Rendus, cxxi, p. 964.

Mitchie, C. Y. (1885), The Larch. Edin burgh and Iondon.

Münch, E. (1909), Untersuchungen über Immunität und Krankheitsempfänglichkeit der Holzpflanzen. Naturwiss. Zeitschr. f. Forst- u. Landwirtschaft, vii, p. 129.

Murray, J. M. (1916), Polyporus Schweinitzii, Fr. Trans. Roy. Scot. Arb. Soc., $\mathrm{xxx}$, p. 56.

Neger, F. W. (1909), Beobachtungen und Erfahrungen über Krankheiten einiger Gehölzsamen. Tharandter forstl. Jahrb., lx, p. 222.

Neumann, J. J. (1914), The Polyporaceae of Wisconsin. Wisconsin Gieol. and Nat. Hist. Survey, Bul. No. 33.

Nisbet, J. (1907), Notes on 'The Novar System of Combating Larch Disease'. Trans. Roy. Scot. Arb. Soc., xx, p. 39.

Pammel, L. H. (1911). Proc. Iowa Acad. Sci., xviii, p. 25.

Patouillard, N. (1883), Tabulae Analyticae Fungorum.

Phillips, W. (1887), British Discomycetes. London.

Plowright, C. B. (1891), Einige Impfversuche mit Rostpilzen. Zeitschr. f. Pflanzenkrankheiten, i, p. 130.

Quélet, L. (1886), Enchiridion Fungorum. 
Rehm, H. (1876), Note on Peziza calycina (Schum.). Grevillea, iv, p. 169. „. . (1896), Ascomyceten, in Rabenhorst's 'Die Pilze Deutschlands, Oesterreichs und der Schweiz'. Leipzig.

Reuter, E. (1909), Schädlinge an Waldbäumen in Norwegen. Zeitschr. f. Pflanzenkrankheiten, xix, p. 330.

Ribbentrop, B. (1908), Root Disease in Scots Pine on Farm Lands due to Polyporus annosus or Allied Species. Trans. Roy. Scot. Arb. Soc., xxi, p. 143.

Richardson, A. D., Borthwick, A. W., and Mackenzie, D. F. (1905), Larch

$\therefore$ Disease Enquiry, Report of Sub-committee. Trans. Roy. Scot. Arb. Soc., xviii, p. 213.

Richardson, A. D. (1909), The Ardross Working Plan and Larch Canker. Trans. Roy. Scot. Arb. Soc., xxii, p. 64.

Rumbold, C. (1908), Beiträge zur Kenntnis der Biologie holzzerstörender Pilze. Naturw. Zeitschr. f. Forst- u. Landwirtschaft, vi, p. 81.

Saccardo, P. A. (1889), Sylloge Fungorum, viii.

Schotte, G. (1917), Lürken och dess betydelse för svensk skogshushållning. Stockholm.

Schrenk, H. von (1900), Fungous Diseases of Forest Trees. U.S. Dept. of Agric. Year Book, 1900, p. 198.

" (1900), Some Diseases of New England Conifers. A Preliminary Report. U.S. Dept. of Agric., Div. of Veg. Physiol. and Pathol., Bull. 25.

Schrenk, H. von, and Spaulding, P. (1909), Diseases of Deciduous Forest Trees. U.S. Dept. of Agric., Bur. of Plant Industry, Bull. 149.

Schumacher, C. F. (1803), Linumeratio Plantarum in partibus Sacllandiace septen trionalis et orientalis, ii.

Simpson, J. (1902), The Disease of the Larch (Larix). Ciard. Chron., 3rd ser., xxxi, pp. 238 and 256.

Smith, R. E. (1902), The Parasitism of Botrytis cinereu. Bot. (iaz., xxxiii. Smith, W. G. (1886), Disease of Larch and Pine Seedlings. Ciard. Chron., N.S., xxvi, p. 18.

Solla, R. F. (1891), Rückschau über die hauptsïchlichen in Italien innerhall, der ersten Hälfte 1891 aufgetretenen P'Alanzenkrankheiten. Zeitschr. f. Pflanzenkrankheiten, i, p. 221.

„ (1912), Pflanzenkrankheiten in Piemont. Zeitsehr. f. Pflunzenkrankheiten, xxii, p. 153.

Somerville, W. (1895), Report of an Enquiry conducted by the Society into the Disease of the Larch. Trans. Eng. Arb. Soc. ii.

" (1898), Report by. Trans. Roy. Scot. Arb. Soc. xv, p. 190.

" (1906), The Novar System of Combating Larch Disease. Journ.

Bd. Agric., London; xii, p. 722.

" (1911), Spruce Leaf Rust. Quart. Journ. Forestry, v, p. 277. 
Somerville, W. (1915), Chrysomyxa Abietis. Quart. Journ. Forestry, ix, p. 253.

" (1917), Chrysomyxa Abietis. Quart. Journ. Forestry, xi, p. 63.

Sowerby, J. (1803), Coloured Figures of English Fungi or Mushrooms, iii, London.

Spaulding, P. (1908), The Treatment of Damping-off in Coniferous Seedlings. U.S. Dept. of Agric., Bur. of Plant Industry, Lab. of Forest Pathology, iv, p. 1.

Stevens, F. L. (1913), The Fungi which cause Plant Disease. New York.

Stirling-Maxwell, Sir John (1914), Mode of Infection of Larch Canker. Trans. Roy. Scot. Arb. Soc., xix, p. 131.

Temme (1885), Ueber Schutz- und Kernholz, seine Bildung und seine physiologische Bedeutung. Landw. Jahrbücher, xiv.

Tubeuf, K. von (1895), Hypodermella laricis. Bot. Centralbl., lxi, p. 48. " (1897), Diseases of Plants. Engl. Ed. by W. G. Smith. London. Tuzson, J. (1901), Ueber die Botrytis-Krankheit junger Nadelholzpflanzen (Botrytis cineren, Pers.). Zeitschr. f. Pflanzenkrankheiten, xi, p. 95.

Vöchting, H. (1892), Über'Transplantation am Pflanzenkörper. Tübingen. Vuillemin, P. (1896), Les Hypostomacées, nouvelle famille de Champignon* parasites. Comptes Rendus, cxxii, p. 543.

Wagncr, G.H. (1899), Beiträgezur Kenn tnis der Pflanzen parasiten. Zeitschr. f. Pflanzenkrankheiten, ix, p. 80.

Wettstein, R. von (1887). Ueber Helotium Willkommii (Hart.) und einige ihm nahe stehende Helotium-Arten. Bot. Centralbl., xxxi, p. 285.

" (1888), Zur Verbreitung des Lärchenkrebspilzes Helolium Willkommii (Hart.). Hedwigia, xxvii, p. 94.

" (1888), Notiz betreffend die Verbreitung der Lärchenkrankheiten. Bot. Centralbl., xxxvi, p. 345.

Whetzel, H. H. (1918), An Outline of the History of Phytopathology. Philadelphia.

Willdenow, C. L. (1787), Florac Berolinensis Prodromus.

Willkomm, M, (1867), Der Rindenkrebs der Lürche oder die Lärchenkrankheit. Microscopische Feinde des Waldes. Dresden.

Zederbauer, E. (1906), Fichtenkrebs. Centralbl. f. d. gesammte Forstwesen, xxvii, p. $]$. 


\section{INDEX}

\section{(* Signifies reference to figures.)}

Abies balsamea, canker on, 26

abnormal wood in larch canker, 31, $32 *$

abscission layer, 10

acacia, false, improvement of soil, 185

aecidiospore, 174

aecidium, 175

aeration of soil, 184-5

Fomes annosus and, 119-121

Al'escheria laricis, 172

Alps, larch canker in, 65, 183

amphitheatre, canker compared with, 20

anchor roots, 184

in relation to Fomes annosus, 117

Anderson, A. P., on Dasyscypha, 26, 39

annular rot caused by Fomes annosus, 99

annulus, 145

Antennaria pithyophila, 25

aphis (see Chermes)

apothecia, of $D$. calycina, 37, 38* ; of Hypodermella laricis, 172

Armillaria mellea, 144-67, 189

basidia, $149,150^{*}$; black line in wood, 155*, 157*; decomposition of wood, 154, 155*, 157*; effects on host, 153-8; ejection of spores, 149, 150; fructification of, 145,149 ; infection by spores, 160 ; infection by rhizomorphs, 161 ; means of prevention, 163, 189 ; method of infection, 159 ; paraphyses, 149, 150*; resinflow, 158; rhizomorphs, 146, 1503 ; species attacked by, 147 ; treatment, 163, 189-91

artificial infections, Armillaria mel. lea, 162; Dasyscypha calycina, 49 ; Fomes annosus, 111

ascus, of Dasyscypha, 38, 40*; Hypodermella, 172; Sphaerella, 170

Alhol, frigate, 1

Atholl, larch at, 1; Duke of, 1, 19
Atkinson, A. F., on Polyporus sulphureus, 137

autoecious rusts, 173

autotrophic plants, 3

Bacteria in hibiting growth of Fomes annosus, 111

basidia, 102

Armillaria mellea, 149, 150*;

Fomes annosus, 102*, 103;

Polyphorus Schweinitzii, 128*

basidiospores, 102*, 103

Berkeley, M. J., biographical note, 20 ; on larch canker, 20

birch, intermediate host of Melam. psoridium betulinum, 176

Blackman, V. H., on Botrytis cinerea, 30 ; on sexuality of rusts, 42

Boden, F., on relation of larch canker to altitude, 65

Borthwick, A. W., on larch canker, 25 ; rusts, 176

branches, source of larch canker, 58 folds at base of, 61

Brefeld, O., biographical note, 86 ; on Fomes annosus, 86; on Armillaria, 162

Brooks, F. T., on Botrytis cinerea, 30

Brown, W., on Botrytis cinerea, 30

buckle connexions, 135, 136*

buds, dormant, infection of canker through, 62

Buller, A. H. R., on spore ejection, 104,150

Calcium oxalate crystals, accumulation of in canker, 28, 29; in cultures of Dasyscypha, 29 ; in phloem, 11*, 12, 13*; in cortex, 11

canker (see larch canker)

cambium, structure of, 14

carbon assimilation, 3

Carruthers, J. B., on larch canker, 25 
Chermes abietis and larch canker, $25,50,53$

chlorophyll, 3,8

Christman, A. H., on sexuality of rusts, 42

Chrysomyxa abietis, 168

Cieslar, A., on distribution of larch canker, 183

clay, sound larch grown on, 121

cluster pine, Polyporus Schweinitzii on, 126

Coeoma laricis, 177

collenchyma in larch stem, 9

conidia, 5

of Dasyscypha, 42 ; Fomes annosus, 104, 105*; Meria, 172; Polyporus sulphureus, 139 ; Sphaerella, 169

conidiophores, 5

of Fomes annosus, 104, 105*, 106 ; Meria, 171

cork layer, 8

at base of branch, $58,59,60^{*}$; formation of, in canker, 30

cortex, 8, 9

Corticium amorphum, 21

cuticle, 9

cuticularized layer, 9

cystidia, of Polyporus Schweinitzii,

128 ; of Trametes Pini, 141

cysts, resin, 13

Damping-off of seedlings, 179-81

Darbishire, O. V., on Ascomycetes, 41

Dasyscypha calycina, 16-79

apothecia, $37,38^{*}$; artificial infections with, 49 ; ascus, $38,40^{*}$; cause of larch eanker, 16 ; false parasitism of, 29; fusion of hyphae, 44; germination of spores, $42,43^{*}$; growth of mycelium round cork layer, 61 ; hymenium, 38*; 'Micrococcusschwärmer' of 'Willkomm, 46 ; mycelial features necessary for canker formation, 33 ; mycelium in larch stem, 26; Penicillium growing on, 41 ; pure cultures, 46, 49; pycnidia, 37, $40^{*}$; saprophytic and parasitic forms, 79 ; saprophytic growth of, 17 ; spermogonia, $37,40^{*}$; spermogonia in agar-agar cultures, 48; spores, collection of, 46 ; ejection of, 42 ; synonymy of, 75 ; temperature relations, 47 ; winter and summer growth, 35

Dasyscypha resinaria, 26

D. Willkommii, 16

de Bary on Botrytis cinerea, 30 de Candolle on larch canker, 19 de Vries on abnormal wood, 32 dead roots, infection of Armillaria

by, 162 ; Fomes annosus, 114 dead trees a source of infection, 3 dry-rot caused by Poria vaporaria, 136

dwarf shoots of larch, 7

Ejection of spores, Armillaria, 149, 150 ; Dasyscypha, 42 ; in Poly. poreae, 104

elm, heart-rot of, 80

Elwes, H. J., on heart-rot, 122

epidermis, 8

excipulum, 38

Facultative parasites, 4

fat in phloem, 12

Ferguson, Sir D. M., plantations at Novar, 70

figured rot caused by Fomes annosus, 99

Fischer, artificial infection with canker, 50

foliar débris, growth of mycelium on, 49

Forbes, A. C., on larch canker, 64, $66,67,68$

Fomes annosus, 82-125

annular rot, 99 ; basidia, 102 ; basidiospores, 102, 103*; black pigment in hyphae, 96 ; black specks in wood, $94^{*}, 96^{*}, 97^{*}$; Brefeld on, 86 ; conidia, 86,100 , 104, 105*, 122 ; conidiophores, $104,105 *, 106$; cultures on soils, 108 ; decomposition of wood, $92-$ 99 ; Elwes on, 122 ; figured rot, 99 ; frequency in first rotation, 116 ; fructification, 100 ; general, 84; germ tube, 104; historical, 86 ; Hartig on, 86, 113 , 121, 122; holes in fructification, 102; holes in wood, 98 ; hymenial layer, $101,102 *$; infection experiments, 111 ; infection through anchor roots, 117, contact, 114, dead roots, 114, soil, 115, spores, 113, tap-roots, 117 ; insoluble gum, 91 ; myce- 
lium in wood, 92; mycelial growth inhibited by bacteria, 111; paraphyses, 102*; prevention, 122 ; primary and secondary rot, 116; pure eultures, 106; red-rot, 88 ; resin, 87 ; rot restricted by insoluble gum, 92 ; secretions induced by, 87-92; soil aeration, 119 ; soluble gum, 88 ; spores carried by rabbits, 113 ; spore ejection mechanism, 104 ; sterigmata, 103 ; treatment, 188 ; turpentine, 87 ; two methods of attack, 84; white patches in wood, 98; wounds necessary for infection of live roots, 114

Fomes ulmarius, 80

frost as a cause of wounds, 53 fructifications of fungi, $\mathbf{5}$

fungus, general account of, 3

Fusoma parasiticum, 180 .

Geotropism of Fomes annosus, 104 gills, 146

goutiness of larch trees, 85

gum, formation of, $28,88,91$

Hail, cause of wounds, 53

Harper, A. G., on abnormal wood, 31

Hartig, R., on abnormal wood, 31 ; Allescheria laricis, 172; biographical note, 22 ; Fomes anno$8 u s, 86$; growth of canker in summer and winter, 35 ; infection by Fomes annosus, 113 ; infection theory criticized, 121; larch canker, 22; Polyporus mollis, 127; Polyporus sulphureus, 138 ; Poria vaporaria, 134 ; Sphaerella laricina, 168; Tra. metes Pini, 146, 147; trenches at Eberswalde, 122; work on tree pathology, 24

Hartigiella laricis, 172

Heart-rot, caused by Fomes annosus, 84-125 ; Polyphorus Schweinitzii, 126-34; $P$. sulphureus, 136-40, 165* ; Poria vaporaria, 134-6; Trametes Pini, 140-3; detection of, 82 ; frequency in first rotation, 116-22; fungicausing, 82 ; general, 80 ; goutiness, 85

Helerobasidion annosum, 86 heteroccious rusts, 173

heterotrophic plants, 3

Hill, A. W., on sieve tubes, 12

honey fungus (see Armillaria mellea)

host, 5

hymenium, of Armillaria, 149, 150*; Dasyscypha, 37, 38*; Fomes annosus, 101, 102*; Polyporus Schweinitzii, 128*; Trametes Pini, 141

hyphae, 4

Hypodermella laricis, 172

Hypostomaceae, 171

Increment borer, use of, 123, 133

inner cortex of larch stem, 10

insoluble gum, 91

isolation trenches, 122,165

Japanese larch, canker on, 50, 69

Kissling, E., on Botrytis cinerea, 30 Kuster, E., on abnormal wood, 31

Larch, first-year shoot of, described, 7 ; introduction of, 1 ; suitable trees for mixing with, $72,185,186$ larch canker, 17-80

abnormal wood, 31 ; accumula. tion of calcium oxalate, resin, and tannin, 28 ; analysis of cankers on main stems, 54; artificial infections, 23,49 ; at base of branches, 55,56 ; connexion with Dasyscypha not proved by Willkomm, 22 ; contributory causes of, 64-67; cork layers obstruct growth of, 30 ; distribution of, 19; earliest notices of, in Britain, 19 ; fatal to young trees, 17 ; frequent in damp situations, 21 ; frost hollows, 66, 73; general, 16 ; importance of wounds ex. aggerated, 62 ; increased growth of stem at back and sides, 36 ; infection through dormant buds, 62 ; measurements of growth of, 24 ; method of formation, 34 ; methods of prevention, 69 ; minimum temperature for growth of, 26 ; mode of infection in nature, 52 ; occurrence at definite levels, 55 ; originating from dead branches, 58 ; passing cork layer at base of branch, 58, 59, 60*; relation to Chermes abietis, 50; 
removal of dead branches, 71 ; secondary causes, 183-8; steplike configuration of, 35 ; summary of chapters on, 73 ; trees may recover from, 18 ; vigorous trees less liable to, 68; (see also Dasyscypha calycina)

Larix leptolepis, canker on, 50

Larix sibirica, canker on, 50

Laslett, T., 1

leaf cushions, 8

leaf diseases, 168

leaf scars, weak points, 10

Leptostroma laricinum, 169

long shoots of larch, 6

Lophodermium laricinum, 169

Loudon, J. C., early notice of larch canker, 19

Mackintosh, C., on larch diseases, 25

Massee, G., on larch canker, 25, 50

medulla, 8,15

medullary ray, 15

in phloem, $11^{*}, 13^{*}$

Melampsora Larici-Capraearum, 178

M. Larici-epitea, 178

M. Larici-populina, 178

M. Larici-tremulae, 178

M. tremulae, 177

Melampsoridium betulinum, $\mathbf{1 7 5}$

Mer, E., on Meria laricis, 171, 172

Meria laricis, 171,172

'Micrococcusschwärmer' of Willkomm, 46

mixed woods less liable to canker, 67

Münch, E., on larch canker, 26

mushroom, instance of saprophyte, 4

mycelium, 4

Nectria ditissima, 33

needle cast, due to Sphaerella laricina, 168; Meria laricis, 171

Newfoundland, larch canker reported from, 19

|

Nieman, ship built of Scots pine, I

Nisbet, J., criticism of Novar system, 70

Novar system of treating canker, 70 nuclei, 41

nursery diseases (see Seedling)

Obligate parasites, 4

oospore of Phytophthora omnivora, 180
Pan in soils, 187

paraphyses, of Armillaria, 149, 150*; of Dasyscypha, 39, 40*; of Fomes annosus, 102* ; of Polyporus Schweinitzii, 126*; of Trametes Pini, 141

parasites, 3,4

parenchyma, 9

pathogenetist, 182

Penicillium sp. growing on Dasyscypha, 41,46

pericycle of larch stem, 11

periderm of larch stem, $9,10 *$

Peridermium laricis, 175

peridium, 175

perithecium of Sphaerella laricina, 170

Peziza calycina (see Dasyscypha calycina)

P. Willkommii, 23

phelloderm, 9

phellogen, 9, 10

phloem of larch stema, $8,11 *, 12$, $13^{*}$

Phytophthora omnivora, 179

pileus, 145

Polyporus destructor, heart-rot attributed to, 2

P. Schweinitzii, 82, 126-34, 189 ; basidia, 128* ; fructification, 127 , 137 ; géneral remarks on, 132 ; hymenium, 128*; in America, 126; paraphyses, $128 *$; rot in wood, 129, 131*, 132*.

$P$. sulphureus, 83, 136-40, 189

conidia, 139; prevention of, 139 ; species affected by, 136, 137; rot in wood, 138

$P$. vaporarius, 134

poplar, 177,178

Poria vaporaria, 83, 134-6

buckle connexions, 135, 136*; causing dry rot, 136

predispositionist, 182

primary and secondary causes of canker, 64

primary rot of Fomes annosus, 116

promycelium of rusts, 174

protoplasm, 4

pure cultures, Armillaria, 162 ; Dasyscypha, 46, 49 ; Fomes annosus, 106; suitable medium for, 47

pycnidia, of Dasyscypha, 37, 40*, 42 ; of rusts, 174] 
Rabbits carrying spores of Fomes annosus, 113

red-rot, caused by Fomes annosus, 88; Polyporus Schweinitzii, 138 resin, $13,28,87,148$

resin cysts, $8,11,13$

resin ducts, $8,9,14$; abnormal, 31 resupinate fructifications, Fomes annosus, 100 ; Poria vaporaria, 134 rhizomorphs, $146,150-3$

Ribbentrop, B., on heart-rot, 122 rusts, 172

Saprophyte, 3, 4

Schrenk, H. von, on Polyporus Schweinitzii, 127, 129 ; on P. sulphureus, 138; on Trametes Pini, 141

Sclerenchymatous elements, 11*, 13 Seots pine, Armillaria on, 147 ; Dasyscypha, 50 ; Fomes annosus, 86 ; Polyporus Schweinitzii, 126 ; Trametes Pini, 140

Secondary causes of larch canker, 64 secondary rot of Fomes annosus, 116 seedling diseases, Fusoma, 180 ; Melampsora, 177; Melampsoridium, 175 ; Meria, 171 ; Phytophthora, 179

Siberian larch, canker on, 50

sieve areas, 12

sieve tubes, $11^{*}, 12$

Smith, R. E., on Botrytis cinerea, 30

Smith, W. G., on Melampsora, 179 soil, cultures of Fomes annosus on, 108 ; in relation to larch canker, 66 ; infection of Fomes annosus through, 115 ; requirements of larch, 184; sections, observations on, 118

soluble gum in stems attacked by Fomes annosus, 88

Somerville, W., on larch canker, 25 ; on Fomes annosus, 84

spermatia, of Dasyscypha, 40*, 42 ; of rusts, 175

spermogonia, of Dasyscypha, 37, 39 , $40^{*}$; in pure cultures, 48 ; of rusts, 174

Sphaerella laricina, 168-71

asei, 170 ; conidia, 169 ; perithecia, 170 spore, 5

sporidia, 174

spruce, Armillaria mellea, 147;

Dasyscypha on needles of, 49 ;

Fomes annosus, 92 ; needle cast encouraged by, 170; Polyporus

Schweinitzii, 126

sterigma, 103

stipe, 145

swarm-spores, 179

Tannin, 12, 14 ; in larch canker, 28

tap-root in relation to Fomes annosus, 117

teleutosorus, 173

teleutospore, 173

temperature, influence on growth of mycelium of Dasyscypha, 47

tracheide, 14

Trametes Pini, 83, 140-3

cystidia, 141 ; fructification, 141 ;

paraphyses, 141 ; rot in wood, 141

Trametes radiciperda, 86

turpentine, secretion induced by Fomes annosus, 87

Tubeuf on Hypodermella laricis, 172

Tyrol, larch canker in, 64

Underplanting larch, 70, 171

uredosorus, 173

uredospore, 173

Vacuoles, 4

Vöchting, $\mathbf{H}$., on abnormal wood, 31

Vuillemin, P., on Meria laricis, 171

Wagner, G., on Armillaria, 161

warted hyphae of Dasyscypha, 37

Welsford, E. S., on Botrytis cinerea, 30

Weymouth pine, Armillaria mellea, 148 ; Fomes annosus, 86; Polyporus Schweinitzii, 126

Willkomm, M.W., biographical note, 21 ; on Dasyscypha calycina, 21, 46

willow, 178, 179

wood, structure of, 14

wounds, causes of, $50,53,54$; infection of Dasyscypha by, 62 ; of Fomes annosus by, 114

Xylem, structure of, 14 




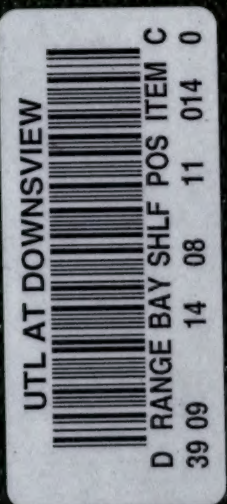

